\title{
Comprehensive Study of a Heavy Fuel Oil Spill: Modeling and Analytical Approaches to Understanding Environmental Weathering
}

\author{
By \\ Karin Lydia Lemkau \\ B.A., Chemistry \\ Wesleyan University, 2004 \\ Submitted in partial fulfillment of the requirements for the degree of \\ Doctor of Philosophy \\ at the \\ MASSACHUSETTS INSTITUTE OF TECHNOLOGY \\ and the \\ WOODS HOLE OCEANOGRAPHIC INSTITUTION
}

JUNE 2012

@2012 Karin L. Lemkau. All rights reserved.

The author hereby grants to MIT and WHOI permission to reproduce and to distribute publicly paper and electronic copies of this thesis document in whole or in part in any medium now known or heareafter created.

Signature of Author

Joint Program in Oceanographic/Applied Ocean Science and Engineering Massachusetts Institute of Technology and Woods Hole Oceanographic Institution May 10, 2012

Certified by

Christopher M. Reddy

Thesis Supervisor

Accepted by

Dr. Bernhard Peucker-Ehrenbrink

Chair, Joint Committee for Marine Chemistry and Geochemistry

Woods Hole Oceanographic Institution 


\title{
Comprehensive Study of a Heavy Fuel Oil Spill: Modeling and Analytical Approaches to Understanding Environmental Weathering
}

\author{
by
}

\author{
Karin L. Lemkau \\ Submitted to the MIT/WHOI Joint Program in Oceanography on May 10, 2012, in partial \\ fulfillment of the requirements for the degree of Doctor of Philosophy in the field of Chemical \\ Oceanography and Environmental Chemistry
}

\begin{abstract}
Driven by increasingly heavy oil reserves and more efficient refining technologies, use of heavy fuel oils for power generation is rising. Unlike other refined products and crude oils, a large portion of these heavy oils is undetectable using the traditional gas chromatography-based techniques on which oil spill science has been based. In the current study, samples collected after the 2007 M/V Cosco Busan heavy fuel oil spill (San Francisco, CA) were analyzed using gas chromatography (GC)-based techniques, numerical modeling and Fourier transform ion cyclotron resonance mass spectrometry (FT-ICR MS) to examine natural weathering of the oil over a one and a half year period. Traditional GC techniques detected variable evidence of evaporation/ dissolution, biodegradation and photodegradation. Petroleum hydrocarbon compounds smaller than $\sim n-\mathrm{C}_{16}$ were rapidly lost due to evaporation and dissolution. Significant biodegradation was not detected until one month post spill while photodegradation was only observed at one field site. To further examine the processes of evaporation and dissolution, samples were analyzed with comprehensive two-dimensional GC $(\mathrm{GC} \times \mathrm{GC})$ and a physiochemical model developed to approximate quantitative apportionment of compounds lost to the atmosphere and water. Model results suggest temperature is the primary control of evaporation. Finally, to examine the prominent non-GC amenable component of the oil, samples were analyzed with FT-ICR MS. Results showed expected clustering of samples, with those samples collected sooner after the spill having the most compositional similarity to the unweathered oil. Analysis of dominant heteroatom classes within the oil showed losses of high molecular weight species and the formation of stable core structures with time. These results highlight the susceptibility to weathering of these higher molecular weight components, previously believed to be recalcitrant in the environment. Research findings indicate that environmental weathering results in removal or alteration of larger alkylated compounds as well as loss of lower molecular weight species through evaporation/dissolution, biodegradation and photodegradation, with a resultant fraction of stable compounds likely to remain in the environment years after the spill. This research demonstrates the advantages of combining multiple analytical and modeling approaches for a fuller understanding of oil spill chemistry.

Thesis Supervisor: Christopher M. Reddy

Title: Senior Scientist Marine Chemistry and Geochemistry, WHOI

Director, Coastal Ocean Institute
\end{abstract}


To my parents,

\section{Jeanne and Phil Lemkau,}

Who gave me the world

And, to all those who have pushed me along the way 


\section{Acknowledgements}

There are so many people that have helped me - personally and scientifically — along this journey. First I would like to thank my advisor Chris Reddy. You have been an amazing mentor, pushing me, allowing me to grow as a scientist and never wavering in your encouragement and support. I appreciate your willingness to explore the world outside of science through your public outreach. Although you may be a scientific workaholic (a topic of debate), you have always been tolerant of those of us who are less so, and I thank you for that. I appreciate the many people and experiences you have introduced me to over the past several years.

I have had the fortune during my tenure at WHOI to work with many amazing individuals. I owe special thanks to my three committee members: Elizabeth Kujawinski, Phil Gschwend, and Jeff Seewald. Though it took me a while to figure out how things worked I appreciate your knowledge, support, and guidance over the last few years. I especially thank Elizabeth Kujawinski, my advisor for my first year and half of graduate school. If it were not for your flexibility and good heart when I was trying to figure out what I wanted to study, my graduate experience would have been very different. I would not be studying what I am today - and what I most enjoy - if it were not for your continued kindness and guidance. You have been a wonderful role model and mentor.

Also, I offer my thanks to Phil and Jeff. Phil, I am grateful for your awesome chemical knowledge and your ability to ask tough questions; although I rarely looked forward to our talks, I always learned from them and for that I will always be grateful. Your enthusiasm is contagious and I hope someday to inspire others as you have inspired me. And thanks to Jeff, for your scientific perspective, guidance and sense of humor. You have played an important role on my committee, and your inquisitiveness and outside perspective have made me question things I never thought to question. You always put me at ease and make me smile.

A special thanks goes to Dave Glover, who agreed to step out of the modeling world to chair my thesis defense. For introducing me to Matlab and for your kindness and mentorship, I am appreciative.

During my graduate work I have been privileged to spend several months working in Switzerland. For this I thank my advisor for encouraging my travel and locating funds to make this possible. I also owe a huge thanks to Sam Arey who welcomed me into his lab group and provided both financial support and scientific guidance. Jonas, Jenn, Deedar, Peter, Petros, Brijesh, Saer and Rebecca, I thank you for your kindness and conversations during my visits. I give special thanks to Jonas Gros who, as graduate student working with Sam on a project similar to my own, generously offered his knowledge and was a great sounding board for ideas and concerns.

I also had the pleasure of working with Alan Marshall's research group at the National High Magnetic Field Laboratory in Tallahassee, Florida. This was an amazing experience; I never imagined that I would have the opportunity to work with such fun and amazing people. Amy 
McKenna and David Podgorski, you are awesome. Being new to the world of FT-ICR MS and wanting to understand and learn as much as I could, my questions were continual and you never wavered in your willingness to help me understand. I could not have asked for a better group to tackle the scientific complexities of this technology. Also, I give thanks to Ryan and the rest of the Marshall group for their hospitality and to my college friend, Abby Scheel, who graciously welcomed me into her home (and onto her only couch) for weeks on end during my Florida visits. It was wonderful to be able to share time with her but I am also grateful for her kindness in sharing her home; there's nothing like a free place to stay with a good friend when you're a grad student.

I am deeply indebted to the WHOI Academic Programs office, both for the financial support which has made my education here possible and for their ongoing help and guidance. When I entered the program, Meg Tivey was the education coordinator for the Marine Chemistry and Geochemistry department (and is now associate dean of the joint program) and she has been a role model and "science mom". I have enjoyed our many conversations over the years and have appreciated your support and advice. Mark Kurz has since taken over this position and I have also appreciated his support through the trials of grad school. And Jim Yoder is one of the kindest people I know; though he runs a program with many students, he knows each of us. He is a constant promoter of education and science, and I am grateful for the teaching opportunities, encouragement and support he has given me. Of course a big thanks extends to Julia Westwater, Tricia Gebbie, Marsha Gnomes, Christine Charette, Valerie Caron, Michelle McCafferty; thank you for your willingness to help with any problem or question, whether related to academic programs or not :o)

My thanks to those with whom I have shared the ever-evolving Reddy lab. My time sharing the lab with Kristin Pangallo and Emily Peacock seemed very brief but I am grateful for the company and support they offered. Emily has been a friend (and neighbor) over the last 5 years and was a huge help when I first entered Chris' lab. Alas, she has since moved on, though her pictures (of Rose and Demi) still speckle the lab. Since Emily's village-ward migration, Catherine Carmichael is our new lab guru. She is an amazing and a wonderful lab mate, always willing to help out in a pinch. Without Catherine, the lab would not run as smoothly as it does. Bob Nelson is a great source of entertainment, knowledge and ideas within the lab. Though I've never been able to figure out if Sean Sylva is actually in our lab or not, he certainly contributes humor and congeniality to the environment. Cameron McIntyre, a seemingly brief resident of the Reddy lab, was a wonderful officemate and instrumentation guru. Sean, Bob and Cameron have helped me figure out a myriad of seemingly impossible instrument problems and their help, insight and humor have been much appreciated. Also, thanks to the post docs who have passed through and provided entertainment, outside perspectives and life to the Reddy lab over the years: Todd ventura, Carlos Guitart, Cristoph Aeppeli.

My graduate experience would have been a much less enjoyable journey if not for my amazing officemates, Kim Popendorf and Cameron McIntyre. Kim has more enthusiasm for just about everything than I have ever seen in one person. Her positive attitude and smile are a welcome 
relief on a bad day (the cupcakes and beer don't hurt either). She has been a rock of support for me, a wonderful late-night work buddy and most importantly a good friend. I can't thank her enough for being there to talk to, commiserate with and share ideas. Cameron, I thank you for your guidance, words of encouragement and scientific inquisitiveness. I have enjoyed our many conversations and I look forward to our paths crossing again.

I want to thank my family. First, although I've been told never to acknowledge him, I want to thank my other half, Camilo. Grad school has been quite an experience, and I am so glad you have been by my side to support me and give me a hug when I needed it most. While I may have done the work described here, I would not have enjoyed it as much as I did, if not for you.

My grandparents Robert G. Parr and Jane Parr have influenced me deeply. My grandfather has sustained a shining career in academia and chemistry that has brought him many years of joy and he has never wanted anything less for those around him. Paparr, I thank you for your support and for your love of science. I hope that someday I find a career that I enjoy as much as you have yours. Nana, your constant support of everyone in your life is not unnoticed. Thanks to you and the rest of my North Carolinian family. I am looking forward to spending more time with all of you once graduate school is over.

Of course I also want to thank my parents. They have always been my number one fans and have provided me with so much support and encouragement over the years. I have enjoyed our many visits and I look forward to being able to spend more time with each of you. I am grateful for all that you have given me and love you both from the bottom of my heart. Also, thanks to my mother for being my secret reader and comma critic; all those readers after you appreciate your efforts.

There are also many others who have supported, inspired and challenged me along the way:

Karen Casciotti, Freddy Valois, Phoebe Lam, Amanda Spivak, Andy Solo, Dave Valentine, Sarah Bagby, Jennifer Kovecses, Matt Barton, Seeps '09 Atlantis Crew, Alvin, Lonny Lippsett, Rich Camilli, John Kessler, Kris McNeill, Andrew Daly, Tim Eglinton, Ben Van Mooy, Carl Lamborg, Mak Saito, Melissa Soule, Krista Longnecker, Maya Bhatia, Andrea Burke, Dan McCorkle, Eoghan Reeves, Prof. Kevin Shea, Prof. Pete Pringle, John Farrington, Prof. Jim McKenna, Desiree Plata, Greg Deitzen, Alexey Schmelev, Jared Severson, Joe Papp, Jessie Kneeland, Caitlin Frame, Abigail Noble, Erin Bertrand, Chris Murphy, John Doherty, Erin Banning, Alysia Cox, Fern Gibbons, Min Xu, David Griffith, Mike Krawczynski, Elizabeth Halliday, Li Ling Hamady, Patricia Tcaciuc, Tyler Geopfert, Emily Roland, Casey Sanger, Dan Repeta, Rudy and Louise Pariser, Judy Duke, Jane and Bob Scott, Mary Stukenberg, Jeanne Ballantine, the Lemkau clan, mi familia Colombiana, Ricardo de Pol Holz, Kate Burner, Nathan Miller, Prae Supcharoen, Abby Kernan Schloss, Mike Barrett, Jill McDermott, Grant, Nick, Joe, Senthil Perumal, the residents of Fye and all the other amazing JP students who have touched my time here. 
Your scientific insight, words of encouragement, emotional support, and our times together will not be forgotten and have been an integral part of my graduate experience.

Finally, I would like to offer special thanks those who kept my social life alive: Camilo Ponton, Fern Gibbons, Kate Burner, Nathan Miller, Ricardo de Pol Holz, Kim Popendorf, Min Xu, Greg Deitzen, Jared Severson, Joe Papp, Alexey Schmelev, John Doherty, Emily Roland and Casey Sanger. My grad school years would have been much quieter without you.

Funding for this research was provided by National Science Foundation Grants, WHOI Academic Program Funds, the WHOI Ocean Ventures Fund, the Coastal Ocean Institute, the Richard and Rhoda Goldman Fund. I am indebted to these funding sources as well as those writing the grants that supported my education. Thanks for believing in me. 


\section{TABLE OF CONTENTS}

\section{Chapter 1. General Introduction: Heavy fuel oils, weathering, and the M/V Cosco}

Busan spill.

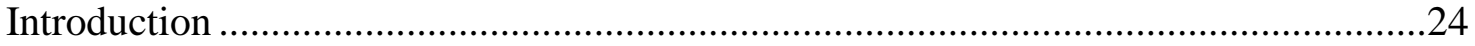

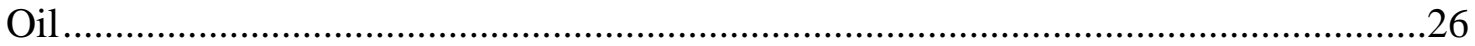

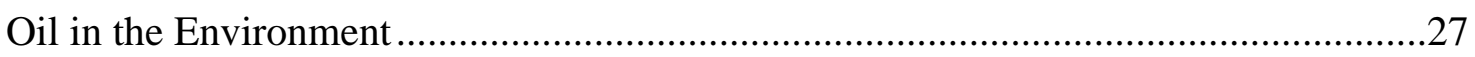

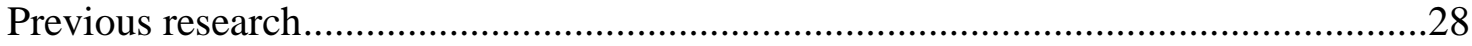

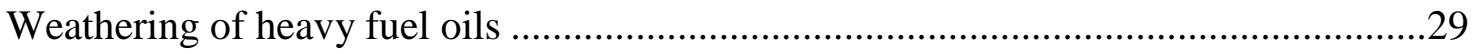

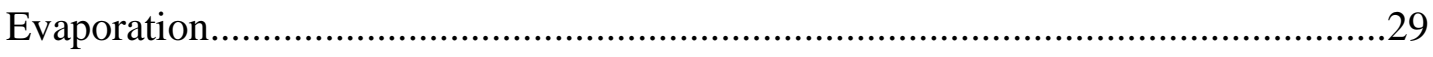

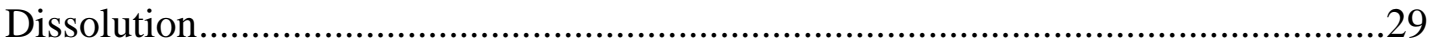

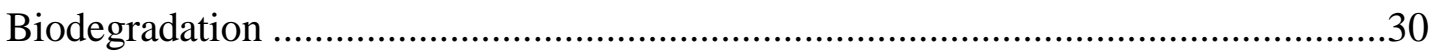

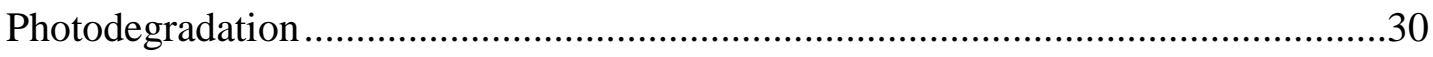

The M/V Cosco Busan spill .............................................................................................31

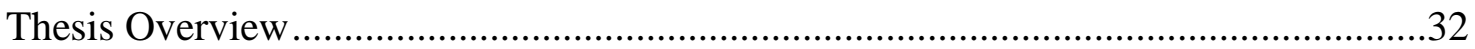

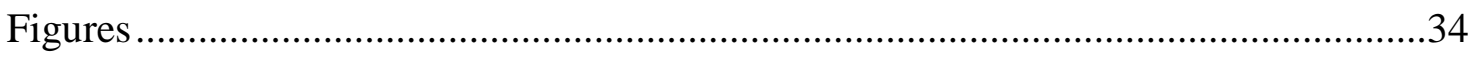

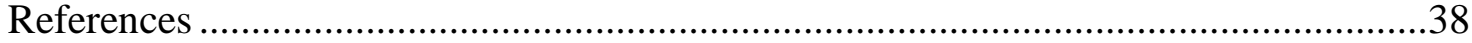

Chapter 2. The M/V Cosco Busan Spill: Source identification and short-term fate .45

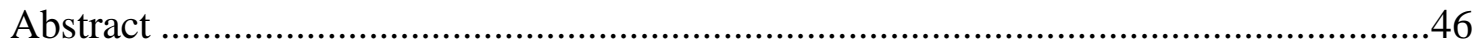

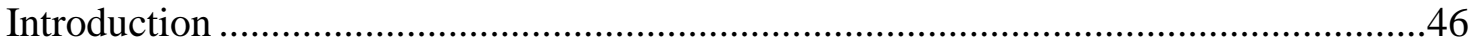

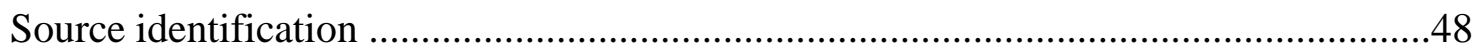

Evaporation/ dissolution.........................................................................................

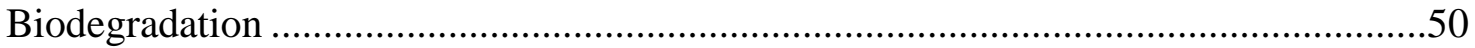

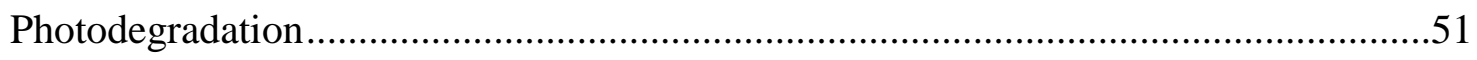

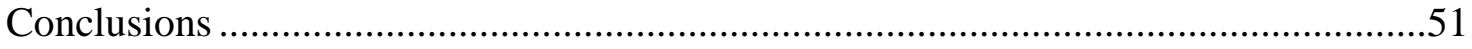

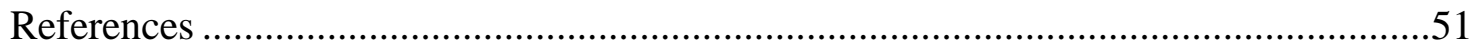

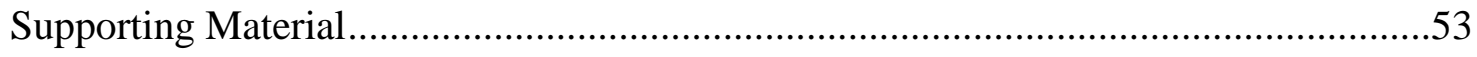


Chapter 3. Evaporation and dissolution trends for oil samples from the $M / V$ Cosco Busan spill................................................................................................................................71

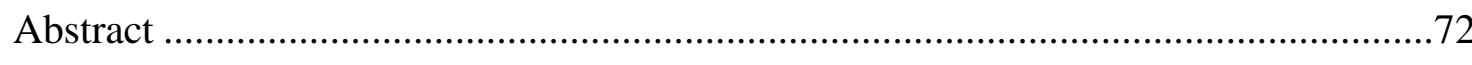

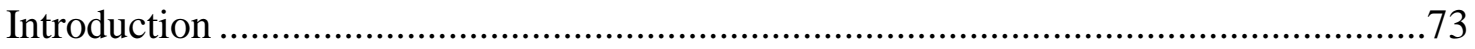

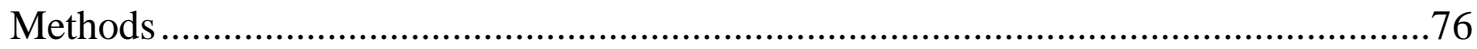

Sample collection and preparation ......................................................................76

Background of the M/V Cosco Busan oil................................................................76

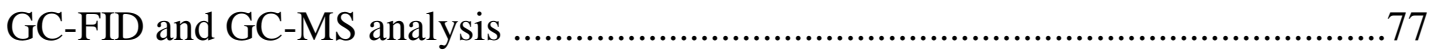

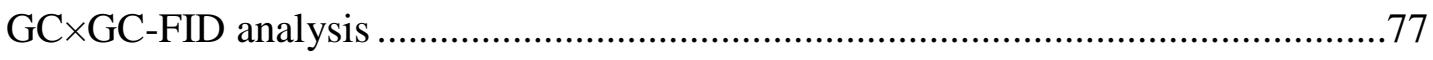

Mapping partitioning properties onto the $\mathrm{GC} \times \mathrm{GC}$ chromatogram ............................78

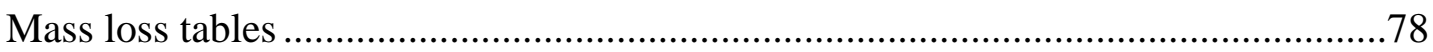

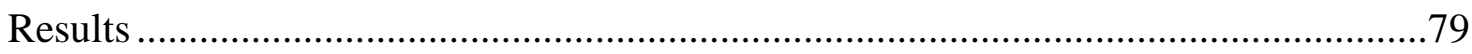

GC-FID

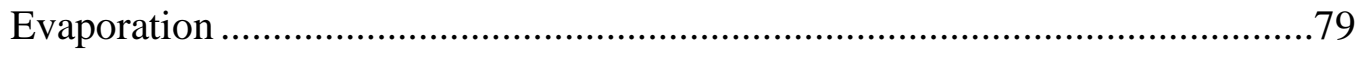

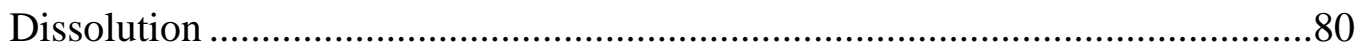

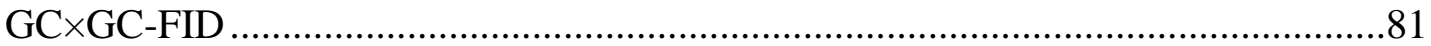

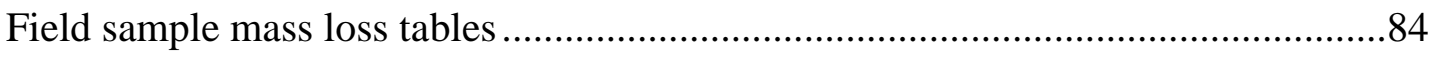

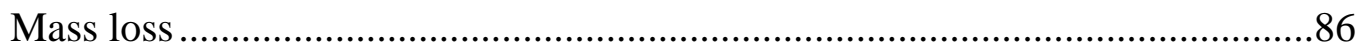

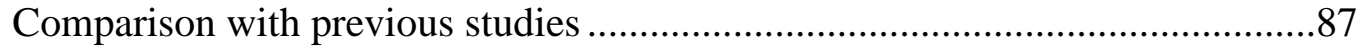

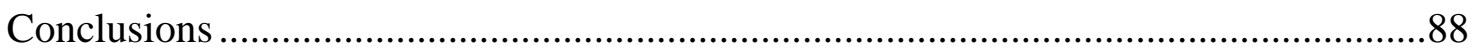

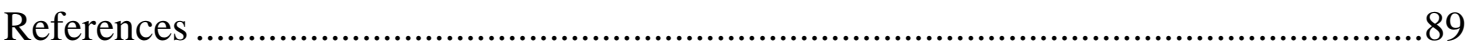

Tables and figures ...............................................................................................

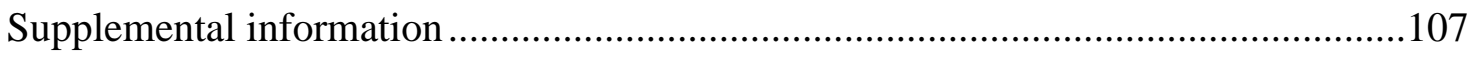

Chapter 4. Quantifying petroleum hydrocarbon input from oil-covered rocks into San Francisco Bay following the M/V Cosco Busan oil spill: Development of a mass transfer model .......................................................................................................................117

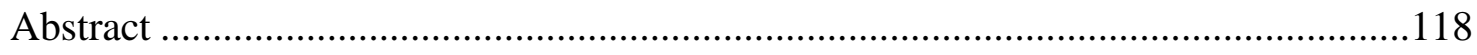

Introduction .........................................................................................119

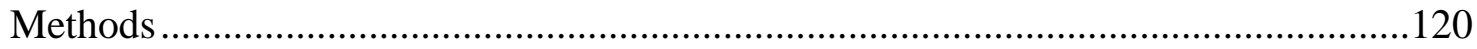


Sample collection and preparation .....................................................................120

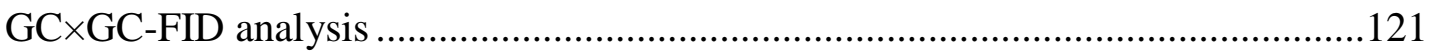

Mapping partitioning properties onto the $\mathrm{GC} \times \mathrm{GC}$ chromatogram .........................121

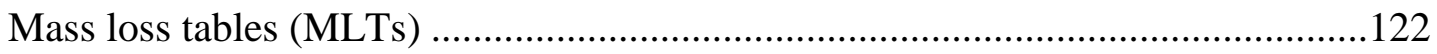

Mass Transfer Model...........................................................................................123

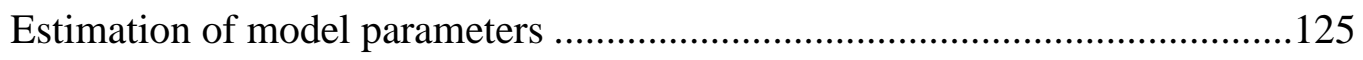

Partitioning coefficients...........................................................................126

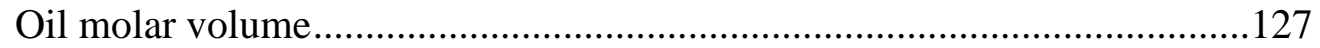

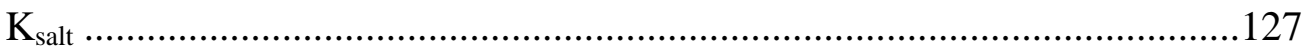

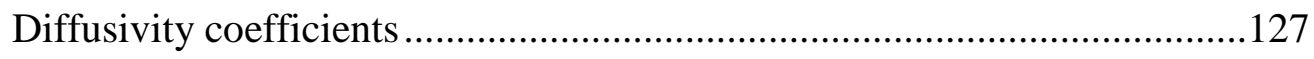

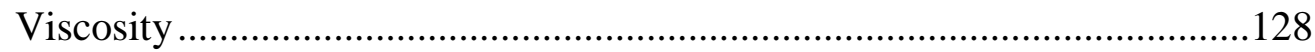

Environmental air and water temperatures................................................129

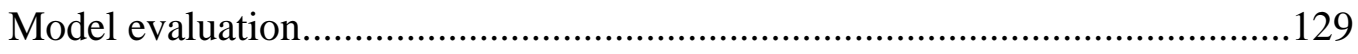

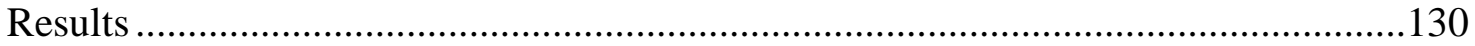

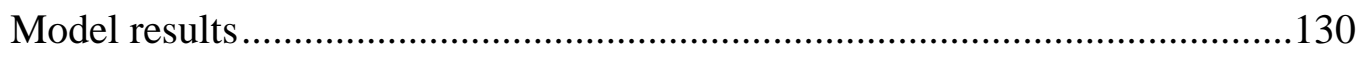

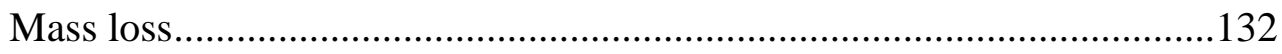

Comparison to laboratory studies ..............................................................133

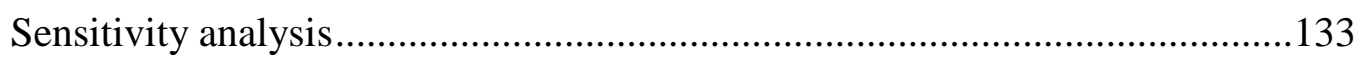

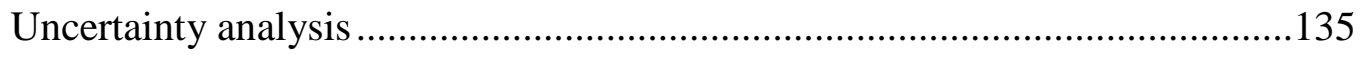

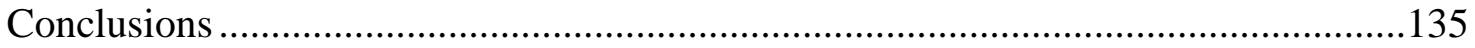

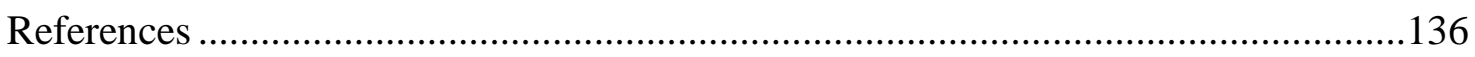

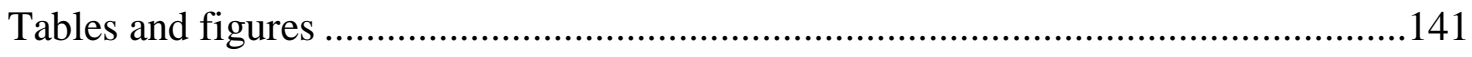

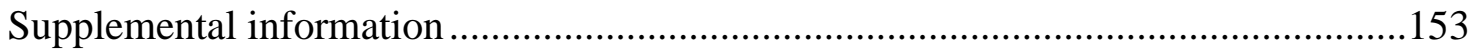

\section{Chapter 5. Oil Spill Weathering: Expanding the analytical window beyond gas} chromatography .................................................................................................................161

Abstract 


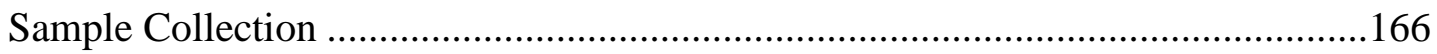

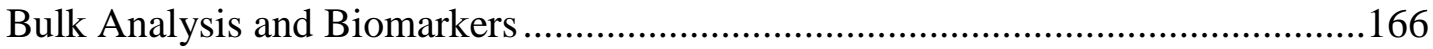

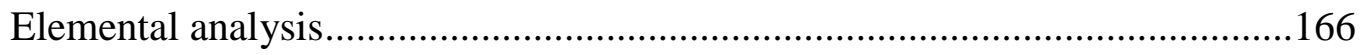

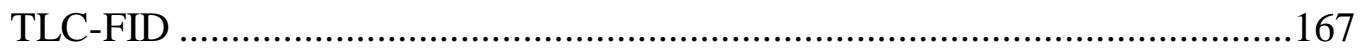

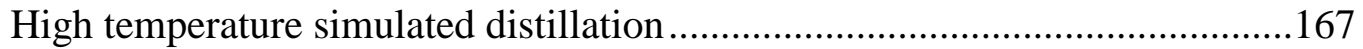

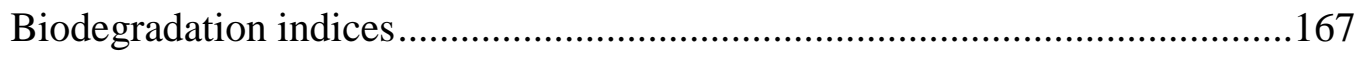

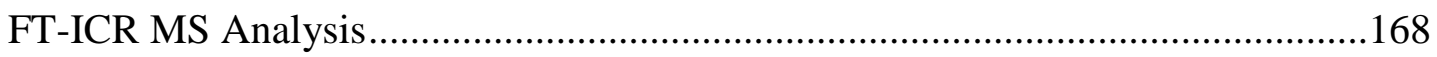

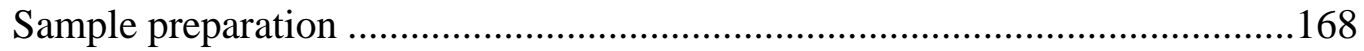

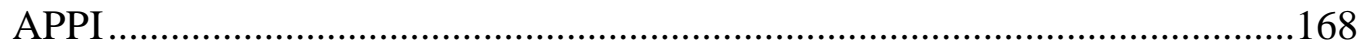

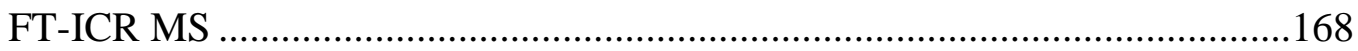

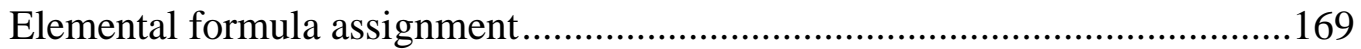

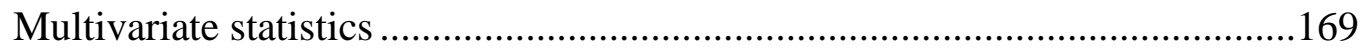

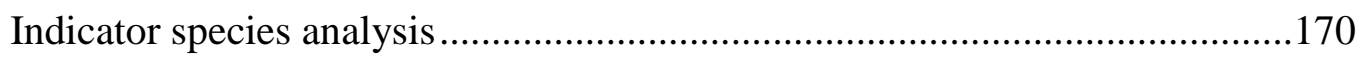

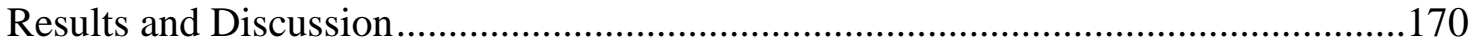

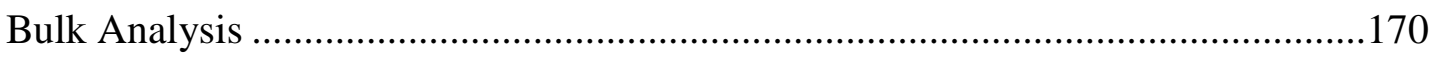

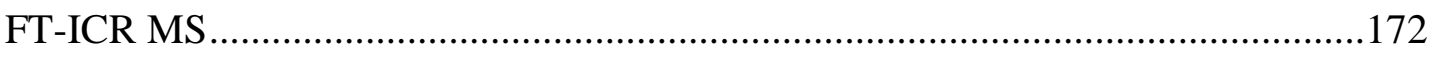

Broadband mass spectral evolution with time ................................................173

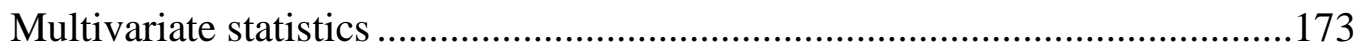

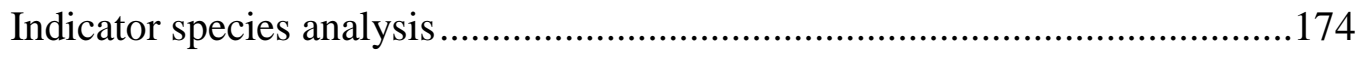

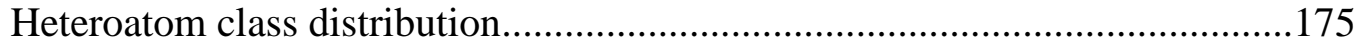

Compositional differences among weathered samples .......................................177

Bringing Technologies Together: a more complete picture .......................................181

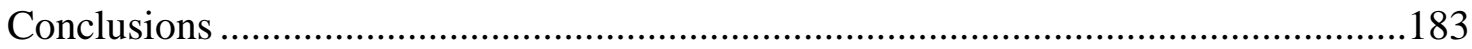

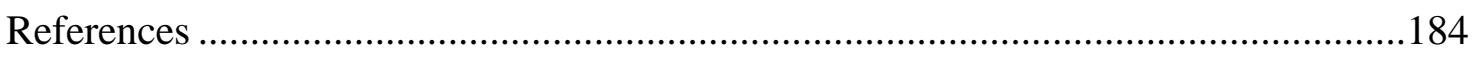

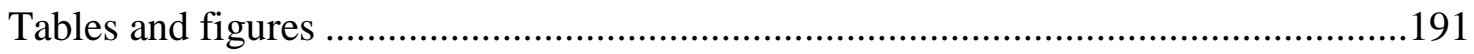

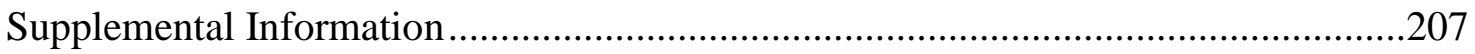

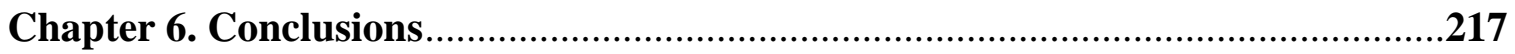




\section{LIST OF FIGURES}

\section{Chapter 1}

Figure 1. Simple schematic of refinery distillation process.........................................34

Figure 2. Plot showing the chemical composition of common crude oil products ...35

Figure 3. Number of oil spills per year since 1970 broken down by size of spill .....36

Figure 4. Map of the San Francisco Bay showing area affected by the M/V Cosco

Busan spill

\section{Chapter 2}

Figure 1. Map of San Francisco Bay showing sampling locations and track of the $\mathrm{M} / \mathrm{V}$ Cosco Busan before and after alliding with the Bay Bridge.

Figure 2. GC-FID chromatograms of oils from the two ruptured tanks (tank 3 and tank 4)

Figure 3. GC-FID chromatograms of the tank 4 oil and shorebird park samples showing evolution of total petroleum hydrocarbon weathering.

Figure 4. GC-FID chromatograms of samples collected 55 days after the spill from three different sampling sites

Figure 5. Total naphthalene content $\left(\mathrm{C}_{0}-\mathrm{C}_{4}\right)$ versus time for the first 80 days post spill.

Figure 6. Time series showing commonly used diagnostic ratios for biodegradation and photodegradation for the first 80 days post spill.

Figure S1.1. Photograph of Shorebird Park showing the 'dirty bathtub ring' left from the M/V Cosco Busan oil spill.

Figure S1.2. Photograph from Point Isabel showing shoreline and an oiled ceramic plate from this site.

Figure S1.3. Photograph showing coastal sampling site of Pirates Cove.

Figure S2. Plot of source ratios for the neat oil and samples collected from each sampling site.

\section{Chapter 3}

Figure 1. GC-FID chromatograms of the unweathered HFO and field samples .......95

Figure 2. Saturated hydrocarbon and aromatic hydrocarbon weathering ratios for field samples collected during the first 80 days post spill 
Figure 3. Annotated GC $\times$ GC chromatogram and mass loss table (MLT) highlighting major compound classes

Figure 4. GC $\times \mathrm{GC}$ chromatograms of the unweathered oil and select field samples.99

Figure 5. GC $\times \mathrm{GC}$ chromatograms of the unweathered oil and select field samples highlighted $n$-alkanes

Figure 6. MLTs of field samples collected 8 to 296 days post spill 103

Figure 7. MLTs of replicate samples from 21 (a) and 55 (b) days post spill 105

Figure S1. Photograph of one sampling site showing "dirty bathtub ring" left by the M/V Cosco Busan spill

Figure S2. Map of San Francisco Bay showing track of the M/V Cosco Busan, location of sampling sites

Figure S3. $\mathrm{C}_{30}-\mathrm{C}_{35}$ hopane peak volumes normalized to $\mathrm{C}_{30}$ hopane volume

Figure S4. GC $\times \mathrm{GC}$ chromatogram of the $n-\mathrm{C}_{10}$ to $n-\mathrm{C}_{24}$ region showing finite boundaries for vapor pressure (vertical lines) and solubility (curved lines), and location of training set for LFERs

Figure S5. Modeled mass loss tables showing theoretical trends resulting from weathering due to only evaporation (a) and dissolution (b)

\section{Chapter 4}

Figure 1. Photograph of one sampling site showing "dirty bathtub ring" left by the M/V Cosco Busan spill

Figure 2. Annotated mass loss table (MLT) of the Tank 4 oil.

Figure 3. Image of field sample collected from Shorebird park 296 days post spill (a) and schematic representation of field samples used as the basis of the mass transfer model (b)

Figure 4. MLTs of field samples and model results for 8, 80 and 296 days post spill

Figure S1. Map of San Francisco Bay showing track of the M/V Cosco Busan, location of sampling sites and collection sites of temperature and insolation data used in modeling

Figure S2. GC $\times \mathrm{GC}$ chromatogram of the $n-\mathrm{C}_{10}$ to $n-\mathrm{C}_{24}$ region showing finite boundaries for vapor pressure (vertical lines) and solubility (curved lines), and location of training set for LFERs 
Figure S3. Plot of oil temperatures during air and water exposure

\section{Chapter 5}

Figure 1. GC-FID chromatogram and high temperature simulated distillation results for the parent $\mathrm{HFO}$ 193

Figure 2. Negative ion APPI FT-ICR mass spectra for parent HFO and field samples representative of Group 1 and Group 2 used in ISA analysis.

Figure 3. Linkage diagrams of cluster analysis results for peak number normalized

presence/absence (a) and relative abundance data (b) ....

Figure 4. Heteroatom class distribution (heteroatom content) of select species for the parent HFO and field samples including an expanded view of oxygen-containing heteroatom classes

Figure 5. Isoabundance-contoured plots of double bond equivalent (DBE) versus carbon number for the $\mathrm{N}_{1}$ class of the parent $\mathrm{HFO}$ and field samples

Figure 6. Isoabundance-contoured plots of DBE versus carbon number for the hydrocarbon class of the parent HFO and field samples

Figure 7. Isoabundance-contoured plots of DBE versus carbon number for the $\mathrm{O}_{1}$ class of the parent HFO and field samples .203

Figure 8. Isoabundance-contoured plots of DBE versus carbon number for the $\mathrm{O}_{2}$ class of the parent HFO and field samples 205

Figure S1. Map of San Francisco Bay showing track of the M/V Cosco Busan and location of Shorebird Park sampling site.

Figure S2. Plots of relative abundance versus DBE for the C30 compounds of the $\mathrm{N} 1$ and NO classes for the parent HFO and field samples with time.

Figure S3. Naphthenic acid-based weathering indicators for the parent HFO and field samples 


\section{LIST OF TABLES}

\section{Chapter 2}

Table 1. Sample collection dates and number of samples collected at each site .......47

Table 2. Select biomarker ratios used to identify the source oil

Table 3. PAH concentrations $\left(\mathrm{mg} \mathrm{g}^{-1}\right.$ ) from representative samples collected at each site from initial day of sampling and 80 days post-spill

Table S1.1. Concentrations $\left(\mathrm{mg} \mathrm{g}^{-1}\right)$ of select PAHs in oil samples collected from Shorebird Park

Table S1.2. Concentrations $\left(\mathrm{mg} \mathrm{g}^{-1}\right)$ of select PAHs in oil samples collected from rocks at Point Island.

Table S1.3. Concentrations $\left(\mathrm{mg} \mathrm{g}^{-1}\right)$ of select PAHs in oil samples collected from plates at Point Island

Table S1.4. Concentrations $\left(\mathrm{mg} \mathrm{g}^{-1}\right)$ of select PAHs in oil samples collected from Pirates Cove

Table S2. BaA, Chr, and $n-\mathrm{C}_{18} /$ phytane data used in figures 5 and 6

\section{Chapter 3}

Table 1. Linear free energy relationships (LFERs) used to map properties onto the

$\mathrm{GC} \times \mathrm{GC}$ chromatogram

\section{Chapter 4}

Table 1. Linear free energy relationships (LFERs) used to map properties onto the

$\mathrm{GC} \times \mathrm{GC}$ chromatogram

Table 2. Mass transfer model input parameters ................................................. 146

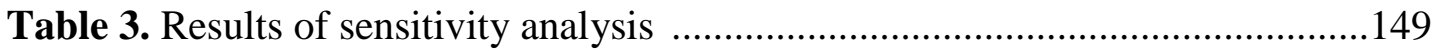

Table 4. Estimated uncertainties for model parameters .....................................150

Table 5. Model parameters and uncertainties ...................................................151

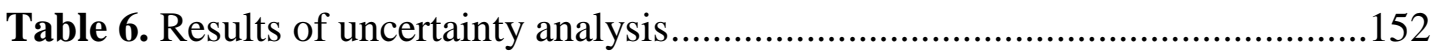

\section{Chapter 5}

Table 1. Saturate, aromatic, and polar content, elemental composition data and biodegradation indies of the parent $\mathrm{HFO}$ and field samples. 
Table 2. Oxygen content and aromaticity of Group 1 and 2 indicator species (IS) for presence/absence and relative abundance data sets 196

Table 3. Summary table of average carbon number, average DBE, and core structures found in parent HFO .200

Table S1. Select biomarker ratios used for source identification of field samples ..210

Table S2. Percent of negative ion APPI peaks shared between parent HFO and field samples analyzed 


\section{List of Acronyms}

APPI

Atmospheric pressure photoionization

DBE Double bond equivalent

ECA ..Emission Control Area

FID Flame ionization detection

FT-ICR MS Fourier transform ion cyclotron resonance mass spectrometry

GC Gas chromatography

$\mathrm{GC} \times \mathrm{GC}$ Comprehensive two-dimensional gas chromatography

HFO. Heavy fuel oil HTSD. High temperature simulated distillation ISO Intermediate fuel oil

LFER Linear free energy relationship

MLT. Mass loss table

PAH Polycyclic aromatic hydrocarbon TLC-FID Thin layer chromatography - flame ionization detection $\mathrm{TPH}$ Total petroleum hydrocarbons 


\section{Chapter 1}

General Introduction: Heavy fuel oils, weathering and the $M / V$ Cosco Busan spill

Karin L. Lemkau 


\section{Introduction}

Currently, oil meets $37 \%$ of the US energy demand, and over the next 20 years, oil consumption is predicted to increase by 33\% (United States Energy Information Administration, 2012). Thirty percent of world oil reserves derive from conventional reservoirs accessible with traditional extraction methods, which yield high value distillates, such as gasoline. The remaining $70 \%$ of reserves include oil sands, heavy oil, and extra heavy oil (Alboudwarej et al., 2006). These heavy products are less valuable due to their high viscosities, high sulfur content and high proportion of large molecules (500 to >1000 Da). However, as fuel prices rise and technology advances, recovery from these reserves is becoming more economically viable. In addition, more efficient vacuum distillation at refineries is increasing yields from all crude oils, resulting in a higher density residuum at the end of the refining process (Figure 1; Stout and Wang 2007). Heavy fuel oils (HFOs) are composed of the residue from crude oil distillation supplemented with a less viscous distillate fuel, or cutting oil, added to reduce viscosity and aid in transport and use (Figure 1; Uhler et al., 2007).

HFOs are used to power marine engines and in power-generation plants on land. Recent advances in marine engines enable vessels to burn heavier, more viscous HFOs than previously possible (RTI International, 2008). With more carrier vessels in service, the lower cost of heavy fuels (currently about $\$ 0.75$ cheaper per gallon than diesel fuel; United States Energy Information Administration, 2012), and oil reserves growing increasingly heavy (Alboudwarej et al., 2006), HFO use is predicted to rise (RTI International, 2008).

Several reasons HFOs are of particular interest include: controversy surrounding their use, increasing use, potentially long-lasting impacts on the environment (Wang et al., 1994) and lack of knowledge regarding their environmental fate. Recent studies have highlighted debate on the continued use of HFOs (Winebrake et al., 2007; Corbett and Winebrake 2008; Fuglestvedt et al., 2009). HFOs contain relatively high amounts of sulfur compared to other refined products and, as a result, burning these fuels results in 
more harmful emissions than alternatives such as diesel or biodiesel fuels. One study estimated reduced air quality caused by emissions from marine vessels burning HFOs to be responsible for the deaths of approximately sixty thousand people worldwide each year, primarily in coastal regions of Europe and East and South Asia (Corbett et al., 2007).

In the last decade, countries have begun creating emission control areas (ECAs); these areas have strict emission regulations and severely limit, among other things, the sulfur content acceptable in fuels. Decreased sulfur emissions can be achieved by switching to more expensive fuels with lower sulfur content or by capturing and scrubbing emissions on ship (RTI International, 2008), although the latter does not diminish the likelihood of a HFO spill. However, even as ECA regions are expanded, with increasing arctic shipping and international trade, the use of HFOs is on the rise (2008).

The larger polar constituents of HFOs from the refinery residue also have potential links to oil spill toxicity (Lubcke-von Varel et al., 2011; Vrabie et al., 2012). One study, by Incardona et al. (2012), focused specifically on the 2007 M/V Cosco Busan oil spill, and found this oil to be lethal at lower than expected concentrations; they found no explanation for this toxicity and pointed to changes in composition due to photochemistry within the uncharacterized high molecular weight compounds as a likely cause (Incardona et al., 2012).

These polar compounds have also been linked to decreased availability of biodegradable compounds in various oils (believed to be due to transport limitations within the oil; Uraizee et al., 1998). Although polar oil components are susceptible to weathering processes (Tjessem and Aaberg 1983; Rontani et al., 1985; Lacotte et al., 1996; Boukir et al., 1998; Garrett et al., 1998; Rojas-Avelizapa et al., 2002), little is known about their fate in the environment.

Though concentrated in these oils, polar and high molecular weight compounds are present in all crude oils; understanding their persistence and toxicity in the environment is relevant for spills of other fuel types as well. For example, even the light sweet crude 
of the Deepwater Horizon incident contained an estimated $10 \%$ of these compounds (Reddy et al., 2011).

Decades of oil spill research have been based on one-dimensional gas chromatography (GC) - based techniques. GC only allows examining of GC-amenable oil components, primarily the saturates and aromatic fractions of oil. Many studies examining weathering processes have focused exclusively on these fractions (Diez et al., 2005; Douglas et al., 2002; Ezra et al., 2000). However, technology has improved and comprehensive twodimensional gas chromatography $(\mathrm{GC} \times \mathrm{GC})$ allows unprecedented detailed examination of these classically studied saturate and aromatic fractions (Farwell et al., 2009; Wardlaw et al., 2008; Arey et al., 2007a). Furthermore, the application of Fourier transform ion cyclotron resonance mass spectrometry (FT-ICR MS) to study non-GC-amenable oil components has been led by scientists studying petroleum reservoirs and has only recently been introduced to the study of oil spills. This expanded view of oil composition allowed by new technology facilitates more thorough and detailed examination of the primary weathering processes affecting spilled oil.

Decisions on heavy fuel usage should take into account the risks of marine spills of HFOs versus alternative fuels, and be based on a thorough understanding of the behavior of these oils in the environment (Reddy 2007). Understanding how oil behaves when spilled, and how nature responds to such impacts is crucial for determining appropriate response to spills, abating damages, and assisting in cleanup and restoration. This thesis focuses on how oil is weathered after release into the environment. Specifically this thesis focuses on the M/V Cosco Busan heavy fuel oil spill which occurred in San Francisco Bay on November 7, 2007.

Oil. Oil is a complex mixture of organic compounds composed primarily of carbon and hydrogen, with trace amounts of nitrogen $(\mathrm{N})$, sulfur $(\mathrm{S})$, and oxygen $(\mathrm{O})$. It is naturally 
occurring and formed on geologic timescales through catagenesis of hydrocarbon-rich source material called kerogen.

The compounds that make up oil vary in size, structure and properties from one carbon to $>100$ carbons (McKenna et al., 2010). They consist of straight chain and branched alkanes ( $n$-, and iso- alkanes respectively), cyclic alkanes, aromatics, aromatics with saturated components, and heterocompounds containing N, S, and O (Figure 2). Considerable attention is often focused on saturates, select branched alkanes (less than 40 carbons) and PAHs (two to six rings). The saturates can provide insights into the processes of evaporation and biodegradation. The PAHs receive most of the attention for toxicity and can be used for oil fingerprinting, and gaining insights into the processes of dissolution and photodegradation (Diez et al., 2007; Plata et al., 2008). While these compounds are certainly worthy of study, they happen to be the most abundant and easiest to measure using traditional gas chromatography methods. The largest classes of compounds are resins and asphaltenes ${ }^{1}$, which are the most polar and heteroatomenriched fraction of oil (Klein et al., 2006) and have been largely overlooked in oil spill studies, in part because appropriate analytical methods did not exist to study weathering processes of these classes.

Oil in the environment. As evidenced by the Deepwater Horizon oil spill (Camilli et al., 2010; Reddy et al., 2011), accidental releases of petroleum continue. The Deepwater Horizon oil spill underscores that with continuing demand for energy, the exploration,

\footnotetext{
${ }^{1}$ Oils are often subdivided in the laboratory to describe oil composition and allow more directed study of specific oil fractions. The most commonly performed SARA separation isolates the saturate, aromatic, resin and asphaltene fractions. Because of their residual nature, HFOs are enriched in resins and asphaltenes (sometimes referred to as the polar I and polar II fractions, or collectively as the polars).
} 
recovery, processing, and transportation of crude oil and distillates pose many opportunities for spillage.

Petroleum is also released into the environment through many pathways including: natural seeps ( $\sim 600$ thousand metric tons per year), land runoff ( $\sim 140$ thousand metric tons per year), and operational discharge ( 306 thousand metric tons per year; National Research Council, 2003). Of these pathways, oil spills are the most publicized and, unlike natural seeps and runoff, which generate a more constant supply of oil to the marine environment, spills tend to result in more dramatic alterations to an ecosystem, because of their abrupt nature. Tanker spills release $\sim 100$ metric tons of oil into the environment each year (National Research Council, 2003) and the Deepwater Horizon spill alone resulted in the release of nearly 639 thousand metric tons into the environment (McNutt et al., 2011; Reddy et al., 2011).

Over the years, improved technology and equipment have contributed to a decrease in the number of oil spills occurring each year. Large spills (>700 metric tons) account for most of the volume of oil spilled through accidental release (National Research Council, 2003). However, most spills occurring each year are much smaller (7-700 metric tons). Tanker vessels carry much more oil than typical ships used for marine transport; hence, accidental releases from these ships are often significant when they occur (i.e. Exxon Valdez, Prestige, Sea Empress). However, spills of non-tanker vessels, such as container ships, are more common, if smaller in size (Jezequel et al., 2003).

Though incidents of accidental oil release are decreasing in frequency (Figure 3) and only represent a small fraction of total oil released into the ocean, the impact of these events on local surroundings is nonetheless significant.

Previous Research. Oil spills have been studied for decades using traditional onedimensional gas chromatography (GC) - based approaches. These studies have provided insight into weathering of the saturate and aromatic fractions of oil. 
There are several well-studied HFO spills, including the 1999 Erika spill off the coast of France (Bordenave et al., 2004; Tronczynski et al., 2004), the 2002 Prestige spill off the coast of Spain (Diez et al., 2005; Jimenez et al., 2006; Diez et al., 2007), and the 2003 Bouchard 120 spill in Buzzards Bay, MA (Nelson et al., 2006; Slater et al., 2006; Arey et al., 2007a; Arey et al., 2007b; Plata et al., 2008). Although several studies have focused on the oil components detectable with gas chromatography techniques, none have examined the prominent high molecular weight compounds. Short-term (weeks to months) weathering studies indicate a rapid initial loss of $n$-alkanes and polycyclic aromatic hydrocarbons (PAHs), followed by slower weathering rates after the first few months (Strand et al., 1992; Ezra et al., 2000). Longer-term studies support the stability of sterane and hopane biomarkers even decades after a spill (Wang et al., 1994). Data from these spills are often presented with little attention to the processes causing the observed changes or the timing of these processes.

Weathering of HFOs. Of the many processes that can impact oil once in the environment, we focus on four of the most universal: evaporation, dissolution, biodegradation and photodegradation. Understanding how each process affects an oil spill is important for efficient response efforts and allocation of cleanup efforts.

Evaporation. Evaporation is the primary weathering process impacting spills during the initial hours after a spill (Stout and Wang 2007), and removes compounds from the oil into the atmosphere where they are diluted and transported away. Evaporation preferentially affects the most volatile compounds, including $n$-alkanes up to $\sim n$ - $\mathrm{C}_{16}$ and one- and two- ring aromatic compounds (Wolfe et al., 1994; Fingas 1995; Stout and Wang 2007). HFOs can lose up to 5\% of their volume due to evaporation (Fingas 1997).

Dissolution. Dissolution can reduce the mass of an oil spill by 1 to 3\% (Stout and Wang 2007). Although this is much less significant than losses due to evaporation, dissolution is an important process when considering the toxicity of an oil spill. Dissolution occurs 
when oil is submerged or washed over by water; compounds are dissolved into surrounding waters, exposing marine plants and animals to their potential toxicity. Dissolution acts on similar low molecular weight compounds as evaporation, preferentially removing the most soluble oil components.

Biodegradation and photodegradation are the two remaining categories of processes impacting oil in the environment. Both of these processes act on longer timescales (weeks to months) than evaporation and dissolution (Stout and Wang 2007) and generally form oxidized products which are more polar and therefore more water soluble than parent hydrocarbons.

Biodegradation. Biodegradation depends on the presence of microorganisms. In an oil spill, it can take time for microbial communities to grow numerous enough to make a measurable dent in the oil present (National Research Council, 2003; Schwarzenbach et al., 2003). Also, some of the more toxic compounds in the oil may be toxic to oildegrading organisms themselves, thus delaying the onset of biodegradation (Scholz et al., 1999). Biodegradation preferentially removes $n$-alkanes over branched alkanes and smaller compounds are generally biodegraded more rapidly than larger aromatic compounds (Nelson et al., 2006; Stout and Wang 2007).

Photodegradation. Photodegradation has minimal impact on the mass of the oil, but results in compound transformations that can potentially release smaller, more toxic, compounds from larger molecular structures within the oil (Garrett et al., 1998; Maki et al., 2001). The more aromatic and alkylated a compound is, the more susceptible it is to photodegradation. Photodegradation occurs through a variety of mechanisms. The resulting products can be more toxic (Lacaze and Villedon de Naide 1976) and, because of their increased polarity, are more likely to dissolve in surrounding waters (Garrett et al., 1998). Photoreactions can also lead to condensation reactions and formation of higher molecular weight products (Garrett et al., 1998). 
The M/V Cosco Busan spill. On November 7, 2007 the M/V Cosco Busan container ship departed from Oakland, CA bound for the Republic of Korea. Dense fog within the Bay decreased visibility and made for hazardous conditions. At 8:30 am, after departing from the Oakland Harbor, the ship allided ${ }^{2}$ with the San Francisco-Oakland Bay Bridge. The allision resulted in a 64-m gash in the ship's single hull and damage to two fuel tanks (Tanks 3 and 4) and one ballast tank (National Transportation Safety Board, 2009).

After the incident, although oil-containing tanks were known to have been ruptured, damage to equipment used to measure oil within the tanks resulted in confusion about the source of the leaked oil and significant underestimation of the volume of oil leaked, initially reported as 146 gallons. The true scale of the spill was not known until hours later; approximately 200,000 L (53,500 gallons) of heavy fuel oil (HFO; group IFO380 3 ) had leaked into San Francisco Bay (Figure 1; Figure 4), exposing over 12 square kilometers of local ecosystems to the oil (Natural Resource Damage Assessment Trustee Agencies, 2011). Aerial photographs taken within days of the spill revealed dark patches

\footnotetext{
${ }^{2}$ An allision is the striking of a fixed object by a moving vessel. Alternatively, a collision occurs when both vessels involved in the incident are in motion.

${ }^{3}$ Within heavy fuel oils used for marine transport, several overlapping nomenclatures are used. The most common is that of the international organization for standardization (International Organization for Standardization, 2010) which divides fuels into categories based on the permitted kinematic viscosity of fuels. There are two categories of heavy fuel oils: IFO380 and IFO180. An IFO380 is an intermediate fuel oil with a maximum kinematic viscosity of $380 \mathrm{cSt}$ $\left(\mathrm{mm}^{2} / \mathrm{s}\right)$ at $50{ }^{\circ} \mathrm{C}$. Each of these categories contains many different fuels used in marine transport, all of which are made, at least in part, from refinery residues.

There are also several parallel naming conventions. The same IFO380 and 180 fuels described above can also be described as bunker fuels - a term that comes from their storage in the bunkers of ships. Of these, there are three subdivisions: A B and C (Uhler et al., 2007). Finally, a numeric system describes the same oils as No.1 to No.6 fuel oils (American Society for Testing and Materials, 2010). Though the ISO nomenclature is relatively standard today, within the literature all of these terms are used. The heavy fuel oil spilled by the M/V Cosco Busan was an IFO380, a bunker C or a No. 6 fuel oil (Uhler et al., 2007).
} 
of oil north and south of the Bay Bridge, and to the north of the Golden Gate Bridge outside of the bay (2007). The oil spill closed public beaches, was estimated to have killed over 6500 birds, and may have contributed to the collapse of local herring populations (Natural Resource Damage Assessment Trustee Agencies, 2011).

Sampling sites were chosen for the current work based on accessibility and either the visual presence of oil and/or the knowledge that the location had been heavily impacted by the spill. My advisor, Christopher Reddy, and I collected oil samples from the intertidal zone of three impacted shorelines (Figure 4): two sites within The Bay (Point Isabel, Shorebird Park) and one site just outside The Bay on the Pacific Coast (Pirates Cove). All sites are rocky shorelines. After the spill, all sites were cleaned by crews to remove oil, except for Pirates Cove which received no attention due to its remote location. No in situ bioremediation was performed; steam cleaning of some heavilyimpacted regions occurred but did not impact any of the samples considered here.

\section{Thesis Overview}

This thesis seeks to apply the best available technology, used commonly in the oil industry, to study the M/V Cosco Busan heavy fuel oil spill.

Chapter two provides a baseline for study of the M/V Cosco Busan spill. Many oil spill studies focus on one particular technique (Nelson et al., 2006) or weathering processes (Slater et al., 2006; Arey et al., 2007a; Arey et al., 2007b; Plata et al., 2008), and often a general overview of the spill is not available. This chapter provides the scientific community with basic information on the spill including confirmation of the source of the spilled oil, basic oil composition and weathering experienced by the oil during the initial 80 days post spill. For this chapter, traditional one-dimensional GC-based techniques were used.

The third and fourth chapters tackle the problem of distinguishing between evaporation and dissolution. Losses of lower-molecular weight compounds were clearly visible, and 
because of the unexpected toxicity of this spill and potential impacts on local herring populations, it was of interest to provide a more in-depth examination of the fate of these low-molecular weight compounds after the spill. Due to the complexity of differentiating evaporation and dissolution, they are often considered jointly in oil spill studies. These chapters seek to track, both qualitatively and quantitatively, the low molecular weight oil compounds that disappear during the initial days of weathering (as demonstrated in Chapter 2). This is done by examining field samples with $\mathrm{GC} \times \mathrm{GC}$ and by exploiting information contained within the two-dimensional retention times to visualize mass losses (Chapter 3). A physicochemical mass transfer model is also developed to quantitatively apportion compound losses to the atmosphere and water (Chapter 4).

In the final data chapter, the evolution of the more polar oil components is examined using Fourier transform ion cyclotron resonance mass spectrometry (FT-ICR MS). This technique provides molecular-level information that is commonly used within the petroleum industry, but which, until recently, had not been applied to examination of an environmental oil spill. The FT-ICR MS technique preferentially detects the most polar oil components traditionally thought to be environmentally recalcitrant (Boukir et al., 1998). This work shows that, quite to the contrary, polar oil components are actively cycled in the environment, as demonstrated by decreasing molecular weight and aromaticity with time. Biodegradation and photodegradation are the most likely processes responsible for these observed changes.

The goal of this thesis is to detail changes within all fractions of a heavy fuel oil with environmental exposure using one-dimensional GC techniques, GC×GC and FT-ICR MS and in doing so illustrate the benefits of combined methodology for studying oil spills. 


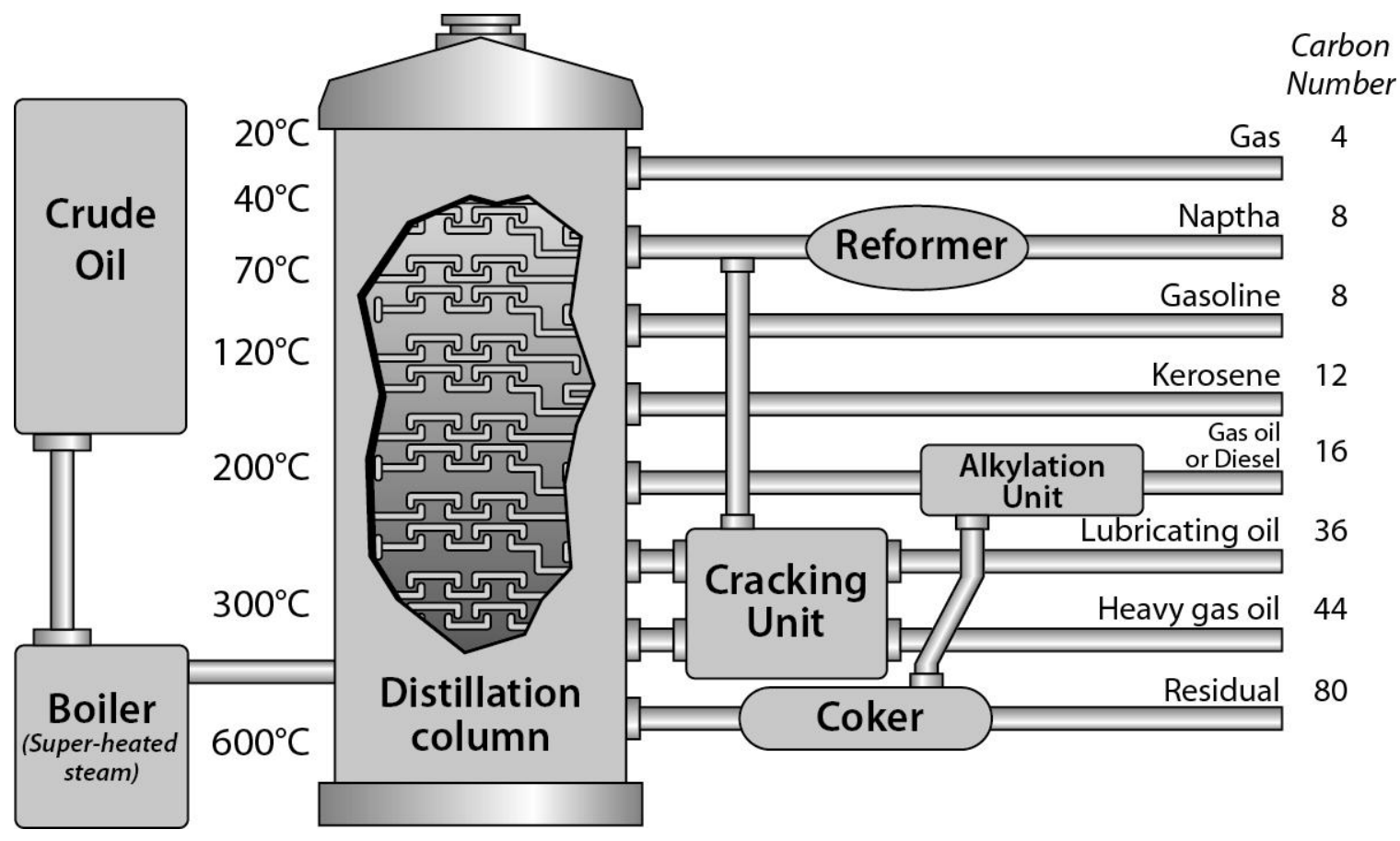

Figure 1. Simplified schematic of the refinery distillation process, including temperature and carbon ranges of distillation cuts and end products. Crude oil is heated and compounds boiling off within specified temperature ranges are collected, processed and sold for use. Although separation is based on boiling point, distillates will contain many compounds, and not only the boiling point but the molecular content of these different distillate fuels varies (Figure 2). Lower boiling point fractions, the lighter distillates, are the most economically valuable fractions of crude oil. After the oil has been heated and desired fractions collected, there remains a residue containing high-boiling compounds. Heavy fuel oils are formed from this high boiling residue mixed with a lighter distillate to reduce viscosity. Modified from MOAB Oil, Inc. (2012). 


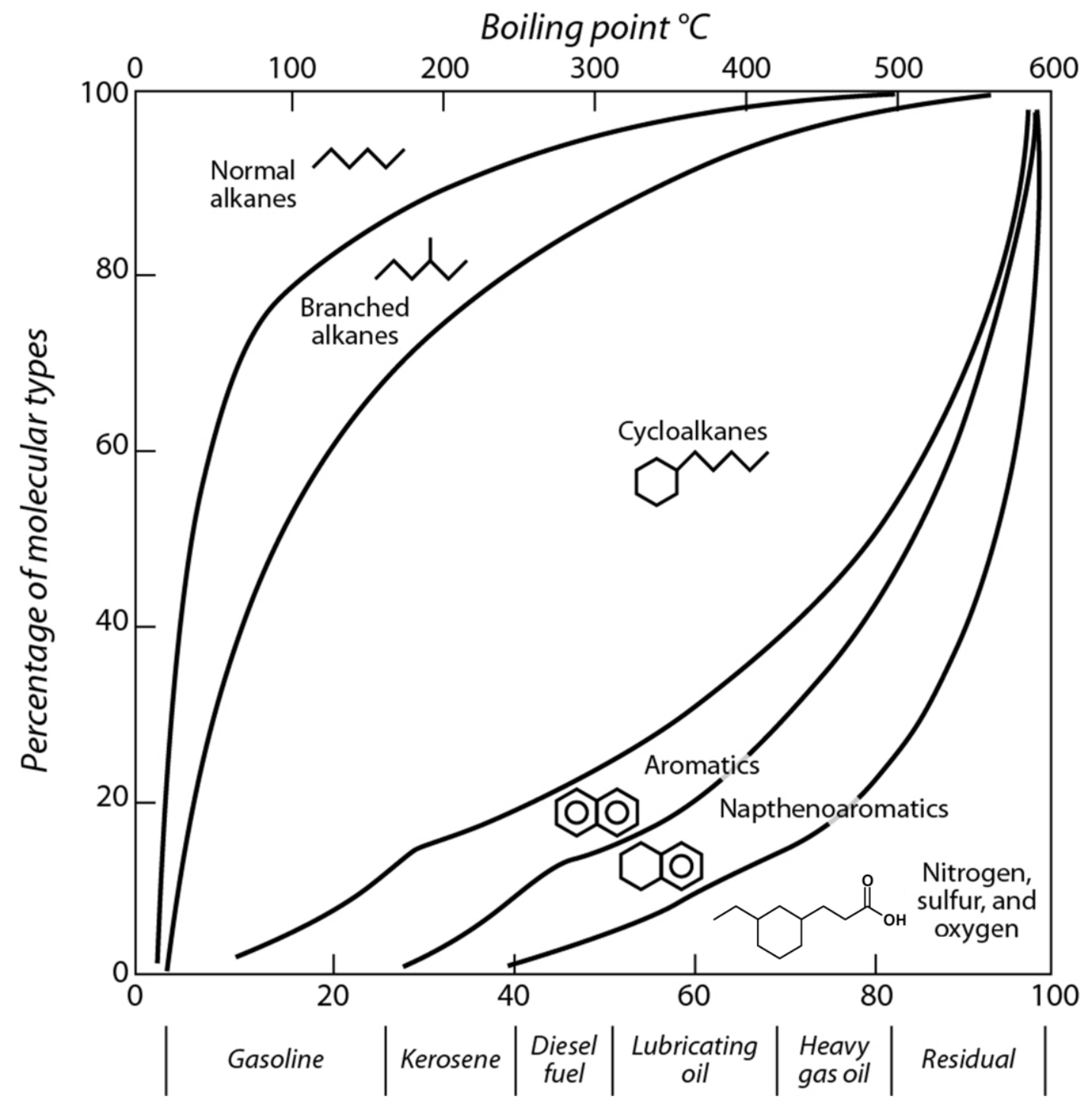

Figure 2. Plot showing the chemical composition of crude oil products shown in Figure 1. On the $\mathrm{x}$-axis is the boiling point and corresponding distillate fraction. The y-axis shows the percent of various molecular types within these distillates. Modified from Hunt (1996). 


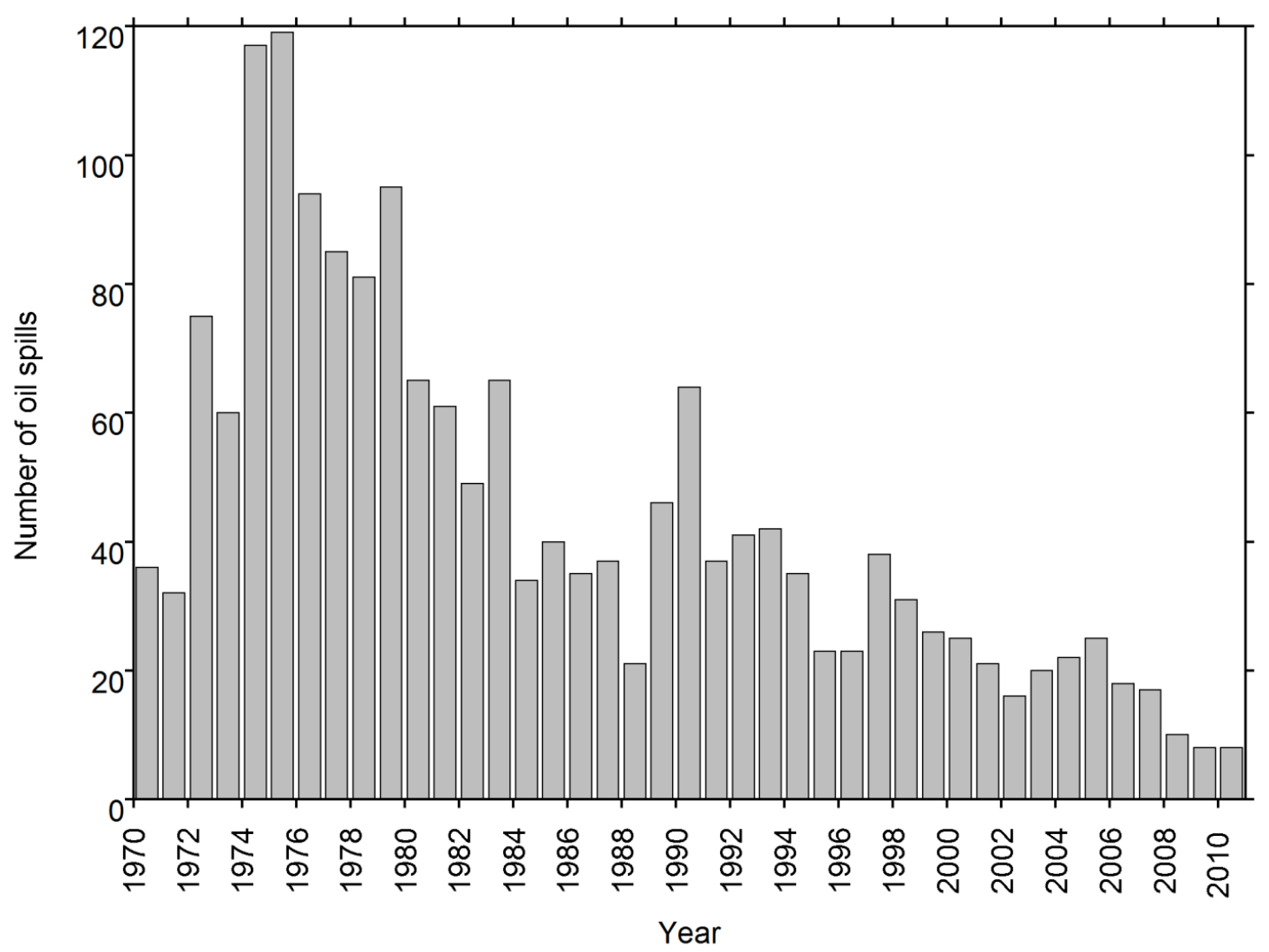

Figure 3. Number of oil spills per year since 1970 (International Tanker Owners Pollution Federation Limited 2011). 


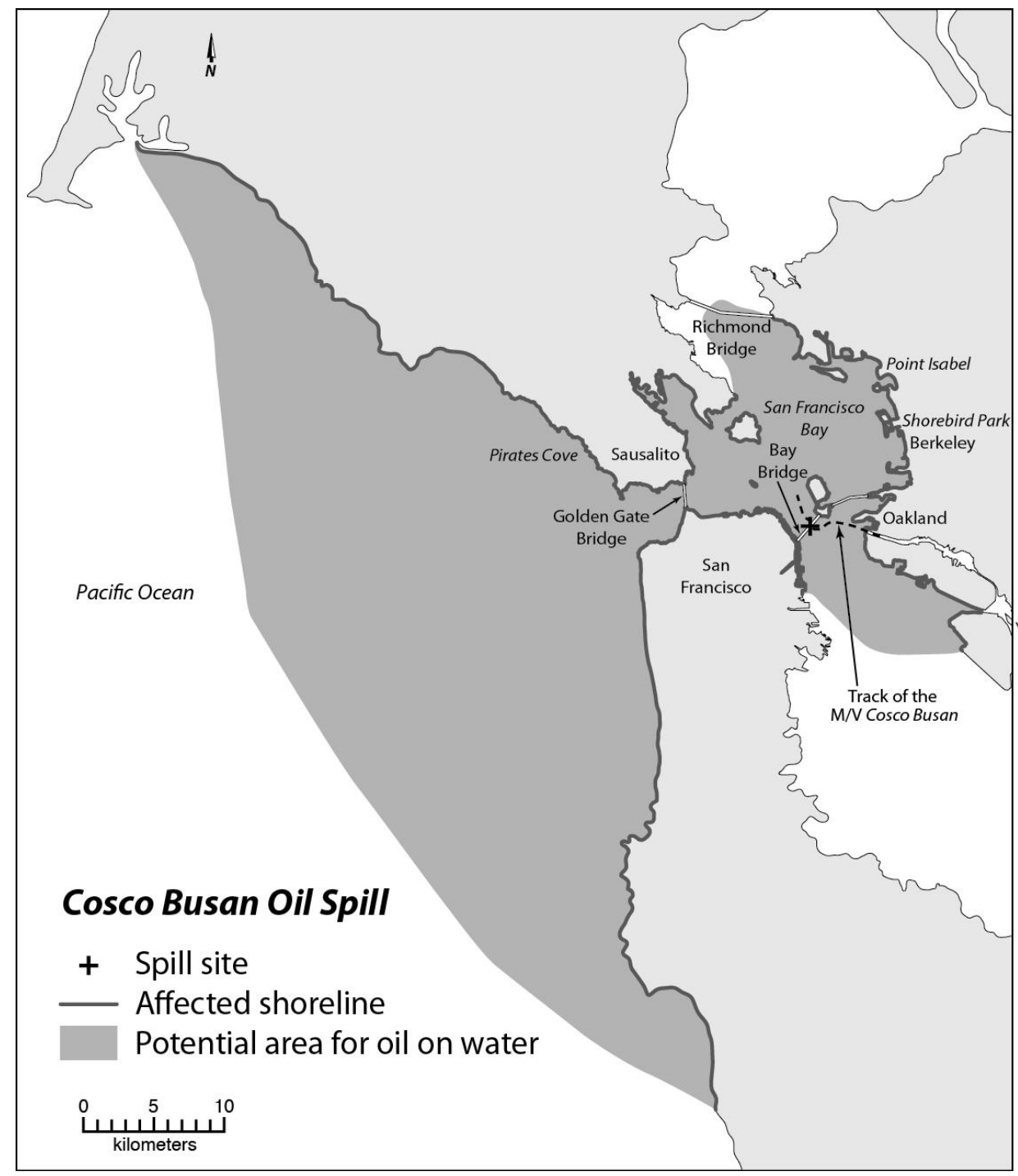

Figure 4. Map of San Francisco Bay area showing areas affected by the M/V Cosco Busan spill including impacted coastlines and water. The spill site is indicated by the black cross (Modified from California Department of Fish and Game, 2012). 


\section{$\underline{\text { References }}$}

Alboudwarej, H., Felix, J., Taylor, S., Badry, R., Bremner, C., Palmer, D., Pattison, K., Beshry, M., Krawchuk, P., Brown, G., Calvo, R., Canas Triana, J. A., Hathcock, R., Koerner, K., Hughes, T., Kundu, D., Cardenas, J. L. and West, C. (2006). "Highlighting Heavy Oil." Oilfield Review: 20.

American Society for Testing and Materials (2010). "Standard Specification for Fuel Oils." West Conshohocken, PA. 7.

Arey, J. S., Nelson, R. K., Plata, D. L. and Reddy, C. M. (2007a). "Disentangling oil weathering using GC $\times$ GC. 2. Mass transfer calculations." Environmental Science \& Technology 41(16): 5747-5755.

Arey, J. S., Nelson, R. K. and Reddy, C. M. (2007b). "Disentangling oil weathering using GCXGC. 1. Chromatogram analysis." Environmental Science \& Technology 41(16): 5738-5746.

Bordenave, S., Jezequel, R., Fourcans, A., Budzinski, N., Merlin, F. X., Fourel, T., GoniUrriza, M., Guyoneaud, R., Grimaud, W., Caumette, P. and Duran, R. (2004).

"Degradation of the "Erika" oil." Aquatic Living Resources 17(3): 261-267.

Boukir, A., Guiliano, M., Asia, L., El Hallaoui, A. and Mille, G. (1998). "A fraction to fraction study of photo-oxidation of BAL 150 crude oil asphaltenes." Analusis 26(9): 358-364.

California Department of Fish and Game. (2012). "Cosco Busan Oil Spill." Retrieved July 5th, 2011, from http://www.dfg.ca.gov/ospr/science/cosco_busan_spill.aspx.

Camilli, R., Reddy, C. M., Yoerger, D. R., Van Mooy, B. A. S., Jakuba, M. V., Kinsey, J. C., McIntyre, C. P., Sylva, S. P. and Maloney, J. V. (2010). "Tracking Hydrocarbon Plume Transport and Biodegradation at Deepwater Horizon." Science 330(6001): 201204.

Corbett, J. J. and Winebrake, J. J. (2008). "Emissions tradeoffs among alternative marine fuels: total fuel cycle analysis of residual oil, marine gas oil, and marine diesel oil." Journal of the Air \&amp; Waste Management Association 58(4): 538-542.

Corbett, J. J., Winebrake, J. J., Green, E. H., Kasibhatla, P., Eyring, V. and Lauer, A. (2007). "Mortality from ship emissions: a global assessment." Environmental Science \& Technology 41(24): 8512-8518.

National Research Council (2003). "Oil in the sea III: inputs, fates and effects." National Academies Press. Washington, D.C. 
Diez, S., Jover, E., Bayona, J. M. and Albaiges, J. (2007). "Prestige oil spill. III. Fate of a heavy oil in the marine environment." Environmental Science \& Technology 41(9): 3075-3082.

Diez, S., Sabate, J., Vinas, M., Bayona, J. M., Solanas, A. M. and Albaiges, J. (2005). "The Prestige oil spill. I. Biodegradation of a heavy fuel oil under simulated conditions." Environmental Toxicology and Chemistry 24(9): 2203-2217.

Douglas, G. S., Owens, E. H., Hardenstine, J. and Prince, R. C. (2002). "The OSSA II pipeline oil spill: the character and weathering of the spilled oil." Spill Science \&amp; Technology Bulletin 7(3-4): 135-148.

Ezra, S., Feinstein, S., Pelly, I., Bauman, D. and Miloslavsky, I. (2000). Weathering of fuel oil spill on the east Mediterranean coast, Ashdod, Israel.

Farwell, C., Reddy, C. M., Peacock, E., Nelson, R. K., Washburn, L. and Valentine, D. L. (2009). "Weathering and the fallout plume of heavy oil from strong petroleum seeps near Coal Oil Point, CA." Environmental Science \& Technology 43(10): 3542-3548.

Fingas, M. F. (1995). "A literature review of the physics and predictive modeling of oil spill evaporation." Journal of Hazardous Materials 42(2): 157-175.

Fingas, M. F. (1997). "Studies on the evaporation of crude oil and petroleum products: I. the relationship between evaporation rate and time." Journal of Hazardous Materials 56(3): 227-236.

Fuglestvedt, J., Berntsen, T., Eyring, V., Isaksen, I., Lee, D. S. and Sausen, R. (2009). "Shipping emissions: from cooling to warming of climate - and reducing impacts on health." Environmental Science \&amp; Technology 43(24): 9057-9062.

Garrett, R. M., Pickering, I. J., Haith, C. E. and Prince, R. C. (1998). "Photooxidation of crude oils." Environmental Science \& Technology 32(23): 3719-3723.

Hunt, J. M. (1996). Petroleum Geochemistry and Geology. New York, W. H. Freeman and Company.

Incardona, J. P., Vines, C. A., Anulacion, B. F., Baldwin, D. H., Day, H. L., French, B. L., Labenia, J. S., Linbo, T. L., Myers, M. S., Olson, O. P., Sloan, C. A., Sol, S., Griffin, F. J., Menard, K., Morgan, S. G., West, J. E., Collier, T. K., Ylitalo, G. M., Cherr, G. N. and Scholz, N. L. (2012). "Unexpectedly high mortality in Pacific Herring embryos exposed to the 2007 Cosco Busan oil spill in San Franciso Bay." Proceedings of the National Academy of Sciences 109(9): E51-E58.

International Organization for Standardization (2010). "Petroleum products - Fuels (class F) - Specifications of marine fuels." Geneva, Switzerland. 29. 
International Tanker Owners Pollution Federation Limited (2011). "Oil Tanker Spill Statistics 2010." London, UK. 8.

Jezequel, R., Menot, L., Merlin, F. X. and Prince, R. C. (2003). "Natural cleanup of heavy fuel oil on rocks: an in situ experiment." Marine Pollution Bulletin 46(8): 983-990.

Jimenez, N., Vinas, M., Sabate, J., Diez, S., Bayona, J. M., Solanas, A. M. and Albaiges, J. (2006). "The Prestige oil spill. 2. Enhanced biodegradation of a heavy fuel oil under field conditions by the use of an oleophilic fertilizer." Environmental Science \& Technology 40(8): 2578-2585.

Klein, G. C., Kim, S., Rodgers, R. P., Marshall, A. G. and Yen, A. (2006). "Mass spectral analysis of asphaltenes. II. Detailed compositional comparison of asphaltenes deposit to its crude oil counterpart for two geographically different crude oils by ESI FT-ICR MS." Energy \& Fuels 20(5): 1973-1979.

Lacaze, J. C. and Villedon de Naide, O. (1976). "Influence of Illumination on Phototoxicity of Crude Oil." Marine Pollution Bulletin 7: 73-96.

Lacotte, D. J., Mille, G., Acquaviva, M. and Bertrand, J. C. (1996). "Arabian light 150 asphaltene biotransformation with $n$-alkanes as co-substrates." Chemosphere 32(9): 17551761.

Lubcke-von Varel, U., Machala, M., Ciganek, M., Neca, J., Pencikova, K., Palkova, L., Vondracek, J., Loffler, I., Streck, G., Reifferscheid, G., Fluckiger-Isler, S., Weiss, J. M., Lamoree, M. and Brack, W. (2011). "Polar Compounds Dominate in Vitro Effects of Sediment Extracts." Environmental Science \& Technology 45(6): 2384-2390.

Maki, H., Sasaki, T. and Harayama, S. (2001). "Photo-oxidation of biodegraded crude oil and toxicity of the photo-oxidized products." Chemosphere 44(5): 1145-1151.

McKenna, A. M., Blakney, G. T., Xian, F., Glaser, P. B., Rodgers, R. P. and Marshall, A. G. (2010). "Heavy petroleum composition. 2. Progression of the Boduszynski model to the limit of distillation by ultrahigh-resolution FT-ICR mass spectrometry." Energy \& Fuels 24: 2939-2946.

McNutt, M., Camilli, R., Guthrie, G., Hsieh, P., Labson, V., Lehr, B., Maclay, D., Ratzel, A. and Sogge, M. (2011). Assessment of flow rate estimates for the Deepwater Horizon/Macondo Well oil spill, Flow Rate Technical Group Report to the National Incident Command, Interagency Solutions Group.

MOAB Oil, Inc. (2012b). "Our Business." Retrieved February 9th, 2012, from http://www.moaboil.com/business.htm. 
National Transportation Safety Board (2009). "Marine accident report: allision of Hong Kong-registered containership M/V Cosco Busan with the delta tower of the San Francisco-Oakland Bay Bridge." Washington, DC. NTSB/MAR-09/01. 1-147.

Nelson, R. K., Kile, B. M., Plata, D. L., Sylva, S. P., Xu, L., Reddy, C. M., Gaines, R. B., Frysinger, G. S. and Reichenbach, S. E. (2006). "Tracking the weathering of an oil spill with comprehensive two-dimensional gas chromatography." Environmental Forensics 7(1): 33-44.

Natural Resource Damage Assessment Trustee Agencies (2011). Cosco Busan Oil Spill: News Update.

Plata, D. L., Sharpless, C. M. and Reddy, C. M. (2008). "Photochemical degradation of polycyclic aromatic hydrocarbons in oil films." Environmental Science \& Technology 42(7): 2432-2438.

Reddy, C. (2007). Would spills of bunker fuel alternatives be even worse? San Francisco Chronicle. San Francisco.

Reddy, C. M., Arey, J. S., Seewald, J. S., Sylva, S. P., Lemkau, K. L., Nelson, R. K., Carmichael, C. A., McIntyre, C. P., Fenwick, J., Ventura, G. T., Van Mooy, B. A. S. and Camilli, R. (2011). "Composition and fate of gas and oil released to the water column during the Deepwater Horizon oil spill." Proceedings of the National Academy of Sciences.

Rojas-Avelizapa, N. G., Cervantes-Gonzalez, E., Cruz-Camarillo, R. and RojasAvelizapa, L. I. (2002). "Degradation of aromatic and asphaltenic fractions by Serratia liquefasciens and Bacillus sp." Bulletin of Environmental Contamination and Toxicology 69(6): 835-842.

Rontani, J. F., Bosserjoulak, F., Rambeloarisoa, E., Bertrand, J. C., Giusti, G. and Faure, R. (1985). "Analytical study of Asthart crude oil asphaltenes biodegradation."

Chemosphere 14(9): 1413-1422.

RTI International (2008). "Global Trade and Fuels Assessment - Future Trends and Effects of Designating Requiring Clean Fuels in the Marine Sector." RTI Project Number 0211577.001 .001 .

Scholz, D. K., Kucklick, J. H., Pond, R., Walker, A. H., Bostrom, A. and Fischbeck, P. (1999). "Fate of Spilled Oil in Marine Waters: where does it go? What does it do? How do dispersants affect it?" (API 4691).

Schwarzenbach, R. P., Gschwend, P. M. and Imboden, D. M. (2003). Environmental Organic Chemistry. Hoboken, Wiley-Interscience. 
Slater, G. F., Nelson, R. K., Kile, B. M. and Reddy, C. M. (2006). "Intrinsic bacterial biodegradation of petroleum contamination demonstrated in situ using natural abundance, molecular-level ${ }^{14} \mathrm{C}$ analysis." Organic Geochemistry 37(9): 981-989.

Stout, S. A. and Wang, Z. (2007). Chemical fingerprinting of spilled or discharged petroleum - methods and factors affecting petroleum fingerprints in the environment. Oil Spill Environmental Forensics: Fingerprinting and Source Identification. S. A. Stout and Z. Wang. Boston, Elsevier: 1-53.

Strand, J. A., Cullinan, V. I., Crecelius, E. A., Fortman, T. J., Citterman, R. J. and Fleischmann, M. L. (1992). "Fate of bunker C fuel oil in Washington coastal habitats following the December 1988 NESTUCCA oil spill." Northwest Science 66(1): 1-14.

Tjessem, K. and Aaberg, A. (1983). "Photochemical transformation and degradation of petroleum residues in the marine environment." Chemosphere 12(11-1): 1373-1394.

Tronczynski, J., Munschy, C., Heas-Moisan, K., Guiot, N., Truquet, I., Olivier, N., Men, S. and Furaut, A. (2004). "Contamination of the Bay of Biscay by polycyclic aromatic hydrocarbons (PAHs) following the T/V "Erika" oil spill." Aquatic Living Resources 17(3): 243-259.

Uhler, A. D., Stout, S. A. and Douglas, G. S. (2007). Chemical heterogeneity in modern marine residual fuel oils. Oil Spill Environmental Forensics: Fingerprinting and Source Identification. Z. Wang and S. A. Stout. Boston, Academic Press: 327-348.

United States Energy Information Administration (2012). "Petroleum \& Other Liquids." U. S. Department of Energy. March 1, 2012.

Uraizee, F. A., Venosa, A. D. and Suidan, M. T. (1998). "A Model for diffusion controlled bioavailability of crude oil components." Biodegradation 8(5): 287-296.

Vrabie, C. M., Sinnige, T. L., Murk, A. J. and Jonker, M. T. O. (2012). "Effect-directed assessment of the bioaccumulation potential and chemical nature of $\mathrm{A} h$ receptor agonists in crude and refined oils." Environmental Science \& Technology.

Wang, Z. D., Fingas, M. and Sergy, G. (1994). "Study of 22-year-old Arrow oil samples using biomarker compounds by GC/MS." Environmental Science \&amp; Technology 28(9): 1733-1746.

Wardlaw, G. D., Arey, J. S., Reddy, C. M., Nelson, R. K., Ventura, G. T. and Valentine, D. L. (2008). "Disentangling oil weathering at a marine seep using GCxGC: Broad metabolic specificity accompanies subsurface petroleum biodegradation." Environmental Science \& Technology 42(19): 7166-7173. 
Winebrake, J. J., Corbett, J. J. and Meyer, P. E. (2007). "Energy use and emissions from marine vessels: A total fuel life cycle approach." Journal of the Air \&amp; Waste Management Association 57(1): 102-110.

Wolfe, D. A., Hameedi, M. J., Galt, J. A., Watabayashi, G., Short, J., O'Claire , C., Rice, S., Michel, J., Payne, J. R., Braddock, J. F., Hanna, S. and Sale, D. (1994). "The fate of the oil spilled from the Exxon Valdez." Environmental Science \& Technology 29(13): $561 \mathrm{~A}-568 \mathrm{~A}$. 


\section{Chapter 2}

\section{The M/V Cosco Busan Spill: source identification and short- term fate}

Karin L. Lemkau ${ }^{\text {a,b }}$, Emily E. Peacock ${ }^{\text {b }}$, Robert K. Nelson ${ }^{\mathrm{b}}$, G. Todd Ventura ${ }^{\mathrm{b}, 1}$, Jennifer L. Kovecses ${ }^{c, 2}$, Christopher M. Reddy ${ }^{b}$

${ }^{\text {a } M I T / W H O I ~ J o i n t ~ P r o g r a m ~ i n ~ O c e a n o g r a p h y / A p p l i e d ~ O c e a n ~ S c i e n c e ~ a n d ~ E n g i n e e r i n g, ~ U S A ~}$

${ }^{\mathrm{b}}$ Department of Marine Chemistry and Geochemistry, Woods Hole Oceanographic Institution, 360 Woods Hole Rd., Woods Hole, MA 02543, USA

This chapter originally appeared as a manuscript in Marine Pollution Bulletin.

It is reproduced here with their permission.

Citation:

Lemkau, K.L., Peacock, E.E., Nelson, R.K., Ventura, G.T., Kovecses, J., Reddy, C.M, 2010. The M/V Cosco Busan spill: Source identification and short-term fate. Marine Pollution Bulletin 60(10), 2123-2123. doi: 10.1016/j.marpolbul.2010.09.001 
Baseline

Edited by Bruce J. Richardson

The objective of BASELINE is to publish short communications on different aspects of pollution of the marine environment. Only those papers which clearly identify the quality of the data will be considered for publication. Contributors to Baseline should refer to 'Baseline-The New Format and Content' (Mar. Pollut. Bull. 60, 1-2).

\title{
The M/V Cosco Busan spill: Source identification and short-term fate
}

\author{
Karin L. Lemkau a,b,*, Emily E. Peacock ${ }^{\text {b }}$, Robert K. Nelson ${ }^{\text {b }}$, G. Todd Ventura ${ }^{\text {b,1 }}$, Jennifer L. Kovecses ${ }^{\text {c,2 }}$, \\ Christopher M. Reddy ${ }^{\mathrm{b}}$
}

${ }^{a}$ MIT/WHOI Joint Program in Oceanography/Applied Ocean Science and Engineering, USA

${ }^{\mathrm{b}}$ Department of Marine Chemistry and Geochemistry, Woods Hole Oceanographic Institution, Woods Hole, MA 02543, USA

${ }^{\text {c }}$ San Francisco Baykeeper, 785 Market Street, Suite 850, San Francisco, CA 94103, USA

\section{A R T I C L E I N F O}

\section{Keywords:}

Heavy fuel oil

Petroleum weathering

Pan Francisco Bay

Oil spills

$\mathrm{M} / \mathrm{V}$ Cosco Busan

\begin{abstract}
A B S T R A C T
Understanding the fate of heavy fuel oils (HFOs) in the environment is critical for sound decisions regarding its usage and spill cleanup. To study weathering of HFOs, we examined the M/V Cosco Busan spill (November 2007; San Francisco Bay, CA, USA). In this baseline report, we identified which ruptured tank (port tank 3 or 4 ) was the source of the spilled oil and characterized changes in the oil composition across location and time. Samples from three impacted shorelines, collected within 80 days of the spill, were analyzed using one- and two-dimensional gas chromatography (GC and GC $\times$ GC, respectively). Weathering varied across sites, but compounds with GC retention times less than $n$ - $C_{16}$ were generally lost by evaporation and dissolution. Changes in $n-C_{18} /$ phytane and benz $[a]$ anthracene/chrysene ratios indicated some biodegradation and photodegradation, respectively.
\end{abstract}

(c) 2010 Elsevier Ltd. All rights reserved.

\section{Introduction}

On November 7, 2007, the container ship M/V Cosco Busan struck the San Francisco-Oakland Bay Bridge (commonly referred to as the Bay Bridge) rupturing three port-side wing tanks: two containing fuel for transport (port tanks 3 and 4) and one ballast tank (port tank 2) (National Transportation Safety Board, 2009). Approximately 200,000 L (53,500 gallons) of heavy fuel oil (HFO; group IFO380) leaked into San Francisco Bay (Fig. 1), impacting $190 \mathrm{~km}$ of coastline (NRDA Trustee Agencies, 2008).

Heavy fuel oils are used to power marine vessels and are important in the global economy; however, despite their prevalence,

* Corresponding author at: MIT/WHOI Joint Program in Oceanography/Applied Ocean Science and Engineering, USA. Tel.: +1 508289 3381; fax: +1 5084572164 . E-mail addresses: klemkau@whoi.edu, klemkau@mit.edu (K.L. Lemkau).

1 Present address: Department of Earth Sciences, University of Oxford, Parks Road, Oxford, OX1 3PR, UK.

2 Present address: San Diego Coastkeeper, 2825 Dewey Road, Suite 200, San Diego, CA 92106, USA

0025-326X/\$ - see front matter $\odot 2010$ Elsevier Ltd. All rights reserved. doi:10.1016/j.marpolbul.2010.09.001 there have only been a few well-studied HFO spills (e.g., the Erika spill of 1999, the 2002 Prestige spill and the 2003 Bouchard 120 spill). These fuels are distinct from distillate fuels (e.g., diesel and gasoline) in that they are prepared from the hydrocarbon residue remaining after crude oil distillation (Uhler et al., 2007) amended with petroleum distillates, or cutting oils, to decrease viscosity and aid in transport and use. Because both crude oils and cutting oils vary, there is no standard HFO (Uhler et al., 2007). Understanding how this variability in composition affects HFO weathering is crucial to predicting impacts and weathering of future spills. With increasing international trade, the use of HFOs is predicted to nearly double in the next decade (RTI International, 2008). Given the potential environmental impacts and predicted increase in HFO use, opportunities to study such spills should be seized. In this study, we identify and characterize the spilled oil from the M/V Cosco Busan and examine changes due to weathering during the first 80 days post-spill, with attention to geographic and temporal variability.

To determine the source of the spilled oil, two samples of neat oil from the ruptured tanks (tanks 3 and 4), were obtained from the 


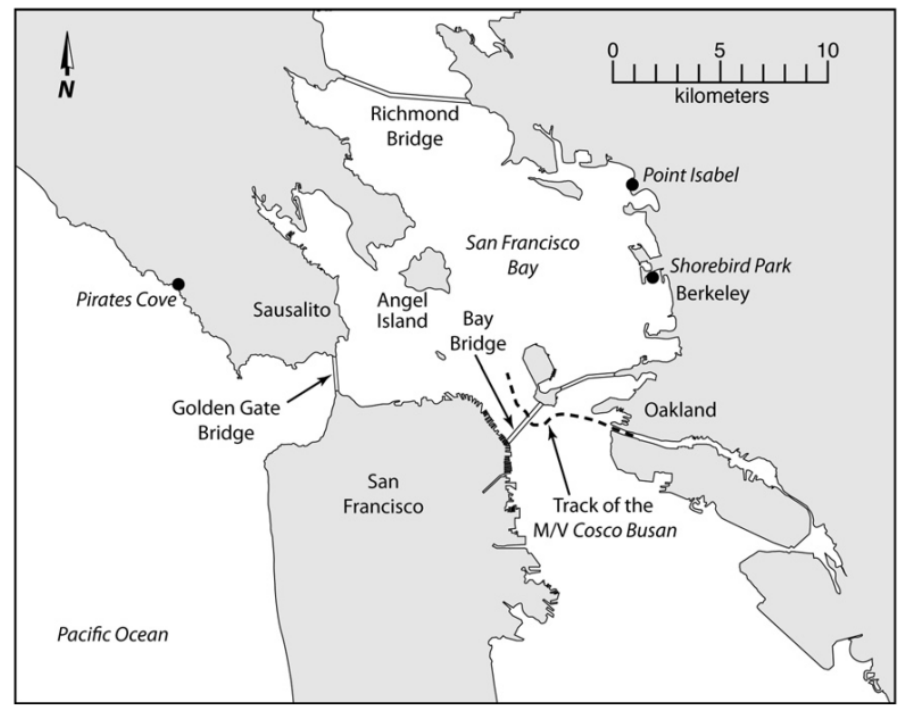

Fig. 1. Map of San Francisco Bay showing sampling locations (black dots) and track of the M/V Cosco Busan before and after alliding with the Bay Bridge.

Table 1

Sample collection dates and the number of samples collected at each site. Day zero is defined as the date of the spill, November 7, 2007.

\begin{tabular}{|c|c|c|c|c|c|c|}
\hline \multirow[t]{2}{*}{ Sampling site } & \multicolumn{6}{|c|}{ Sampling date } \\
\hline & $\begin{array}{l}11 / 15 / 2007 \\
\text { (day } 8 \text { ) }\end{array}$ & $\begin{array}{l}11 / 28 / 07 \\
\text { (day 21) }\end{array}$ & $\begin{array}{l}\text { 12/11-12/12/07 } \\
\text { (days } 34-35 \text { ) }\end{array}$ & $\begin{array}{l}1 / 1-1 / 2 / 08 \\
\text { (days 55-56) }\end{array}$ & $\begin{array}{l}1 / 24-1 / 26 / 08 \\
\text { (days } 78-80 \text { ) }\end{array}$ & Total samples \\
\hline Shorebird Park & 2 & 5 & 4 & 5 & 3 & 19 \\
\hline Point Isabel Rocks & - & - & 5 & 2 & 2 & 9 \\
\hline Point Isabel Plates & - & - & - & 6 & 3 & 9 \\
\hline Pirates Cove & - & - & - & 5 & 7 & 12 \\
\hline
\end{tabular}

National Oceanic and Atmospheric Administration following continuous chain-of-custody procedures. For the other analyses, field samples were collected as oiled-coated rocks and scrapings at three coastal sites during the first 80 days after the spill: Shorebird Park, Point Isabel and Pirates Cove (Fig. 1). Since Point Isabel had been the dumpsite of the Technical Porcelain and Chinaware Company; oil samples from both rocks and discarded ceramic plates were collected from that site. Pictures and descriptions of sampling sites can be found in the supporting information (S1).

Sampling at Shorebird Park began one week post-spill, whereas sampling at Point Isabel and Pirates Cove began 1 and 2 months after the spill, respectively. Sampling dates and numbers of samples collected at each site are shown in Table 1. Rocks were stored in glass jars with Teflon-lined caps. When no small rocks were present, oil was scraped from large rocks or boulders with a clean stainless steel spatula and stored in combusted $\mathrm{Al}$-foil envelopes. Over time, oil became more difficult to find, in part because of cleanup efforts that continued until sites met the "no oil observed" requirement (Moore et al., 2008b), and required sample collection from increasingly sheltered areas at each site (e.g., the undersides of rocks). Active cleanup at all sample collection sites ended on or before December 28, 2007. Samples were transported to Woods Hole, MA and frozen $\left(-20^{\circ} \mathrm{C}\right)$.

Samples were dissolved in dichloromethane $\left(\sim 5 \mathrm{mg} \mathrm{mL}^{-1}\right)$ and stored in amber glass vials with Teflon-lined caps until analysis (Uhler et al., 2007). Separate aliquots were used for GC with flame ionization detection (GC-FID), mass spectrometry detection (GC$\mathrm{MS}$ ), and comprehensive two-dimensional gas chromatography $(\mathrm{GC} \times \mathrm{GC})($ Nelson et al., 2006).
Complete methods for GC analyses can be found in the supporting material (S2). Briefly, non-polar glass capillary columns were used for GC-FID and GC-MS separations. GC-FID analysis was performed on a Hewlett-Packard Series II GC using cool-on-column injection. GC-MS analysis was performed on an Agilent 6890 Series GC with an Agilent 5937 MS detector operating in full scan mode. We analyzed for the following parent PAHs and their alkylated homologs: naphthalene, fluorene, phenanthrene/anthracene, dibenzothiophene. We also measured benz $[a]$ anthracene $(\mathrm{BaA})$, chrysene (Chr), benzo[a]pyrene (BaP) and benzo[e]pyrene (BeP). Response factors were determined using $n$-alkane and perdeuterated internal standards for GC-FID and GC-MS, respectively. All laboratory blanks were free of petroleum compounds.

GC $\times$ GC-MS and GC $\times$ GC-FID conditions were similar to methods previously described (Nelson et al., 2006). Briefly, first dimension separations were performed on a non-polar column resulting in a boiling point separation, while second dimension separations were performed on a polar column yielding a polarity-base separation. GC $\times$ GC-MS and GC $\times$ GC-FID were used for identification and quantification. Once collected, each $\mathrm{GC} \times \mathrm{GC}-$ FID image was base-plane subtracted (Reichenbach et al., 2003) and normalized to the conserved biomarker $17 \alpha(\mathrm{H}), 21 \beta(\mathrm{H})$-hopane (Prince et al., 1994). A complete list of biomarkers analyzed can be found in Table 2 .

Because of confusion surrounding the source of the spilled oil, we first sought to identify the source oil. Based on oil levels in the two ruptured tanks, authorities agreed that only one of the tanks leaked into the bay; however, an initial report identifying tank 3 as the source of the spilled oil conflicts with subsequent reports 
(Moore et al., 2008a; United States Coast Guard, 2009). Since both tanks were ruptured and vessels can carry fuels with distinctly different properties (Hoffman and Quinn, 1979; Reddy and Quinn, 1999), prudence demanded additional verification.

To determine which ruptured tank was the source of the spilled oil, we used a modified Nordtest (Hansen et al., 2007) to compare field samples to the two potential source oils (tanks 3 and 4). This method consists of 3 levels of analysis: levels 1 and 2 compare chromatographic traces and diagnostic ratios from GC-FID and GC-MS, respectively. These diagnostic ratios include biomarker ratios as well as ratios of alkylated PAH compounds. Level 3 analysis consists of statistical tests of these diagnostic ratios. Level 1 and level 2 analyses were performed on all field samples and the two neat oils, while level 3 analysis was undertaken for 16 representative

Table 2

Select biomarker ratios used to identify the source oil, based on a GC × GC-modified Nordtest method described by Hansen et al. (2007). Ratios for M/V Cosco Busan tank 3 and 4 oils are presented, as well as average values from samples collected after the spill and Monterey oil values for comparison. Ratios were obtained by GC $\times$ GC-MS analysis ${ }^{\mathrm{a}}$.

\begin{tabular}{lllll}
\hline Biomarker ratios & $\begin{array}{l}\text { Cosco } \\
\text { Busan } \\
\text { tank 3 } 3\end{array}$ & $\begin{array}{l}\text { Cosco } \\
\text { Busan } \\
\text { tank } 4\end{array}$ & $\begin{array}{l}\text { SF Bay field } \\
\text { samples }(n=16)^{\mathrm{b}}\end{array}$ & $\begin{array}{l}\text { Monterey } \\
\text { oil }^{\mathrm{c}}\end{array}$ \\
\hline Triplet $^{\mathrm{d}}$ & 0.671 & 2.89 & $2.96 \pm 0.12$ & 4.12 \\
$\mathrm{C}_{29} \alpha \beta / \mathrm{C}_{30} \mathrm{C} \alpha \beta^{\mathrm{e}}$ & 1.06 & 0.832 & $0.817 \pm 0.032$ & 0.826 \\
$\mathrm{C}_{28} \alpha \beta \beta \mathrm{R} / \mathrm{C}_{29} \alpha \beta \beta \mathrm{R}^{\mathrm{f}}$ & 0.935 & 0.966 & $0.962 \pm 0.055$ & 1.28 \\
$\mathrm{C}_{30} \mathrm{O} / \mathrm{C}_{30} \alpha \beta^{\mathrm{g}}$ & 0.133 & 0.202 & $0.220 \pm 0.0091$ & 0.0424 \\
$\mathrm{C}_{23} / \mathrm{Tm}^{\mathrm{h}}$ & 1.69 & 2.48 & $2.44 \pm 0.13$ & 3.43 \\
$\mathrm{C}_{29}(22 \mathrm{~S}+22 \mathrm{R}) / \mathrm{Tm}^{\mathrm{i}}$ & 0.558 & 1.00 & $1.01 \pm 0.051$ & 0.675 \\
$\mathrm{C}_{28} \alpha \beta / \mathrm{Tm}^{\mathrm{j}}$ & 0.0961 & 0.234 & $0.222 \pm 0.017$ & 7.35 \\
$\mathrm{Ts} / \mathrm{Tm}^{\mathrm{k}}$ & 0.677 & 0.308 & $0.317 \pm 0.012$ & 0.0968 \\
$\mathrm{C}_{32}$ IsoA/biphytane & 4.47 & 0.239 & $0.254 \pm 0.040$ & 0.195 \\
\hline
\end{tabular}

${ }^{a} \mathrm{GC} \times \mathrm{GC}-\mathrm{MS}$ provides a higher signal to noise and better resolution than GCMS analysis (Gaines et al., 2007).

b Field samples collected from Shorebird Park, Point Isabel and Pirates Cove spanning from 8 to 80 days post-spill. Samples were analyzed and individually spanning from 8 to 80 days post-spill. Samples were analyzed and individually
compared to the potential source oils; all were determined to be similar to the tank

4 oil.

c Monterey oil is a common source of tar balls found along the California coast (Hostettler et al., 2004).

${ }^{d}$ Ratio of $\mathrm{C}_{26}$ tricyclic terpanoids ( $\mathrm{S}+\mathrm{R}$ epimers) to $\mathrm{C}_{24}$ tetracyclic terpanoids.

e Ratio of $17 \alpha(\mathrm{H}), 21 \beta(\mathrm{H})-30$-norhopane to $17 \alpha(\mathrm{H}), 21 \beta(\mathrm{H})$-hopane.

${ }^{f}$ Ratio of 24-methyl- $5 \alpha(\mathrm{H}), 14 \beta(\mathrm{H}), 17 \beta(\mathrm{H}), 20 \mathrm{R}$-cholestane to 24-ethyl$5 \alpha(\mathrm{H}), 14 \beta(\mathrm{H}), 17 \beta, 20 \mathrm{R}$-cholestane.

$\mathrm{g}$
Ratio of $18 \alpha(\mathrm{H})$-oleanane to $17 \alpha(\mathrm{H}), 21 \beta(\mathrm{H})$-hopane.

h Ratio of $\mathrm{C}_{23}$ tricyclic terpanoids to $17 \alpha(\mathrm{H})$-22,29,30-trisnorhopane.
h

Ratio of $\mathrm{C}_{23}$ tricyclic terpanoids to $17 \alpha(\mathrm{H})-22,29,30$-trisnorhopane.
Ratio of $\mathrm{C}_{29}$ tricyclic terpanoids ( $\mathrm{S}+\mathrm{R}$ epimers) to $17 \alpha(\mathrm{H})-22,29,30-$ trisnorhopane.

${ }^{j}$ Ratio of $17 \alpha(\mathrm{H}), 21 \beta(\mathrm{H})-28,30$-bisnorhopane to $17 \alpha(\mathrm{H})$-22,29,30-trisnorhopane,

${ }^{k}$ Ratio of $18 \alpha(\mathrm{H})-22,29,30$-trisnorneohopane to $17 \alpha(\mathrm{H})$-22,29,30-trisnorhopane.

${ }^{1}$ Ratio of a $\mathrm{C}_{32}$ isoprenoid alkane (identified by GC $\times$ GC-MS) to biphytane. field samples and the two neat oils. Both GC-FID and GC-MS fingerprints from samples were consistent with those from the tank 4 oil (Fig. 2). Additionally, diagnostic ratios, including that of the $C_{3}$-dibenzothiophenes to the $C_{3}$-phenanthrenes, from these analyses were also consistent with tank 4 values (Douglas et al., 1996; Fig. S2). For level 3 analysis of biomarker ratios we utilized GC $\times$ GC-MS and GC $\times$ GC-FID instead of GC-MS due to the higher signal to noise and higher resolution with these techniques (Gaines et al., 2007). Biomarker ratios of these samples were found to be consistent with the tank 4 oil (with 95\% confidence; Hansen et al., 2007). A summary of several diagnostic ratios for the tank 3 and 4 oils, M/V Cosco Busan field samples, and Monterey oil (a potential source of oil contamination from natural oil seeps in the area; Hostettler et al., 2004) is shown in Table 2.

The tank 4 oil is characterized by an $n$-alkane range from $n-C_{10}$ to greater than $n-C_{45}$ with most of the GC-detectable mass residing in an elution window between $n-C_{16}$ and $n-C_{38}$ (Fig. 2). The $n$-alkanes have a unimodal distribution centered at $n-C_{24}$ to $n-C_{26}$. Abundant alkylated two and three ring PAHs, presumably from the cutting oil (Uhler et al., 2007), are also present, as is 2-methyl anthracene, a PAH not frequently observed in crude oils but formed during the refining process (Uhler et al., 2007). These features are consistent with the tank 4 oil being a HFO composed of a refinery residue blended with a lighter distillate cutting oil.

Having identified tank 4 as the source of the spilled oil, we proceeded to analyze our field samples for evidence of weathering, focusing on dissolution/evaporation, biodegradation and photodegradation. We analyzed 49 field samples, collected within the initial 80 days post-spill, by GC-FID and GC-MS. Figs. 3 and 4 and Table 3 present data illustrating the general trends observed. Various degrees of weathering were observed at all sites.

The effects of evaporation and dissolution are difficult to disentangle. These processes act on similar, lower molecular weight, compounds that elute early on a non-polar GC column (Arey et al., 2005, 2007a,b). Because of the similar target compounds, one-dimensional techniques are not adequate to definitively isolate the individual impacts of these processes (Arey et al., 2005, 2007a,b). Generally, evaporation is considered the dominant weathering process during the initial days after an oil spill (Stout and Wang, 2007 and references therein). Here we report on the combined effects of these processes.

All sampling locations experienced similar losses consistent with dissolution and evaporation (e.g., Arey et al., 2007a,b; Wang et al., 1995). The GC-FID chromatograms from Shorebird Park show a progressive loss of early-eluting compounds following the spill (Fig. 3). Similar changes occurred at the other two sites; however, these trends are less visible due to the delayed start of

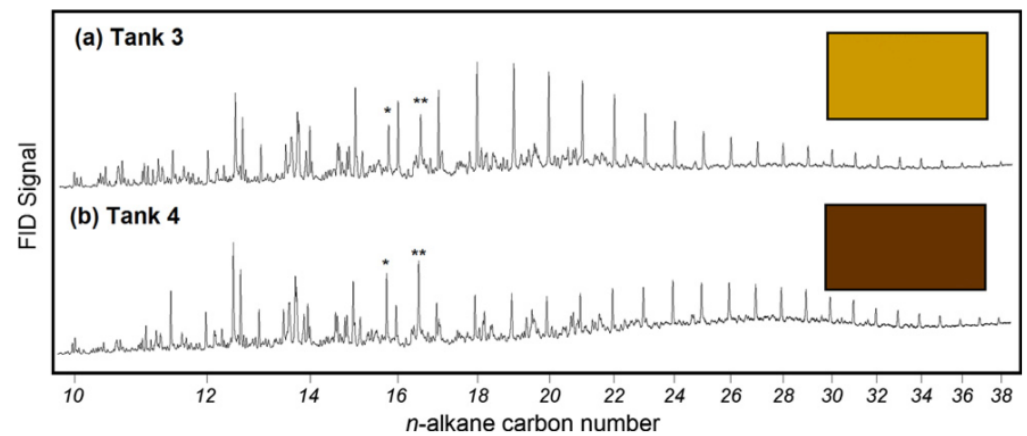

Fig. 2. GC-FID chromatograms of the oils from the two ruptured tanks (a) tank 3 and (b) tank 4 . Insets show respective oils photographed at a $10 \mu \mathrm{g} \mathrm{mL}^{-1}$ dilution in dichloromethane. Tank 3 is mustard in color while tank 4 is a dark coffee color. Asterisks indicate internal and external standards, $n$-hexadecane- $d_{34}()$ and octyl ether ( $)$, respectively. 


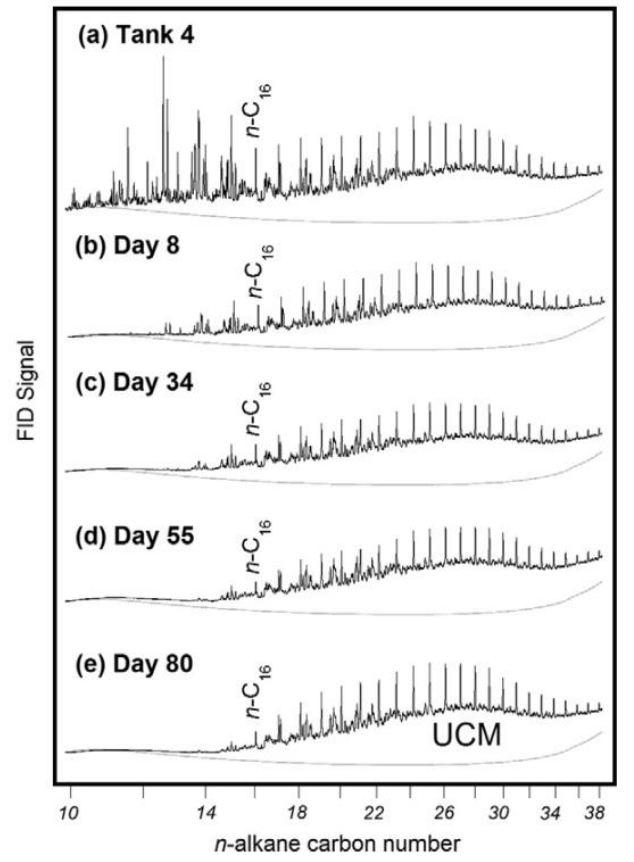

Fig. 3. GC-FID chromatograms of the tank 4 oil (a) and Shorebird Park samples (b)(e) showing evolution of total petroleum hydrocarbon weathering. The dichloromethane baseline is shown in gray below each chromatogram.

sampling at these sites. At Shorebird Park, $n$-alkanes up to $n-C_{16}$ were lost by day 80 , but $n$-alkane distributions between $n-C_{16}$ and $n-\mathrm{C}_{45+}$ remained unchanged with time (Fig. 3 ). Though the ob-

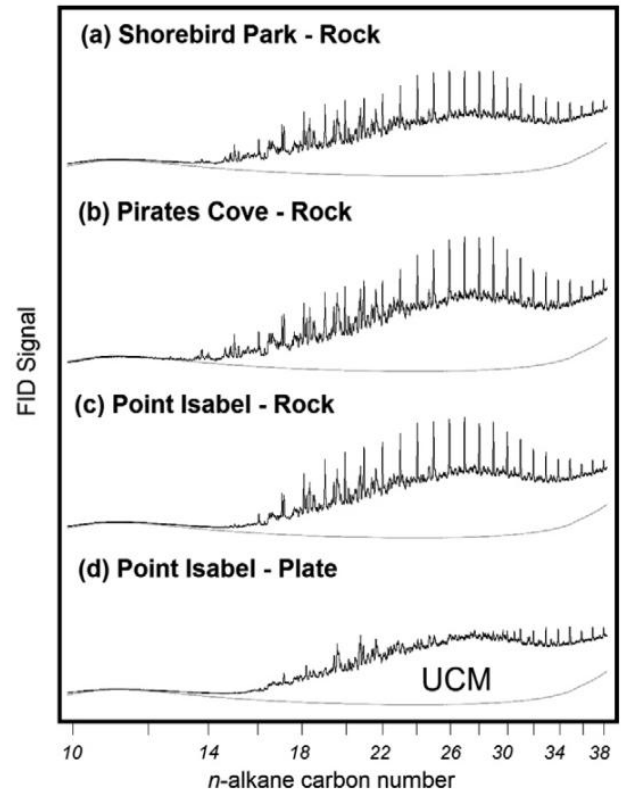

Fig. 4. GC-FID chromatograms of samples collected 55 days after the spill from three different sampling sites (a)-(c). Substrate appears to have a dramatic impact on weathering as seen in Point Isabel rock (c) and plate scrapings (d). The dichloromethane baseline is shown in gray below each chromatogram.

served changes are visually dramatic, measured TPHs did not change significantly over time; the $n-C_{10}$ to $n-C_{16}$ region, from which most of the compounds were lost, accounts for less than $17 \%$ of TPHs in the tank 4 oil. Fig. $4 \mathrm{a}-\mathrm{c}$ presents representative

Table 3

PAH concentrations $\left(\mathrm{mg} \mathrm{g}^{-1}\right)$ from representative samples collected at each site from initial day of sampling and 80 days post-spill. Note the change in initial day of sample collection between each site.

\begin{tabular}{|c|c|c|c|c|c|c|c|}
\hline \multirow[t]{2}{*}{ Compound } & \multirow[t]{2}{*}{ Cosco Busan tank 4} & \multicolumn{2}{|c|}{ Shorebird Park } & \multicolumn{2}{|c|}{ Point Isabel } & \multicolumn{2}{|c|}{ Pirates Cove } \\
\hline & & Day $8^{\text {a }}$ & Day 80 & Day $35^{\mathrm{a}}$ & Day 80 & Day $55^{\mathrm{a}}$ & Day 78 \\
\hline Naphthalene & 1.72 & 0.0886 & ND & ND & ND & ND & ND \\
\hline$C_{1}$-naphthalenes & 3.35 & 0.494 & ND & ND & ND & ND & ND \\
\hline $\mathrm{C}_{2}$-naphthalenes & 4.79 & 1.46 & ND & 0.382 & 0.267 & 0.368 & 0.236 \\
\hline $\mathrm{C}_{3}$-naphthalenes & 4.52 & 1.96 & 0.596 & 0.781 & 0.716 & 1.09 & 0.641 \\
\hline $\mathrm{C}_{4}$-naphthalenes & 2.65 & 1.49 & 0.801 & 0.792 & 0.689 & 1.10 & 0.696 \\
\hline ¿naphthalenes & 17.0 & 5.49 & 1.52 & 2.04 & 1.70 & 2.59 & 1.60 \\
\hline Fluorene & 0.195 & 0.0872 & 0.0415 & 0.0385 & 0.0352 & 0.0530 & 0.0383 \\
\hline $\mathrm{C}_{1}$-fluorenes & 0.556 & 0.334 & 0.275 & 0.226 & 0.217 & 0.303 & 0.228 \\
\hline $\mathrm{C}_{2}$-fluorenes & 1.22 & 0.868 & 0.767 & 0.711 & 0.586 & 0.859 & 0.767 \\
\hline $\mathrm{C}_{3}$-fluorenes & 1.37 & 1.06 & 0.998 & 0.971 & 0.776 & 1.07 & 0.963 \\
\hline ¿fluorenes & 3.34 & 2.35 & 2.08 & 1.95 & 1.61 & 2.28 & 2.00 \\
\hline Phenanthrene & 0.785 & 0.493 & 0.420 & 0.365 & 0.398 & 0.421 & 0.313 \\
\hline$C_{1}$-phenanthrenes/anthracenes & 2.51 & 1.83 & 1.79 & 1.48 & 1.41 & 1.52 & 1.19 \\
\hline $\mathrm{C}_{2}$-phenanthrenes/anthracenes & 4.04 & 3.23 & 3.09 & 2.67 & 2.34 & 2.65 & 2.03 \\
\hline $\mathrm{C}_{3}$-phenanthrenes/anthracenes & 4.03 & 3.34 & 3.02 & 2.78 & 2.21 & 2.60 & 1.97 \\
\hline $\mathrm{C}_{4}$-phenanthrenes/anthracenes & 2.78 & 2.36 & 1.97 & 1.95 & 1.43 & 1.78 & 1.37 \\
\hline ¿phenanthrenes/anthracenes & 14.1 & 11.2 & 10.3 & 9.25 & 7.79 & 8.97 & 6.87 \\
\hline Dibenzothiophene & 0.235 & 0.131 & 0.118 & 0.0914 & 0.108 & 0.121 & 0.0829 \\
\hline$C_{1}$-dibenzothiophenes & 0.904 & 0.607 & 0.617 & 0.498 & 0.523 & 0.545 & 0.453 \\
\hline $\mathrm{C}_{2}$-dibenzothiophenes & 1.54 & 1.18 & 1.14 & 0.981 & 0.934 & 0.965 & 0.772 \\
\hline $\mathrm{C}_{3}$-dibenzothiophenes & 1.57 & 1.27 & 1.18 & 1.08 & 0.911 & 1.03 & 0.817 \\
\hline$\Sigma$ dibenzothiophenes & 4.25 & 3.18 & 3.05 & 2.65 & 2.48 & 2.66 & 2.12 \\
\hline$C_{3}$-dibenzothiophenes $/ C_{3}$-phenantherene ${ }^{b}$ & 0.389 & 0.379 & 0.392 & 0.389 & 0.413 & 0.396 & 0.414 \\
\hline$\Sigma \mathrm{PAHs}^{\mathrm{c}}$ & 38.7 & 22.3 & 16.9 & 15.9 & 13.6 & 16.5 & 12.6 \\
\hline
\end{tabular}

a Note differences in initial date of sampling for each site.

${ }^{\mathrm{b}}$ Ratio commonly used for source identification (Douglas et al., 1996).

c Sum of naphthalenes, fluorenes, phenanthrenes/anthracenes and dibenzothiophenes. 
GC-FID chromatograms from each site at 55 days post-spill. As observed for Shorebird Park (Fig. 3), all sites experienced decreasing $n$-alkane concentrations through day 55 with increases in concentration on day 80 . This trend is consistent with collection of less weathered samples from sheltered areas as exposed oil was removed by cleanup crews and became more difficult to find (Hayakawa et al., 2006; Irvine et al., 2006). Contamination from another source is not suspected since biomarkers and PAH source ratios of collected samples match the tank 4 oil (Table 2, Fig. S2).

$\mathrm{PAH}$ losses were also consistent with evaporation and dissolution (Arey et al., 2007a,b; Eganhouse and Calder, 1976; Sutton and Calder, 1975; McAuliffe, 1966). PAHs from six representative samples are shown in Table 3 (PAH data for all samples is presented in Table S1). Naphthalenes are of special interest due to their toxicity, and with other low molecular weight PAHs are often used to monitor recovery after a spill (Boehm and Page, 2007; Page et al., 2002). Naphthalene content decreased rapidly following the spill with neat oil values of $17.0 \pm 1.7 \mathrm{mg} \mathrm{g}^{-1}$ dropping to less than $6 \mathrm{mg} \mathrm{g}^{-1}$ within the first 8 days after the spill. Concentrations continued to decrease until leveling off at approximately $2 \mathrm{mg} \mathrm{g}^{-1}$ 55 days post-spill (Fig. 5). Point Isabel samples contained the lowest measured naphthalene concentrations. As is often observed, $\mathrm{PAH}$ loss was related to size with larger, more alkylated PAHs being more recalcitrant (e.g., Ezra et al., 2000; Prince et al., 2003; Wang et al., 1994). Final concentrations of fluorenes, phenanthrenes and dibenzothiophenes are highest in samples from Shorebird Park; Pirates Cove samples had the lowest concentrations of these PAHs.

We can examine biodegradation within our samples by monitoring the loss of more labile $n$-alkanes relative to more recalcitrant branched isoprenoid alkanes (Peters et al., 2005). We evaluated the $n-C_{17} /$ pristane and $n-C_{18} /$ phytane ratios (Fig. 6a; only the latter is shown), commonly used as early indicators of biodegradation (Blumer and Sass, 1972; Burns and Teal, 1979; Wang et al., 1994, 1998; Wang and Fingas, 1995a).

At Shorebird Park the $n-C_{18}$ phytane ratio decreases from the neat oil ratio 35 days post-spill, indicating a lag of several weeks before biodegradation was detectable. This observed time lag before onset of biodegradation (based on the $n$ - $\mathrm{C}_{18} /$ phytane ratio) was comparable to the one to two month delays reported for the

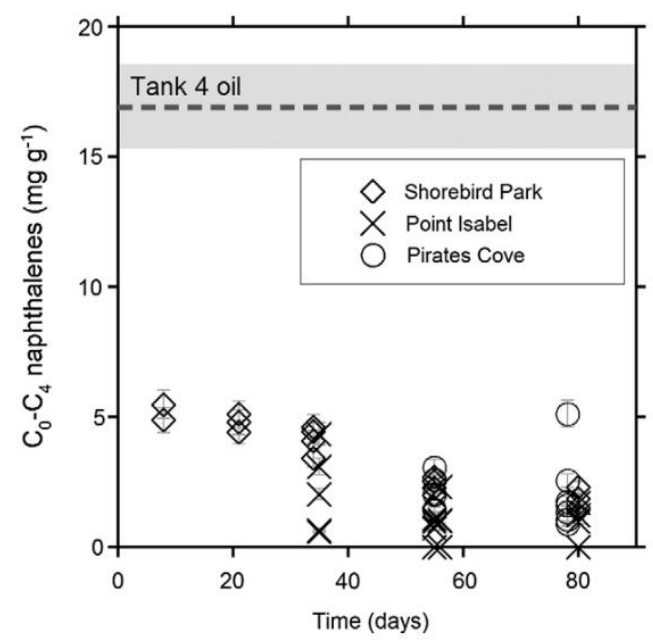

Fig. 5. Total naphthalene content $\left(C_{0}-C_{4}\right)$ versus time. Error bars shown indicate $\pm 10 \%$ based on calculated precision of measurements. Data for this figure is presented in Table S1. coastal Bouchard 120 (Arey et al., 2007a; Slater et al., 2006) and the marine Prestige (Diez et al., 2007) HFO spills, but longer than the lag after the Eshkol power station HFO spill (Ezra et al. 2000). Biodegradation rates also differ across these spills. These differences can be attributed to variations in local environments such as temperature, exposure to water, nutrient loading, and amount of the spilled oil (Atlas, 1981).

This study cannot speak to lags experienced at Point Isabel and Pirates cove, where biodegradation was already detectible in the first set of samples ( 35 and 55 days post-spill, respectively). However, from the decreasing $n-C_{18} /$ phytane ratios at Point Isabel, it appears that biodegradation continued in the weeks following our initial sample collection.

At Point Isabel, oil samples collected from plates and rocks show roughly the same loss of earlier-eluting compounds, however, $n$-alkane distributions of samples collected from these two substrates were different (Fig. 4c and d). In plate samples, the $n$-alkanes were almost entirely removed, while they were still prominent in comparable rock samples from the same time. Among the collected plates, the extent of $n$-alkane removal varied; nearly complete removal up to at least $n-C_{24}$ occurred in all samples, while losses extending up to $n-C_{30}$ occurred in some samples.

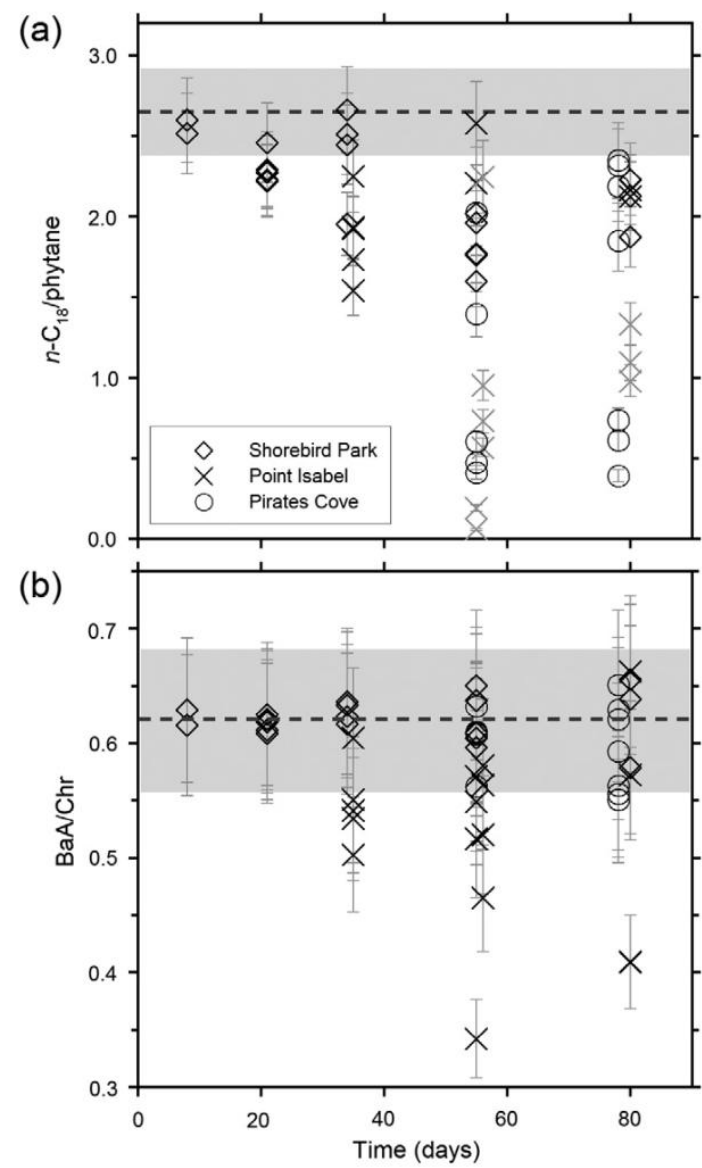

Fig. 6. Time series showing commonly used diagnostic ratios for (a) biodegradation and (b) photodegradation. Gray ' $x$ 's indicate plate samples collected at Point Isabel. Error bars indicate $\pm 10 \%$ based on calculated precision of measurements. Data fo this figure is presented in Table S2. 
Extensive degradation of $n$-alkanes was also seen in several samples from the exposed site of Pirates Cove. Ratios of $n-C_{18} /$ phytane reflect these differences between substrates. Rock and plate samples collected 55 days after the spill show distinct biodegradation patterns with $n-C_{18} /$ phytane ratios of $2.39 \pm 0.26 \quad(n=2)$ and $0.79 \pm 0.79(n=6)$, respectively (Fig. $6 a)$. One plate sample, collected 55 days after the spill, does not follow this trend and has a higher ratio value of 2.25 , similar to collected rock samples; this sample falls greater than two standard deviations from the average plate values and highlights the variability observed at a single site. Similar trends of lower ratios for plate samples are evident at 80 days post-spill $(2.15 \pm 0.03, n=2$, and $1.14 \pm 0.18, n=3$, for rock and plate samples, respectively). Though no measurements were made, the oil layer on collected plates appeared thinner than layers observed on rock samples. Thinner oil layers would result in less sub-surface oil shielded from weathering processes. Bordenave et al. (2004) observed similar increased $n$-alkane removal with decreased sample thickness.

To evaluate biodegradation of PAHs, we compared GC-MS ion traces for the $\mathrm{C}_{2^{-}}$, and $\mathrm{C}_{3}$-naphthalenes and the $\mathrm{C}_{1^{-}}, \mathrm{C}_{2^{-}}$, and $\mathrm{C}_{3}$-dibenzothiophenes and phenanthrenes to the tank $4 \mathrm{PAH}$ distributions (Bayona et al., 1986; Budzinski et al., 1998; Diez et al., 2005; Kropp et al., 1997; Peacock et al., 2007; Prince et al., 2003; Wang and Fingas, 1995b; Wang et al., 1998). No preferential degradation of phenanthrenes, dibenzothiophenes or $\mathrm{C}_{1}$ - and $\mathrm{C}_{2}$-naphthalenes was observed; however, some changes in $\mathrm{C}_{3}$-naphthalenes isomers are suggested by relative changes of two peaks in the $\mathrm{m} / \mathrm{z} 170$ window. To explore further, we also examined these relative changes via GC $\times$ GC-MS. Using collected mass spectra, from one- and two-dimensional techniques, and the work of Rowland et al. (1984) these two peaks were tentatively identified as the 1,4,6and 1,3,5- (coeluting) and 2,3,6- $C_{3}$-naphthalene isomers. These alterations are unexpected given the unaltered $C_{2}$-naphthalene distributions, generally known to be more susceptible to biodegradation (Atlas 1981; Wang et al., 1998).

Photodegradation was examined using ratios of PAHs that weather similarly by other processes but have been shown to photodegrade at different rates: $\mathrm{BaA}$ to $\mathrm{Chr}$ and $\mathrm{BaP}$ to BeP (Fig. 6b; only the former is shown) (Behymer and Hites, 1988; Douglas et al., 2002; Plata et al., 2008). About one month after the spill these ratios began to decrease indicating the onset of photodegradation. Point Isabel is the only site to show any significant degradation of the $\mathrm{BaA}$ to $\mathrm{Chr}$ ratio in the initial 80 days, and the extent of degradation at this site is highly variable. The low impact of photodegradation on samples from the other sites is similar to that observed for the Prestige oil samples where ratios of phenanthrene, chrysene and their $\mathrm{C}_{3}$-derivatives indicated no significant photodegradation 1 year after the spill (Diez et al., 2007).

Few studies have examined the $\mathrm{BaA}$ to $\mathrm{Chr}$ and $\mathrm{BaP}$ to $\mathrm{BeP}$ ratios in field samples (Douglas et al., 2002; Plata et al., 2008). The most relevant study was that of Plata et al., who examined the Bouchard 120 HFO spill. Plata et al. (2008) measured pseudo-first-order disappearance rates of $18 \times 10^{-3} \mathrm{~d}^{-1}$ and $9 \times 10^{-3} \mathrm{~d}^{-1}$ for BaA and chrysene Chr, respectively; they could not determine the specific mechanisms of degradation but model estimates suggested that direct photodegradation could not account for all observed compound loss. Degradation rates for this study were roughly one-tenth those of Plata et al. (2008). This could be due to several factors such as differences in temperature, light exposure, cloud/ fog cover and other environmental variables. Regardless, our results support the conclusions of Plata et al. (2008) and Douglas et al. (2002) that alterations in photosensitive PAHs can be useful in examining the impacts of photodegradation.

In summary, this study presents a first examination of the extent and variability of weathering across location and time in oil samples collected from the $2007 \mathrm{M} / \mathrm{V}$ Cosco Busan spill. Within the first 55 days post-spill all samples showed similar losses of low molecular weight compounds, consistent with dissolution and evaporation. PAH concentrations decreased in all samples though at the end of the 80-day study period low levels of toxic naphthalenes persisted in many samples across each of the sites.

Significant variability in biodegradation and photodegradation was observed across and within sampling sites. Overall, the most weathered samples were from Point Isabel and the exposed coastal site Pirates Cove (Fig. 1). It is important to note that apparent site-related differences in biodegradation and photodegradation may be due to variability of our discrete samples rather than differences among sites. Pirates Cove and Point Isabel samples showed the greatest alteration due to these processes. At Point Isabel (Fig. 1), where oiled plates and rocks were collected, differences in biodegradation were observed between these two substrates. Oil appears to biodegrade more rapidly on ceramic plates than on rock samples though no large differences were observed in other weathering parameters. Photodegradation at Point Isabel was greater and more variable than that experienced at other sampling sites, consistent with increased sun exposure at this site due to its relatively flat surroundings and western orientation. Similar degradation was not observed at the western-oriented Pirates Cove perhaps as a result of the high rock walls and large boulders at this site shielding collected samples. Shorebird Park samples were the least impacted by photodegradation and biodegradation with diagnostic ratios remaining essentially constant with time.

Understanding the variability in weathering across geographic location and time is important to inform decisions on HFO use in addition to accurately assessing the impacts of a spill and guiding site restoration as required by the Oil Pollution Act of 1990 (33 U.S.C 2701-2761). To our knowledge, this work presents the first examination of the $\mathrm{M} / \mathrm{V}$ Cosco Busan spill. This paper provides baseline data on the weathering experienced at several sites around the bay and should be of interest to local authorities and oil-spill scientist studying this, and future HFO spills.

\section{Acknowledgements}

We thank Drs. James Quinn and John Farrington for their constructive comments. We also wish to thank Ms. Bryce Reddy for assistance with sample collection, Mr. Jack Cook for assistance with figures and Mr. Tom Kleindinst for photographs of samples. This work was supported by the Richard and Rhoda Goldman Fund, the Coastal Ocean Institute, the Ocean Ventures Fund, and the Seaver Institute.

\section{Appendix A. Supplementary data}

Supplementary material, including pictures and descriptions of sampling sites (S1), GC-FID, GC-MS, GC $\times$ GC-MS and GC $\times$ GCFID methods (S2), complete PAH data for all samples (Table S1), sample source ratios (Fig. S2) and data for Fig. 6 (Table S2) can be found, in the online version, at doi:10.1016/j.marpolbul. 2010.09.001

\section{References}

Arey, J.S., Nelson, R.K., Xu, L., Reddy, C.M., 2005. Using comprehensive twodimensional gas chromatography retention indices to estimate environmental partitioning properties for a complete set of diesel fuel hydrocarbons. Analytical Chemistry 77, 7172-7182.

Arey, J.S., Nelson, R.K., Plata, D.L., Reddy, C.M., 2007a. Disentangling oil weathering using GC $\times$ GC. 2. Mass transfer calculations. Environmental Science and Technology 41, 5747-5755.

Arey, J.S., Nelson, R.K., Reddy, C.M., 2007b. Disentangling oil weathering using GC $\times$ GC. 1. Chromatogram analysis. Environmental Science and Technology 41, $5738-5746$ 
Atlas, R.M., 1981. Microbial degradation of petroleum hydrocarbons: an environmental perspective. Microbiological Reviews 45, 180-209.

Bayona, J.M., Albaiges, J. Solanas, A.M. Pares, R., Garrigues, P., Ewald, M., 1986 Selective aerobic degradation of methyl-substituted polycyclic aromatichydrocarbons in petroleum by pure microbial cultures. International Journal of Environmental Analytical Chemistry 23, 289-303.

Behymer, T.D., Hites, R.A., 1988. Photolysis of polycyclic aromatic hydrocarbons adsorbed on fly ash. Environmental Science and Technology 22, 1311-1319.

Blumer, M., Sass, J., 1972. Oil pollution: persistence and degradation of spilled fuel oil. Science 176, 1120

Boehm, P.D., Page, D.S., 2007. Exposure elements in oil spill risk and natura resource damage assessments: a review. Human and Ecological Risk Assessment 13, 418-448.

Bordenave, S., Jezequel, R., Fourcans, A., Budzinski, N., Merlin, F.X., Fourel, T., GoniUrriza, M., Guyoneaud, R., Grimaud, W., Caumette, P., Duran, R., 2004 Degradation of the "Erika" oil. Aquatic Living Resources 17, 261-267.

Budzinski, H., Raymond, N., Nadalig, T., Gilewicz, M., Garrigues, P., Bertrand, J.C. Caumette, P., 1998. Aerobic biodegradation of alkylated aromatic hydrocarbons by a bacterial community. Organic Geochemistry $28,337-348$.

Burns, K.A., Teal, J.M., 1979. The West Falmouth oil spill: hydrocarbons in the salt marsh ecosystem. Estuarine and Coastal Marine Science 8, 349-360.

Diez, S., Sabate, J., Vinas, M., Bayona, J.M., Solanas, A.M., Albaiges, J., 2005. The Prestige oil spill. I. Biodegradation of a heavy fuel oil under simulated
conditions. Environmental Toxicology and Chemistry 24, 2203-2217.

Diez, S., Jover, E., Bayona, J.M., Albaiges, J., 2007. Prestige oil spill. III. Fate of a heavy oil in the marine environment. Environmental Science and Technology 41 3075-3082.

Douglas, G.S., Bence, A.E., Prince, R.C., McMillen, S.J., Butler, E.L., 1996. Environmental stability of selected petroleum hydrocarbon source and weathering ratios. Environmental Science and Technology 30, 2332-2339.

Douglas, G.S., Owens, E.H., Hardenstine, J., Prince, R.C., 2002. The OSSA II pipeline oil spill: the character and weathering of the spilled oil. Spill Science and Technology Bulletin 7, 135-148.

Eganhouse, R.P., Calder, J.A., 1976. Solubility of medium molecular weight aromatic hydrocarbons and effects of hydrocarbon co-solutes and salinity. Geochimica Et Cosmochimica Acta 40, 555-561.

Ezra, S., Feinstein, S., Pelly, I., Bauman, D., Miloslavsky, I., 2000. Weathering of Fue Oil Spill on the East Mediterranean Coast. Ashdod, Israel. pp. 1733-1741.

Gaines, R.B., Frysinger, G.S., Reddy, C.M., Nelson, R.K., 2007. Oil spill source identification by comprehensive two-dimensional gas chromatography $(G C \times G C)$. In: Wang, Z., Stout, S.A. (Eds.), Oil Spill Environmental Forensics: Fingerprinting and Source Identification. Elsevier, Boston, pp. 169-202.

Hansen, A.B., Daling, P.S., Faksness, L.-G., Sorheim, K.R., Kienhuis, P., Duus, R., 2007. Emerging CEN methodology for oil spill identification. In: Wang, Z., Stout, S.A. (Eds.), Oil Spill Environmental Forensics: Fingerprinting and Source (Eds.), Oil Spill Environmental Forensics:
Identification. Elsevier, Boston, pp. 229-256.

Hayakawa, K., Nomura, M., Nakagawa, T., Oguri, S., Kawanishi, T., Toriba, A., Kizu, R. Sakaguchi, T., Tamiya, E, 2006. Damage to and recovery of coastlines polluted Sakaguchi, T., Tamiya, E., 2006. Damage to and recovery of coastlines polluted
with C-heavy oil spilled from the Nakhodka. Water Research 40, 981-989.

Hoffman, E.J., Quinn, J.G., 1979. Gas chromatographic analyses of Argo Merchant oil and sediment hydrocarbons at the wreck site. Marine Pollution Bulletin 10, 2024 .

Hostettler, F.D., Rosenbauer, R.J., Lorenson, T.D., Dougherty, J., 2004. Geochemical characterization of tarballs on beaches along the California coast. Part I shallow seepage impacting the Santa Barbara Channel Islands, Santa Cruz, Santa Rosa and San Miguel. Organic Geochemistry 35, 725-746.

Irvine, G.V., Mann, D.H., Short, J.W., 2006. Persistence of 10-year old Exxon Valdez oil on Gulf of Alaska beaches: the importance of boulder-armoring. Marine Pollution Bulletin 52, 1011-1022.

Kropp, K.G., Andersson, J.T., Fedorak, P.M., 1997. Biotransformations of three dimethyldibenzothiophenes by pure and mixed bacterial cultures. Environmental Science and Technology 31, 1547-1554.

McAuliffe, C., 1966. Solubility in water of paraffin, cycloparaffin, olefin, acetylene, cycloolefin and aromatic hydrocarbons. Journal of Physical Chemistry 70, $1267-$ 1275 .

Moore, C., Dudgeon, R., Berge, J., Sheehan, L., Cameron, J.R., Sargent, R., Curtis, L., Dietrich, K., Lehmann, S., 2008a. Incident Specific Preparedness Review (ISPR) M/V Cosco Busan Oil Spill in San Francisco Bay: Report on Initial Response Phase. Dietrich, K., Lehmann, S., McPherson, S.B., 2008b. Incident Specific Preparedness Dietrich, K., Lehmann, S., McPherson, S.B., 2008b. Incident Specific Preparedness
Review (ISPR) M/V Cosco Busan Oil Spill in San Francisco Bay: Part II and Final Review.

National Transportation Safety Board, 2009. Marine Accident Report: Allision of Hong Kong-Registered Containership M/V Cosco Busan with the Delta Tower of the San Francisco-Oakland Bay Bridge. National Transportation Safety Board, Washington, DC. pp. 1-147.
Nelson, R.K., Kile, B.M., Plata, D.L., Sylva, S.P., Xu, L., Reddy, C.M., Gaines, R.B., Frysinger, G.S. Reichenbach, S.E. 2006. Tracking the weathering of an oil spill with comprehensive two-dimensional gas chromatography. Environmental Forensics 7, 33-44.

NRDA Trustee Agencies (Natural Resource Damage Assessment Trustee Agencies: California Department of Fish and Game, California State lands Commission, United States Fish and Wildlife Service, National Park Service, Bureau of Land Management, National Oceanic and Atmospheric Administration), Octobe 2008. Fact Sheet - Natural Resource Damage Assessment and Restoration Planning for the Cosco Busan Oil Spill: Update.

Page, D.S., Boehm, P.D., Stubblefield, W.A., Parker, K.R., Gilfillan, E.S., Neff, J.M., Maki, A.W., 2002. Hydrocarbon composition and toxicity of sediments following the Exxon Valdez oil spill in Prince William Sound, Alaska, USA. Environmental Toxicology and Chemistry 21, 1438-1450.

Peacock, E.E., Hampson, G.R., Nelson, R.K., Xu, L., Frysinger, G.S., Gaines, R.B. Farrington, J.W., Tripp, B.W., Reddy, C.M., 2007. The 1974 spill of the Bouchard 65 oil barge: petroleum hydrocarbons persist in Winsor Cove salt marsh sediments. Marine Pollution Bulletin 54, 214-225.

Peters, K.E., Walters, C.C., Moldowan, J.M., 2005. Biodegradation Parameters. The Biomarker Guide: Biomarkers and Isotopes in Petroleum Exploration and Earth History, second ed. Cambridge University Press, New York. pp. 645-708.

Plata, D.L., Sharpless, C.M., Reddy, C.M., 2008. Photochemical degradation of polycyclic aromatic hydrocarbons in oil films. Environmental Science and Technology 42, 2432-2438.

Prince, R.C., Elmendorf, D.L., Lute, J.R., Hsu, C.S., Haith, C.E., Senius, J.D., Dechert, G.J. Douglas, G.S., Butler, E.L., 1994. 17- $\alpha(\mathrm{H}), 21-\beta(\mathrm{H})$-hopane as a conserved internal marker for estimating the biodegradation of crude oil. Environmental Science and Technology 28, 142-145.

Prince, R.C., Garrett, R.M., Bare, R.E., Grossman, M.J., Townsend, T., Suflita, J.M., Lee, K., Owens, E.H., Sergy, G.A., Braddock, J.F., Lindstrom, J.E., Lessard, R.R., 2003. The roles of photooxidation and biodegradation in long-term weathering of crude and heavy fuel oils. Spill Science and Technology Bulletin 8, 145-156.

Reddy, C.M., Quinn, J.G., 1999. GC-MS analysis of total petroleum hydrocarbons and polycyclic aromatic hydrocarbons in seawater samples after the North Cape oil spill. Marine Pollution Bulletin 38, 126-135.

Reichenbach, S.E., Ni, M.T., Zhang, D.M., Ledford, E.B., 2003. Image background removal in comprehensive two-dimensional gas chromatography. Journal of Chromatography A 985, 47-56.

Rowland, S.J., Alexander, R., Kagi, R.I., 1984. Analysis of trimethylnaphthalenes by capillary gas chromatography. Journal of Chromatography 294, 407-412.

RTI International, 2008. Global Trade and Fuels Assessment - Future Trends and Effects of Designating Requiring Clean Fuels in the Marine Sector. Research Triangle Park.

Slater, G.F., Nelson, R.K., Kile, B.M., Reddy, C.M., 2006. Intrinsic bacterial biodegradation of petroleum contamination demonstrated in situ using natural abundance, molecular-level ${ }^{14} \mathrm{C}$ analysis. Organic Geochemistry 37. 981-989.

Stout, S.A., Wang, Z., 2007. Chemical fingerprinting of spilled or discharged petroleum - methods and factors affecting petroleum fingerprints in the petroleum - methods and factors affecting petroleum fingerprints in the environment. In: Stout, S.A., Wang, Z. (Eds.), Oil Spill Environmental

Sutton, C., Calder, J.A., 1975. Solubility of alkylbenzenes in distilled water and seawater at $25.0^{\circ} \mathrm{C}$. Journal of Chemical and Engineering Data 20, 320-322.

Uhler, A.D., Stout, S.A., Douglas, G.S., 2007. Chemical heterogeneity in moder marine residual fuel oils. In: Wang, Z., Stout, S.A. (Eds.), Oil Spill Environmental Forensics: Fingerprinting and Source Identification. Academic Press, Boston, pp. 327-348.

United State Coast Guard, 2009. Report of investigation into the allision of the Cosco Busan into the delta tower of the San Francisco-Oakland Bay Bridge in San Francisco Bay on November 7, 2007. United States Coast Guard, pp. 1-34.

Wang, Z.D., Fingas, M., Sergy, G., 1994. Study of 22-year-old Arrow oil samples using biomarker compounds by GC/MS. Environmental Science and Technology 28 $1733-1746$

Wang, Z.D., Fingas, M., Sergy, G., 1995. Chemical characterization of crude oil residues from an arctic beach by GC/MS and GC/FID. Environmental Science and Technology 29, 2622-2631.

Wang, Z., Fingas, M., 1995a. Use of methyldibenzothiophenes as markers for differentiation and source identification of crude and weathered oils. ifferentiation and source identification of crude
Environmental Science and Technology 29, 2842-2849.

Wang, Z.D., Fingas, M., 1995b. Study of the effects of weathering on the chemical composition of a light crude oil using GC/MS GC/FID. Journal of Microcolumn Separations 617,639.

Wang, Z.D., Fingas, M., Blenkinsopp, S., Sergy, G., Landriault, M., Sigouin, L., Foght, J., Semple, K., Westlake, D.W.S., 1998. Comparison of oil composition changes due to biodegradation and physical weathering in different oils. Journal of Chromatography A 809, 89-107. 


\title{
Supporting Material
}

for

\section{The M/V Cosco Busan spill: Source Identification and Short-Term Fate}

\author{
Karin L. Lemkau ${ }^{\text {a,b,*, Emily E. Peacock }}{ }^{\text {b }}$, Robert K. Nelson ${ }^{\text {b }}$, G. Todd Ventura ${ }^{\text {b, }}$, \\ Jennifer L. Kovecses ${ }^{c, 2}$, and Christopher M. Reddy ${ }^{b}$ \\ ${ }^{a}$ MIT/WHOI Joint Program in Oceanography/Applied Ocean Science and Engineering \\ ${ }^{\mathrm{b}}$ Department of Marine Chemistry and Geochemistry, Woods Hole Oceanographic \\ Institution, Woods Hole, MA 02543, USA \\ ${ }^{\mathrm{c}}$ San Francisco Baykeeper, 785 Market Street, Suite 850, San Francisco, CA 94103, USA \\ ${ }^{1}$ Present address: Department of Earth Sciences, University of Oxford, Parks Road, \\ Oxford, OX1 3PR, UK \\ ${ }^{2}$ Present address: San Diego Coastkeeper, 2825 Dewey Road, Suite 200, San Diego CA \\ 92106, USA
}

*Corresponding author E-mail: klemkau@whoi.edu Tel: 508-289-3381; Fax: 508-457-2164

\section{Contents of Supporting Material}

S1. Images and descriptions of sampling sites. Page 55-60.

Figure S1.1. Photograph of Shorebird Park (Figure 1) showing the 'dirty bathtub ring' left from the M/V Cosco Busan oil spill.

Figure S1.2. Photograph from Point Isabel (Figure 1) showing shoreline and an oiled ceramic plate from this site.

Figure S1.3. Photograph showing the coastal site of Pirates Cove.

S2. Detailed instrumental methods. Pages 61-63. 
S2.1. GC-FID methods.

S2.2. GC-MS methods.

S2.3. GC $\times$ GC-FID methods.

S2.4. GC $\times$ GC-MS methods.

Table S1. PAH data for all field samples. Page 64-67.

Table S1.1. Shorebird Park samples.

Table S1.2. Point Isabel rock samples.

Table S1.3. Point Isabel plate samples.

Table S1.4. Pirates Cove samples.

Figure S2. Commonly used source ratio $\left(\mathrm{D}_{3} / \mathrm{P}_{3}\right)$ plotted against a common weathering ratio $\left(D_{3} / C_{3}\right)$ for all samples analyzed at each site. Page 68.

Table S2. BaA, Chr, and $n-\mathrm{C}_{18}$ /phytane data used in Figures 6 and 7. Page 69.

S3. Supplemental References. Page 70. 


\section{S1. Site descriptions}

Shorebird Park (Figure S1.1) is defined by large rocks and riprap that comprises a protective wall. The site is partly shaded due to the steepness of the wall and the proximity of trees; samples were collected from a southern facing shoreline. Point Isabel (Figure S1.2) is characterized by riprap and small rocks, and is the former dumpsite of the Technical Porcelain and Chinaware Company; oil samples from both rocks and discarded ceramic plates were collected from this site (Figure S1.2b). Point Isabel is not shaded and samples were collected from a western facing shoreline. Both Shorebird Park and Point Isabel are located within the bay and have relatively low wave energy (Figure 1). Pirates Cove (Figure S1.3) is a coastal area outside of the bay with higher wave energy. This site consists of a west-facing alcove with high rock walls surrounding a small sandy beach with 1 to $1.5 \mathrm{~m}$ sized boulders close to the wall base.

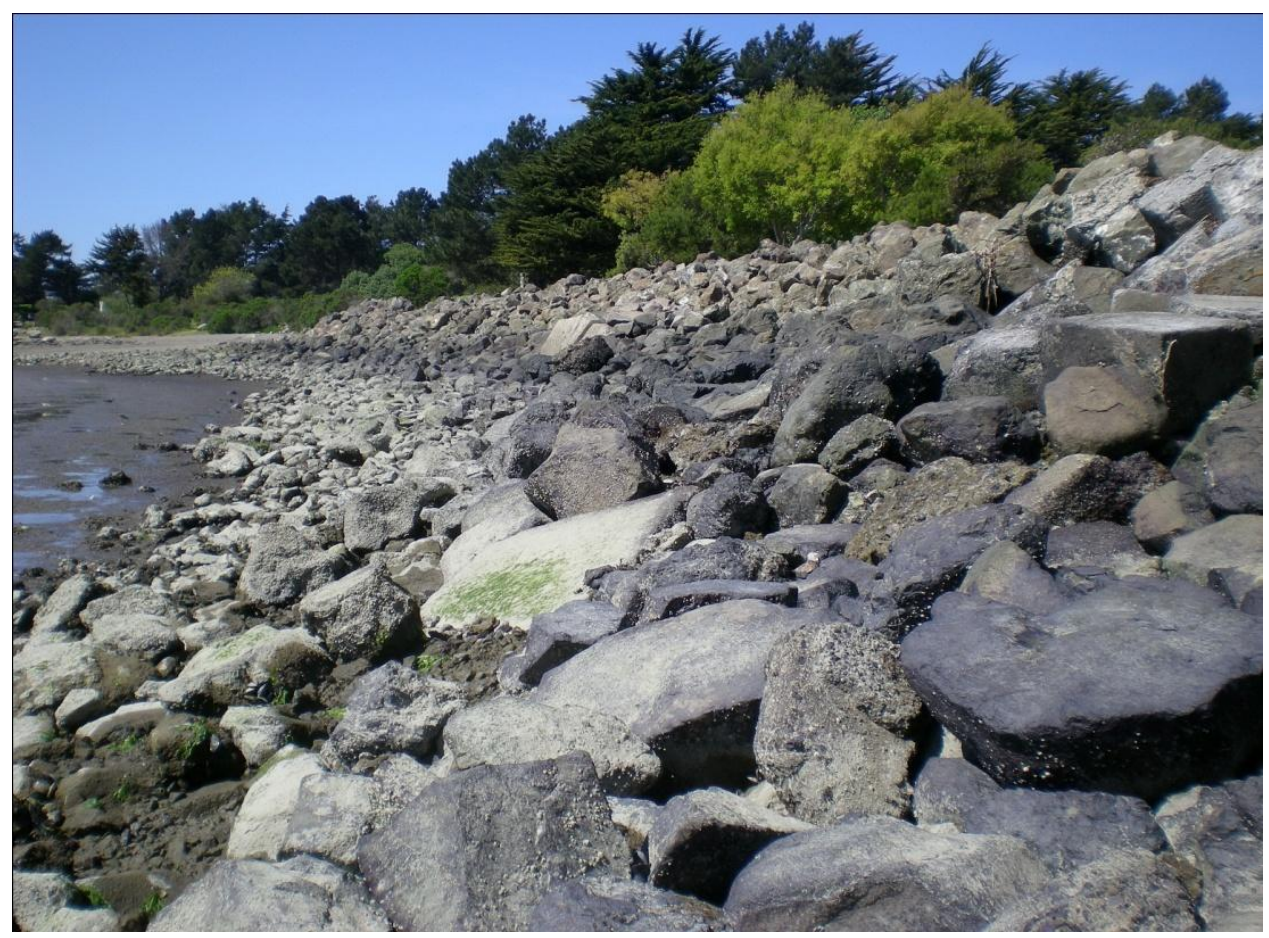

Figure S1.1. The 'dirty bathtub ring' left from the M/V Cosco Busan oil spill at Shorebird Park. Picture taken 4/11/2009, 511 days post spill, during a subsequent sampling trip. (Photo by Karin Lemkau, Woods Hole Oceanographic Institution) 
(a)

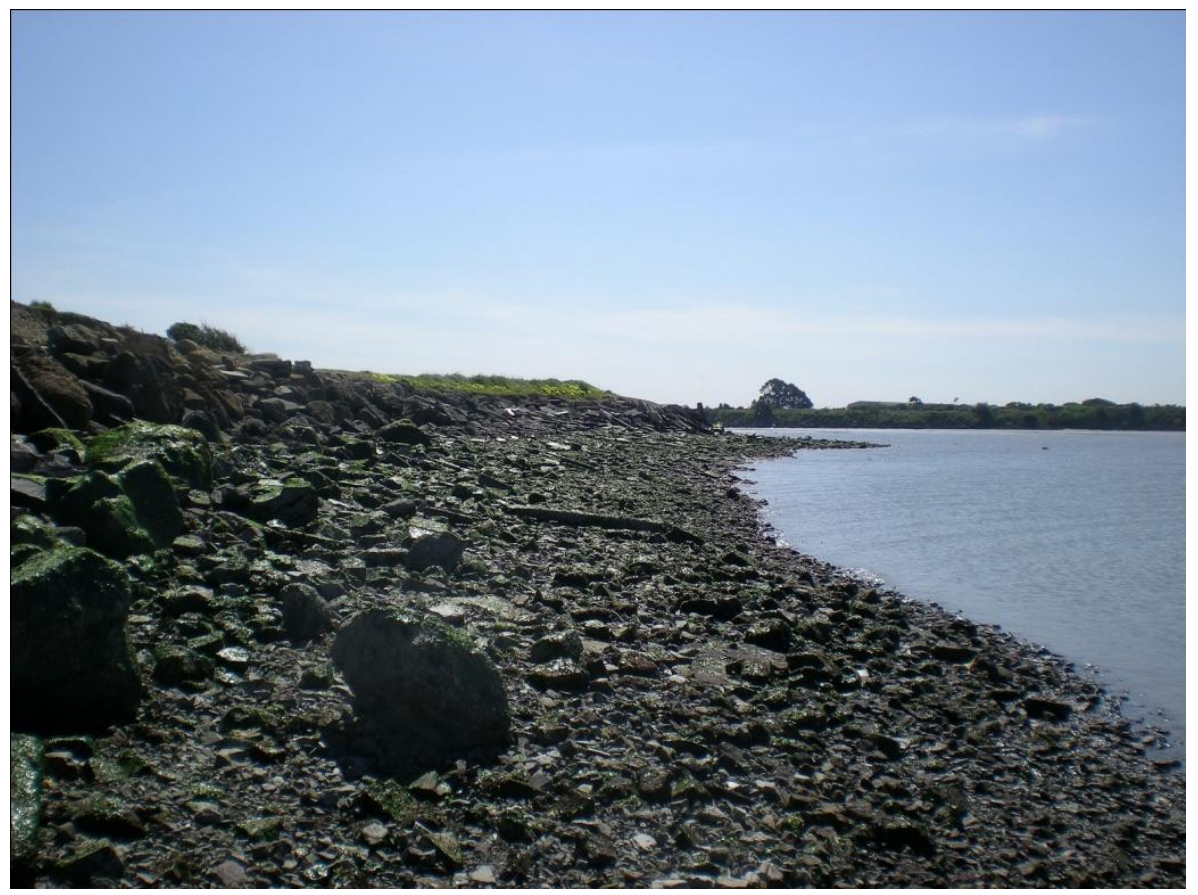

(b)

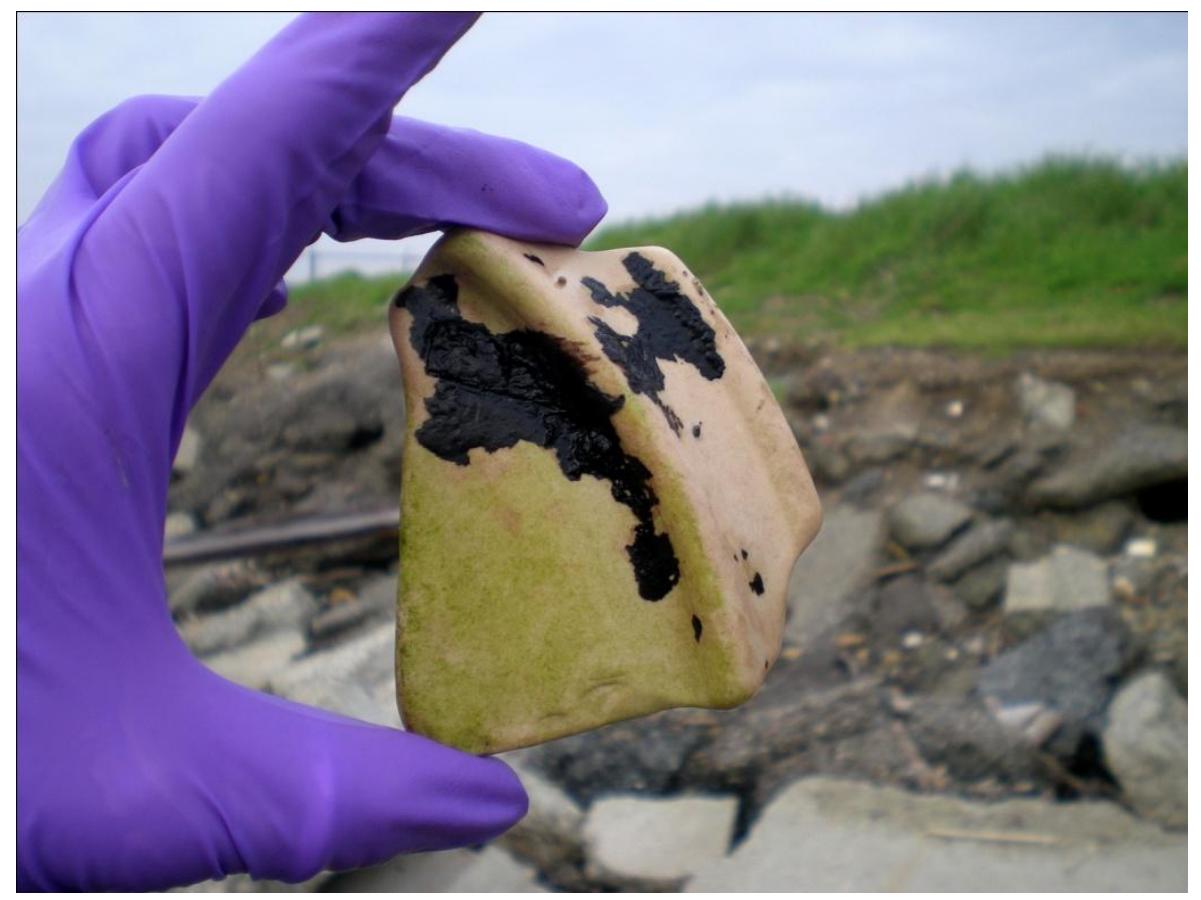

Figure S1.2. (a) Photograph of Point Isabel beach showing exposed rocky shoreline. (b) Close up picture of an oiled plate fragment. Photographs taken 2/1/2010, 817 days post spill, during a subsequent sampling trip. (Photo by Karin Lemkau, Woods Hole Oceanographic Institution) 
(a)

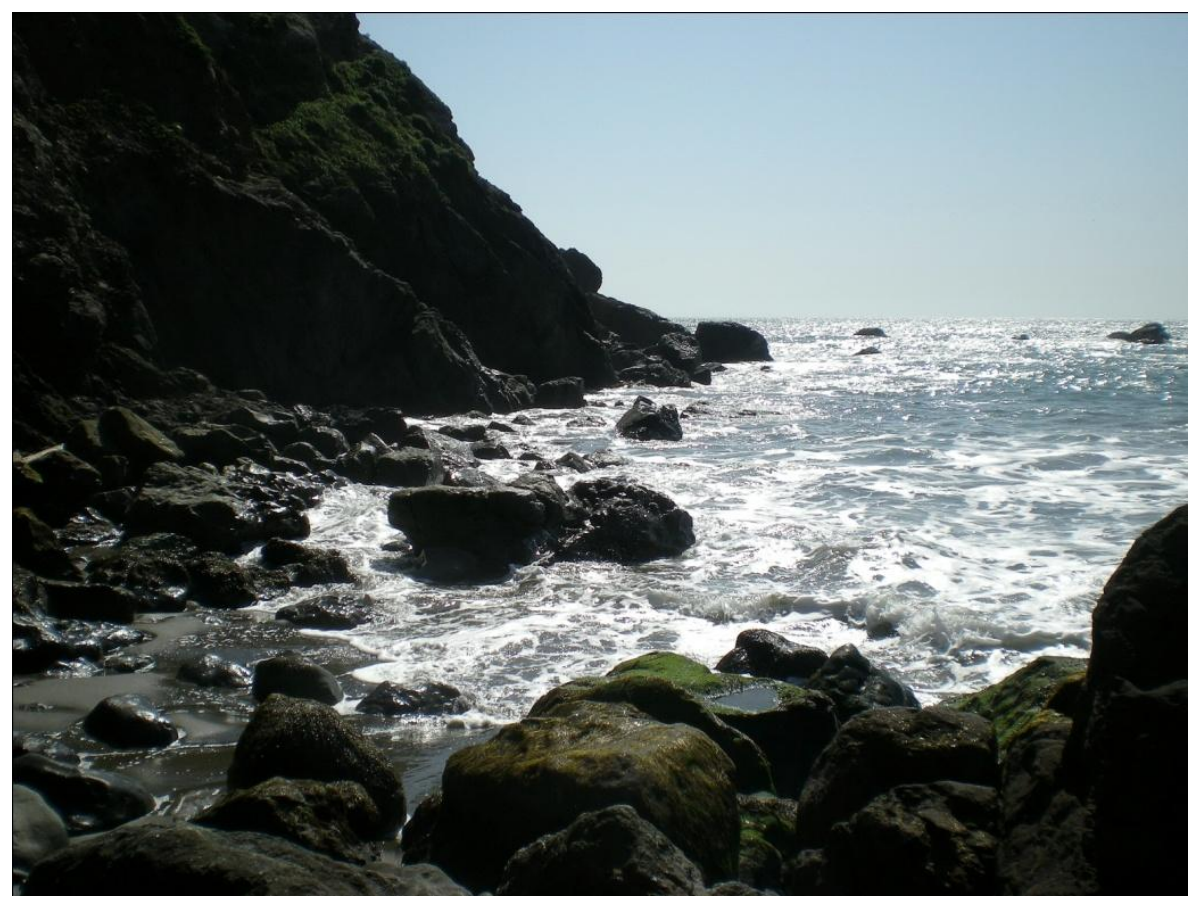

(b)

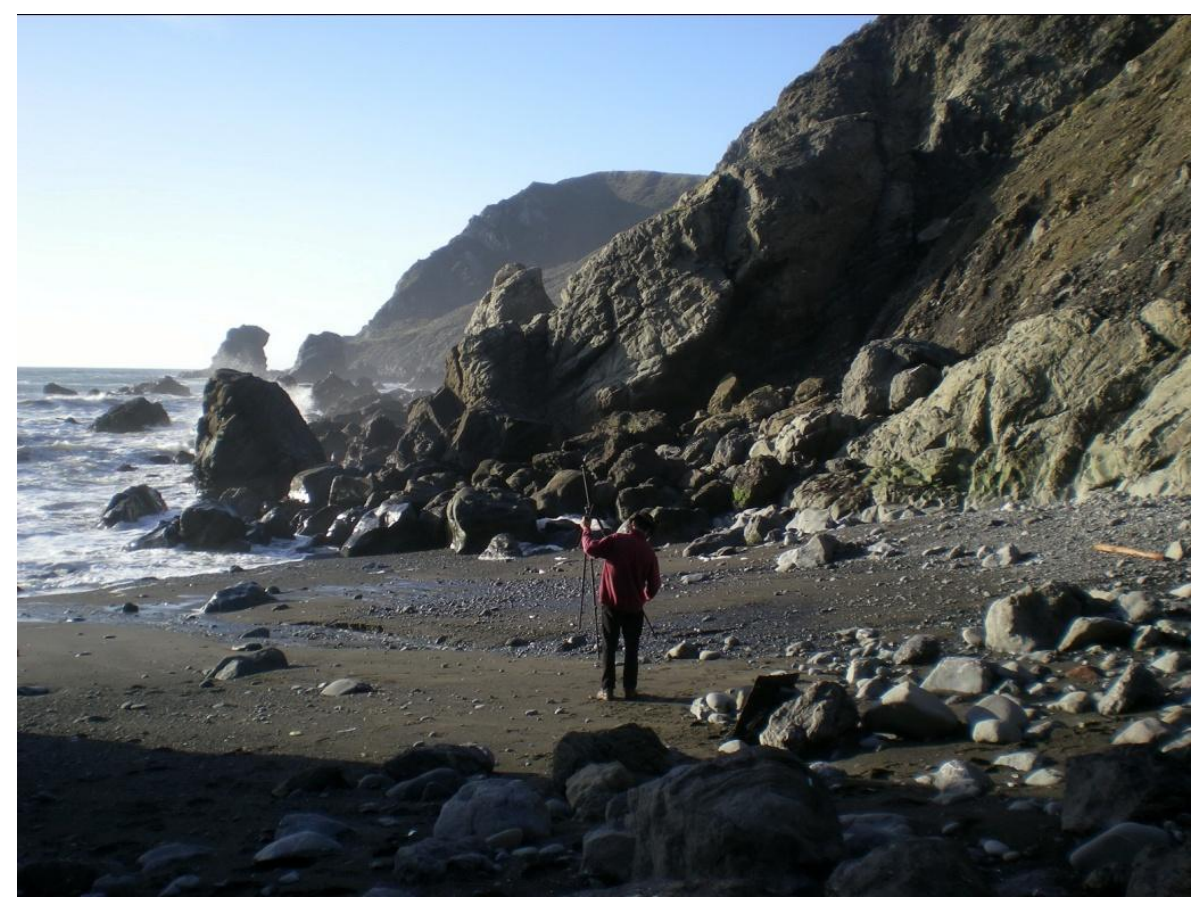

Figure S1.3. Photograph of the coastal site Pirates Cove. Taken 1/30/2010, 815 days post spill, during a subsequent sampling trip. (Photo by Karin Lemkau, Woods Hole Oceanographic Institution) 


\section{S2.1. GC-FID analysis}

The GC-FID system was a Hewlett-Packard 5890 Series II gas chromatograph with an FID. A $1 \mathrm{~mL}$ aliquot of each sample solution was spiked with $10 \mu \mathrm{g}$ each of $n$ hexadecane- $d_{34}$ and octyl ether (internal and recovery standards respectfully). Samples $(0.5 \mu \mathrm{l})$ were injected cool-on-column and separated on a $100 \%$ dimethyl polysiloxane capillary column (J\&W DB-1MS, $30 \mathrm{~m}$ length, $0.25 \mathrm{~mm}$ I.D., $0.25 \mu \mathrm{m}$ film thickness) with $\mathrm{H}_{2}$ as the carrier gas at a constant flow of $5 \mathrm{~mL} \mathrm{~min}^{-1}$. The $\mathrm{GC}$ oven was programmed from $45^{\circ} \mathrm{C}(5 \mathrm{~min}$ hold $)$ and ramped at $6{ }^{\circ} \mathrm{C} \mathrm{min}{ }^{-1}$ to $315{ }^{\circ} \mathrm{C}$ and then at 20 ${ }^{\circ} \mathrm{C} \min ^{-1}$ to $320{ }^{\circ} \mathrm{C}$ (30 min hold). Total petroleum hydrocarbons (TPHs) were quantified by integrating the total area of the FID signal and using response factors determined from $n$-alkane standards. Using standard baseline subtraction techniques, several regions of the chromatograms were integrated representing $n$-alkane carbon numbers: $\mathrm{C}_{10}-\mathrm{C}_{25}, \mathrm{C}_{25}-\mathrm{C}_{45}$ and $\mathrm{C}_{45+}$ (Uhler et al., 2007). Laboratory blanks were free of petroleum compounds. The average percent recovery of the internal standard was $97.2 \pm 3.4 \%$. Precision, based on the analysis of 6 duplicate pairs of field samples, was $10 \%$ or lower for TPHs. Dichloromethane blanks were run regularly. Due to the high asphaltene content of our samples and the cool-on-column injection, daily instrument runs included periodic analysis of the tank 4 oil, to ensure consistent chromatographic separations. The guard column was cut regularly to eliminate significant accumulation of these non-GC amendable components. Our estimated method detection limit, based on the replicate analysis of HFO via Glaser et al. (1981), was $5 \mathrm{mg} \mathrm{g}^{-1}$ of oil for TPH and $0.3 \mathrm{ng} \mathrm{g}^{-1}$ of oil for individual alkanes.

Standards used in GC-FID and other GC-based techniques were obtained from Cambridge Isotope Laboratories Inc. (deuterated alkanes and PAHs), Aldrich Chemical ( $n$-alkanes, hopanes, steranes, and a large suite of PAHs), National Institute of Standards and Technology (ether lipid derivatives, linear alkylbenzenes), and Chiron (alkylcyclohexanes and alkylcyclopentanes) and Professor Roger Summons (Massachusetts Institute of Technology; additional alkylcyclopentanes). 


\section{S2.2. GC-MS analysis}

The GC-MS system consisted of an Agilent 6890 series gas chromatograph with an Agilent 5973 mass selective detector (GC-MS). Sample aliquots (0.5 mL) were spiked with $5 \mu \mathrm{g}$ each of $o$-terphenyl (recovery standard) and 1,4-dichlorobenzene- $d_{4}$, naphthalene- $d_{8}$, acenaphthene- $d_{10}$, dibenzothiophene- $d_{8}$, fluorene- $d_{10}$, phenanthrene- $d_{10}$, fluoranthene- $d_{10}$, perylene- $d_{12}$ and chrysene- $d_{12}$ (internal standards). Samples ( $3 \mu \mathrm{L}$ ) were injected into a programmable temperature vaporization inlet. Inlet temperature was programmed from $52{ }^{\circ} \mathrm{C}(0.10 \mathrm{~min}$ hold $)$ and ramped at $720{ }^{\circ} \mathrm{C} \min ^{-1}$ to $325{ }^{\circ} \mathrm{C}(8 \mathrm{~min}$ hold), then at $720{ }^{\circ} \mathrm{C} \mathrm{min}^{-1}$ to $350{ }^{\circ} \mathrm{C}$ (5 min hold). The instrument was operated in fullscan mode ranging from 50 to 800 daltons. Compounds were separated on a J\&W DB5MS capillary column (60 m length, $0.25 \mathrm{~mm}$ I.D., $0.25 \mu \mathrm{m}$ film thickness) with He carrier gas at a constant flow of $1.5 \mathrm{~mL} \mathrm{~min}^{-1}$. The GC oven was programmed from $50{ }^{\circ} \mathrm{C}$ (1 min hold) and ramped at $20{ }^{\circ} \mathrm{C} \min ^{-1}$ to $115^{\circ} \mathrm{C}(10 \mathrm{~min}$ hold $)$, then at $5{ }^{\circ} \mathrm{C} \mathrm{min}^{-1}$ to $320{ }^{\circ} \mathrm{C}$ (10 min hold). We analyzed for the following parent PAHs and their alkylated homologs: naphthalene $(\mathrm{m} / \mathrm{z}, 128)$, fluorene $(\mathrm{m} / \mathrm{z}, 166)$, phenanthrene/anthracene $(\mathrm{m} / \mathrm{z}$ 178), dibenzothiophene $(m / z, 184)$. We also measured benz $[a]$ anthracene $(\mathrm{BaA}, m / z 228)$, chrysene (Chr, $m / z$ 228), benzo[a]pyrene (BaP, $m / z$ 252) and benzo[e]pyrene $(\mathrm{BeP}, m / z$ 252). Based on replicate analysis, precision of PAH content in oil was $10 \%$ or lower. Method detection limits ranged from 0.01 to $0.2 \mu \mathrm{g} \mathrm{PAH} \mathrm{g}^{-1}$ oil (Glaser et al., 1981). Solvent blanks were free of PAHs and other petroleum hydrocarbons.

\section{S2.3. $G C \times G C-M S$ analysis}

The GC×GC-MS system consisted of an Agilent 6890N gas chromatograph coupled to a Pegasus IV time of flight mass spectrometric detection system. Sample extracts $(2 \mu \mathrm{L})$ were injected into a $300{ }^{\circ} \mathrm{C}$ splitless injector $(0.5 \mathrm{~min}$ purge time $)$. The first-dimension separation was performed on a $100 \%$ dimethyl polysiloxane Restek Rtx1MS Crossbond column, (20 m length, $0.20 \mathrm{~mm}$ I.D., $0.2 \mu \mathrm{m}$ film thickness) programmed from $35^{\circ} \mathrm{C}$ (5 min hold) and ramped to $315^{\circ} \mathrm{C}$ at $1.75{ }^{\circ} \mathrm{C} \mathrm{min}^{-1}$. 
Compounds eluting from the first dimension column were cryogenically trapped and reinjected (modulated) onto a second dimension column with a modulation time of 9 seconds. Second-dimension separations were performed on a 50\% phenyl polysilphenylene-siloxane column (SGE BPX50, $1 \mathrm{~m}$ length, $0.10 \mathrm{~mm}$ I.D., $0.1 \mu \mathrm{m}$ film thickness) programmed from $60{ }^{\circ} \mathrm{C} \mathrm{(5} \mathrm{min} \mathrm{hold)} \mathrm{and} \mathrm{ramped} \mathrm{to} 340{ }^{\circ} \mathrm{C}$ at $1.75{ }^{\circ} \mathrm{C} \mathrm{min}{ }^{-1}$. Helium was the carrier gas with a constant flow rate of $1.05 \mathrm{~mL} \mathrm{~min}^{-1}$. The transfer line to the MS was deactivated fused silica ( $0.5 \mathrm{~m}$ length, $0.18 \mathrm{~mm}$ I.D.) held at a constant temperature of $280{ }^{\circ} \mathrm{C}$. The source temperature was $225^{\circ} \mathrm{C}$ and detector voltage was 1575 volts; the MS employs a $70 \mathrm{eV}$ electron ionization and operates at a push pulse rate of $5 \mathrm{kHz}$. The instrument was operated in full-scan mode ranging from 50 to 675 daltons and the detector signal was sampled at 50 spectra per second.

\section{S2.4. $G C \times G C-F I D$ analysis}

The GC $\times$ GC-FID system consisted of an Agilent 7890A chromatograph coupled with a flame ionization detector. The extract $(2-3 \mu \mathrm{L})$ was injected into a $300{ }^{\circ} \mathrm{C}$ splitless mode injector ( 1 min purge time). The columns that were used had identical properties as those described for the GCXGC-MS analysis. The first column was programmed from 42 ${ }^{\circ} \mathrm{C}$ (10 min hold) and ramped to $317{ }^{\circ} \mathrm{C}$ at $1.25^{\circ} \mathrm{C} \mathrm{min}^{-1}$. The second column was programmed from $65^{\circ} \mathrm{C}(10$ min hold $)$ and ramped to $340{ }^{\circ} \mathrm{C}$ at $1.25^{\circ} \mathrm{C} \mathrm{min}{ }^{-1}$. Compounds were injected onto the second column with a modulation time of 10 seconds. Hydrogen was the carrier gas, with a constant flow rate of $1.00 \mathrm{~mL} \mathrm{~min}^{-1}$. The FID detector signal was sampled at 100 data points per second. Each $\mathrm{GC} \times \mathrm{GC}$ image was base-plane subtracted to remove the FID offset (Reichenbach et al., 2003), and GC $\times \mathrm{GC}$ chromatograms were normalized to the conserved biomarker $17 \alpha(\mathrm{H}), 21 \beta(\mathrm{H})$-hopane (Prince et al., 1994), enabling visualization of relative concentration changes between samples (Nelson et al., 2006; Wardlaw et al., 2008). Across samples, sufficient first- and second-dimension retention time reproducibility allowed direct point-by-point subtraction of hopane-normalized $\mathrm{GC} \times \mathrm{GC}$ chromatograms. 


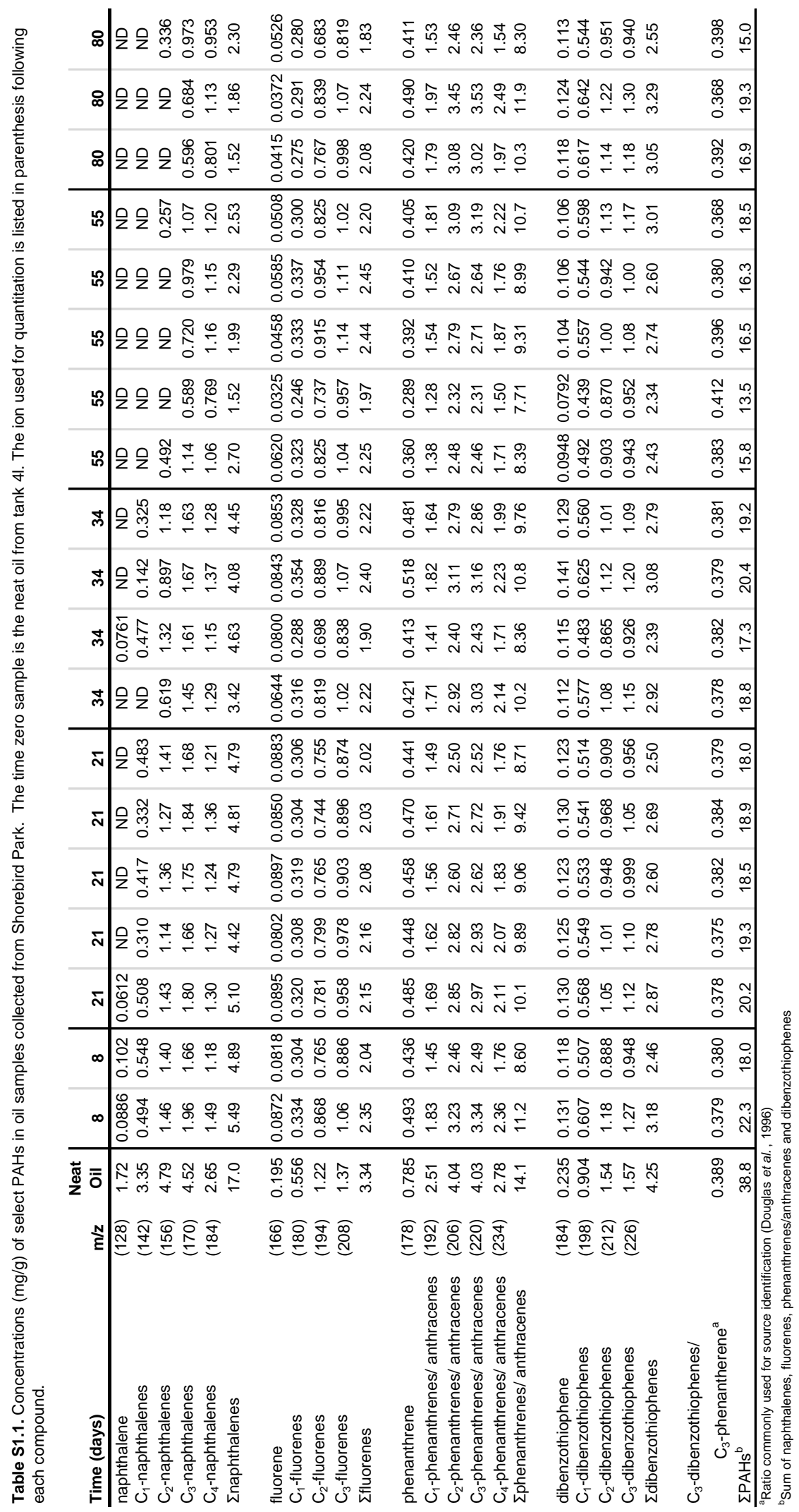


Table S1.2. Concentrations $(\mathrm{mg} / \mathrm{g})$ of select PAHs in oil samples collected from rocks at Point Isabel. The time zero sample is the neat oil from tank 4 . The ion used for quantitation is listed in parenthesis following each compound.

\begin{tabular}{|c|c|c|c|c|c|c|c|c|c|c|c|}
\hline Time (days) & $m / z$ & $\begin{array}{c}\text { Neat } \\
\text { Oil }\end{array}$ & 35 & 35 & 35 & 35 & 35 & 55 & 55 & 80 & 80 \\
\hline naphthalene & $(128)$ & 1.72 & $\overline{N D}$ & $\overline{N D}$ & $\overline{N D}$ & $\overline{N D}$ & $\overline{N D}$ & $\overline{N D}$ & ND & $\overline{N D}$ & $\overline{N D}$ \\
\hline $\mathrm{C}_{1}$-naphthalenes & (142) & 3.35 & ND & ND & ND & ND & 0.344 & ND & ND & ND & ND \\
\hline $\mathrm{C}_{2}$-naphthalenes & (156) & 4.79 & ND & 0.648 & 0.382 & ND & 1.12 & ND & ND & ND & 0.267 \\
\hline $\mathrm{C}_{3}$-naphthalenes & (170) & 4.52 & 0.168 & 1.26 & 0.781 & 0.178 & 1.59 & 0.291 & 0.240 & 0.447 & 0.716 \\
\hline $\mathrm{C}_{4}$-naphthalenes & (184) & 2.65 & 0.379 & 1.11 & 0.792 & 0.454 & 1.24 & 0.657 & 0.449 & 0.734 & 0.689 \\
\hline Enaphthalenes & & 17.0 & 0.577 & 3.10 & 2.04 & 0.654 & 4.34 & 0.970 & 0.727 & 1.23 & 1.70 \\
\hline fluorene & (166) & 0.195 & ND & 0.0661 & 0.0385 & 0.0134 & 0.0826 & 0.0205 & 0.0168 & 0.0298 & 0.0352 \\
\hline $\mathrm{C}_{1}$-fluorenes & (180) & 0.556 & 0.121 & 0.305 & 0.226 & 0.161 & 0.327 & 0.249 & 0.186 & 0.253 & 0.217 \\
\hline $\mathrm{C}_{2}$-fluorenes & (194) & 1.22 & 0.527 & 0.873 & 0.711 & 0.681 & 0.832 & 0.864 & 0.702 & 0.748 & 0.586 \\
\hline $\mathrm{C}_{3}$-fluorenes & (208) & 1.37 & 0.816 & 1.15 & 0.971 & 0.975 & 1.00 & 1.15 & 0.969 & 0.974 & 0.776 \\
\hline ¿fluorenes & & 3.34 & 1.46 & 2.39 & 1.95 & 1.83 & 2.24 & 2.29 & 1.88 & 2.01 & 1.61 \\
\hline phenanthrene & $(178)$ & 0.785 & 0.285 & 0.473 & 0.365 & 0.331 & 0.441 & 0.359 & 0.345 & 0.397 & 0.398 \\
\hline $\mathrm{C}_{1}$-phenanthrenes/ anthracenes & (192) & 2.51 & 1.35 & 1.77 & 1.48 & 1.53 & 1.58 & 1.53 & 1.32 & 1.75 & 1.41 \\
\hline $\mathrm{C}_{2}$-phenanthrenes/ anthracenes & (206) & 4.04 & 2.66 & 3.17 & 2.67 & 2.80 & 2.71 & 2.80 & 2.35 & 3.02 & 2.34 \\
\hline $\mathrm{C}_{3}$-phenanthrenes/ anthracenes & $(220)$ & 4.03 & 2.76 & 3.24 & 2.78 & 2.91 & 2.77 & 2.90 & 2.36 & 2.92 & 2.21 \\
\hline $\mathrm{C}_{4}$-phenanthrenes/ anthracenes & (234) & 2.78 & 1.97 & 2.26 & 1.95 & 2.05 & 1.93 & 2.00 & 1.67 & 1.90 & 1.43 \\
\hline ¿phenanthrenes/ anthracenes & & 14.1 & 9.02 & 10.9 & 9.25 & 9.61 & 9.43 & 9.58 & 8.05 & 9.99 & 7.79 \\
\hline dibenzothiophene & (184) & 0.235 & 0.0653 & 0.122 & 0.0914 & 0.0771 & 0.121 & 0.0952 & 0.0866 & 0.104 & 0.108 \\
\hline $\mathrm{C}_{1}$-dibenzothiophenes & (198) & 0.904 & 0.445 & 0.600 & 0.498 & 0.505 & 0.562 & 0.537 & 0.486 & 0.601 & 0.523 \\
\hline $\mathrm{C}_{2}$-dibenzothiophenes & (212) & 1.54 & 0.973 & 1.12 & 0.981 & 1.03 & 1.01 & 1.05 & 0.909 & 1.11 & 0.934 \\
\hline $\mathrm{C}_{3}$-dibenzothiophenes & (226) & 1.57 & 1.07 & 1.21 & 1.08 & 1.16 & 1.07 & 1.15 & 0.972 & 1.16 & 0.911 \\
\hline ¿dibenzothiophenes & & 4.25 & 2.56 & 3.05 & 2.65 & 2.77 & 2.77 & 2.83 & 2.45 & 2.97 & 2.48 \\
\hline \multicolumn{12}{|l|}{$\mathrm{C}_{3}$-dibenzothiophenes/ } \\
\hline $\mathrm{C}_{3}$-phenantherene $\mathrm{a}^{\mathrm{a}}$ & & 0.389 & 0.389 & 0.374 & 0.389 & 0.399 & 0.387 & 0.396 & 0.412 & 0.395 & 0.413 \\
\hline$\Sigma \mathrm{PAHs} \mathrm{s}^{\mathrm{b}}$ & & 38.8 & 13.6 & 19.4 & 15.9 & 14.9 & 18.8 & 15.7 & 13.1 & 16.2 & 13.6 \\
\hline
\end{tabular}

${ }^{a}$ Ratio commonly used for source identification (Douglas et al., 1996)

${ }^{\mathrm{b}} \mathrm{Sum}$ of naphthalenes, fluorenes, phenanthrenes/anthracenes and dibenzothiophenes 
Table S1.3. Concentrations $(\mathrm{mg} / \mathrm{g})$ of select PAHs in oil samples collected from plates at Point Isabel. The time zero sample is the neat oil from tank 4 . The ion used for quantitation is listed in parenthesis following each compound.

\begin{tabular}{|c|c|c|c|c|c|c|c|c|c|c|}
\hline Time (days) & $\mathrm{m} / \mathbf{z}$ & $\begin{array}{c}\text { Neat } \\
\text { Oil }\end{array}$ & 55 & 55 & 56 & 56 & 56 & 56 & 80 & 80 \\
\hline naphthalene & (128) & 1.72 & ND & ND & ND & ND & ND & ND & ND & ND \\
\hline $\mathrm{C}_{1}$-naphthalenes & $(142)$ & 3.35 & ND & ND & ND & ND & ND & ND & ND & ND \\
\hline $\mathrm{C}_{2}$-naphthalenes & (156) & 4.79 & ND & ND & ND & ND & 0.405 & ND & ND & ND \\
\hline $\mathrm{C}_{3}$-naphthalenes & (170) & 4.52 & ND & 0.257 & 0.277 & 0.373 & 0.875 & ND & 0.374 & ND \\
\hline $\mathrm{C}_{4}$-naphthalenes & (184) & 2.65 & 0.501 & 0.806 & 0.722 & 0.597 & 0.950 & 0.261 & 0.582 & 0.194 \\
\hline ¿naphthalenes & & 17.0 & 0.501 & 1.08 & 1.02 & 1.00 & 2.30 & 0.261 & 0.985 & 0.194 \\
\hline fluorene & $(166)$ & 0.195 & 0.00872 & 0.0145 & 0.0177 & 0.0231 & 0.0422 & ND & 0.0183 & ND \\
\hline $\mathrm{C}_{1}$-fluorenes & $(180)$ & 0.556 & 0.100 & 0.196 & 0.255 & 0.233 & 0.281 & 0.0777 & 0.178 & 0.0600 \\
\hline $\mathrm{C}_{2}$-fluorenes & (194) & 1.22 & 0.641 & 0.852 & 0.894 & 0.784 & 0.843 & 0.337 & 0.532 & 0.325 \\
\hline $\mathrm{C}_{3}$-fluorenes & (208) & 1.37 & 1.09 & 1.13 & 1.19 & 1.02 & 1.02 & 0.511 & 0.731 & 0.575 \\
\hline ¿fluorenes & & 3.34 & 1.84 & 2.19 & 2.36 & 2.06 & 2.18 & 0.926 & 1.46 & 0.960 \\
\hline phenanthrene & $(178)$ & 0.785 & ND & ND & 0.233 & 0.321 & 0.253 & 0.103 & 0.277 & 0.139 \\
\hline $\mathrm{C}_{1}$-phenanthrenes/ anthracenes & (192) & 2.51 & 0.562 & 0.782 & 1.37 & 1.28 & 1.25 & 0.658 & 1.29 & 1.00 \\
\hline $\mathrm{C}_{2}$-phenanthrenes/ anthracenes & $(206)$ & 4.04 & 2.46 & 2.42 & 2.65 & 2.30 & 2.43 & 1.40 & 2.26 & 2.10 \\
\hline $\mathrm{C}_{3}$-phenanthrenes/ anthracenes & $(220)$ & 4.03 & 3.03 & 2.72 & 2.84 & 2.14 & 2.35 & 1.51 & 2.17 & 2.10 \\
\hline $\mathrm{C}_{4}$-phenanthrenes/ anthracenes & $(234)$ & 2.78 & 2.19 & 1.92 & 2.07 & 1.50 & 1.67 & 1.06 & 1.40 & 1.37 \\
\hline ¿phenanthrenes/ anthracenes & & 14.1 & 8.24 & 7.84 & 9.15 & 7.54 & 7.95 & 4.74 & 7.39 & 6.71 \\
\hline dibenzothiophene & $(184)$ & 0.235 & 0.0134 & 0.0267 & 0.0622 & 0.0841 & 0.0770 & 0.0258 & 0.0779 & 0.0325 \\
\hline $\mathrm{C}_{1}$-dibenzothiophenes & (198) & 0.904 & 0.239 & 0.344 & 0.495 & 0.479 & 0.467 & 0.224 & 0.469 & 0.340 \\
\hline $\mathrm{C}_{2}$-dibenzothiophenes & $(212)$ & 1.54 & 0.939 & 0.910 & 0.925 & 0.883 & 0.881 & 0.519 & 0.884 & 0.806 \\
\hline $\mathrm{C}_{3}$-dibenzothiophenes & $(226)$ & 1.57 & 1.23 & 1.06 & 1.08 & 0.934 & 0.928 & 0.612 & 0.896 & 0.860 \\
\hline ¿dibenzothiophenes & & 4.25 & 2.42 & 2.34 & 2.56 & 2.38 & 2.35 & 1.38 & 2.33 & 2.04 \\
\hline \multicolumn{11}{|l|}{$\mathrm{C}_{3}$-dibenzothiophenes/ } \\
\hline$C_{3}$-phenantherene ${ }^{a}$ & & 0.389 & 0.404 & 0.389 & 0.380 & 0.436 & 0.394 & 0.405 & 0.413 & 0.409 \\
\hline$\Sigma \mathrm{PAHs}^{\mathrm{b}}$ & & 38.8 & 12.5 & 13.5 & 15.1 & 13.0 & 14.8 & 7.04 & 12.2 & 9.71 \\
\hline
\end{tabular}




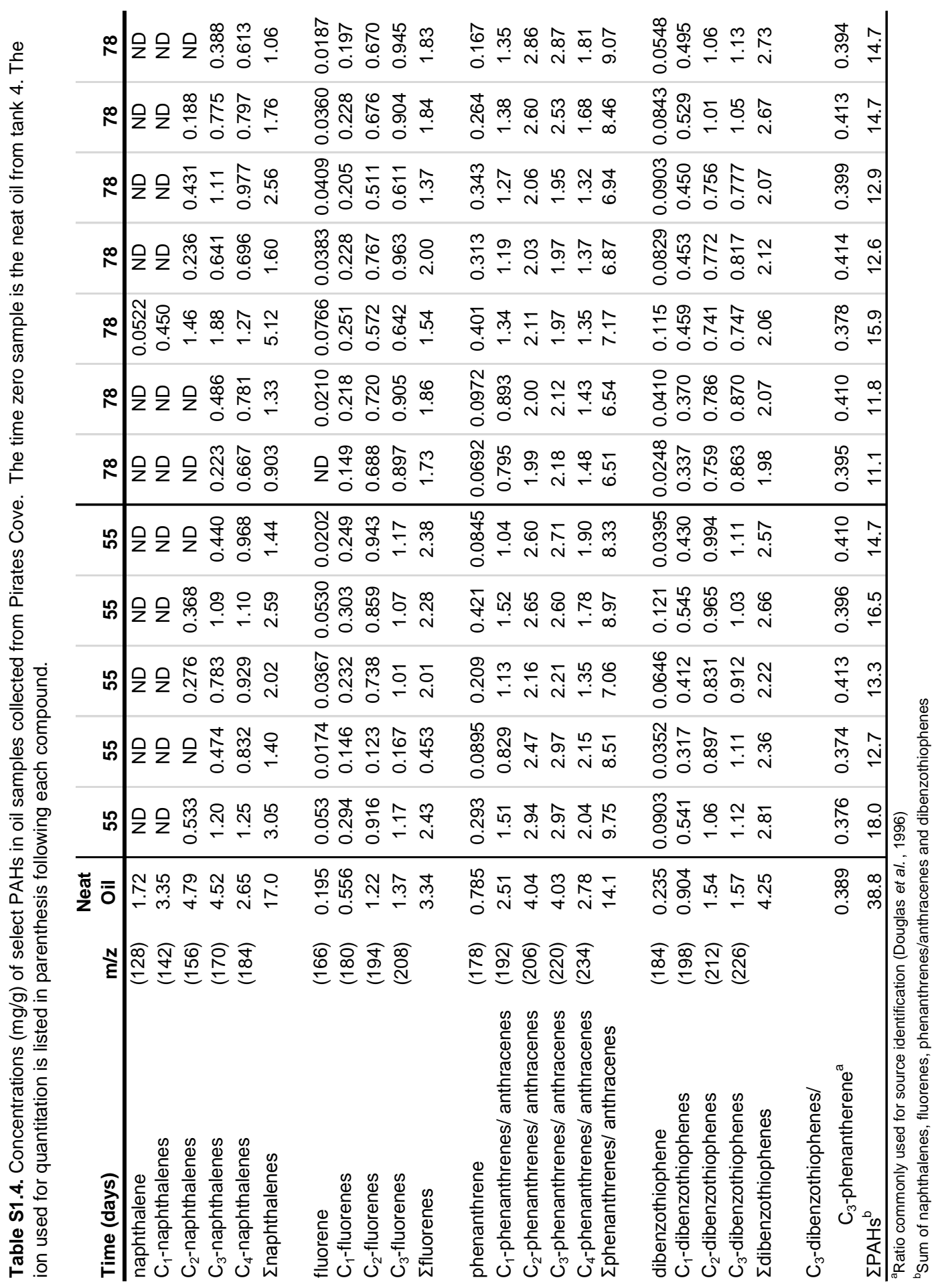




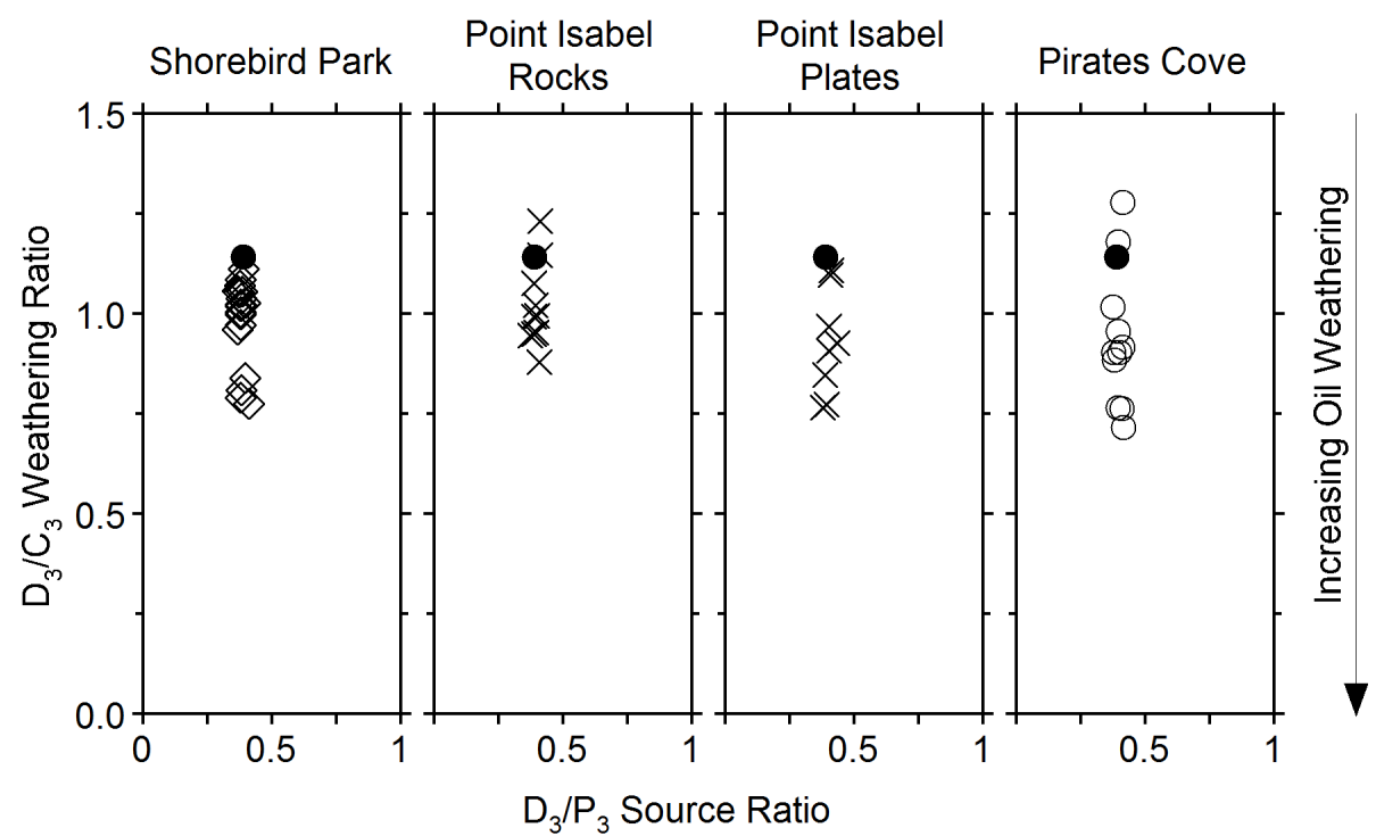

Figure S2. Commonly used source ratio $\left(\mathrm{D}_{3} / \mathrm{P}_{3}\right)$ plotted against a common weathering ratio $\left(D_{3} / C_{3}\right)$ for all samples analyzed at each site. Typically the $\mathrm{D}_{3} / \mathrm{P}_{3}$ ratio for heavy fuel oils is between 0 and 0.9 and, for other fuel types up to 3 (Uhler et al., 2007; Douglas et al., 1996). Weathering ratios can range from 0 to 12 for crude oils spilled, with decreasing ratios indicating greater weathering (Douglas et al., 1996). All collected samples have source ratios consistent with the tank 4 oil. The $\mathrm{D}_{3} / \mathrm{C}_{3}$ ratio indicates samples at all sites experienced similar weathering excluding rock samples from Point Isabel which showed less weathering. 
Table S2. BaA, Chr, and $n-\mathrm{C}_{18} /$ phytane data used in figures 5 and 6 .

\begin{tabular}{|c|c|c|c|c|c|c|}
\hline Site* $^{*}$ & Time & $\begin{array}{l}\text { Sample } \\
\text { ID \# }\end{array}$ & $\begin{array}{c}\mathrm{BaA} \\
(\mathrm{mg} / \mathrm{g})\end{array}$ & $\begin{array}{c}\text { Chr } \\
(\mathrm{mg} / \mathrm{g})\end{array}$ & $\begin{array}{l}\mathrm{BaA} / \\
\mathrm{Chr}\end{array}$ & $\begin{array}{c}n-\mathrm{C}_{18} / \\
\text { Phytane }\end{array}$ \\
\hline CB & 0 & 73 & 0.133 & 0.215 & 0.621 & 2.60 \\
\hline SB & 8 & 1 & 0.111 & 0.180 & 0.616 & 2.52 \\
\hline SB & 8 & 2 & 0.0948 & 0.151 & 0.629 & 2.60 \\
\hline SB & 21 & 3 & 0.102 & 0.166 & 0.612 & 2.46 \\
\hline SB & 21 & 4 & 0.106 & 0.170 & 0.625 & 2.22 \\
\hline SB & 21 & 5 & 0.0918 & 0.151 & 0.609 & 2.23 \\
\hline SB & 21 & 6 & 0.0956 & 0.154 & 0.619 & 2.28 \\
\hline SB & 21 & 7 & 0.0905 & 0.146 & 0.621 & 2.29 \\
\hline SB & 34 & 8 & 0.110 & 0.172 & 0.637 & 1.95 \\
\hline SB & 34 & 9 & 0.0891 & 0.143 & 0.624 & 2.66 \\
\hline SB & 34 & 10 & 0.117 & 0.184 & 0.634 & 2.51 \\
\hline SB & 34 & 11 & 0.104 & 0.168 & 0.617 & 2.45 \\
\hline SB & 55 & 30 & 0.108 & 0.181 & 0.597 & 2.02 \\
\hline SB & 55 & 31 & 0.114 & 0.178 & 0.637 & 1.77 \\
\hline SB & 55 & 33 & 0.121 & 0.199 & 0.609 & 1.96 \\
\hline SB & 55 & 34 & 0.118 & 0.182 & 0.651 & 1.77 \\
\hline SB & 55 & 35 & 0.114 & 0.188 & 0.605 & 1.60 \\
\hline SB & 80 & 62 & 0.124 & 0.190 & 0.656 & 2.13 \\
\hline SB & 80 & 63 & 0.114 & 0.197 & 0.579 & 2.23 \\
\hline SB & 80 & 64 & 0.104 & 0.163 & 0.639 & 1.87 \\
\hline PI & 35 & 12 & 0.0890 & 0.177 & 0.503 & 1.93 \\
\hline PI & 35 & 13 & 0.119 & 0.221 & 0.541 & 1.54 \\
\hline PI & 35 & 14 & 0.0994 & 0.186 & 0.534 & 1.73 \\
\hline PI & 35 & 15 & 0.105 & 0.191 & 0.551 & 2.25 \\
\hline PI & 35 & 16 & 0.107 & 0.176 & 0.605 & 1.94 \\
\hline PI & 55 & 24 & 0.115 & 0.209 & 0.549 & 2.21 \\
\hline PI & 55 & 25 & 0.0648 & 0.189 & 0.343 & 2.58 \\
\hline PI & 80 & 65 & 0.126 & 0.190 & 0.663 & 2.12 \\
\hline PI & 80 & 66 & 0.0679 & 0.166 & 0.409 & 2.17 \\
\hline PIP & 55 & 23 & 0.114 & 0.220 & 0.517 & 0.06 \\
\hline PIP & 55 & 27 & 0.113 & 0.197 & 0.571 & 0.19 \\
\hline PIP & 56 & 37 & 0.112 & 0.216 & 0.520 & 0.73 \\
\hline PIP & 56 & 38 & 0.0817 & 0.176 & 0.465 & 2.25 \\
\hline PIP & 56 & 40 & 0.109 & 0.188 & 0.581 & 0.95 \\
\hline PIP & 56 & 41 & 0.117 & 0.208 & 0.564 & 0.57 \\
\hline PIP & 80 & 67 & 0.0869 & 0.152 & 0.573 & 1.33 \\
\hline PIP & 80 & 68 & 0.0681 & 0.166 & 0.409 & 0.98 \\
\hline PIP & 80 & 69 & -- & -- & -- & 1.10 \\
\hline PC & 55 & 19 & 0.122 & 0.200 & 0.610 & 1.40 \\
\hline PC & 55 & 20 & 0.102 & 0.168 & 0.610 & 0.41 \\
\hline PC & 55 & 21 & 0.101 & 0.159 & 0.632 & 0.61 \\
\hline PC & 55 & 22 & 0.110 & 0.181 & 0.608 & 2.03 \\
\hline PC & 55 & 28 & 0.116 & 0.207 & 0.562 & 0.48 \\
\hline PC & 78 & 51 & 0.0956 & 0.170 & 0.563 & 0.39 \\
\hline PC & 78 & 52 & 0.0964 & 0.163 & 0.593 & 0.61 \\
\hline PC & 78 & 53 & 0.0885 & 0.136 & 0.651 & 2.35 \\
\hline PC & 78 & 54 & 0.0967 & 0.176 & 0.551 & 2.32 \\
\hline PC & 78 & 55 & 0.0895 & 0.144 & 0.621 & 2.19 \\
\hline PC & 78 & 56 & 0.0878 & 0.158 & 0.556 & 1.85 \\
\hline PC & 78 & 57 & 0.108 & 0.171 & 0.629 & 0.74 \\
\hline
\end{tabular}




\section{S3. Supplemental References}

Douglas, G.S., Bence, A.E., Prince, R.C., McMillen, S.J., Butler, E.L., 1996.

Environmental stability of selected petroleum hydrocarbon source and weathering ratios. Environmental Science \& Technology 30, 2332-2339.

Glaser, J.A., Foerst, D.L., McKee, G.D., Quave, S.A., Budde, W.L., 1981. Trace analyses for wastewaters. Environmental Science \& Technology 15, 1426-1435.

Nelson, R.K., Kile, B.M., Plata, D.L., Sylva, S.P., Xu, L., Reddy, C.M., Gaines, R.B., Frysinger, G.S., Reichenbach, S.E., 2006. Tracking the weathering of an oil spill with comprehensive two-dimensional gas chromatography. Environmental Forensics 7, 33-44.

Prince, R.C., Elmendorf, D.L., Lute, J.R., Hsu, C.S., Haith, C.E., Senius, J.D., Dechert, G.J., Douglas, G.S., Butler, E.L., 1994. 17- $\alpha(\mathrm{H}), 21-\beta(\mathrm{H})$-hopane as a conserved internal marker for estimating the biodegradation of crude oil. Environmental Science \& Technology 28, 142-145.

Reichenbach, S.E., Ni, M.T., Zhang, D.M., Ledford, E.B., 2003. Image background removal in comprehensive two-dimensional gas chromatography. Journal of Chromatography A 985, 47-56.

Uhler, A.D., Stout, S.A., Douglas, G.S., 2007. Chemical heterogeneity in modern marine residual fuel oils. In: Wang, Z., Stout, S.A. (Eds.), Oil Spill Environmental Forensics: Fingerprinting and Source Identification. Academic Press, Boston, pp. 327-348.

Wardlaw, G.D., Arey, J.S., Reddy, C.M., Nelson, R.K., Ventura, G.T., Valentine, D.L., 2008. Disentangling oil weathering at a marine seep using $\mathrm{GC} \times \mathrm{GC}$ : broad metabolic specificity accompanies subsurface petroleum biodegradation. Environmental Science \& Technology 42, 7166-7173. 


\section{Chapter 3}

Evaporation and dissolution trends for oil samples from the M/V Cosco Busan spill

Karin L. Lemkau 


\title{
Evaporation and dissolution trends for oil samples from the M/V Cosco Busan spill
}

\begin{abstract}
Evaporation and dissolution are two weathering processes affecting oil spills. Though their distinction is important for understanding oil toxicity and its fate in the environment, quantifying their effects is difficult. We investigated these processes following the $\mathrm{M} / \mathrm{V}$ Cosco Busan heavy fuel oil spill (San Francisco Bay, CA; November 2007). First, we used traditional one-dimensional gas chromatography (GC)-based techniques to attempt to disentangle the roles of evaporation and dissolution processes in oil-covered rocks and scrapings from the coastline of San Francisco Bay. We then examined these field samples by comprehensive two-dimensional gas chromatography $(\mathrm{GC} \times \mathrm{GC})$, which can separate petroleum components based on their relative vapor pressures and polarities. The resulting data within the chromatograms are presented as mass loss tables (MLTs) which allow for visualization of weathering trends as a function of vapor pressure and aqueous solubility. MLTs enable assignment of observed losses to specific regions of the GC $\times \mathrm{GC}$ chromatogram and show evaporation to be the dominant process removing hydrocarbon compounds with higher vapor pressures from these samples.
\end{abstract}

Keywords: M/V Cosco Busan, heavy fuel oil, petroleum, weathering, evaporation, dissolution, mass loss tables 


\section{INTRODUCTION}

After the 2007 M/V Cosco Busan heavy fuel oil (HFO) spill in San Francisco Bay, a ring of oil coated the shorelines (Figure S1). Due to the relatively easy access to affected areas and the small volume spilled (200,000 liters), it was assumed that long-term environmental impact from the spill would be minimal. However, populations of herring decreased dramatically, and in 2009 the herring fishery closed for the first time since its establishment in the 1870s (Rogers, 2009). It is possible that natural population fluctuations, long-term population declines, and low precipitation during 2008 (resulting in unfavorably high salinity conditions) may have contributed to these declines. Yet, there is compelling evidence that despite the small volume released, the spilled oil was a contributing factor (Incardona et al., 2012). No data on hydrocarbon concentrations within the water column were collected after the M/V Cosco Busan spill. Nonetheless, studies on local herring performed after the spill revealed unexpectedly high mortality in herring embryos exposed to the oil (Incardona et al., 2012). Incardona et al. (2012) were unable to determine the compounds responsible for the unexpected toxicity despite trying to correlate it with compounds usually associated with oil toxicity, namely polycyclic aromatic hydrocarbons (PAHs). It is possible that the source of observed toxicity was outside of the analytical window of select saturates and PAHs typically analyzed.

However, field-based studies may provide insight into the presence of the broad array of compounds within the water after the spill.

During and following the clean-up, oiled rocks could have been a significant input term for delivery of hydrocarbons back into the water column. Here we use comprehensive two-dimensional gas chromatography $(\mathrm{GC} \times \mathrm{GC})$ to examine possible hydrocarbon inputs from oil-covered shorelines following the spill.

For any study examining the fate of water-soluble oil components, the role of evaporation needs to be considered as well. Evaporation transfers compounds to the atmosphere where they are effectively removed from the spill area (though with potentially detrimental effects to volunteers performing cleanup; Morita et al., 1999; Carrasco et al., 
2006; Perez-Cadahia et al., 2007; Sim et al., 2010; Cheong et al., 2011; Eom et al., 2011; Jeong et al., 2011). By comparison, dissolution draws compounds from the oil into the water column where they are bioavailable and potentially toxic to marine organisms, such as herring. The ability to distinguish between evaporation and dissolution is challenging because these processes affect similar low molecular weight and high volatility compounds. Isolating the effects of these processes using one-dimensional gas chromatography (GC) techniques typically used to study oil spills is only marginally effective (Stout and Wang 2007).

Ratios of compounds detected using GC-based techniques are commonly used to learn about weathering processes. Briefly, weathering ratios exploit compounds that behave similarly with respect to all processes except the process of interest. For example, a ratio to examine biodegradation will utilize compounds that have similar solubilities, vapor pressures, and photo reactivities, but different rates of biodegradation (i.e. $n$ $\mathrm{C}_{18}$ /phytane). Similarly, ratios for examining dissolution rely on finding compounds that have similar vapor pressures but different aqueous solubilities.

Finding appropriate compound pairs for evaporation and dissolution is difficult because both processes affect similar types of compounds. Smaller compounds have both higher vapor pressures and higher solubilities (because of the decreased solute cavitation energy) than larger compounds. Even under the best circumstances, compounds used for these ratios are affected, to some degree, by both processes. Thus conventional compound ratios cannot provide a robust accounting of where compounds are going. Arey et al., (2007a) reviewed commonly used ratios determined by GC to study evaporation and dissolution (Arey et al., 2007a). An alternative approach presented by Snape et al. (2005) used gravimetric measurement of loss coupled with GC-FID and compound vapor pressures to examine evaporative loss. However, compound coelution limits estimation of compound-specific evaporative losses and the method developed can only be used in the absence of dissolution. 
Previous work has demonstrated the effectiveness of $\mathrm{GC} \times \mathrm{GC}$ for isolating evaporation and dissolution weathering processes (Arey et al., 2005; Arey et al., 2007a; Arey et al., 2007b; Wardlaw et al., 2008). GC $\times \mathrm{GC}$ relies on compound separation based on the molecular interactions (dipole-dipole electrostatic attraction, hydrogen bonding and Van de Waals forces) between individual compounds and the stationary phase within the column.

The most common form of $\mathrm{GC} \times \mathrm{GC}$, and the type used here, employs a non-polar column to separate compounds in the first dimension and a slightly more polar column to separate compounds in the second dimension. Van der Waals interactions are the most important interactions with a non-polar column and Van der Waals attractive forces are closely related to compound vapor pressure. For this reason, separations on a non-polar column are often considered to be volatility-based. Second dimension separations are typically performed on a slightly more polar column where interactions are dominated by dipoledipole interactions (though Van der Waals interactions are also occurring; Dimandja 2004). Because dipole-dipole interactions are driven by compound polarity, the second dimension separation is often considered to be polarity-based even though other molecular interactions are occurring. For consistency with other GC $\times$ GC-based work, here we will refer to the first and second dimension separations as volatility and polaritybased, respectively. Because polarity is closely related to compound solubility, vapor pressure and polarity information can be used to examine evaporation and dissolution weathering processes.

One study by Arey et al. examined the Bouchard 120 heavy fuel oil spill (Arey et al., 2007a; Arey et al., 2007b), which occurred in Buzzards Bay, MA in 2003. Using novel visualization techniques, Arey et al., (2007a) were able to examine compound losses due to evaporation and dissolution.

In the current study, we examine samples collected after the M/V Cosco Busan HFO spill. We examine results based on scrapings from oil-covered rocks via $\mathrm{GC} \times \mathrm{GC}$ to identify losses of compounds and identify signatures of evaporation and dissolution. 


\section{METHODS}

2.1. Sample collection and preparation. Oil residues were scraped from three rocky shorelines in and around San Francisco Bay following the 2007 M/V Cosco Busan (Figure S2). For detailed descriptions of all sampling sites the reader is referred to Lemkau et al. (2010). For GC analysis, samples from all three sites were analyzed. Because of the higher sampling frequency at Shorebird Park (Berkeley, CA; Figure S2), samples from this site are the focus for the $\mathrm{GC} \times \mathrm{GC}$ work presented here. Previous work on samples from Shorebird Park found varying degrees of biodegradation and evaporation/dissolution; no photodegradation was detected during the initial 80 days after the spill (Lemkau et al., 2010).

Briefly, oil was scraped with a stainless steel spatula from coastal rocks and stored in combusted Al-foil envelopes. Samples were transported to Woods Hole, MA and frozen $\left(-20^{\circ} \mathrm{C}\right)$ until analysis. Two oil-containing tanks were ruptured during the allision (Tanks 3 and 4). Samples from both port-side Tanks 3 and 4 were provided by the National Oceanic and Atmospheric Administration per chain-of-custody procedures. Previous work comparing the biomarker ratios of each tank to field samples revealed that Tank 4 was the source of the oil released (Lemkau et al., 2010).

2.2. Background of the M/V Cosco Busan oil. The oil released was a heavy fuel oil, made from a refinery residue and a lighter, less viscous cutting oil. The oil spilled by the M/V Cosco Busan was a group IFO380 HFO. The unweathered oil from Tank 4 contains GC-amenable compounds ranging from $n-\mathrm{C}_{10}$ to greater than $n$ - $\mathrm{C}_{45}$ with most of the GCamenable mass eluting between $n-\mathrm{C}_{16}$ and $n-\mathrm{C}_{38}$ (Figure 1a). Because of the residual nature of heavy fuel oils, they contain many components not detectable via GC. A major portion of this non GC-amenable fraction is asphaltenes which are large ( $\sim 500$ to $>1000$ Da) heteroatom enriched compounds. Bulk sulfur content of the Tank 4 oil was 1.76\% (measured by Midwest Microlabs, Indianapolis, IN) and the oil contained $~ 16 \%$ asphaltenes as measured by precipitation in hexane. 
2.3. GC-FID and GC-MS analysis. Samples were analyzed according to methods previously described (Lemkau et al., 2010). GC with flame ionization detection (GCFID) was used to quantify total petroleum hydrocarbons and $n$-alkanes used in weathering ratios. Gas chromatography with mass spectrometry (GC-MS) was used to measure parent PAHs and alkylated homologs of naphthalene, fluorene, phenanthrene/anthracene, and dibenzothiophene.

2.4. GC $\times$ GC-FID analysis. $\mathrm{GC} \times \mathrm{GC}$ analysis was performed on the unweathered oil and on nine representative samples from Shorebird Park, collected 8, 21, 34, 55 80, 139 and 296 days after the spill.

The methods followed closely those of "method A" from the work of Arey et al., 2005. Briefly, first dimension, separations were performed on a non-polar column (Restek RTX1, 100\% polysiloxane, $18.6 \mathrm{~cm}$ length, $0.25 \mathrm{~mm}$ ID and $0.25 \mu \mathrm{m}$ film thickness) programmed from $35^{\circ} \mathrm{C}$ (5 min hold) and ramped to $320{ }^{\circ} \mathrm{C}$ at $1{ }^{\circ} \mathrm{C} \mathrm{min}{ }^{-1}$. Second dimension separations were performed on a more polar column (SGE BPX-50, 50\% phenylpolysiphenylene siloxane, $1.0 \mathrm{~m}$ long, $0.10 \mathrm{~mm} \mathrm{ID}$ and $0.10 \mu \mathrm{m}$ film thickness) programmed from $43{ }^{\circ} \mathrm{C}$ ( 5 min hold $)$ and ramped to $350{ }^{\circ} \mathrm{C}$ at $1.08{ }^{\circ} \mathrm{C} \mathrm{min}^{-1}$.

Each chromatogram was baseline subtracted (Reichenbach et al., 2003) and all FID signal eluting more than 0.5 seconds before $n$-alkanes in the second dimension were considered artifactual (i.e., modulated column bleed) and set to zero.

All chromatograms were normalized to the conserved biomarker $17 \alpha(\mathrm{H})-21 \beta(\mathrm{H})$-hopane (Prince et al., 1994) to enable comparison among samples. Although degradation of hopane can occur on relatively short timescales (Frontera-Suau et al., 2002), examination of $\mathrm{C}_{31}-\mathrm{C}_{35}$ hopanes showed negligible preferential degradation, consistent with previous work (Wang et al., 2001; Frontera-Suau et al., 2002; Figure S3), and indicate that $17 \alpha(\mathrm{H})-21 \beta(\mathrm{H})$-hopane is conserved and appropriate as an external standard (Janak 1987). 


\subsection{Mapping partitioning properties onto the GC $\times$ GC Chromatogram. Previous}

work has described many of the steps involved in mapping physical and chemical properties onto the two-dimensional GC×GC space (Arey et al., 2005; Arey et al., 2007a). Assuming all compounds to be hydrocarbons, first and second retention times were converted to retention indices (van Den Dool and Kratz 1963; Arey et al., 2005). This removes the impact of temperature programs and lab-specific variability from obtained retention times. Employing these retention indices, previously developed linear free energy relationships (LFERs) were then used to estimate hypothetical pure component liquid vapor pressures and aqueous solubilities for first and second retention indices of the chromatogram (Arey et al., 2005; Table 1).

Due to the training set used to develop LFERs (Figure S4), vapor pressure and solubility estimates are only valid for the $n-\mathrm{C}_{10}$ to $n-\mathrm{C}_{24}$ carbon range. Compounds less than $n-\mathrm{C}_{10}$ are assumed to evaporate quickly whereas those greater than $n-\mathrm{C}_{24}$ are assumed to be unaffected by evaporation and dissolution. These assumptions are consistent with evaporation and water-washing trends (Fingas 2004; Nelson et al., 2006; Arey et al., 2007a; Arey et al., 2007b; Mao et al., 2009).

Chromatograms were divided into discrete cells based on contours of hydrocarbon liquid vapor pressures and solubilities (0.5 and $0.2 \log$ units respectively; Figure S4), allowing grouping of compounds of similar properties. Cell mass was defined as the sum of all pixel heights within each cell. To avoid dramatic changes in cell mass if retention times were to shift slightly between samples, each pixel within the chromatogram was weighted so that peaks near cell boundaries were partially assigned to all surrounding cells in such a way that mass was conserved (Arey et al., 2007a).

2.6. Mass Loss Tables (MLTs). Field samples and model results are presented as MLTs created by projecting each discrete cell of the chromatogram onto a two-dimensional space delineated by contours of the calculated aqueous solubility and vapor pressure of that cell (Arey et al., 2007b). The cells within the chromatogram can be thought of as theoretical "compounds" with vapor pressure and solubility characteristics defined by 
their location within the two-dimensional space. MLTs present the log-transformed mass fraction remaining $(\log ([\mathrm{Mt}] /[\mathrm{M} 0]))$ and allow visualization of "compound" loss compared to the unweathered Tank 4 oil (Figure 3). White indicates no change while blue and red indicate mass loss and mass gain relative to the unweathered oil. Approximate compound locations within the GCXGC chromatogram and corresponding MLT space are annotated in Figure 3.

\section{RESULTS}

3.1. GC-FID. We first examined weathering of field samples through 296 days post-spill, using samples collected from Shorebird Park (Figure 1). Because separations were performed on a non-polar column, elution order can be correlated to solute size, with smaller compounds eluting first (Poole 2003; Dimandja 2004). Rapid loss of lower molecular weight compounds is observed, and eight days after the spill nearly all compounds eluting before $n-C_{12}$ have been removed. After 80 days, losses extend up to $n$ $\mathrm{C}_{15}$. With increasing time, there was a continuing loss of lower molecular weight compounds, and by 296 days nearly all compounds eluting before $n-C_{17}$ were removed. This extent of weathering is consistent with that noted for previous spills (Wang and Fingas 1995c; Ezra et al., 2000; Douglas et al., 2002; Nelson et al., 2006). The compounds removed include many of the most well-known toxic compounds within oil such as the naphthalenes (Degraeve et al., 1982; French-McCay 2002).

Observed losses can generally be attributed to the combined processes of evaporation and dissolution (Wang et al., 1995a; Snape et al., 2005; Diez et al., 2007; Lemkau et al., 2010).

3.1.1 Evaporation. To examine oil evaporation, we employed the saturated hydrocarbon weathering ratio (SHWR). This ratio examines the relative loss of low molecular weight $n$-alkanes to higher molecular weight $n$-alkanes less affected by evaporation (Figure $2 \mathrm{a}$; Boehm et al., 1982): 


$$
\mathrm{SHWR}=\left(\sum n-\mathrm{C}_{10} \text { to } n-\mathrm{C}_{25}\right) /\left(\sum n-\mathrm{C}_{17} \text { to } n-\mathrm{C}_{25}\right)
$$

The SHWR values in field samples decrease from a Tank 4 oil value of 1.58 to 1.19 within 8 days post-spill and continue to decrease more slowly, dropping to $1.11 \pm 0.07$ by 35 days post-spill (Figure 2a). Values then level off, with little change for the remainder of the study period ( $1.07 \pm 0.04$ at 80 days post-spill). The initial rapid decline in the SHWR suggests that evaporation began shortly after the spill, consistent with the rapid loss of naphthalene (Lemkau et al., 2010). The SHWR ratio shows no clear signs of continuing evaporation after 55 days post-spill.

During the initial days after an oil spill, evaporation is generally assumed to be the dominant weathering process (Stout and Wang 2007 and references therein). Slater et al. (2006) and Ezra et al. (2000) observed similar decreases attributed to evaporation after the Bouchard 120 and Eshkol power station spills respectively. Using similar ratios, Ezra et al. (2000) observed a rapid loss of lower molecular weight $n$-alkanes immediately following the spill, with continued loss through the first 6 months. In contrast, the observed evaporative losses for the Prestige HFO spill were more gradual with time (Diez et al., 2007).

The SHWR metric is designed to diagnose compositional changes that arise from evaporation. However, small compounds included in these ratios are also subject to removal through other processes, mainly dissolution.

3.1.2. Dissolution. By taking advantage of the different aqueous solubilities of $\mathrm{PAH}$ compounds, it is possible to evaluate the impact of dissolution on our field samples (Figure 2b). Smaller and less alkylated PAHs are generally more soluble and therefore preferentially removed from the oil to the surrounding waters (McAuliff 1966; Sutton and Calder 1975; Eganhouse and Calder 1976). One traditionally used ratio is the aromatic weathering ratio (AWR) introduced by Boehm et al., (1982; Figure 2b). This ratio examines the loss of smaller and more soluble PAH isomers relative to large PAH compounds (Boehm et al., 1982; Figure 2b): 


$$
\begin{gathered}
\mathrm{AWR}=(\text { total naphthalenes }+ \text { total fluorenes }+ \text { total phenanthrenes }+ \text { total } \\
\text { dibenzothiophenes }) /(\text { total phenanthrenes }+ \text { total dibenzothiophenes })
\end{gathered}
$$

Similar to the SHWR, the AWR drops immediately following the spill (2.11 in the Tank 4 oil to $1.58 \pm 0.06$ at 8 days post-spill), suggesting dissolution is occurring. However, because lower molecular weight aromatic compounds are susceptible to both evaporation and dissolution, the extent of each process is unknown.

In summary, according to the indicators examined here, both evaporation and dissolution affected the fate of the M/V Cosco Busan oil. Scatter within ratio values suggest that not all samples are equally affected by these processes. Quantitative determination of process contributions to compound loss is complicated by the small number of compounds used in ratios and by the coelution of compounds on the GC. Also, ratios only calculate average losses (based on compounds used in each ratio) which will not be accurate for all compounds within the oil. Therefore, with this data alone, it is not possible to accurately determine the relative impact of these processes on a compound-by-compound basis. A more inclusive, reliable and accurate method for distinguishing these processes is needed.

3.2. GC $\times$ GC-FID. To further examine the fate of GC-amenable compounds, we examined samples by GCxGC-FID. This technique offers an order of magnitude improvement in detection limit over one-dimension techniques and enables easy visualization of mixture composition and compound classes present (Nelson et al., 2006; Ventura et al., 2010). One benefit of GC×GC-based techniques is that they utilize all GCamenable compounds within an oil to examine weathering trends, not just those compounds whose identities are known (or visible using one-dimensional chromatography). Coupled with the high resolution of $\mathrm{GC} \times \mathrm{GC}$ this enables a much more thorough examination of oil components and changes of these compounds with time as compared to one-dimensional GC techniques. Used in conjunction with FID detection, which has a response factor of $\sim 1 \mathrm{pAmp} \mathrm{s}{ }^{-2}, \mathrm{GC} \times \mathrm{GC}$ also allows for quantification of individual oil components without need for extensive calibration curves. This makes 
$\mathrm{GC} \times \mathrm{GC}$ a powerful tool for examining and quantifying all GC-amenable components within these mixtures, whether or not the identities of individual analytes are known.

Here, $\mathrm{GC} \times \mathrm{GC}$ is used to separate compounds based on differences in volatility and polarity. Petroleum compounds (the most polar of which are only semi-polar by organic chemistry standards) with relatively higher polarities will have greater elution times in the second dimension and appear towards the top of the chromatogram, whereas larger compounds have greater elution times in the first dimension, resulting in an increase in molecular size from left to right across the chromatogram. This results in compounds ordered by carbon number along the $\mathrm{x}$ axis and chemical class (alkanes, cycloalkanes and one- two- and multi-ring aromatics and their alkylated homologs) along the y axis (Nelson et al., 2006; Ventura et al., 2010). Many other identifiable and unidentifiable compounds are also visible within the oil. Major compound classes present within the unweathered oil are annotated in Figure 3a.

GC $\times$ GC-FID chromatograms of four samples are presented in Figures 4 and 5. Compound presence/absence within the GC×GC-FID chromatograms is more easily visualized in Figure 4, and Figure 5 presents a three dimensional mountain plot allowing better visualization of analyte concentration changes within the samples, particularly for the $n$-alkane compounds.

Because separations are based on differences in volatility and polarity (related to vapor pressure and solubility respectively; Arey et al., 2005), GC×GC chromatograms allow examination of the processes of evaporation and dissolution. We would expect evaporation to preferentially remove compounds with higher vapor pressures; thus an evaporation signature would be seen as a loss of compounds along the first dimension and spanning the entire second dimension (Reddy et al., 2002). Alternatively, dissolution would be expected to preferentially remove the smallest and most soluble compounds, resulting in a loss trend emanating from the upper left-hand corner of the $\mathrm{GC} \times \mathrm{GC}$ space (Reddy et al., 2002; Arey et al., 2005; Arey et al., 2007a). 
By 8 days post-spill, most compounds eluting before $n-\mathrm{C}_{14}$ in the first dimension have been removed across the entire second dimension, including indanes, substituted benzenes and naphthalene. Incomplete removal of compounds through $\sim n-\mathrm{C}_{17}$ is also apparent. Losses are also present within the parent and less alkylated fluorenes, phenanthrenes and dibenzothiophenes. Loss of these relatively more soluble compounds, while compounds of similar vapor pressure remain unaltered, is consistent with the effects of dissolution.

By 80 days post-spill, complete losses of low molecular weight compounds have been extended through $n$ - $\mathrm{C}_{15}$. Only low levels of $\mathrm{C}_{3}$-naphthalenes are present within the samples and the majority of $\mathrm{C}_{4}$-naphthalenes have also been lost. Minimal losses of the most soluble compounds are observed. Weathering of the fluorenes continues, though phenanthrenes remain unchanged. Due to higher vapor pressures, $n$-alkanes are lost faster than their comparable branched counterparts. By 80 days post-spill, many compounds eluting between the $n$-alkanes and PAHs in the second dimension (which were visible at 8 days post-spill) have been removed. These trends are consistent with losses due to evaporation and dissolution.

By 296 days post-spill, we observe only slightly more losses in the early eluting compounds than at 80 days post-spill. Complete losses progress through approximately $n$ $\mathrm{C}_{17}$. Removal of phenanthrene and dibenzothiophene homologs continues through 296 days post-spill. Some decreases in more soluble compounds are noticeable, though it is difficult to determine if these losses are consistent with those observed for other compounds of similar vapor pressure. Normal alkanes greater than $n-\mathrm{C}_{19}$ show no changes in distribution. Losses of smaller $n$-alkanes are probably primarily the result of evaporation and biodegradation.

These two-dimensional chromatograms provide an opportunity to investigate presence of impacts due to evaporation and dissolution on field samples. Overall, many trends are consistent with the combined effects of evaporation and dissolution. However, visual inspection of chromatograms is difficult. We can examine losses numerically for 
individual peaks, however this technique is time consuming, and does not allow easy visualization of loss trends within samples. It is also important to note that, although there appears to be a dominant trend of evaporation in our samples, compounds are likely lost due to both evaporation and dissolution. For example, compounds in the upper left of the GC $\times \mathrm{GC}$ chromatogram are particularly susceptible to both of these processes.

3.3. Field Sample Mass Loss Tables (MLTs). To better visualize and assess evaporation and dissolution trends, we use MLTs to examine mass losses relative to the unweathered oil. MLTs allow visualization of mass loss patterns of $\mathrm{GC} \times \mathrm{GC}$ analytes distributed by vapor pressure (first dimension) and aqueous solubility (second dimension) (Figure 3b). It is expected that compounds of higher vapor pressure will be preferentially removed through evaporation. This would appear as an "evaporation front" moving from left to right across the MLT with time. Conversely, loss through dissolution would appear as a loss in the most soluble compounds; this trend would appear as a "dissolution front" as compounds are lost across the top rows of the mass loss tables (Figure S5).

MLTs offer several advantages in examining GC $\times$ GC data. First, because MLTs are based on modeled compound properties and not retention times that vary from lab to lab, they avoid the effects of general operating conditions such a temperature programs (column length; column quality; flow rates). This allows easier comparison of samples between laboratories and facilitates comparison of model results with field samples. Although MLTs do not show all of the detailed information present within a GC $\times \mathrm{GC}$ chromatogram, they provide an easy means of visualizing regions of interest which can then be explored in more detail in the original chromatogram. Finally, with MLTs, the need for absolute registration is not critical for comparing samples using difference, ratio or other techniques, whereas similar operations on $\mathrm{GC} \times \mathrm{GC}$ chromatograms would be problematic (Nelson et al., 2006).

Figure 6 shows the MLTs and location of evaporation fronts for field samples. In these MLTs, blue indicates mass loss and red indicates mass gain within the sample relative to the unweathered Tank 4 oil. Black boxes in the upper right quadrant represent regions in 
the log vapor pressure-log solubility space that fall outside the $\mathrm{GC} \times \mathrm{GC}$ chromatogram. Variability in cells along the edge of this region is believed to be noise due to small masses present within these cells and is considered artifactual. Here we define the evaporation front as the region where all cells corresponding to a given vapor pressure show greater than $80 \%$ loss.

The earliest sample, collected 8 days after the spill, already shows a clear loss of volatile compounds exhibiting an evaporation front at $10^{\circ} \mathrm{Pa}$. Over time, the evaporation front moves to the right across the mass loss table, reaching $10^{-0.4}$ Pa by 55 days post-spill and $10^{-1.4} \mathrm{~Pa} 296$ days post-spill. Initial rapid losses through day 8 decelerate and there is a slower and relatively continuous progression of the evaporation front through 296 days. This is roughly in agreement with one-dimensional evaporative indices, both approaches suggesting that evaporative loss affects samples mostly during the initial days post-spill.

Dissolution trends are visible in some field samples, although visualization of such trends is complicated by noise as described above. The day 8 and 21 samples appear to show greater losses of less soluble compounds compared to more soluble compounds, inconsistent with dissolution. However, an apparent dissolution front is present within the 34 to 296 day samples, where losses of more soluble compounds are superimposed on and consistently extend past the evaporation front. In the sample from day 34 , this dissolution front reaches $10^{-4.5} \mathrm{~mol} \mathrm{~L}^{-1}$. By day 80 , losses extend to $10^{-5} \mathrm{~mol} \mathrm{~L}^{-1}$. In the 296 day sample, which perhaps shows the clearest dissolution signal, the dissolution front remains in the same location but losses attributable to dissolution are greater than in earlier samples.

At two time points (days 21 and 55), two discrete samples were analyzed to examine the variability of weathering experienced at this site. These samples were chosen based on their GC-FID chromatograms and represent the complete variability in weathering observed at these time points. Specifically, GC-FID chromatograms of the day 21 samples showed slight differences in losses of smaller compounds, suggesting differing 
degrees of evaporation/dissolution, whereas the day 55 samples showed similar front end losses but differing degrees of $n$-alkane degradation.

The two discrete samples from 21 days post-spill showed minimal variation in the location of the evaporation front (from $10^{0}$ to $10^{0.6} \mathrm{~Pa}$; Figure 7 ); however, a clear difference in weathering of the least soluble compounds is evident. While one sample, 21a, follows the same general weathering trends as samples at other time points, sample $21 \mathrm{~b}$ shows an apparent preservation of the least soluble compounds. The location of these compounds corresponds to the iso- and $n$-alkanes, small aromatics and cyclic alkanes (Figure 3b) which are preferentially impacted by biodegradation (Atlas 1981; Atlas and Bartha 1992). The observed preservation of these compounds does not match with expected biodegradation or evaporation trends, and the source of this weathering pattern is not clear. Replicates from 55 days post-spill show some variation in the location of the evaporation front $\left(10^{-0.8}\right.$ to $\left.10^{-0.4} \mathrm{~Pa}\right)$ and in extent of dissolution. While the dissolution signal is unclear in sample 55a, sample 55b experienced losses of more soluble compounds with a dissolution front at $\sim 3 \times 10^{-5} \mathrm{~mol} \mathrm{~L}^{-1}$. Although the extent of evaporation seen within these samples is relatively stable, these samples demonstrate variability in the extent of weathering and in the impact of specific weathering processes within one sampling site over time.

3.3.1. Mass loss. Based on the mass loss tables, we can calculate an estimated mass loss of $55 \%$ at 296 days post-spill for the $n-\mathrm{C}_{10}$ to $n-\mathrm{C}_{24}$ region described by the MLTs. However, including the chromatogram mass outside of this range $\left(<n-\mathrm{C}_{10}\right.$ and $\left.>n-\mathrm{C}_{24}\right)$ and for asphaltene content yields a total mass loss of only $2.6 \%$ by 296 days post-spill. Nearly $90 \%$ of this loss occurred by 8 days post-spill.

This low mass loss is consistent with the percent cutting oil generally used in making heavy fuel oils (Uhler et al., 2007). This mass loss is due to removal of compounds < n$\mathrm{C}_{20}$. Very few changes are observed in the MLTs for compounds with vapor pressures lower than $n-\mathrm{C}_{20}$. The observed asymmetry in weathering between smaller and larger compounds within field samples from the M/V Cosco Busan spill suggests that refinery 
residue is potentially long-lived in the environment. In short, the cutting oil, originally added to reduce the viscosity of the residue aids in dispersing the HFO after a spill. However, once released, the oil is transported to shorelines where the smaller compounds that primarily originated from the cutting oil are weathered and removed, leaving the refinery residue on the rocks. This chapter is focused on the lighter oil components impacted by evaporation and dissolution, but the residue portion of this oil and its behavior in the environment has potentially long-term environmental implications as well. This fraction will be examined in more detail in Chapter 5.

3.3.2. Comparison with previous studies. The Bouchard 120 was another heavy fuel oil spill that occurred in Buzzards Bay, MA in April 2003. Following that spill, several studies investigated the weathering of the spilled oil with time. Sample collection times align reasonably well with our sample collection for the M/V Cosco Busan spill, allowing a unique opportunity to compare the weathering experienced by these two oils. Here we compare our samples with the surf zone samples of Arey et al. (2007a), as their weathering exposure is most similar to that of the samples from the M/V Cosco Busan spill.

Using a similar mass loss table approach, Arey et al. (2007a and b) examined samples collected from impacted shorelines in West Falmouth, MA. Based on visual inspection, the evaporation fronts for the Bouchard 120 samples (as described by Arey et al., 2007a) appear to fall in the range of $\sim 80 \%$ compound loss (the definition used for the current study) for a given vapor pressure. This is consistent with reported evaporation front location between $10^{-0.5}$ and $10^{\circ} \mathrm{Pa}$ for 10 to 86 days post-spill.

Overall weathering experienced by these two oils, as viewed using MLTs, is similar. Samples from both spills showed an initial rapid progression of the evaporation front (up to 8 days for the current study and through 16 days for the Bouchard 120 samples) after which evaporative losses slow significantly. At 114 and 139 days respectively, the locations of evaporation fronts for the Bouchard 120 have progressed farther than those for the M/V Cosco Busan samples $\left(10^{-1.5}\right.$ and $\left.10^{-0.6} \mathrm{~Pa}\right)$. By 296 days post-spill the 
evaporation front of the M/V Cosco Busan sample is roughly equal to that observed 114 days after the Bouchard 120 spill $\left(10^{-1.4}\right.$ and $\left.10^{-1.5} \mathrm{~Pa}\right)$. Samples from the M/V Cosco Busan spill show a more consistent progression of the evaporation front with time. Dissolution trends are also similar between the spills, though the last Bouchard 120 sample examined (day 114) shows a stronger signal than any of the field samples from the M/V Cosco Busan.

\section{CONCLUSIONS}

GC-FID analysis indicates evaporation and dissolution affect our samples but could not provide compound-specific or quantitative information regarding the effects of these processes. We then used $\mathrm{GC} \times \mathrm{GC}$ and mass loss tables to visualize collected field samples and to examine the impacts of evaporation and dissolution. Evaporation appears to be the dominant process affecting higher vapor pressure compound within our field samples.

Traditional GC-based compound ratio approaches become unusable within weeks of a spill because compounds within the defined ratios are lost due to weathering. The $\mathrm{GC} \times \mathrm{GC}$ and MLT techniques presented here use the majority of GC amenable oil components to examine weathering processes, making them useful on much longer timescales than ratio-based approaches.

MLTs are an improvement over examination of one- or two-dimensional chromatograms alone. MLTs enable easy visualization of evaporation and dissolution signatures and comparisons between laboratories. MLTs enable determination of regions of interest within the $\mathrm{GC} \times \mathrm{GC}$ space and can also be useful for detection of other weathering processes. However, because MLTs only show mass losses relevant to the unweathered HFO, they do not allow conclusions regarding the transport of compounds into the water or atmosphere; compound losses contributing to an apparent evaporation trend may be due to dissolution. In Chapter 4, we develop a mass transfer model and use MLTs to quantitatively apportion compound losses due to evaporation and dissolution. 


\section{ACKNOWLEDGEMENTS}

I would like to thank J. Samuel Arey, Robert K. Nelson, and Christopher M. Reddy, who will be co-authors on the submitted version of this manuscript. I also thank Jonas Gros and Phillip M. Gschwend who provided thoughtful discussions and comments on this manuscript. This work was supported by WHOI academic program funds, the Richard and Rhoda Goldman Fund, the Seaver Institute and the NSF grants EAR-0950670 and OCE-0960841.

\section{REFERENCES}

Arey, J. S., Nelson, R. K., Plata, D. L. and Reddy, C. M. (2007b). "Disentangling oil weathering using GC $\times$ GC. 2. Mass transfer calculations." Environmental Science \& Technology 41(16): 5747-5755.

Arey, J. S., Nelson, R. K. and Reddy, C. M. (2007a). "Disentangling oil weathering using GC×GC. 1. Chromatogram analysis." Environmental Science \& Technology 41(16): 5738-5746.

Arey, J. S., Nelson, R. K., Xu, L. and Reddy, C. M. (2005). "Using comprehensive twodimensional gas chromatography retention indices to estimate environmental partitioning properties for a complete set of diesel fuel hydrocarbons." Analytical Chemistry 77(22): $7172-7182$.

Atlas, R. M. (1981). "Microbial degradation of petroleum hydrocarbons: an environmental perspective." Microbiological Reviews 45(1): 180-209.

Atlas, R. M. and Bartha, R. (1992). "Hydrocarbon biodegradation and oil spill bioremediation." Advances is Microbial Ecology 12: 287 - 338.

Boehm, P. D., Fiest, D. L., Mackay, D. and Paterson, S. (1982). "Physical-chemical weathering of petroleum hydrocarbons from the Ixtoc-I blowout: chemical measurements and a weathering model." Environmental Science \& Technology 16(8): 498-505.

Carrasco, J. M., Lope, V., Perez-Gomez, B., Aragones, N., Suarez, B., Lopez-Abente, G., Rodriguez-Artalejo, F. and Pollan, M. (2006). "Association between health information, use of protective devices and occurrence of acute health problems in the Prestige oil spill clean-up in Asturias and Cantabria (Spain): a cross-sectional study." Bmc Public Health 6. 
Cheong, H. K., Ha, M., Lee, J. S., Kwon, H., Ha, E. H., Hong, Y. C., Choi, Y., Jeong, W. C., Hur, J., Lee, S. M., Kim, E. J. and Im, H. (2011). "Hebei Spirit oil spill exposure and subjective symptoms in residents participating in clean-up activities." Environmental Health and Toxicology 26: 9 pages.

Degraeve, G. M., Elder, R. G., Woods, D. C. and Bergman, H. L. (1982). "Effects of naphthalene and benzene on fathead minnows and rainbow trout." $\underline{\text { Archives of }}$ Environmental Contamination and Toxicology 11(4): 487-490.

Diez, S., Jover, E., Bayona, J. M. and Albaiges, J. (2007). "Prestige oil spill. III. Fate of a heavy oil in the marine environment." Environmental Science \& Technology 41(9): 3075-3082.

Dimandja, J. M. D. (2004). "GC x GC." Analytical Chemistry 76(9): 167A-174A.

Douglas, G. S., Owens, E. H., Hardenstine, J. and Prince, R. C. (2002). "The OSSA II pipeline oil spill: the character and weathering of the spilled oil." Spill Science \&amp; Technology Bulletin 7(3-4): 135-148.

Eganhouse, R. P. and Calder, J. A. (1976). "Solubility of medium molecular weight aromatic hydrocarbons and effects of hydrocarbon co-solutes and salinity." Geochimica Et Cosmochimica Acta 40(5): 555-561.

Eom, S. Y., Kim, Y. S., Jeong, W. C., Hur, J., Moon, S. I., Kim, J. H., Yim, D. H., Kim, Y. D., Kang, J. W. and Kim, H. (2011). "Effects of the crude oil exposure by Hebei Spirit oil spill on oxidative stress in residents and clean-up volunteers of Taean, Korea." Epidemiology 22(1): S236-S236.

Ezra, S., Feinstein, S., Pelly, I., Bauman, D. and Miloslavsky, I. (2000). Weathering of fuel oil spill on the east Mediterranean coast, Ashdod, Israel.

Fingas, M. F. (2004). "Modeling evaporation using models that are not boundary-layer regulated." Journal of Hazardous Materials 107(1-2): 27-36.

French-McCay, D. P. (2002). "Development and application of an oil toxicity and exposure model, OilToxEx." Environmental Toxicology and Chemistry 21(10): 20802094.

Frontera-Suau, R., Bost, F. D., McDonald, T. J. and Morris, P. J. (2002). "Aerobic biodegradation of hopanes and other biomarkers by crude oil-degrading enrichment cultures." Environmental Science \& Technology 36(21): 4585-4592.

Incardona, J. P., Vines, C. A., Anulacion, B. F., Baldwin, D. H., Day, H. L., French, B. L., Labenia, J. S., Linbo, T. L., Myers, M. S., Olson, O. P., Sloan, C. A., Sol, S., Griffin, F. J., Menard, K., Morgan, S. G., West, J. E., Collier, T. K., Ylitalo, G. M., Cherr, G. N. 
and Scholz, N. L. (2012). "Unexpectedly high mortality in Pacific Herring embryos exposed to the 2007 Cosco Busan oil spill in San Franciso Bay." Proceedings of the National Academy of Sciences 109(9): E51-E58.

Janak, J., Ed. (1987). Thin-Layer Chromatography with Flame Ionization Detection. Boston, D. Reidel Publishing Company.

Jeong, W., Lee, J., Kim, H., Hur, J., Eom, S. Y., Cheong, H. K., Ha, M., Lee, I., Cho, E., Rho, S. and Jee, Y. (2011). "Long-term Health Effects of Hebei Spirit Oil Spill on Cleanup Workers." Epidemiology 22(1): S128-S129.

Lemkau, K. L., Peacock, E. E., Nelson, R. K., Ventura, G. T., Kovecses, J. L. and Reddy, C. M. (2010). "The M/V Cosco Busan spill: source identification and short-term fate." Marine Pollution Bulletin 60(11): 2123-2129.

Mao, D. B., Lookman, R., Van De Weghe, H., Weltens, R., Vanermen, G., De Brucker, N. and Diels, L. (2009). "Estimation of ecotoxicity of petroleum hydrocarbon mixtures in soil based on HPLC-GCXGC analysis." Chemosphere 77(11): 1508-1513.

McAuliff, C. (1966). "Solubility in water of paraffin, cycloparaffin, olefin, acetylene, cycloolefin and aromatic hydrocarbons." Journal of Physical Chemistry 70(4): 12671275.

Morita, A., Kusaka, Y., Deguchi, Y., Moriuchi, A., Nakanaga, Y., Iki, M., Miyazaki, S. and Kawahara, K. (1999). "Acute health problems among the people engaged in the cleanup of the Nakhodka oil spill." Environmental Research 81(3): 185-194.

Nelson, R. K., Kile, B. M., Plata, D. L., Sylva, S. P., Xu, L., Reddy, C. M., Gaines, R. B., Frysinger, G. S. and Reichenbach, S. E. (2006). "Tracking the weathering of an oil spill with comprehensive two-dimensional gas chromatography." Environmental Forensics 7(1): 33-44.

Perez-Cadahia, B., Lafuente, A., Cabaleiro, T., Pasaro, E., Mendez, J. and Laffon, B. (2007). "Initial study on the effects of Prestige oil on human health." Environment International 33(2): 176-185.

Poole, C. F. (2003). The Essence of Chromatography. Boston, Elsevier.

Prince, R. C., Elmendorf, D. L., Lute, J. R., Hsu, C. S., Haith, C. E., Senius, J. D., Dechert, G. J., Douglas, G. S. and Butler, E. L. (1994). "17- $\alpha(\mathrm{H}), 21-\beta(\mathrm{H})$-hopane as a conserved internal marker for estimating the biodegradation of crude oil." Environmental Science \&amp; Technology 28(1): 142-145.

Reddy, C. M., Eglinton, T. I., Hounshell, A., White, H. K., Xu, L., Gaines, R. B. and Frysinger, G. S. (2002). "The West Falmouth oil spill after thirty years: the persistence of 
petroleum hydrocarbons in marsh sediments." Environmental Science \& Technology 36(22): 4754-4760.

Reichenbach, S. E., Ni, M. T., Zhang, D. M. and Ledford, E. B. (2003). "Image background removal in comprehensive two-dimensional gas chromatography." Journal of Chromatography A 985(1-2): 47-56.

Rogers, P. (2009) "Herring fishing closed in San Franciso Bay for first time ever." $\underline{\text { Santa }}$ Cruz Sentinel.

Sim, M. S., Jo, I. J. and Song, H. G. (2010). "Acute health problems related to the operation mounted to clean the Hebei Spirit oil spill in Taean, Korea." Marine Pollution Bulletin 60(1): 51-57.

Snape, I., Harvey, P. M. A., Ferguson, S. H., Rayner, J. L. and Revill, A. T. (2005). "Investigation of evaporation and biodegradation of fuel spills in Antarctica - I. A chemical approach using GC-FID." Chemosphere 61(10): 1485-1494.

Stout, S. A. and Wang, Z. (2007). Chemical fingerprinting of spilled or discharged petroleum - methods and factors affecting petroleum fingerprints in the environment. Oil Spill Environmental Forensics: Fingerprinting and Source Identification. S. A. Stout and Z. Wang. Boston, Academic Press: 1-53.

Sutton, C. and Calder, J. A. (1975). "Solubility of alkylbenzenes in distilled water and seawater at $25.0^{\circ} \mathrm{C}$." Journal of Chemical and Engineering Data 20(3): 320-322.

Uhler, A. D., Stout, S. A. and Douglas, G. S. (2007). Chemical heterogeneity in modern marine residual fuel oils. Oil Spill Environmental Forensics: Fingerprinting and Source Identification. Z. Wang and S. A. Stout. Boston, Academic Press: 327-348.

van Den Dool, H. and Kratz, P. D. (1963). "A generalization of retention index system including linear temperature programmed gas-liquid partition chromatography." Journal of Chromatography 11(4): 463-\&.

Ventura, G. T., Raghuraman, B., Nelson, R. K., Mullins, O. C. and Reddy, C. M. (2010). "Compound class oil fingerprinting techniques using comprehensive two-dimensional gas chromatography (GC x GC)." Organic Geochemistry 41(9): 1026-1035.

Wang, Z. D. and Fingas, M. (1995c). "Study of the effects of weathering on the chemical composition of a light crude oil using GC/MS GC/FID." Journal of Microcolumn Separations: 617-639.

Wang, Z. D., Fingas, M., Owens, E. H., Sigouin, L. and Brown, C. E. (2001). "Long-term fate and persistence of the spilled Metula oil in a marine salt marsh environment: degradation of petroleum biomarkers." Journal of Chromatography A 926(2): 275-290. 
Wang, Z. D., Fingas, M. and Sergy, G. (1995a). "Chemical characterization of crude oil residues from an arctic beach by GC/MS and GC/FID." Environmental Science \&amp; Technology 29(10): 2622-2631.

Wardlaw, G. D., Arey, J. S., Reddy, C. M., Nelson, R. K., Ventura, G. T. and Valentine, D. L. (2008). "Disentangling oil weathering at a marine seep using GC $\times \mathrm{GC}$ : broad metabolic specificity accompanies subsurface petroleum biodegradation." Environmental Science \& Technology 42(19): 7166-7173. 
Table 1. Linear free energy relationships (LFERs) used to map vapor pressure $\left(\mathrm{p}_{\mathrm{L}}\right)$ and aqueous solubility properties $\left(\mathrm{P}_{\mathrm{i}}\right)$ onto $\mathrm{GC} \times \mathrm{GC}$ chromatograms using first and second dimension retention indices $\left(\mathrm{I}_{\mathrm{i}, 1}\right.$ and $\left.\mathrm{I}_{\mathrm{i}, 2}\right)$.

$$
\log \mathrm{P}_{\mathrm{i}}=\mathrm{aI}_{\mathrm{i}, 1}+\mathrm{bI}_{\mathrm{i}, 2}+\mathrm{c}
$$

\begin{tabular}{lccc}
\multicolumn{1}{c}{ Property } & $\mathrm{a}$ & $\mathrm{b}$ & $\mathrm{c}$ \\
\hline $\log \mathrm{P}_{\mathrm{L}}(\mathrm{Pa})$ & $-0.00461 \pm 0.0001$ & -- & $6.78 \pm 0.15$ \\
$\log \mathrm{C}_{\mathrm{L}}^{\mathrm{w}}\left(\mathrm{mol} \mathrm{L}^{-1}\right)$ & $-0.0176 \pm 0.0007$ & $0.0134 \pm 0.0006$ & $-2.24 \pm 0.21$ \\
\hline
\end{tabular}

${ }^{a}$ The $\mathrm{GC} \times \mathrm{GC}$ temperature program used in the current work is intermediate to those of methods $\mathrm{A}$ and $\mathrm{B}$ from Arey et al. (2005). As such, values for LFER constants $a, b$ and $c$ for the current work were calculated as averages of values obtained by Arey et al. (2005) for their methods A and B. 


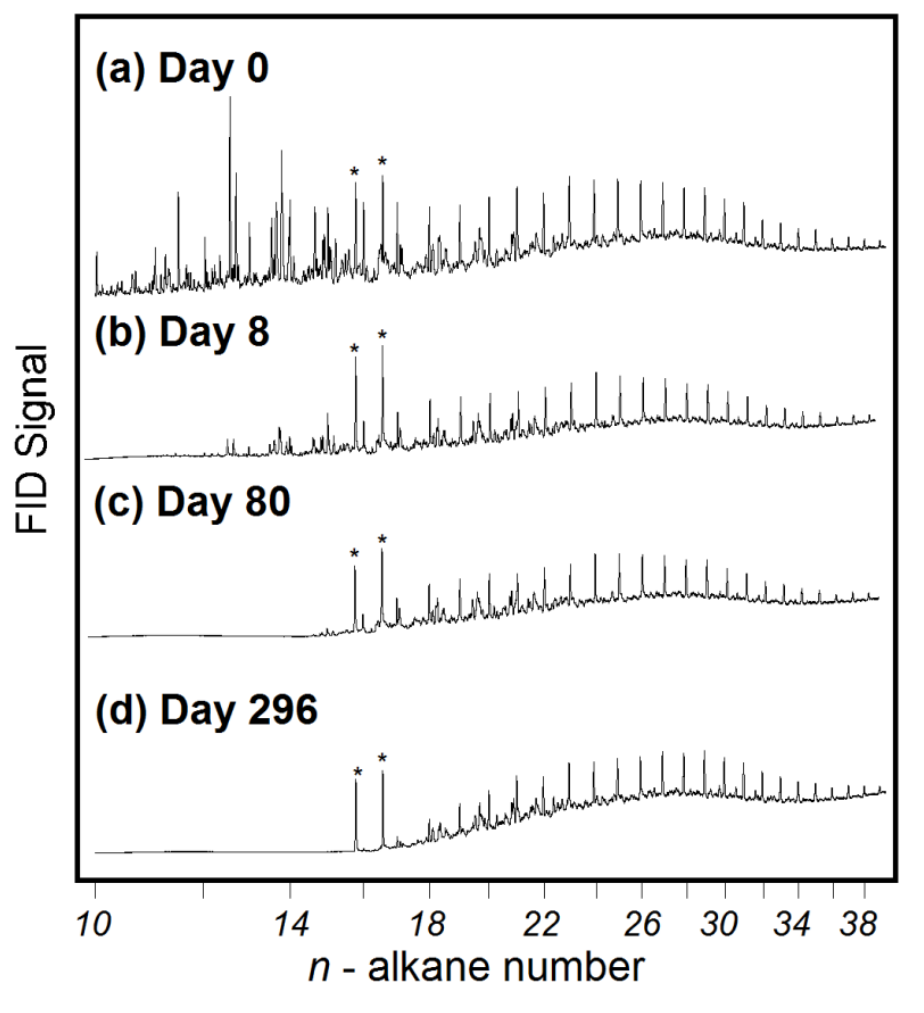

Figure 1. GC-FID chromatograms of the unweathered Tank 4 oil (a) and field samples collected from Shorebird Park (b)-(d), showing the progressive loss of lower molecular weight hydrocarbons during the 296 days after the spill. Asterisks indicate internal and external standards, $n$-hexadecane- $d_{34}$ and dioctyl ether, respectively. 


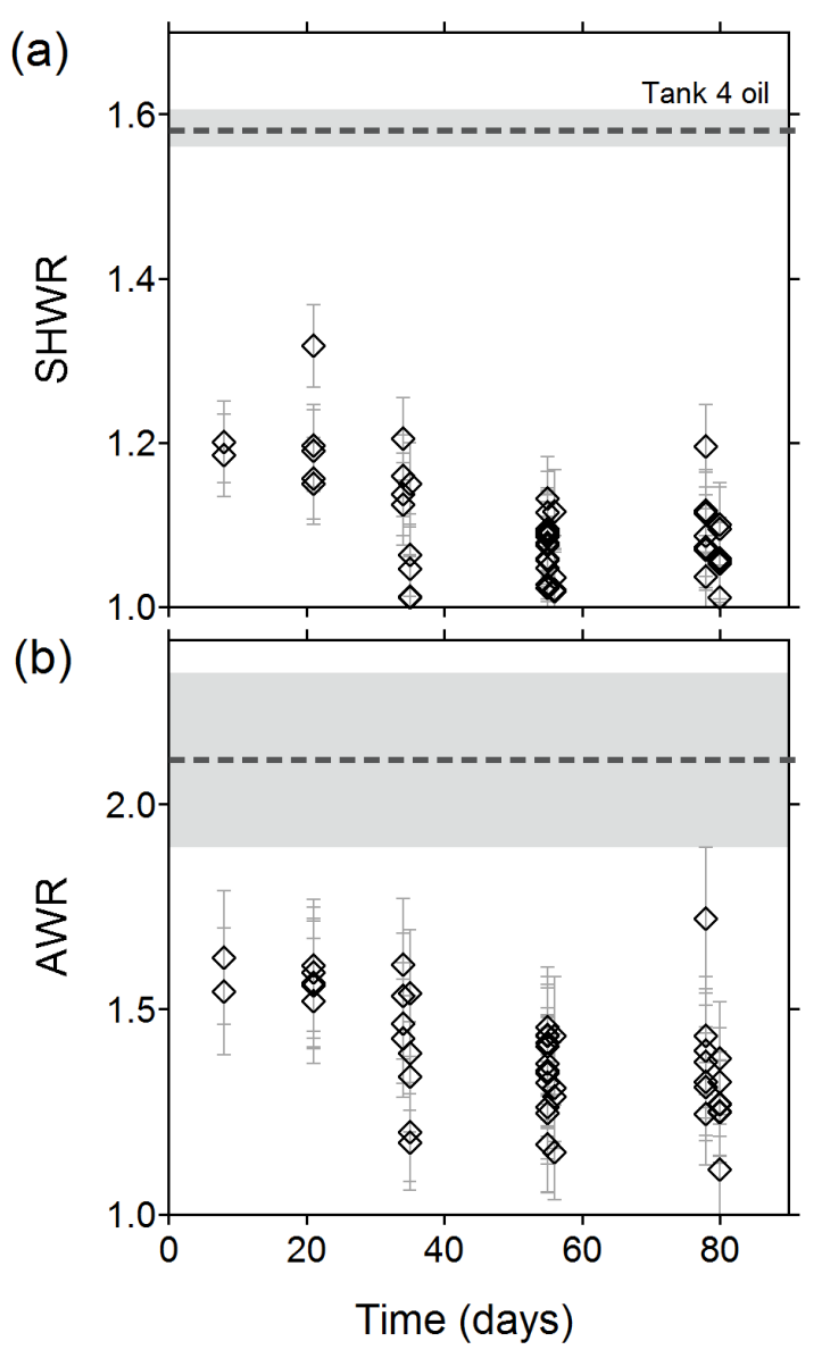

Figure 2. Saturated hydrocarbon and aromatic hydrocarbon weathering ratios for field samples collected during the first 80 days post-spill. Saturated hydrocarbon ratio (a) is most sensitive to changes due to evaporation, whereas the aromatic hydrocarbon ratio (b) responds to dissolution. The ratio of these two indicators (c) suggests dissolution may be affecting field samples. Data presented in this figure are from three sites around the bay, including Shorebird Park, the focus of this chapter (Lemkau et al., 2010). 


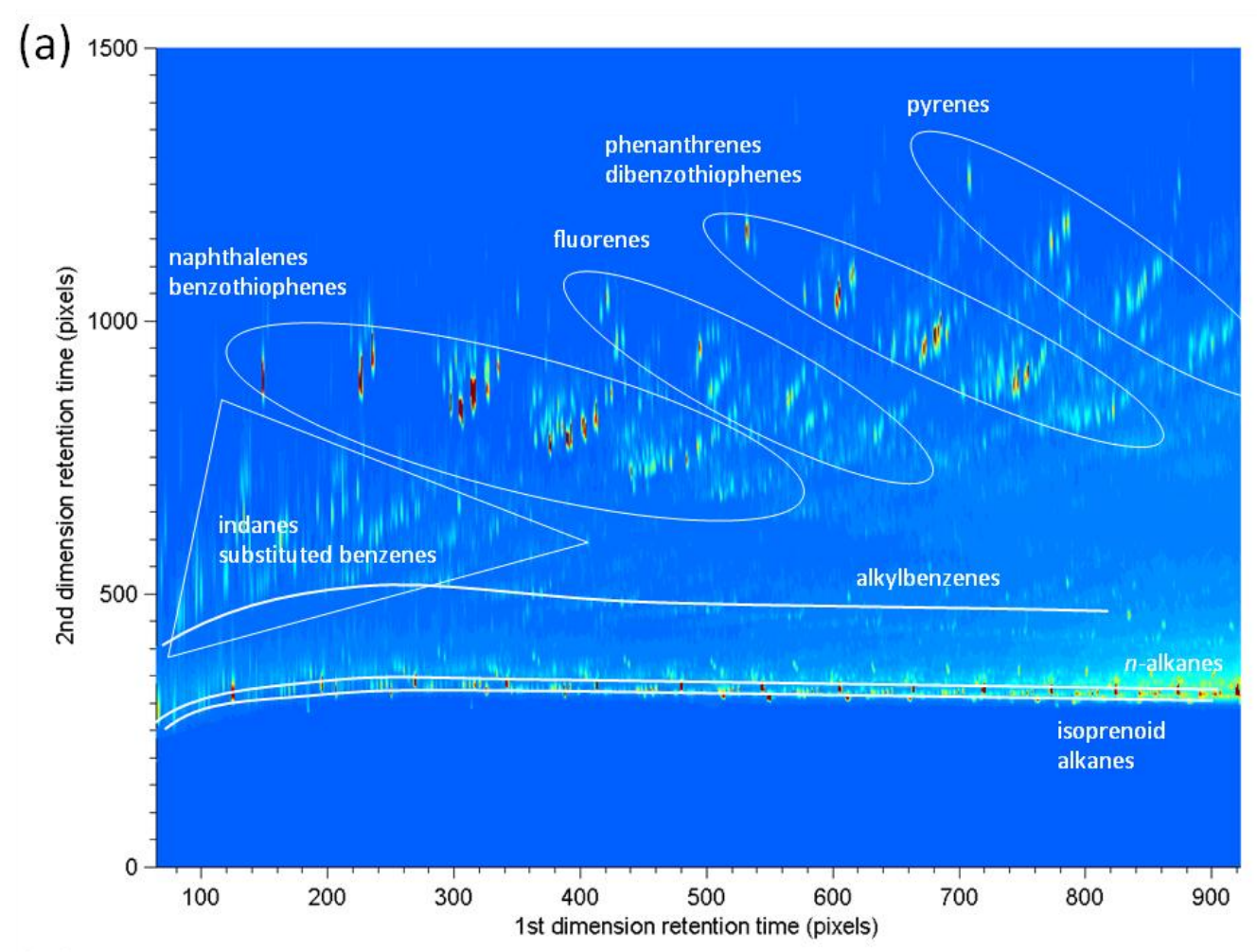

(b)

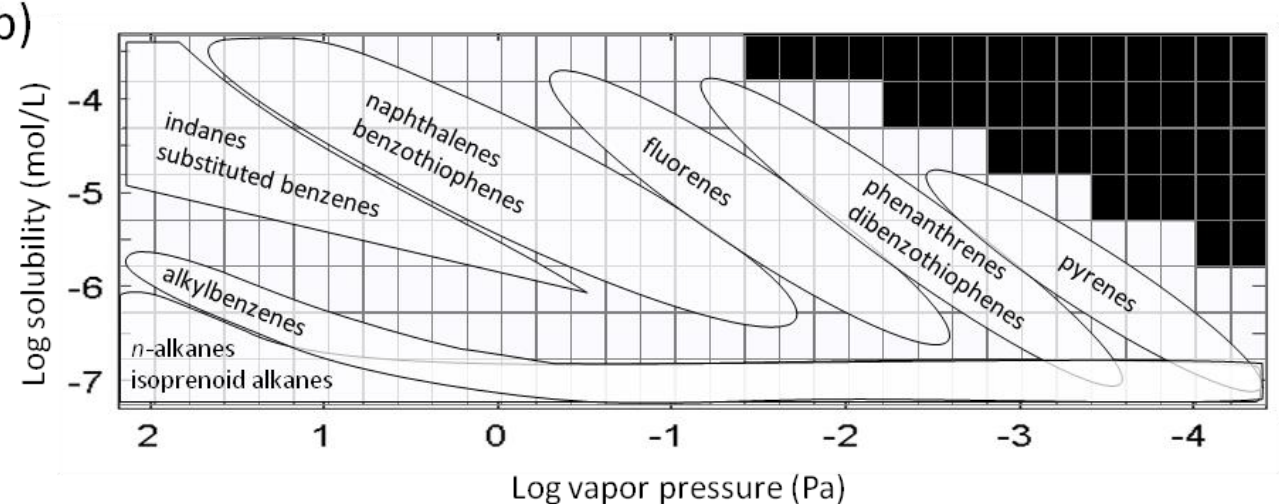

Log vapor pressure (Pa)
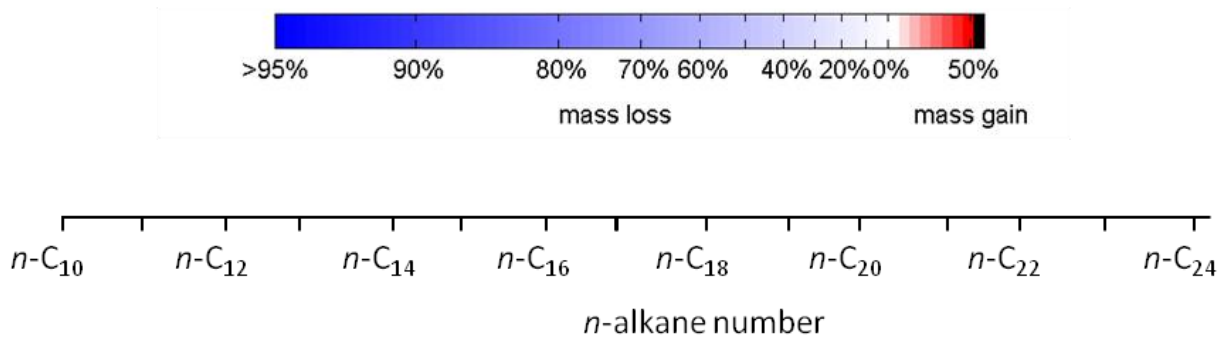

Figure 3. Annotated GC $\times$ GC-FID chromatogram of the unweathered oil (a) and mass loss table of the Tank 4 oil (b) showing locations of major compound classes in these two-dimensional spaces. 
(a) unweathered oil
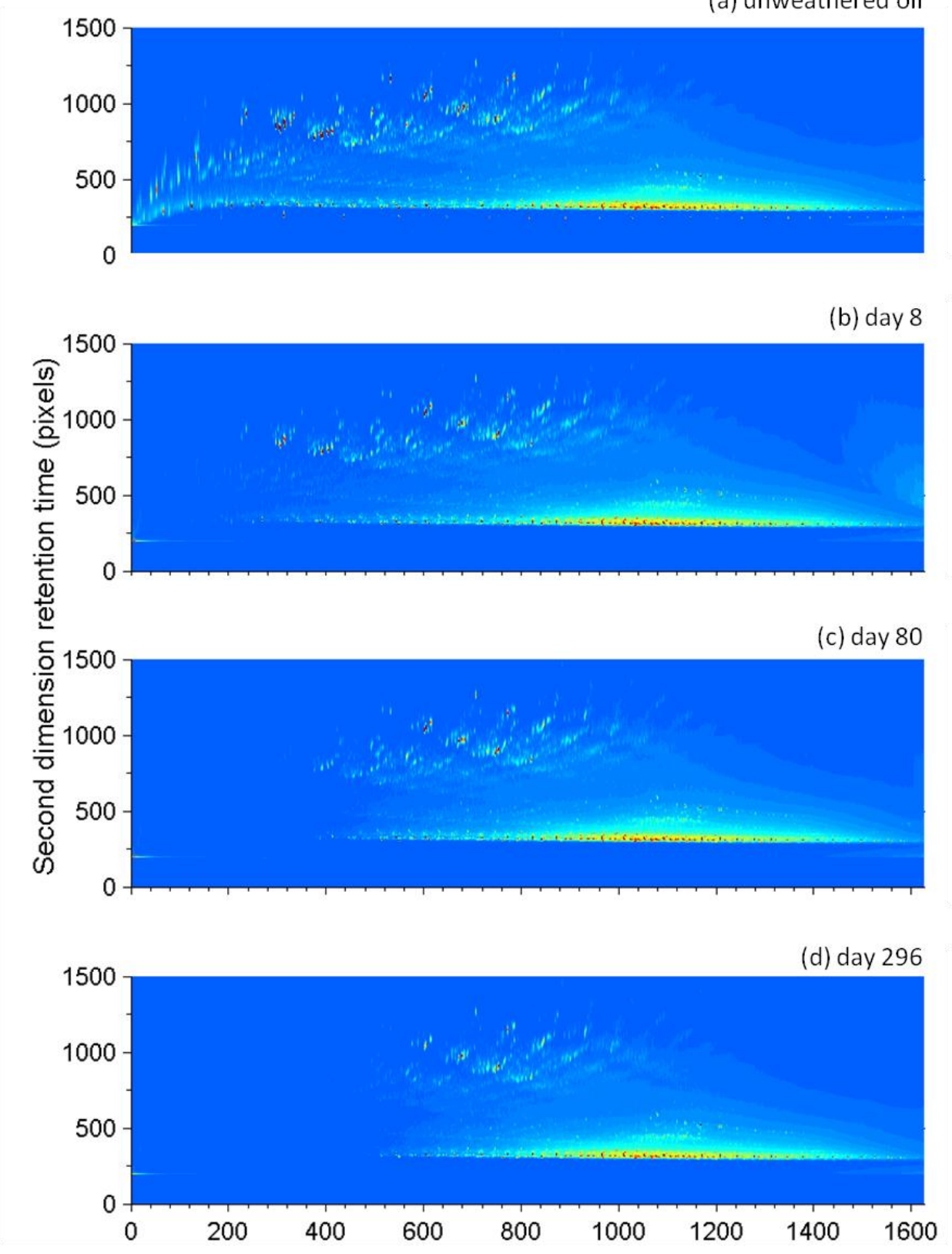

First dimension retention time (pixels)

Figure 4. GC $\times$ GC-FID chromatograms of the unweathered oil (a) and samples from 8 days (b), 80 days (c) and 296 days (d) post-spill. GC×GC chromatograms provide a much more detailed knowledge regarding oil composition compared with one-dimensional techniques. Warmer colors indicate greater abundance. Parent PAHs and alkylated derivatives are clearly visible as are hundreds of other compounds of both known and unknown identity. Each of these compounds can be used to examine weathering trends. 
(a) Unweathered oil

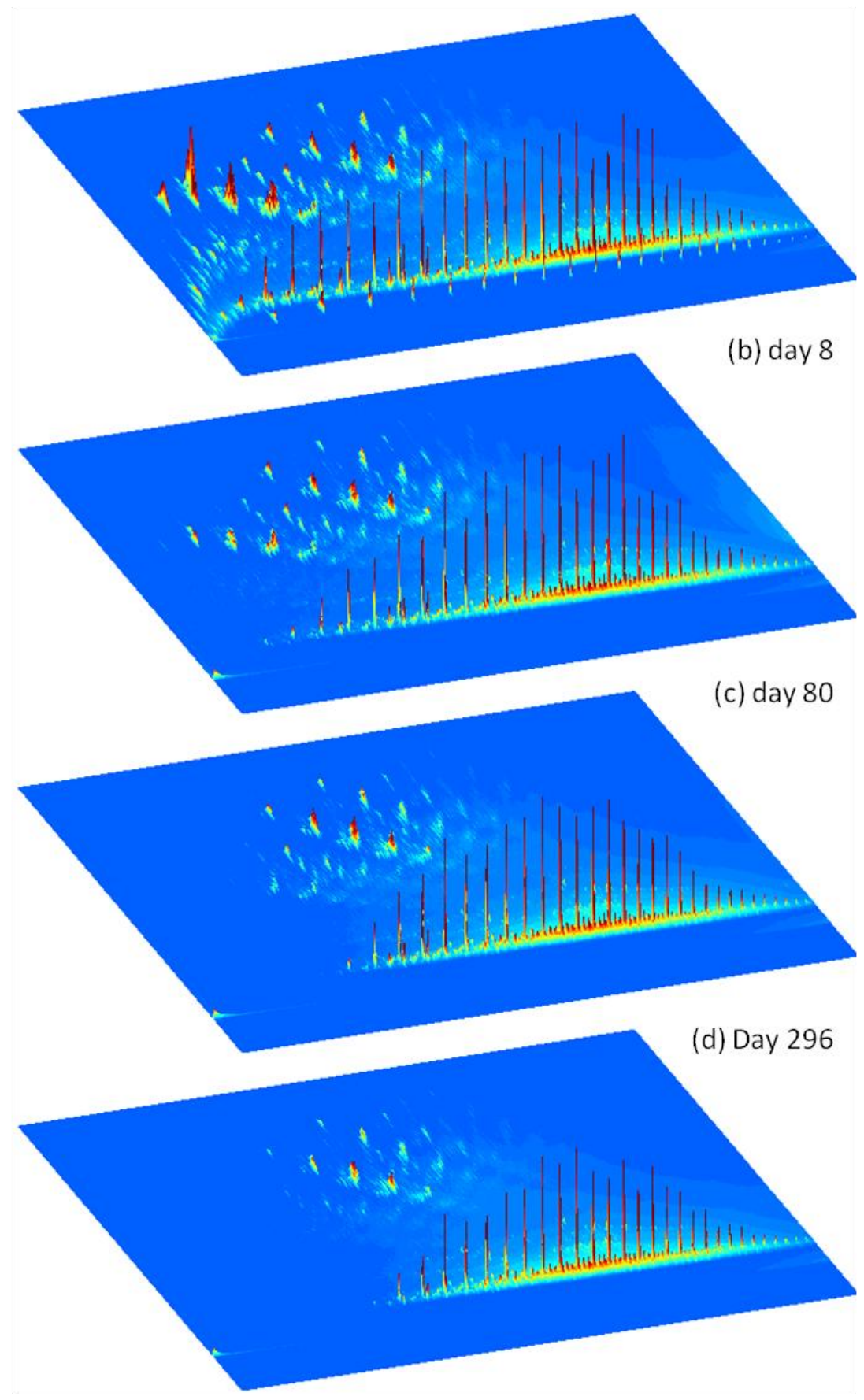

Figure 5. GC $\times$ GC-FID chromatograms of the unweathered oil (a) and samples from 8 days (b), 80 days (c) and 296 days (d) post-spill displayed as mountain plots. This visualization allows easier visualization of magnitude changes across samples, particularly within the $n$-alkanes. 


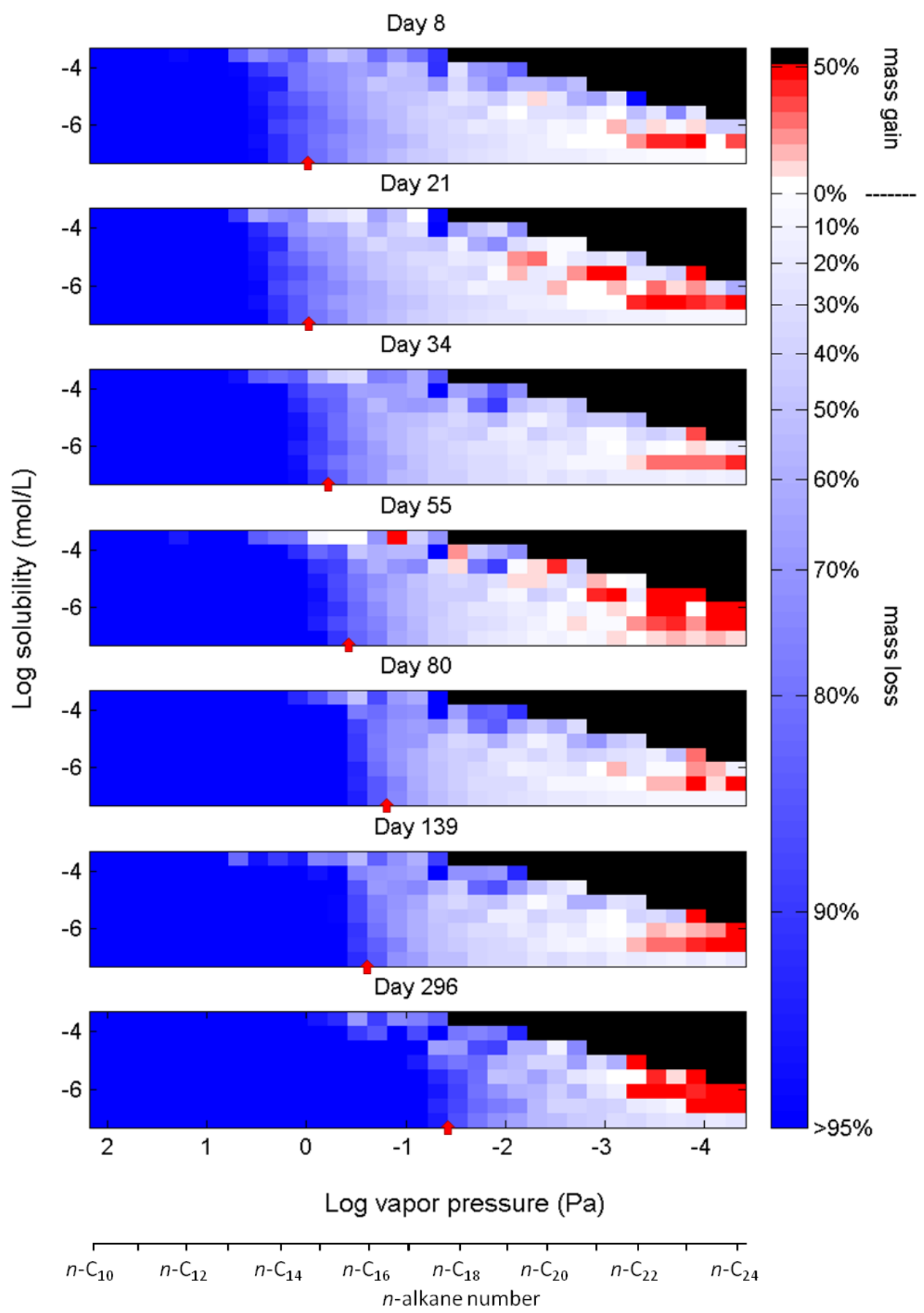

Figure 6. Mass loss tables of field samples collected from 8 to 296 days post-spill. Blue indicates a relative loss of compounds and red indicates no change or slight increase in mass relative to the unweathered oil. Red arrows indicate the location of the evaporation front for each sample, defined as the loss of greater than $80 \%$ of compounds present at a given vapor pressure. 

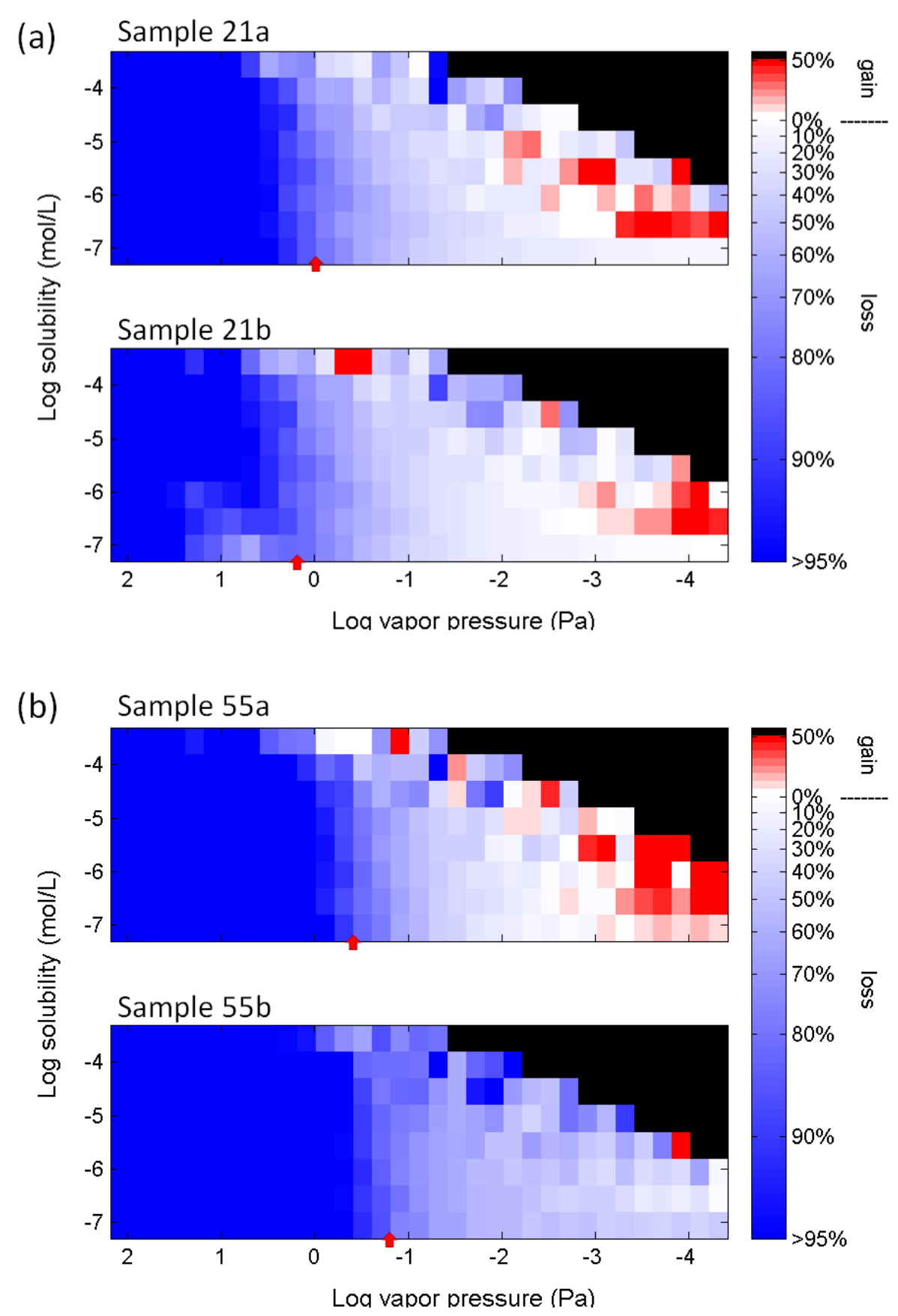

Figure 7. MLTs of discrete samples sets collected 21 days (a) and 55 days after the spill (b). While discrete samples from the same day show similar progression of the evaporation front (red triangles) differences in other weathering processes are visible. Discrete samples from day 21 show unexpected preservation of compounds typically removed through biodegradation and evaporation. Day 55 samples show differences in dissolution. 


\section{Supplemental Information}

\section{for \\ Evaporation and dissolution trends for oil samples from the M/V Cosco Busan spill}

\section{Contents of Supplemental Information}

Figure S1. Photograph of one sampling site showing "dirty bathtub ring" 511 days postspill. Page 109.

Figure S2. Map of San Francisco Bay showing path of the M/V Cosco Busan and location of sampling sites. Page 111.

Figure S3. $\mathrm{C}_{30}-\mathrm{C}_{35}$ hopane distributions for unweathered HFO and field samples. Page 112.

Figure S4. GC $\times$ GC-FID chromatogram of the $n-\mathrm{C}_{10}$ to $n$ - $\mathrm{C}_{24}$ region showing finite boundaries for vapor pressure (vertical lines) and solubility (curved lines). Page 113.

Figure S5. MLTs illustrating pure weathering processes of evaporation and dissolution. Page 115.

S1. Supplemental references. Page 116. 


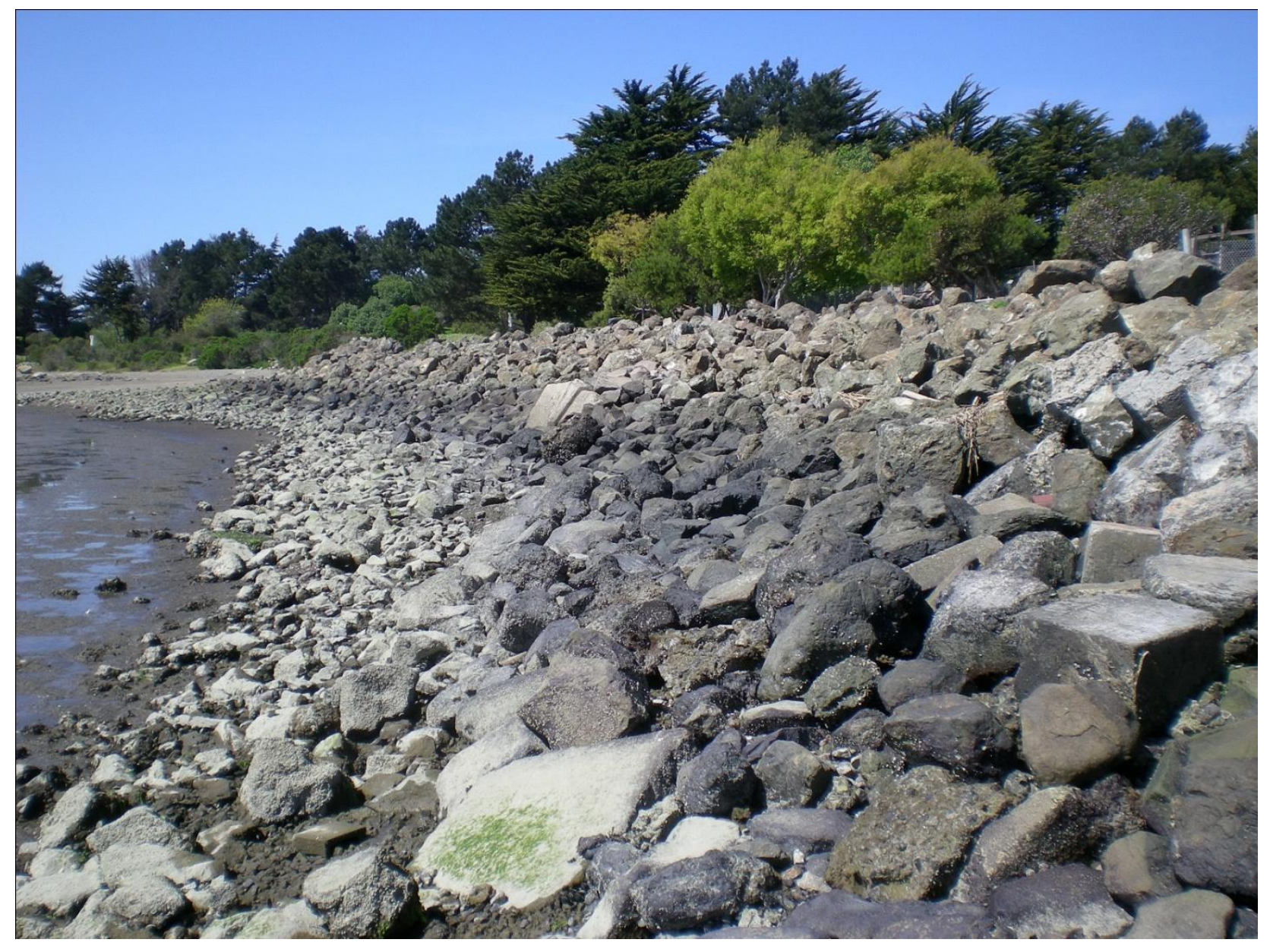

Figure S1. Photograph of one sampling site showing "dirty bathtub ring" left by the M/V Cosco Busan spill. Image taken 511 days post-spill (photo by Karin Lemkau, Woods Hole Oceanographic Institution). 


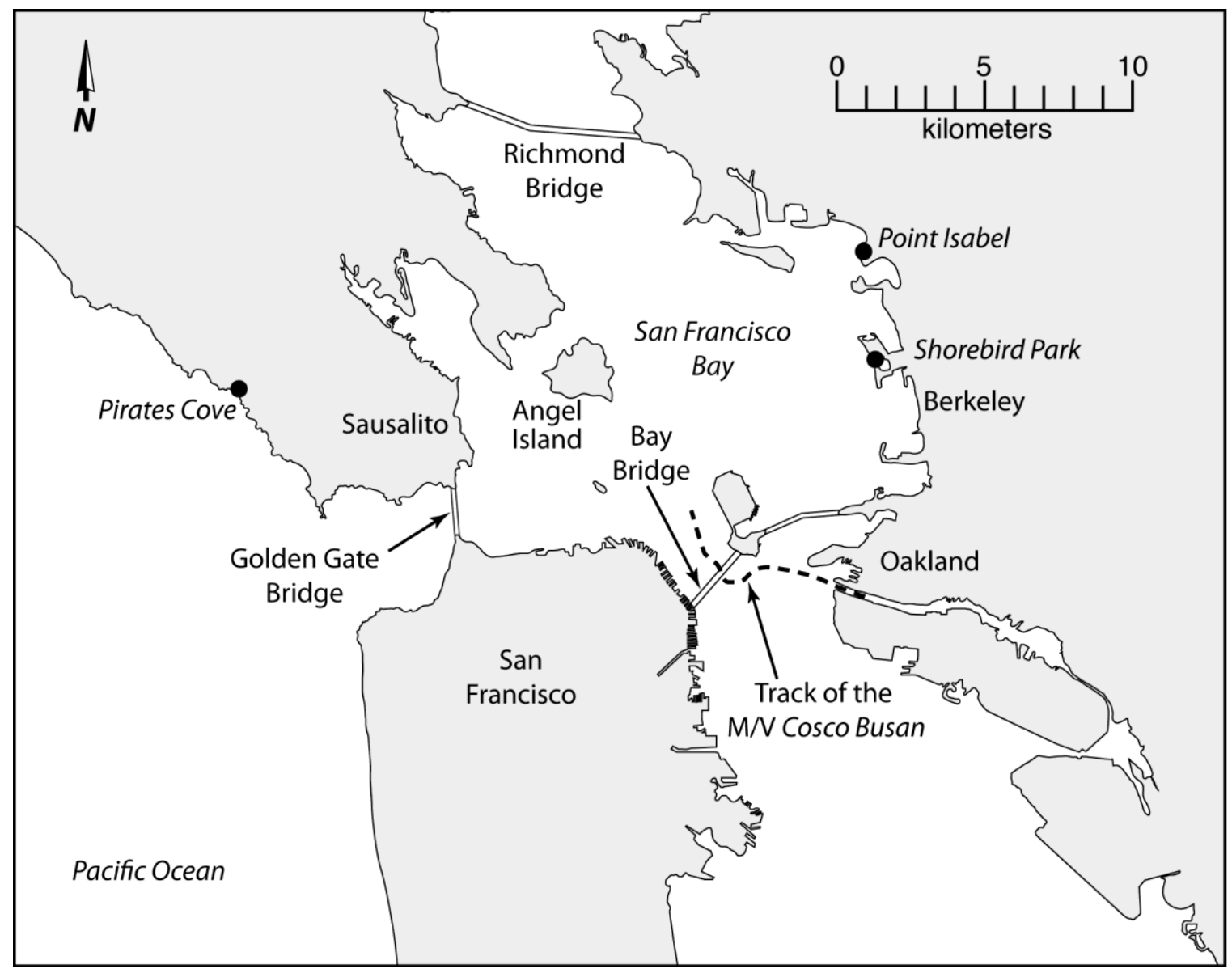

Figure S2. Map of San Francisco Bay showing track of the M/V Cosco Busan and location of sampling sites. Sampling sites are indicated by black dots. 


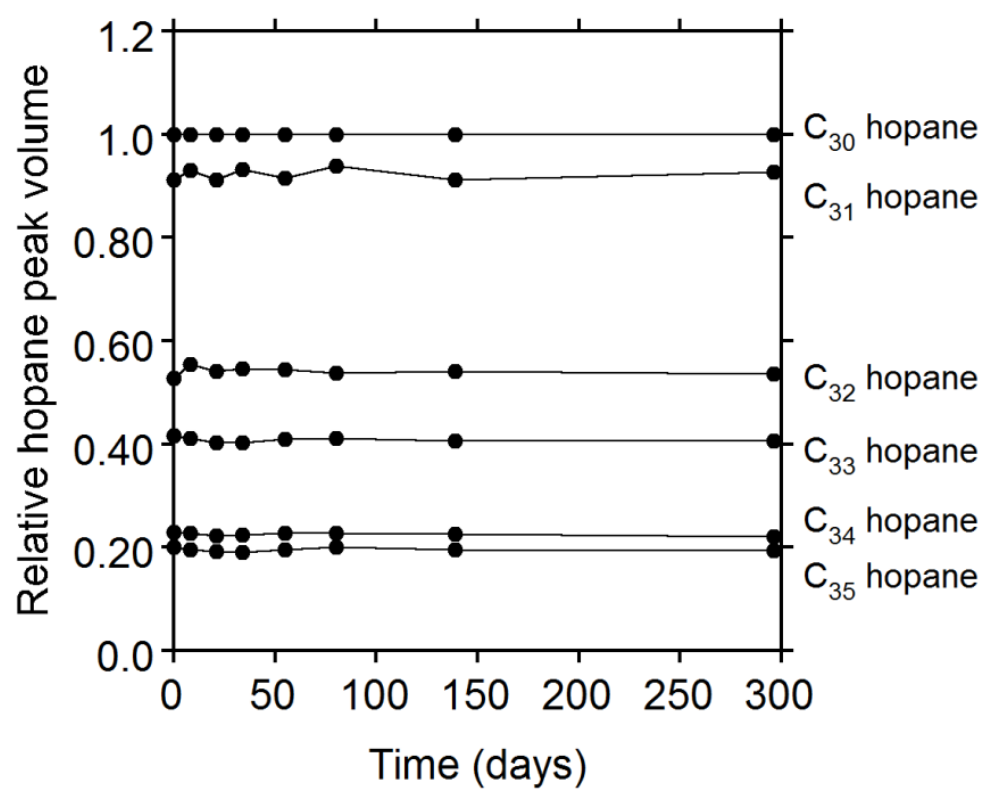

Figure S3. $\mathrm{C}_{30}-\mathrm{C}_{35}$ hopane peak volumes normalized to $\mathrm{C}_{30}$ hopane volume. Hopanes are preferentially degraded: $\mathrm{C}_{30}>\mathrm{C}_{31}>\mathrm{C}_{32}>\mathrm{C}_{33}>\mathrm{C}_{34}>\mathrm{C}_{35}$ (Frontera-Suau, et al., 2002). Constant ratios of all $\mathrm{C}_{31}-\mathrm{C}_{35}$ hopanes to $\mathrm{C}_{30}$ hopane with time indicate no detectable degradation of hopane compounds at 300 days post-spill. 


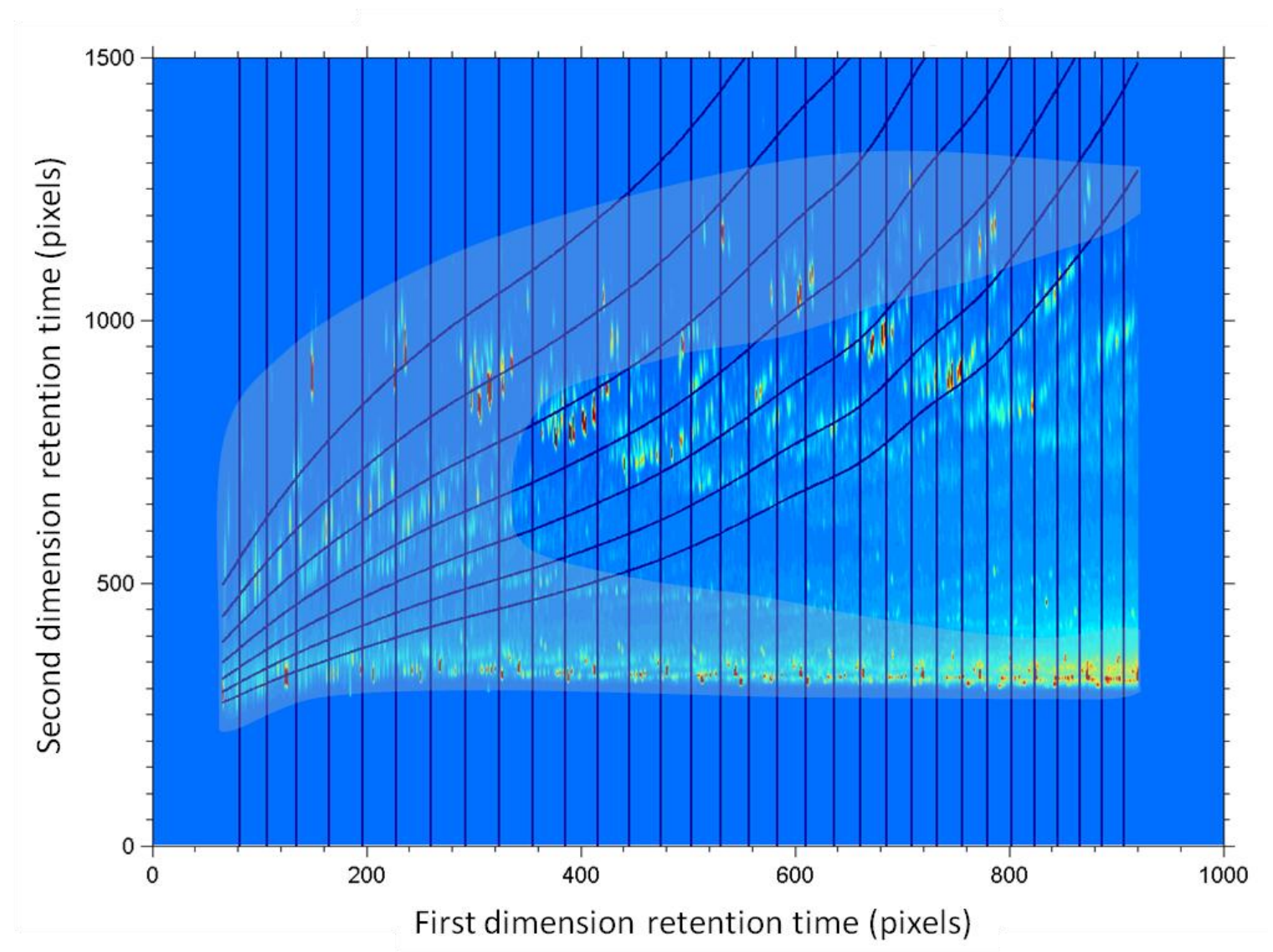

Figure S4. GC $\times$ GC-FID chromatogram of the $n-\mathrm{C}_{10}$ to $n$ - $\mathrm{C}_{24}$ region showing finite boundaries for vapor pressure (vertical lines) and solubility (curved lines) used to create cells of mass loss tables. Grey mask indicates location of training set used for determination of linear free energy relationships (Table 1; Arey et al., 2005). 


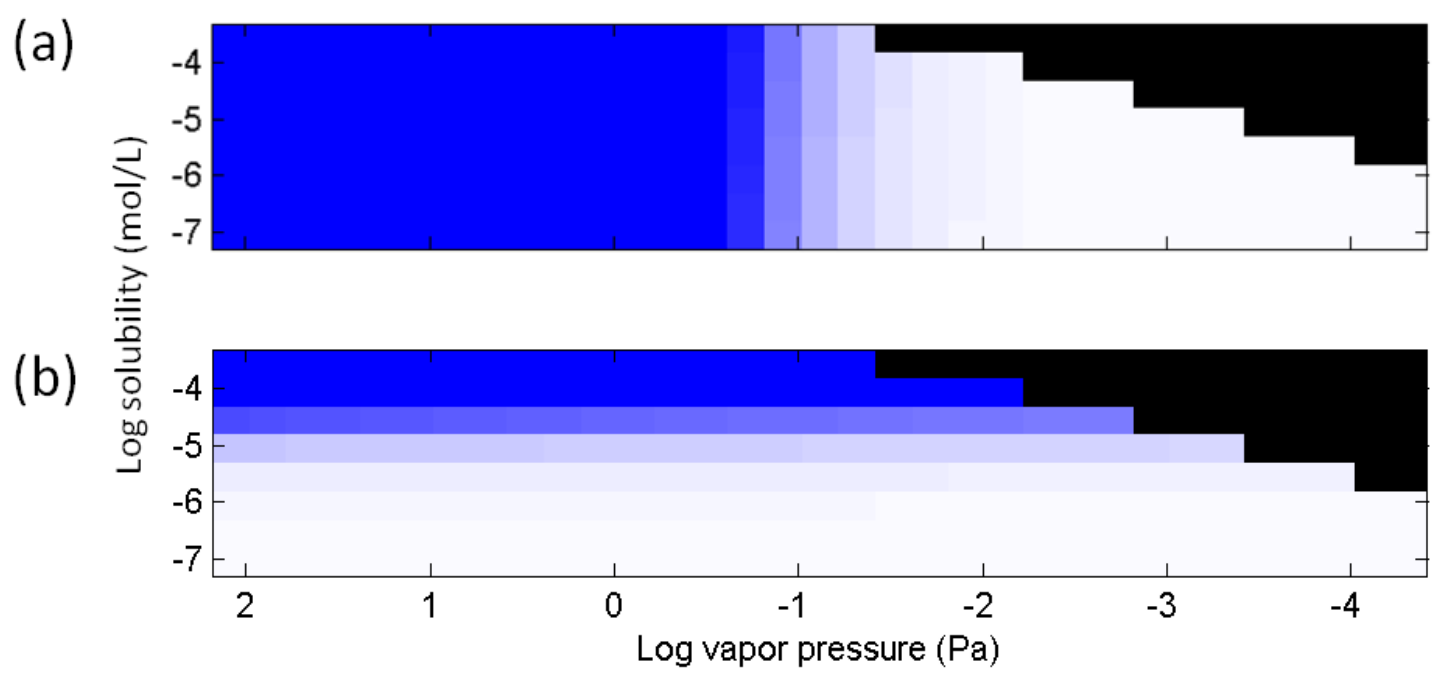

Figure S5. Modeled mass loss tables showing (a) "evaporation front", assuming only evaporation is occurring and (b) "dissolution front" if only dissolution is occurring. In these MLTs, blue indicates mass loss and white indicates no change in mass relative to the unweathered oil. Black boxes in the upper right quadrant represent regions in the log vapor pressure - log solubility space that fall outside the $\mathrm{GC} \times \mathrm{GC}$ chromatogram. 


\section{S1. Supplemental References}

Arey, J. S., Nelson, R. K., Xu, L. and Reddy, C. M. (2005). "Using comprehensive twodimensional gas chromatography retention indices to estimate environmental partitioning properties for a complete set of diesel fuel hydrocarbons." Analytical Chemistry 77(22): 7172-7182.

Frontera-Suau, R., Bost, F. D., McDonald, T. J. and Morris, P. J. (2002). "Aerobic biodegradation of hopanes and other biomarkers by crude oil-degrading enrichment cultures." Environmental Science \& Technology 36(21): 4585-4592. 


\section{Chapter 4}

Quantifying petroleum hydrocarbon input from oil-covered rocks into San Francisco Bay following the M/V Cosco Busan oil spill: Development of a mass transfer model

Karin L. Lemkau 


\title{
Quantifying petroleum hydrocarbon input from oil-covered rocks into San Francisco Bay following the M/V Cosco Busan oil spill: Development of a mass transfer model
}

\begin{abstract}
Following an oil spill, characterizing and distinguishing losses of hydrocarbons from evaporation and dissolution are necessary for calculating mass balances, assessing exposures, and estimating damages. We investigated these processes following the 2007 M/V Cosco Busan heavy fuel oil spill (San Francisco Bay, CA). In Chapter 3, we identified evaporation and dissolution signatures within field samples (oil-covered rocks) using comprehensive two-dimensional gas chromatography $(\mathrm{GC} \times \mathrm{GC})$. To gain a more quantitative understanding, here we develop a physiochemical model to describe evaporation and dissolution. This model incorporates diffusion within the oil film on the rocks itself as a potential limit to losses. Model results are consistent with evaporation and dissolution trends observed in the mass loss tables (MLTs). The model underestimates observed losses for compounds with vapor pressures $<\sim 10^{0.5} \mathrm{~Pa}$. Oil temperature (when exposed to air) was found to drive modeled evaporative loss. Estimated model uncertainty was $\pm 14 \%$ for dissolution and $\pm 7 \%$ for evaporation depending on compound location within the MLT. While the MLTs provide invaluable insights into the fate of spilled oil, the quantitative capabilities of the model provide a useful tool for examining the effects of evaporation and dissolution on oil. For example, the model was able to estimate evaporative losses for naphthalene as well as its alkylated homologs. Though closely related in structure naphthalene was found to partition $82 \%$ into the atmosphere (18\% into the water column) while $97 \%$ of $\mathrm{C}_{3}$-naphthalenes were lost to evaporation.
\end{abstract}

Keywords: M/V Cosco Busan, heavy fuel oil, petroleum, weathering, evaporation, dissolution, diffusion, wall-boundary model, mass loss tables 


\section{INTRODUCTION}

Following the M/V Cosco Busan heavy fuel oil (HFO) spill in San Francisco Bay (November 2007), a ring of oil coated bay shorelines (Figure 1). In the years after the spill, populations of herring decreased dramatically. There is evidence that the spill may have been the cause of this decline. Incardona et al. (2012) found unexpectedly high mortality in herring embryos exposed to the oil. Toxicity is the result of high concentrations of petroleum hydrocarbons within the water column. Understanding inputs for hydrocarbons to local waters following a spill can enable educated management of environmental resources after a spill and further our understanding of oil weathering. Here we develop a physiochemical model to quantify inputs of individual petroleum hydrocarbons from oil-covered rocks to San Francisco Bay waters following the spill.

In Chapter 3, we examined field samples collected after the spill using one and comprehensive two-dimensional gas chromatography (GC and GC $\times$ GC). Sample compositional information was also presented in the form of mass loss tables (MLTs), which allowed visualization of evaporation and dissolution trends within field samples. However, because MLTs only show mass losses relevant to the unweathered HFO, they do not allow quantitative conclusions regarding the transport of compounds into the water or atmosphere.

Previous work has demonstrated the utility of physiochemical models to quantify losses from these individual processes. Arey et al.(2007a, 2007b) examined the Bouchard 120 heavy fuel oil spill by calculating retention indices from first and second dimension retention times. The authors developed a physiochemical model of oil weathering due to evaporation and dissolution, and quantified the contribution of these processes to compositional changes in the spilled oil (Arey et al., 2007b). Arey et al. (2007b) reported that $51 \%$ of naphthalene was transferred into the air and $49 \%$ into the water column, and $80 \%$ of the closely-related $\mathrm{C}_{3}$-naphthalenes, were evaporated and only $20 \%$ dissolved into surrounding waters. This work showed the potential for computer simulations and 
comprehensive compositional changes in the oil to predict detailed mass transfer to air and water in the environment.

During and following the clean-up of the M/V Cosco Busan spill, oiled rocks could have been a significant input term for delivery of hydrocarbons back into the water column. In this study, we develop a physiochemical model to enable quantitative apportionment of individual compounds to evaporation and dissolution. This is particularly necessary for this case where the impact of the spill remains unknown and where water column data following the spill is limited. We then compare our model results with field samples collected after the M/V Cosco Busan HFO spill. This effort is distinct from previous models because it allows composition of the oil film to vary with depth as diffusion out of the oil occurred.

\section{METHODS}

2.1. Sample collection and preparation. Oil residues were scraped from three rocky shorelines in and around San Francisco Bay following the 2007 M/V Cosco Busan (Figure S1). For detailed descriptions of all sampling sites the reader is referred to Lemkau et al. (2010). Because of the higher sampling frequency at Shorebird Park (Berkeley, CA; Figure S1), samples from this site are the focus for the GC $\times \mathrm{GC}$ work presented here. Oil was scraped with a stainless steel spatula from coastal rocks and stored in combusted Al-foil envelopes. Samples were transported to Woods Hole, MA, and frozen $\left(-20^{\circ} \mathrm{C}\right)$ until analysis.

Two oil-containing tanks were ruptured during the allision (Tanks 3 and 4). Samples from both port-side Tanks 3 and 4 were provided by the National Oceanic and Atmospheric Administration per chain-of-custody procedures. Previous work revealed that Tank 4 was the source of the oil released by comparing the biomarker ratios of each tank to field samples (Lemkau et al., 2010). The Tank 4 oil was a group IFO380 HFO (see nomenclature discussion in Chapter 1 ) which contained $\sim 16 \%$ asphaltenes (large, 
heteroatom enriched, non-GC amenable compounds) as measured by precipitation in hexane.

2.4. GC $\times$ GC-FID analysis. $\mathrm{GC} \times \mathrm{GC}$ analysis was performed on the unweathered oil and nine representative samples from Shorebird Park, collected 8, 21, 34, 55 80, 139 and 296 days after the spill.

The methods followed closely those of "method A" from the work of Arey et al., 2005. Briefly, first dimension separations were performed on a non-polar column (Restek RTX1, 100\% polysiloxane, $18.6 \mathrm{~cm}$ length, $0.25 \mathrm{~mm}$ ID and $0.25 \mu \mathrm{m}$ film thickness) programmed from $35^{\circ} \mathrm{C}$ ( 5 min hold) and ramped to $320{ }^{\circ} \mathrm{C}$ at $1{ }^{\circ} \mathrm{C} \mathrm{min}^{-1}$. Second dimension separations were performed on a more polar column (SGE BPX-50, 50\% phenylpolysiphenylene siloxane, $1.0 \mathrm{~m}$ long, $0.10 \mathrm{~mm}$ ID and $0.10 \mu \mathrm{m}$ film thickness) programmed from $43{ }^{\circ} \mathrm{C}$ ( 5 min hold) and ramped to $350{ }^{\circ} \mathrm{C}$ at $1.08{ }^{\circ} \mathrm{C} \mathrm{min}{ }^{-1}$. Each chromatogram was baseline subtracted (Reichenbach et al., 2003) and all FID signal eluting more than 0.5 seconds before $n$-alkanes in the second dimension were considered artifactual (i.e., modulated column bleed) and set to zero. All chromatograms were normalized to the conserved biomarker $17 \alpha(\mathrm{H})-21 \beta(\mathrm{H})$-hopane (Prince et al., 1994) to enable comparison among samples. In Chapter 3, this biomarker was shown to be conserved within our samples and thus appropriate for use as an external standard.

\subsection{Mapping partitioning properties onto the GCxGC Chromatogram. Previous} work has described many of the steps involved in mapping physical and chemical properties onto the two-dimensional GC×GC space (Arey et al., 2005; Arey et al., 2007a). Assuming all compounds to be hydrocarbons, first and second dimension retention times were converted to retention indices (van Den Dool and Kratz 1963; Arey et al., 2005). This removes the impact of temperature programs and lab-specific variability from obtained retention times. Employing these retention indices, previously 
developed linear free energy relationships (LFERs) were then used to estimate hypothetical pure component liquid vapor pressure, aqueous solubility, enthalpy of vaporization and molar mass for first and second retention indices of the chromatogram (Arey et al., 2005; Table 1). These properties were used to estimate oil-air and oil-water partitioning properties according to Raoult's law as described below.

Due to the training set used to develop LFERs (Figure S2), vapor pressure and solubility estimates are only valid for the $n$ - $\mathrm{C}_{10}$ to $n$ - $\mathrm{C}_{24}$ carbon range. Compounds less than $n$ - $\mathrm{C}_{10}$ are assumed to evaporate quickly whereas those greater than $n-\mathrm{C}_{24}$ are assumed unaffected by evaporation and water washing. These assumptions are consistent with evaporation and water-washing trends (Fingas 2004; Nelson et al., 2006; Arey et al., 2007a; Arey et al., 2007b; Mao et al., 2009).

Chromatograms were divided into discrete cells based on contours of hydrocarbon liquid vapor pressures and solubilities ( 0.5 and $0.2 \log$ units respectively; Figure S2), allowing grouping of compounds of similar properties. Cell mass was defined as the sum of all pixel heights within each cell. To avoid dramatic changes in cell mass, if retention times were to shift slightly between samples, each pixel within the chromatogram was weighted so that peaks near cell boundaries were partially assigned to all surrounding cells, in such a way that mass was conserved (Arey et al., 2007a).

2.6. Mass Loss Tables (MLTs). Field samples and model results are presented as MLTs which are created by projecting each discrete cell of the chromatogram onto a twodimensional space delineated by contours of the calculated aqueous solubility and vapor pressure of that cell (Arey et al., 2007b). The cells within the chromatogram can be thought of as theoretical "compounds" with vapor pressure and solubility characteristics defined by their location within the two-dimensional space. MLTs present the logtransformed mass fraction remaining $(\log ([\mathrm{Mt}] /[\mathrm{M} 0]))$ and allow visualization of "compound" loss compared to the unweathered Tank 4 oil (Figure 2). 
MLTs allow easy visualization of mass loss relative to the unweathered Tank 4 oil. Compounds of higher vapor pressure will be preferentially removed through evaporation. This would appear as an "evaporation front" moving from left to right across the MLT with time. The evaporation front is defined as the region where lower-solubility $\left(<10^{-5.5}\right.$ mol L ${ }^{-1}$, roughly compounds with lower solubilities than $\mathrm{C}_{3}$-naphthalenes) cells corresponding to a given vapor pressure show greater than $80 \%$ loss. Conversely, loss through dissolution would appear as a loss in the most soluble compounds; this trend would appear as a "dissolution front" as compounds are lost across the top rows of the mass loss tables.

In these MLTs, blue indicates mass that is lost from the sample and red indicates mass gain relative to the unweathered Tank 4 oil. Black boxes in the upper right quadrant represent regions in the log vapor pressure - log solubility space that fall outside the $\mathrm{GC} \times \mathrm{GC}$ chromatogram. In field samples, variability in cells along the edge of this region is believed to be noise due to small masses present within these cells and is considered artifactual. Detailed descriptions of field samples have been described previously. They are presented here to allow comparison to modeled MLT results.

2.7. Mass transfer model. A mass-transfer model was developed to enable quantitative estimation of compounds lost from the oil due to evaporation and dissolution:

$$
\frac{d M_{i}}{d t}=\left(\frac{d M_{i}}{d t}\right)_{\text {evap }}+\left(\frac{d M_{i}}{d t}\right)_{d i s s}
$$

where $\mathrm{t}$ is time and $\mathrm{M}_{\mathrm{i}}$ is the mass of compound $i$ in the oil. Due to the high viscosity of the oil and thickness of samples collected, mass removal was assumed to be controlled by diffusion of compounds within the oil itself, partitioning into surrounding media (atmosphere/water), and transport across an air or water boundary layer. A schematic showing the general setup of the model is presented in Figure $3 \mathrm{~b}$. 
The oil itself was treated in discrete layers to allow for compositional variability with depth. Similarly, due to time-dependence of many parameters, oil losses were evaluated as the sum of changes occurring over discrete time steps. Partitioning and mass loss through the boundary layer into the atmosphere were calculated using wall boundary equations (Schwarzenbach et al., 2003):

$$
\left(\frac{d M_{i}}{d t}\right)_{\text {evap }}=\frac{D_{i, a i r}}{\delta_{o i l} \delta_{a i r}}\left(\frac{M_{i, a i r}^{e q}-M_{i, a i r}^{0}}{1+\Psi(t)}\right)
$$

with: $\quad \Psi(t)=\left(\frac{\Delta t \pi}{D_{i, o i l}}\right)^{1 / 2}\left(\frac{D_{i, \text { air }}}{\delta_{\text {air }}} \frac{1}{K_{i, \text { oil /air }}}\right)$

where $D_{i, \text { air }}$ and $D_{i, \text { oil }}$ are the diffusion coefficients within the air boundary layer and oil $\left(\mathrm{m}^{2} \mathrm{~h}^{-1}\right)$ for compound $i, \delta_{\text {air }}$ is the air-side boundary layer thickness $(\mathrm{m}), \delta_{\text {oil }}$ is the thickness of the uppermost oil layer (m), $M_{i, a i r}^{e q}$ is the compound mass in the air $(\mathrm{kg})$ calculated from compound concentrations in equilibrium with the uppermost layer of oil $\left(C_{i, a i r}^{e q}=C_{i, o i l}^{0} / K_{i, \text { oil } / \text { air }}\right)$ where $C_{i, \text { air }}^{e q}=M_{i, \text { air }}^{e q} /\left(\right.$ Area $\left.\cdot \delta_{\text {oil }}\right) \cdot M_{i, \text { air }}^{0}$ is the mass of compound $i$ in the air $(\mathrm{kg})$ and is assumed to be zero due to air renewal. $K_{i, \text { oil/ air }}$ is the oil /air partitioning coefficient for compound $i$ (unitless) and $\Delta \mathrm{t}$ is the model time step (h). Complementary equations can be written to describe flux into the water:

$$
\left(\frac{d M_{i}}{d t}\right)_{\text {diss }}=\frac{D_{i, \text { water }}}{\delta_{\text {oil }} \delta_{\text {water }}}\left(\frac{M_{i, \text { watr }}^{e q}-M_{i, \text { water }}^{0}}{1+\Psi(t)}\right)
$$

with: $\Psi(t)=\left(\frac{\Delta t \pi}{D_{i, \text { oil }}}\right)^{1 / 2}\left(\frac{D_{i, \text { water }}}{\delta_{\text {water }}} \frac{1}{K_{i, \text { oil } / \text { water }}}\right)$

Based on the composition of the unweathered oil, the model initially assumes that compounds are evenly distributed within the oil. As compounds diffuse out of the 
uppermost oil layer, losses are propagated through the discrete sub-surface oil layers according to Fick's second law:

$$
\frac{\partial M_{i}}{\partial t}=\frac{\partial}{\partial x}\left(-D_{i, o i l} \frac{\partial M_{i}}{\partial x}\right)
$$

where $x$ is the size of the depth step in the oil (m). Previous models have generally ignored diffusion within the oil itself (Mackay and Matsugu 1973; Goodwin et al., 1976;

Drivas 1982; Stiver and Mackay 1984; Stiver et al., 1989) or have assumed the oil to be a well-mixed reservoir with a constant supply of compounds to the air/ oil or water/oil interface (Arey et al., 2007b). Our approach allows for depth-dependent depletion of compounds within the oil over time. Thus each compound develops its own diffusion profile and concentrations in the surface oil are lower for compounds lost through modeled evaporation and dissolution. As compounds are removed from the oil, oil properties (such as viscosity and molar volume) also change within each oil layer and in turn affect compound diffusivities and other properties as detailed below. All equations use SI units (kg, m, s, K, and moles) unless otherwise noted.

Weathering was modeled for mid-tidal samples exposed to the atmosphere for 12 hours and the water for 12 hours each day. The impacts of the different processes of evaporation and dissolution were tuned by variation in environmental temperature, resulting in different partition and diffusion coefficients for periods of air and water exposure. Oil characteristics and select parameters used in the model are presented in Table 2.

2.7.1. Estimation of model parameters. Parameters needed to solve equations 1 to 6 were estimated using a variety of techniques. Air-oil and water-oil partition coefficients were estimated using Raoult's law, assumed applicable to hydrocarbons in a petroleum mixture (Cline et al., 1991). Assuming all compounds to be hydrocarbons, mapping of molar mass, enthalpy of vaporization and pure component liquid vapor pressures (Section 
2.5; Table 1) across the two-dimensional space allowed for estimation of these parameters as well as molecular radii (assuming spherical compound shapes), molar volumes, and diffusion coefficients within the air boundary layer, water and oil as detailed below.

2.7.1.1. Partitioning Coefficients. Estimation of several parameters has been previously described (Arey et al., 2007b). Briefly, pure liquid vapor pressure and solubility properties were used to estimate oil-air and oil-water partitioning coefficients for each cell of the chromatogram according to equations (3) and (4):

$$
\begin{aligned}
& K_{i, \text { air/oil }}=\frac{P_{i, \ell}^{*} \times V_{m}}{R \times T} \\
& K_{i, \text { water/oil }}=\frac{C_{i, \text { sat }}^{*} \times V_{m}}{K_{\text {salt }}}
\end{aligned}
$$

where $\mathrm{P}_{i, L}^{*}$ is the hypothetical pure component liquid vapor pressure $\left(\mathrm{kg} \mathrm{m}^{-1} \mathrm{~s}^{-2}\right), \mathrm{V}_{\mathrm{m}}$ is the molar volume of the oil $\left(\mathrm{m}^{3} \mathrm{~mol}^{-1}\right), \mathrm{K}_{\text {salt }}$ is a factor accounting for the effect of salinity on hydrocarbon solubility, $\mathrm{C}_{\mathrm{i} \text {,sat }}^{*}$ is the hypothetical aqueous solubility at saturation (mol $\mathrm{m}^{-3}$ ) of compound $\mathrm{i}$ (where compounds are assumed to form ideal solutions having activity coefficients of 1$), \mathrm{R}$ is the molar gas constant $\left(\mathrm{m}^{2} \mathrm{~kg} \mathrm{~mol}^{-1} \mathrm{~K}^{-1} \mathrm{~s}^{-2}\right)$ and $\mathrm{T}$ is temperature $(\mathrm{K})$. Because of the strong temperature dependence of vapor pressure, environmentally relevant values for the model were calculated using estimated oil temperatures during air and water exposure (see section 2.7.1.6 on Environmental air and water temperatures) and the Clausius-Clapeyron equation:

$$
P_{i, l}^{*}=P_{i, l}\left(T_{r e f}\right) e^{\left[-\frac{\Delta H_{i, a p p}}{R}\left(\frac{1}{T}-\frac{1}{T_{r f}}\right)\right]}
$$

where $P_{i, l}\left(T_{\text {ref }}\right)$ is the vapor pressure $\left(\mathrm{m}^{3} \mathrm{~mol}^{-1}\right)$ for compound $i$ at the reference temperature (K; estimated from the LFER in Table 1$), \Delta \mathrm{H}_{\mathrm{i} \text {,vap }}$ is the enthalpy of 
vaporization $\left(\mathrm{kg} \mathrm{m}^{2} \mathrm{~s}^{-2} \mathrm{~mol}^{-1}\right)$ for compound $i$, and $\mathrm{mw}_{i}$ is the molar mass $\left(\mathrm{kg} \mathrm{mol}^{-1}\right)$ for compound $i$. The reference temperature used was $298 \mathrm{~K}$.

2.7.1.2. Oil Molar Volume. Oil molar volume of compounds within the modeled region of the chromatogram was calculated using the formula:

$$
V_{n C_{10}-n C_{24}}(t)=\frac{\sum_{i=1}^{N}\left(M_{i}(t) \times m w_{i}\right)}{\sum_{i=1}^{N} M_{i}(t) \times \rho_{\text {oil }}}
$$

where $\mathrm{V}_{n \mathrm{C} 10-n \mathrm{C} 24}$ is the average molar volume $\left(\mathrm{m}^{3} \mathrm{~mol}^{-1}\right)$ for compounds within the $n-\mathrm{C}_{10}$ to $n-\mathrm{C}_{24}$ region of the chromatogram, $\rho_{\text {oil }}$ is the density of the oil $\left(\mathrm{kg} \mathrm{m}^{-3}\right)$, and $M_{i}(t)$ is the mass $(\mathrm{kg})$ of compound $i$ at time $\mathrm{t}$, and $\mathrm{N}$ is the number of cells or "compounds" $(i)$ analyzed. Equation 7 is an underestimate of the total oil molar volume, as it does not account for molar volume of the recalcitrant masses including the prominent asphaltene fraction and those compounds rapidly evaporated. The asphaltenes have the highest molar mass and size, and will therefore likely have a large impact on the true molar volume of the oil. Even though they are not detected by GC, their impact on oil weathering must be considered. For this reason oil molar volume $\left(\mathrm{V}_{\text {oil }}\right)$ was calculated as a weighted average, accounting for asphaltene content, asphaltene molar volume, and molar volume for the modeled chromatogram region. An estimated asphaltene molar volume of $8.4 \times 10^{-4} \mathrm{~m}^{3}$ $\mathrm{mol}^{-1}$ was calculated using theoretical asphaltene structures (Mullins 2008). Initial asphaltene content was experimentally measured to be $16 \%$ (by mass).

2.7.1.3. $K_{\text {salt }}$. $\mathrm{K}_{\text {salt }}$ was estimated for individual compounds from aqueous solubilities according to empirical relationship (Ni et al., 2003):

$$
K_{i, \text { salt }}=-0.027 \times \log C_{i, \text { sat }}^{*}+0.135
$$

2.7.1.4. Diffusivity Coefficients. Molar masses that were estimated for the chromatogram space (using the LFER in Table 1) allowed estimation of cell diffusivities according to the equations (Schwarzenbach et al., 2003): 


$$
\begin{aligned}
& D_{i, a i r}=\frac{1.74 \times 10^{-6}}{m w^{0.65}} \\
& D_{i, \text { water }}=\frac{2.0 \cdot 10^{-10}}{m w^{0.71}}
\end{aligned}
$$

Individual compound diffusivities within the oil were predicted according to the work of Davis et al. (1980) using the relationship:

$$
D_{i, o i l} \eta_{o i l}^{p}=\frac{A T}{298.2}
$$

where $\eta_{\text {oil }}$ is oil viscosity $\left(\mathrm{kg} \mathrm{m}^{-1} \mathrm{~s}^{-1}\right)$, $\mathrm{T}$ is temperature $(\mathrm{K})$, and $\mathrm{p}$ and $\mathrm{A}$ are unitless and calculated according to:

$$
\begin{gathered}
p=\frac{0.1296 \times 10^{-9}}{r}+1.166 \\
10^{10} A=0.0005036 \cdot e^{\left(1.5124 \times 10^{-9} / r\right)}
\end{gathered}
$$

Where $\mathrm{r}$ is the estimated molecular radii $(\mathrm{m})$ based on molar mass estimates for each cell.

2.7.1.5. Viscosity. Viscosity was corrected for both changes with temperature and oil composition at each time step and within each oil layer, allowing for depth-dependent changes in oil viscosity with increased weathering over time. Changes in viscosity with temperature were estimated according to Martinez-Boza et al. (2011) using coefficients for an IFO380:

$$
\log \left(\frac{\eta_{\text {oil }}(T)}{\eta_{\text {oil }}\left(T_{r e f}\right)}\right)=\frac{3.76\left(T-T_{r e f}\right)}{86.5+\left(T-T_{r e f}\right)}
$$

Where $\eta_{\text {oil }}\left(T_{\text {ref }}\right)$ is the oil viscosity $\left(\mathrm{kg} \mathrm{m}^{-1} \mathrm{~s}^{-1}\right)$ at a known temperature, and temperatures are in Celsius. Following temperature correction, the viscosity was adjusted to account 
for changes in composition, as smaller compounds are lost through weathering, according to (Mackay et al., 1980; Sebastiao and Soares 1995; Arey et al., 2007b):

$$
\eta_{\text {oil }}(t)=\eta_{\text {oil }}\left(t_{0}\right) e^{10(\text { fractionlost })}
$$

Where $\eta_{\text {oil }}(\mathrm{t})$ is the viscosity $\left(\mathrm{kg} \mathrm{m}^{-1} \mathrm{~s}^{-1}\right)$ of the weathered oil at time $t, \eta_{\text {oil }}\left(\mathrm{t}_{0}\right)$ is the initial oil viscosity and fraction lost is the portion of oil lost due to weathering at time $t$.

2.7.1.6. Environmental air and water temperatures. Assuming all samples were in the mid-tidal region, oil was assumed to be exposed to the atmosphere $50 \%$ of the time and the water for $50 \%$ of the time. Hourly air and water temperature data were obtained from a National Ocean Service weather station in nearby Alameda, California (Figure S1, Figure S3; National Oceanic and Atmospheric Administration, 2011). Relevant oil temperatures during water exposure $\left(\mathrm{T}_{\text {oil,water }}\right)$ were estimated as the temperature of the water. The oil temperature during air exposure $\left(\mathrm{T}_{\text {oil,air }}\right)$ was calculated assuming the oil to be a black body, and using air temperature and incoming solar radiation data. Solar radiation data were obtained from the San Francisco Public Utilities Commission (San Francisco Public Utilities Commission, 2011), which maintains dozens of insolation monitors around San Francisco. Data used here was from Pier 40, across the Bay and $\sim 9.5 \mathrm{~km}$ from our sampling sites (Figure S1).

Insolation data are available for only one time point per day and these values were assumed constant over a 12-hour period. The correct alignment of tides and light hours was not considered. Where data were not available, values from previous and following days were averaged.

2.7.2. Model evaluation. A sensitivity analysis was performed to determine how changes in select parameters affected model output. Model sensitivity to oil and boundary layer thicknesses, diffusivities, temperatures, estimated and measured oil properties, parameters mapped onto the chromatogram (solubility, vapor pressure and molar mass), and $\mathrm{K}_{\text {salt }}$ were all considered. Each parameter was varied by $+/-10 \%$, a typical variation 
for sensitivity analyses, to examine sensitivity of predicted evaporated and dissolved masses and differences between model results and field data.

A simplified uncertainty analysis was also performed to examine variability of model results due to parameter uncertainties. Uniform distribution of each of the parameter was assumed. With these constraints ten randomly-generated data sets were created for input into the model. Variability in model output from these ten model runs were assumed to represent a reasonable estimate of model variability due to uncertainties in input parameters. Percent standard errors were calculated from predicted mass losses.

\section{RESULTS}

If evaporation and dissolution are assumed to be governed by the physical and chemical properties of the individual compounds within the oil, we can model these processes using calculated vapor pressure and solubility data. If the model can accurately reproduce MLTs of field samples, with a quantitative basis behind compound losses, then mass apportionments of individual compounds to air and water are be possible. Also, differences between model results and field samples indicate the presence of alternative loss mechanisms such as biodegradation and photodegradation.

3.1. Model results. The mass transfer model predicts trends consistent with expected losses due to evaporation and dissolution. Figure 4 shows MLTs for the field samples collected 8, 80 and 296 days post-spill and the corresponding model results. Field samples have been described previously (Chapter 3). The model predicts an evaporation front that moves across the mass loss table with time from $10^{0} \mathrm{~Pa}\left(\sim \mathrm{C}_{3}\right.$-naphthalenes $)$ at 8 days to $10^{-1.6} \mathrm{~Pa}\left(\sim \mathrm{C}_{1}\right.$-phenanthrenes) at 296 days post-spill. A dissolution front is also predicted moving down the MLT with time $\left(10^{-3.5}\right.$ to $10^{-5.5} \mathrm{~mol} \mathrm{~L}^{-1}$ at 8 and 296 days post-spill). This equates to initial losses of compounds with solubilities similar to naphthalene and subsequent losses occurring to the $\mathrm{C}_{1^{-}}, \mathrm{C}_{2^{-}}$and finally $\mathrm{C}_{3^{-}}$-naphthalenes 
by 296 days post spill. These trends are consistent with expectations about dissolution and evaporation and match observed trends within field samples.

Examination of differences between the model and field data indicate a general underestimation of mass loss by the model. The model estimates are more accurate for compounds more volatile than the $\mathrm{C}_{3}$-naphthalenes (vapor pressures $>10^{-0.3} \mathrm{~Pa}$ ), while underestimating losses of less volatile compounds (by up to 40\%). Overall the model underestimates total mass loss. This underestimation is more extreme with longer model run-times. For example, day 8 and day 80 results underestimate the total mass loss by $\sim 16 \%$ while predicted mass loss 296 days post-spill is underestimated by nearly $\sim 27 \%$. This increase in model error with run-time is likely a consequence of changes in mass distribution within the MLTs. For example, as mass is removed from cells of higher vapor pressures $\left(>\sim 10^{0.5} \mathrm{~Pa}\right)$, proportionally more mass resides in the lower vapor pressure cells $\left(<\sim 10^{0.5} \mathrm{~Pa} ; 70 \%\right.$ vs. $99 \%$ in lower vapor pressure boxes for the unweathered and 296 day samples, respectively). Because of the larger mass fraction of oil residing within these lower vapor pressure cells, small errors in estimated losses will be amplified accordingly within the MLTs. Losses from other processes, such as biodegradation or photodegradation, from these boxes may also contribute to this error.

The relatively good match between the model and field samples suggest evaporation and dissolution are the primary weathering processes affecting the $n-\mathrm{C}_{10}$ to $n-\mathrm{C}_{24}$ region examined. Because these processes dominate we can use the model to make quantitative predictions of mass loss on a compound specific basis. The relative partitioning of naphthalene compounds to the air and atmosphere is different than obtained by Arey et al. (2007b). They found naphthalene to partition 51 and $49 \%$ into the air and water respectively. Increasingly alkylated naphthalenes were calculated to partition more strongly into the atmosphere with $\mathrm{C}_{3}$-naphthalenes transferred $80 \%$ into the air and $20 \%$ into the water column (Arey et al., 2007b). Here we observed even less dissolution of naphthalenes. Naphthalene itself is calculated to be transferred $82 \%$ into the atmosphere and only $18 \%$ to the water column. The $\mathrm{C}_{3}$-naphthalenes partitioned $98 \%$ and $2 \%$ into the 
atmosphere and water. These differences between our model results and those of Arey et al. (2007) are due in large part to the higher oil temperatures, during air exposure, estimated in this study.

The power of this model is the ability to calculate mass losses and apportionment into the air or water for individual compounds (identity of the compound is not necessary) within the oil. Examining compounds with similar vapor pressures but different solubilities shows the different partitioning of these compounds. For example, $82 \%$ of naphthalene is evaporated compared to $100 \%$ of the less soluble compound $n-\mathrm{C}_{11}$ which has a similar vapor pressure. Phenanthrene is similar to the $\mathrm{C}_{3}$-naphthalenes in solubility, but has a lower vapor pressure. Smaller losses of phenanthrene to the atmosphere, compared with $\mathrm{C}_{3}$-naphthalenes (27\% vs. $98 \%$ ), are consistent with its comparative larger size and lower vapor pressure.

3.1.1. Mass loss. Assuming all of the oil spilled became stranded on the shore, and that the oil film thickness on rocks is uniform $(0.85 \mathrm{~mm}$ thick as determined for field samples analyzed here), we calculate a total of $\sim 520 \mathrm{~kg}$ of naphthalene were transferred from the beached oil into the environment during the 300 days after the spill. Of the naphthalene lost from the oil $\sim 82 \%$ was transferred into the atmosphere and 18\% ( 94 kg) into the water column. Of the estimated $\sim 107 \mathrm{~kg}$ of phenanthrene within the spilled oil, $\sim 29 \mathrm{~kg}$ are estimated to have been dissolved into surrounding waters during the 300 days following the spill.

These results suggest that during the 300 days post spill, petroleum hydrocarbons continued to dissolve into San Francisco Bay waters from stranded oil on rockyshorelines. Table 3 presents model estimated losses due to evaporation and dissolution for a range of individual petroleum compounds. The ability of the model to predict compound-specific apportionments allows more accurate accounting of oil components within the water column following a spill. This detailed information is a vast improvement on qualitative ratio-based techniques possible with one-dimensional chromatography. 
3.2. Comparison to laboratory studies. Modeled losses from the surface oil layer due to evaporation were compared to results from laboratory studies. A study by Fingas (1998) examined evaporation rates of specific hydrocarbons with and without wind. Examining the same suit of compounds with our model we observed similar relative decreases in evaporation rates with increased molar mass. Modifying the air boundary layer thickness within the model also enabled examination of the behavior of our model with the presence of wind. For example, environmental air boundary layers are typically on the order of $10 \mathrm{~mm}$; increased wind speeds will decrease this boundary layer thickness. We observed similar differences in evaporation rates with increased wind presence (decreased air-side boundary layer thickness) as those reported by Fingas et al., (1998).

Beverley et al. (1999) also presents experimental evaporation rates for several $n$-alkanes. The model was able to predict relative trends in evaporation rates among these compounds. These results suggest the treatment of evaporation within the model is mathematically accurate and consistent with experimental data. Comparison of dissolution behavior to laboratory studies was not performed, though the model of these processes should be mathematically equivalent.

3. 3. Sensitivity analysis. A sensitivity analysis was performed to gain a better understanding of the most important parameters in determining model results (Table 4). Model parameters were systematically varied by $+/-10 \%$ to identify which parameters are the most important to accurately constrain when applying this model in the future. Table 4 shows a select list of parameters used by the model and the impact of varying these parameters on the model results.

Results from a sensitivity analysis of the model suggest that estimated $\mathrm{T}_{\text {oil,air }}$ is the most important parameter in calculating evaporative losses. The model is very sensitive to changes in estimated oil temperatures when exposed to the atmosphere. Decreased temperatures reduce compound vapor pressures, air/oil partition coefficients, compound 
diffusivities within the oil, and increase oil viscosity. These changes result in decreased losses due to evaporation. Because evaporation and dissolution are processes competing for the same compounds, decreased temperatures also result in increased dissolution of compounds into the water column, as found in previous studies (Gros, 2010). These results suggest that spills at higher latitudes will experience reduced evaporation and a greater degree of dissolution than a comparable spill occurring in a warmer climate. This increased dissolution may also result in greater water column concentrations of toxic compounds and contribute to increased spill toxicities within cooler environments. Temperature also has implications for the residence time of hydrocarbon compounds; spills in cooler climates could potentially result in slower natural oil weathering. This is of importance given increased Arctic shipping and drilling.

Oil film thickness is also known to cause differences in weathering (Arey et al., 2007a; Arey et al., 2007b; Wardlaw et al., 2008; Gros, 2010) and the sensitivity analysis confirms the importance of this parameter. Both evaporation and dissolution are sensitive to oil film thickness with a change in oil film thickness having approximately equal impacts mass loss from both processes (Table 4). Evaporation is relatively insensitive to all other parameters examined. However, dissolution is also sensitive to the water boundary layer thickness, diffusivities in the water, aqueous solubilities and salt content. Though these parameters are not within our control, sensitivity of dissolution indicates their importance in model output. More accurate estimates, particularly for $\mathbf{K}_{\text {salt }}$ (parameter with the highest uncertainty) will improve model performance.

Because of the estimation method of oil temperature when exposed to the air, from air temperature and solar radiation data, this parameter has a high level of uncertainty (Table 5). Future field-based measurements may provide more accurate oil temperature estimates and aid in reducing the uncertainty within temperature estimates. Sensitivity to oil film thickness suggests this is an appropriate target for more accurate measurement during future studies. 
3. 4. Uncertainty analysis. A simplified uncertainty analysis using randomized parameter values was used to gain an understanding of errors in model predictions. Table 5 lists select model parameters and associated uncertainties. The model was found to be most sensitive to: oil film thickness, water-side boundary layer thickness, diffusivities in water, oil temperature when exposed to the atmosphere, aqueous solubility and $\mathrm{K}_{\text {salt }}$. Therefore only these six parameters were considered in the uncertainty analysis.

Model predictions for apportionment of naphthalene and phenanthrene to the atmosphere and water column were considered. These compounds represent a wide range of vapor pressures and variations in solubilities and molar masses predicted by the model. Table 5 presents evaporation and dissolution losses of naphthalene and phenanthrene, relative to the base model, for ten model runs using randomized parameter inputs.

Even though the modeled evaporation is highly sensitive. to oil temperature, and dissolution is sensitive to numerous parameters, uncertainty on model estimates is reasonable. Based on standard errors (calculated from mass differences) model uncertainties of dissolution estimates are approximately $\pm 14 \%$ and are comparable for both naphthalene and phenanthrene. Errors in evaporation estimates are lower and show dependence on location within the MLT. Errors in predicted evaporation for naphthalene are $\pm 3 \%$ while errors for phenanthrene are $\pm 7 \%$.

Extension of this analysis to include a wider range of solubilities and to investigate model predictions on shorter timescales would be desirable. Also, a more comprehensive Monte Carlo simulation would provide higher confidence in estimates of model uncertainty.

\section{CONCLUSIONS}

The mass transfer model developed here is consistent with laboratory results and is able to accurately reproduce MLTs of field samples collected after the $2007 \mathrm{M} / \mathrm{V}$ Cosco Busan HFO spill. The model predicts mass losses of individual oil components to the atmosphere and water column for a heavy fuel oil. The model underestimates total mass 
losses of lower vapor pressure compounds $\left(<\sim 10^{0.5} \mathrm{~Pa}\right)$, however, overall losses are predicted within $\sim 20 \%$ of observed values. Examination of the model indicates it is particularly sensitive to changes in estimated oil temperatures during atmospheric exposure. This implies that estimated oil temperatures are the primary factor controlling modeled evaporative losses after the spill. A simplified uncertainty analysis suggests this model is able to predict evaporative and dissolution losses with uncertainties of $7 \%$ and $14 \%$ respectively. To enable more accurate modeling oil temperature during atmospheric exposure and oil thickness should be targeted for accurate measurement following a spill. Better constraints on oil temperature and thickness will improve model performance in future applications.

\section{ACKNOWLEDGEMENTS}

I would like to thank J. Samuel Arey, Robert K. Nelson, and Christopher M. Reddy, who will be co-authors on the submitted version of this manuscript. I am also thankful to Jonas Gros, Dave Glover, and Phillip M. Gschwend who provided thoughtful discussions and comments on this manuscript. This work was supported by WHOI academic program funds, the Richard and Rhoda Goldman Fund, the Seaver Institute and the NSF grants EAR-0950670 and OCE-0960841.

\section{REFERENCES}

Arey, J. S., Nelson, R. K., Xu, L. and Reddy, C. M. (2005). "Using comprehensive twodimensional gas chromatography retention indices to estimate environmental partitioning properties for a complete set of diesel fuel hydrocarbons." Analytical Chemistry 77(22): 7172-7182. 
Arey, J. S., Nelson, R. K. and Reddy, C. M. (2007a). "Disentangling oil weathering using GC $\times$ GC. 1. Chromatogram analysis." Environmental Science \& Technology 41(16): 5738-5746.

Arey, J. S., Nelson, R. K., Plata, D. L. and Reddy, C. M. (2007b). "Disentangling oil weathering using GC $\times$ GC. 2. Mass transfer calculations." Environmental Science \& Technology 41(16): 5747-5755.

Beverley, K. J., Clint, J. H. and Fletcher, P. D. I. (1999). "Evaporation rates of pure liquids measured using a gravimetric technique." Physical Chemistry Chemical Physics 1(1): 149-153.

Cline, P. V., Delfino, J. J. and Rao, P. S. C. (1991). "Partitioning of aromatic constituents into water from gasoline and other complex solvent mixtures." Environmental Science \& Technology 25(5): 914-920.

Davis, H. T., Tominaga, T. and Evans, D. F. (1980). "Correlation between tracer diffusivity, solvent viscosity, and solute sizes." Aiche Journal 26(2): 313-314.

Drivas, P. J. (1982). "Calculation of evaporative emissions from multicomponent liquid spills." Environmental Science \& Technology 16(10): 726-728.

Fingas, M. F. (1998). "Studies on the evaporation of crude oil and petroleum products II. Boundary layer regulation." Journal of Hazardous Materials 57(1-3): 41-58.

Fingas, M. F. (2004). "Modeling evaporation using models that are not boundary-layer regulated." Journal of Hazardous Materials 107(1-2): 27-36.

Goodwin, S. R., Mackay, D. and Shiu, W. Y. (1976). "Characterization of evaporation rates of complex hydrocarbon mixtures under environmental conditions." Canadian Journal of Chemical Engineering 54(4): 290-294.

Gros, J. (2010). Chemical transport modelling for the 2009 North Sea Dutch oil spill experiment. Laboratoire de Modélisation de la Chimie Environnementale. Lausanne, Switzerland, École Polytechnique Fédérale de Lausanne. M.S.: 64.

Incardona, J. P., Vines, C. A., Anulacion, B. F., Baldwin, D. H., Day, H. L., French, B. L., Labenia, J. S., Linbo, T. L., Myers, M. S., Olson, O. P., Sloan, C. A., Sol, S., Griffin, F. J., Menard, K., Morgan, S. G., West, J. E., Collier, T. K., Ylitalo, G. M., Cherr, G. N. and Scholz, N. L. (2012). "Unexpectedly high mortality in Pacific Herring embryos exposed to the 2007 Cosco Busan oil spill in San Franciso Bay." Proceedings of the National Academy of Sciences 109(9): E51-E58.

International Organization for Standardization (2010). "Petroleum products - Fuels (class F) - specifications of marine fuels." ISO. Switzerland. 
Lemkau, K. L., Peacock, E. E., Nelson, R. K., Ventura, G. T., Kovecses, J. L. and Reddy, C. M. (2010). "The M/V Cosco Busan spill: source identification and short-term fate." Marine Pollution Bulletin 60(11): 2123-2129.

Ni, N. and Yalkowsky, S. H. (2003). "Prediction of Setschenow constants." International Journal of Pharmaceutics 254(2): 167-172.

Mackay, D. and Matsugu, R. S. (1973). "Evaporation rates of liquid hydrocarbon spills on land and water." Canadian Journal of Chemical Engineering 51(4): 434-439.

Mackay, D., Buist, I., Mascarenhas, R. and Paterson, S. (1980). "Oil spill processes and models."

Mao, D. B., Lookman, R., Van De Weghe, H., Weltens, R., Vanermen, G., De Brucker, N. and Diels, L. (2009). "Estimation of ecotoxicity of petroleum hydrocarbon mixtures in soil based on HPLC-GCXGC analysis." Chemosphere 77(11): 1508-1513.

Martinez-Boza, F. J., Martin-Alfonso, M. J., Gallegos, C. and Fernandez, M. (2011). "High-Pressure Behavior of Intermediate Fuel Oils." Energy \& Fuels 25(11): 5138-5144.

Mullins, O. C. (2008). "Review of the molecular structure and aggregation of asphaltenes and petroleomics." Spe Journal 13(1): 48-57.

National Oceanic and Atmospheric Administration. (May 7, 2011). "Tides and Currents." National Ocean Service. Retrieved May 7, 2011, from http://tidesandcurrents.noaa.gov/geo.shtml?location=9414750.

Nelson, R. K., Kile, B. M., Plata, D. L., Sylva, S. P., Xu, L., Reddy, C. M., Gaines, R. B., Frysinger, G. S. and Reichenbach, S. E. (2006). "Tracking the weathering of an oil spill with comprehensive two-dimensional gas chromatography." Environmental Forensics 7(1): 33-44.

Prince, R. C., Elmendorf, D. L., Lute, J. R., Hsu, C. S., Haith, C. E., Senius, J. D., Dechert, G. J., Douglas, G. S. and Butler, E. L. (1994). "17- $\alpha(\mathrm{H}), 21-\beta(\mathrm{H})$-hopane as a conserved internal marker for estimating the biodegradation of crude oil." Environmental Science \&amp; Technology 28(1): 142-145.

Reichenbach, S. E., Ni, M. T., Zhang, D. M. and Ledford, E. B. (2003). "Image background removal in comprehensive two-dimensional gas chromatography." Journal of Chromatography A 985(1-2): 47-56.

San Francisco Public Utilities Commission (2011). Solar Radiation Data - Pier 40.

Schwarzenbach, R. P., Gschwend, P. M. and Imboden, D. M. (2003). Environmental Organic Chemistry. Hoboken, Wiley-Interscience. 
Sebastiao, P. and Soares, C. G. (1995). "Modeling the fate of oil spills at sea." Spill Science \& Technology Bulletin 2(2-3): 121-131.

Stiver, W. and Mackay, D. (1984). "Evaporation rate of spills of hydrocarbons and petroleum mixtures." Environmental Science \& Technology 18(11): 834-840.

Stiver, W., Shiu, W. Y. and Mackay, D. (1989). "Evaporation times and rates of specific hydrocarbons in oil spills." Environmental Science \& Technology 23(1): 101-105.

van Den Dool, H. and Kratz, P. D. (1963). "A generalization of retention index system including linear temperature programmed gas-liquid partition chromatography." Journal of Chromatography 11(4): 463-\&.

Wardlaw, G. D., Arey, J. S., Reddy, C. M., Nelson, R. K., Ventura, G. T. and Valentine, D. L. (2008). "Disentangling oil weathering at a marine seep using GC $\times$ GC: broad metabolic specificity accompanies subsurface petroleum biodegradation." Environmental Science \& Technology 42(19): 7166-7173. 


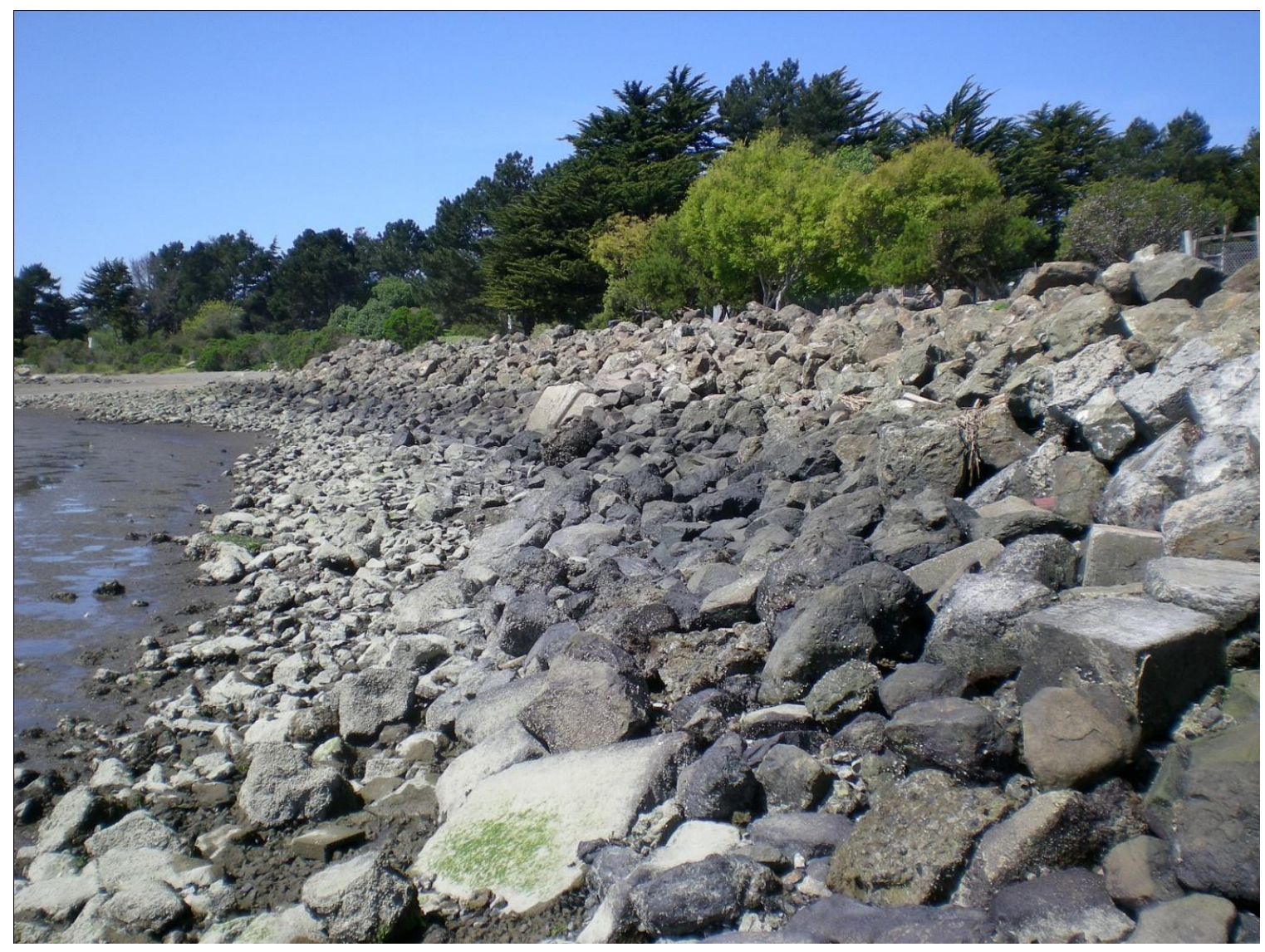

Figure 1. Photograph of Shorebird Park sampling site (Figure S1) showing "dirty bathtub ring" left by the M/V Cosco Busan spill. Image taken 511 days post-spill (photo by Karin Lemkau, Woods Hole Oceanographic Institution). 
Table 1. Linear free energy relationships (LFERs) used to map vapor pressure $\left(p_{L}\right)$, aqueous solubility $\left(C^{W}{ }_{L}\right)$, enthalpy of vaporization $\left(\Delta \mathrm{H}_{\text {vap }}\right)$ and molar mass $\left(\mathrm{mm}_{\mathrm{i}}\right)$ properties $\left(\mathrm{P}_{\mathrm{i}}\right)$ onto $\mathrm{GC} \times \mathrm{GC}$ chromatograms using first and second dimension retention indices $\left(\mathrm{I}_{\mathrm{i}, 1}\right.$ and $\left.\mathrm{I}_{\mathrm{i}, 2}\right)$.

$$
\log P_{i}=a I_{i, 1}+b I_{i, 2}+c
$$

\begin{tabular}{lccc}
\multicolumn{1}{c}{ Property } & $\mathrm{a}$ & $\mathrm{b}$ & $\mathrm{c}$ \\
\hline $\log \mathrm{P}_{\mathrm{L}}(\mathrm{Pa})$ & $-0.00461 \pm 0.0001$ & -- & $6.78 \pm 0.15$ \\
$\log \mathrm{C}_{\mathrm{L}}^{\mathrm{w}}\left(\mathrm{mol} \mathrm{L}^{-1}\right)$ & $-0.0176 \pm 0.0007$ & $0.0134 \pm 0.0006$ & $-2.24 \pm 0.21$ \\
$\Delta \mathrm{H}_{\mathrm{vap}}\left(\mathrm{J} \mathrm{mol}^{-1}\right)$ & $0.066 \pm 0.005$ & $-0.024 \pm 0.005$ & $12.9 \pm 2.4$ \\
$\mathrm{mw}_{\mathrm{i}}\left(\mathrm{g} \mathrm{mol}^{-1}\right)$ & 0.296 & -0.169 & 26.7 \\
\hline
\end{tabular}

${ }^{a}$ The GC×GC temperature program used in the current work is intermediate to those of methods $A$ and $B$ from Arey et al., 2005. As such, values for LFER constants a, $b$ and $c$ for the current work were calculated as averages of values obtained by Arey et al. (2005) for their methods A and B. 


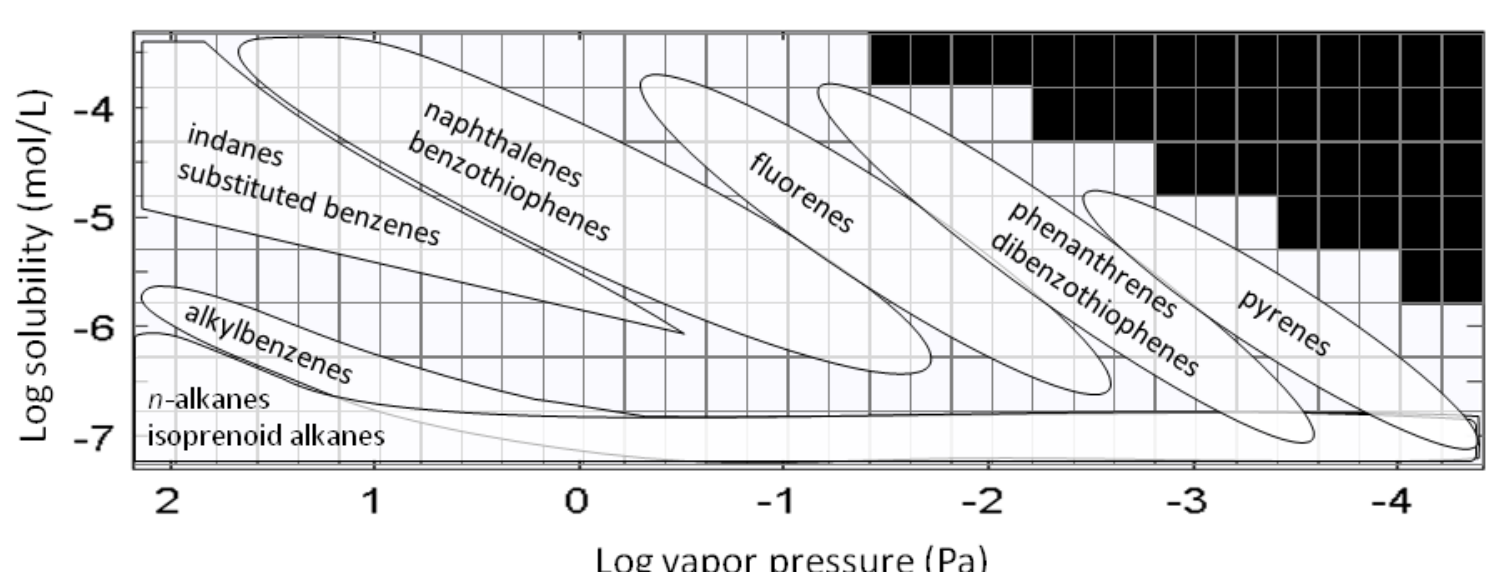

Log vapor pressure $(\mathrm{Pa})$

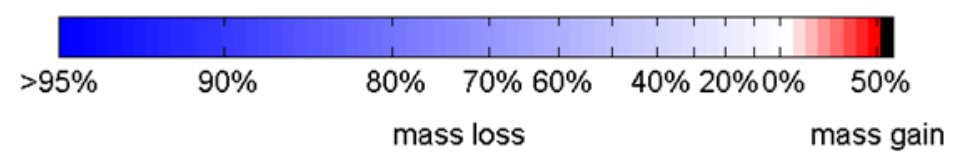

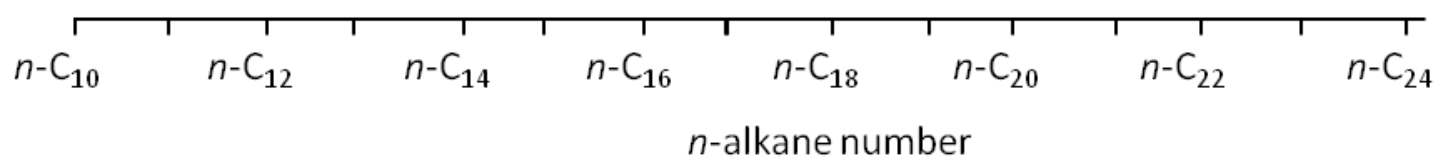

Figure 2. Annotated mass loss table (MLT) of the Tank 4 oil showing locations of major compound classes in these two-dimensional spaces. 
(a)

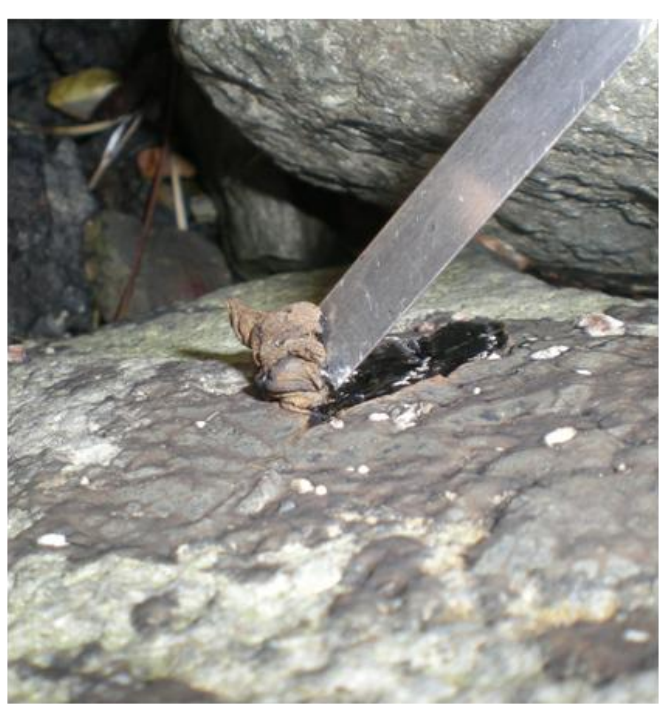

(b)

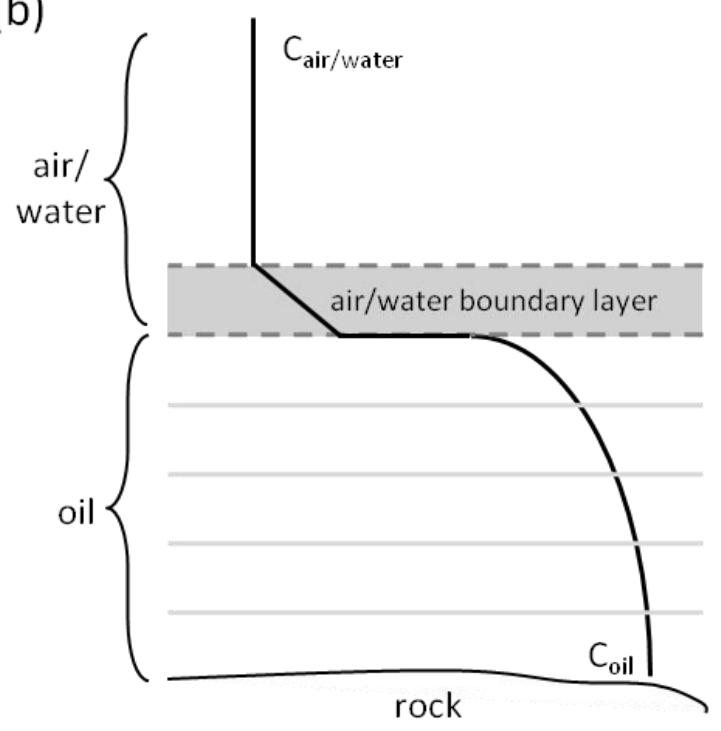

Figure 3. (a) Image of field sample collected from Shorebird Park 296 days post-spill and (b) the schematic representation of field samples used as the basis of the mass transfer model. The mass transfer model can be described by a wall boundary with a boundary layer. This schematic shows a concentration profile of a compound within the air, across the air/water boundary layer and through the oil. The oil was subdivided into layers to allow oil properties, such as viscosity, to change with depth. 
Table 2. Mass transfer model input parameters. ${ }^{a}$

\begin{tabular}{lcc} 
Parameter & Abbreviation & Value \\
\hline \hline water-side boundary layer thickness $^{\mathrm{b}}$ & $\delta_{\text {water }}$ & $0.0002 \mathrm{~m}$ \\
air-side boundary layer thickness $^{c}$ & $\delta_{\text {air }}$ & $0.002 \mathrm{~m}$ \\
oil thickness & $\delta_{\text {oil }}$ & $0.00085 \mathrm{~mm}$ \\
water temperature $^{d}$ & $\mathrm{~T}_{\text {water }}$ & 282 to $298 \mathrm{~K}$ \\
air temperature $^{\mathrm{d}}$ & $\mathrm{T}_{\text {air }}$ & 278 to $308 \mathrm{~K}$ \\
oil density & $\rho_{\text {oil }}$ & $950 \mathrm{~kg} \mathrm{~m}^{-3}$ \\
oil viscosity & $\mu_{\text {oil }}$ & $0.361 \mathrm{~kg} \mathrm{~m}^{-1} \mathrm{~s}^{-1}$ \\
asphaltene content & -- & $16 \%$ \\
volume of spill & -- & $180000 \mathrm{~L}^{-1}$ \\
asphaltene molar volume & $\mathrm{V}_{\text {asphaltenes }}$ & $0.00084 \mathrm{~m}^{3} \mathrm{~mol}^{-1}$ \\
\hline
\end{tabular}

${ }^{a}$ Parameters varying with compound identity are not listed.

${ }^{\mathrm{b}}$ Arey et al., 2007b

${ }^{c}$ Air-side boundary layer thickness is used to tune model for wind and thermal convection of the oil. Both of these processes would effectively decrease the air-boundary layer and thus the value used here is lower than typical environmental values $(\sim 10 \mathrm{~mm})$.

${ }^{\mathrm{d}}$ See supporting information Figure 3 
(a) Field samples
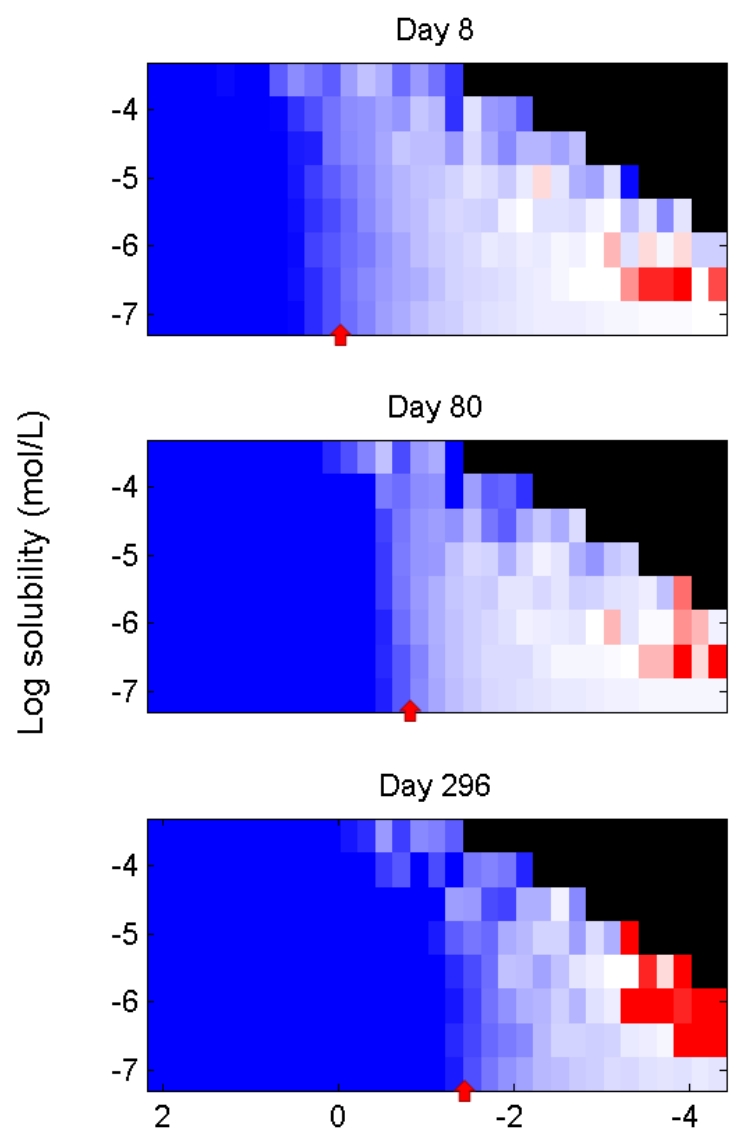

(b) Model

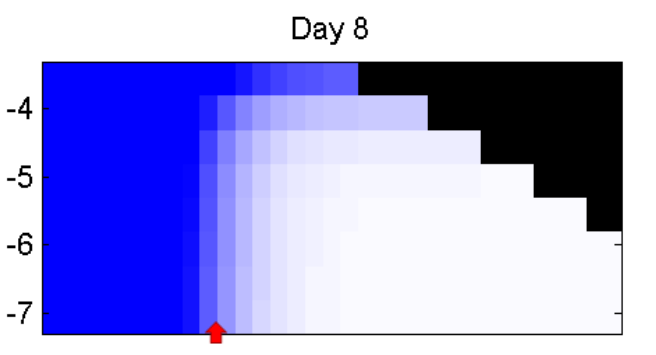

Day 80

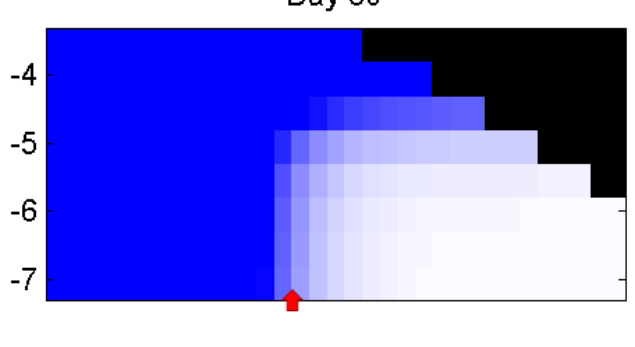

Day 296

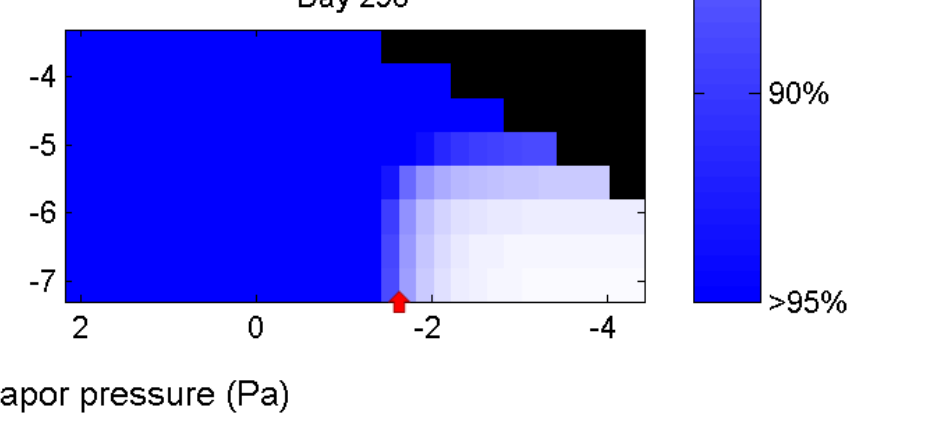

Figure 4. MLTs of field samples (a) and model results for 8, 80, and 296 days post-spill (b). 
Table 3. Modeled losses due to evaporation and dissolution for select compounds.

\begin{tabular}{|c|c|c|c|c|}
\hline \multirow[b]{2}{*}{ Compound } & \multicolumn{2}{|c|}{8 days } & \multicolumn{2}{|c|}{296 days } \\
\hline & $\begin{array}{c}\% \text { loss due to } \\
\text { dissolution }\end{array}$ & $\begin{array}{l}\% \text { loss due to } \\
\text { evaporation }\end{array}$ & $\begin{array}{c}\% \text { loss due to } \\
\text { dissolution }\end{array}$ & $\begin{array}{l}\text { \% loss due to } \\
\text { evaporation }\end{array}$ \\
\hline$n-C_{11}$ & $3 \%$ & $97 \%$ & $0 \%$ & $100 \%$ \\
\hline$n-C_{12}$ & $6 \%$ & $94 \%$ & $0 \%$ & $100 \%$ \\
\hline naphthalene & $20 \%$ & $80 \%$ & $18 \%$ & $82 \%$ \\
\hline $\mathrm{C}_{1}$-naphthalenes & $33 \%$ & $67 \%$ & $29 \%$ & $71 \%$ \\
\hline $\mathrm{C}_{2}$-naphthalenes & $30 \%$ & $70 \%$ & $6 \%$ & $94 \%$ \\
\hline $\mathrm{C}_{3}$-naphthalenes & $71 \%$ & $29 \%$ & $9 \%$ & $91 \%$ \\
\hline fluorene & $83 \%$ & $17 \%$ & $60 \%$ & $40 \%$ \\
\hline phenanthrene & $98 \%$ & $3 \%$ & $73 \%$ & $27 \%$ \\
\hline $\mathrm{C}_{1}$-phenanthrene & $99 \%$ & $1.0 \%$ & $65 \%$ & $35 \%$ \\
\hline $\mathrm{C}_{2}$-phenanthrene & $100 \%$ & $0 \%$ & $88 \%$ & $12 \%$ \\
\hline $\mathrm{C}_{3}$-phenanthrene & $100 \%$ & $0 \%$ & $98 \%$ & $2 \%$ \\
\hline chrysene & $68 \%$ & $32 \%$ & $42 \%$ & $58 \%$ \\
\hline
\end{tabular}


Table 4. Select list of parameters used by the model and the impact of varying these parameters on the model results. Those parameters having large effects on both evaporation and dissolution are in bold.

\begin{tabular}{|c|c|c|c|c|c|c|c|c|}
\hline \multirow[b]{2}{*}{ Parameter } & \multirow[b]{2}{*}{$\begin{array}{l}\text { Initial model } \\
\text { value } \\
\end{array}$} & \multirow[b]{2}{*}{$\begin{array}{l}\text { Variation } \\
\text { applied }\end{array}$} & \multicolumn{3}{|c|}{8 days } & \multicolumn{3}{|c|}{296 days } \\
\hline & & & $\begin{array}{c}\% \text { change in } \\
\text { amount } \\
\text { dissolved }^{\mathrm{a}}\end{array}$ & $\begin{array}{c}\% \text { change in } \\
\text { amount } \\
\text { evaporated }^{\mathrm{a}}\end{array}$ & $\begin{array}{l}\% \text { change in } \\
\text { model error }^{\mathrm{a}}\end{array}$ & $\begin{array}{c}\% \text { change in } \\
\text { amount } \\
\text { dissolved }^{\mathrm{a}} \\
\end{array}$ & $\begin{array}{l}\% \text { change in } \\
\text { amount } \\
\text { evaporated }^{\mathrm{a}}\end{array}$ & $\begin{array}{l}\% \text { change in } \\
\text { model error }\end{array}$ \\
\hline base model & & & $0.059 \%$ & $1.3 \%$ & $-16 \%$ & $1.1 \%$ & $11 \%$ & $-27 \%$ \\
\hline \multirow{2}{*}{ oil film thickness } & \multirow{2}{*}{$0.00085 \mathrm{~m}$} & $+10 \%$ & $-7.4 \%$ & $-6.9 \%$ & $2.4 \%$ & $-4.5 \%$ & $-3.0 \%$ & $2.7 \%$ \\
\hline & & $-10 \%$ & $8.8 \%$ & $7.9 \%$ & $-2.7 \%$ & $5.1 \%$ & $3.3 \%$ & $-3.1 \%$ \\
\hline \multirow{2}{*}{$\begin{array}{l}\text { water-side boundary layer } \\
\text { thickness }\end{array}$} & \multirow{2}{*}{$0.0002 \mathrm{~m}$} & $+10 \%$ & $-8.4 \%$ & $0.061 \%$ & $0.33 \%$ & $-7.2 \%$ & $0.36 \%$ & $0.94 \%$ \\
\hline & & $-10 \%$ & $9.9 \%$ & $-0.084 \%$ & $-0.39 \%$ & $8.5 \%$ & $-0.42 \%$ & $-1.1 \%$ \\
\hline \multirow{2}{*}{$\begin{array}{l}\text { air-side boundary layer } \\
\text { thickness }\end{array}$} & \multirow{2}{*}{$0.002 \mathrm{~m}$} & $+10 \%$ & $0.84 \%$ & $-4.2 \%$ & $1.9 \%$ & $2.2 \%$ & $-2.9 \%$ & $1.7 \%$ \\
\hline & & $-10 \%$ & $-1.0 \%$ & $4.8 \%$ & $-2.2 \%$ & $-2.4 \%$ & $3.2 \%$ & $-1.9 \%$ \\
\hline \multirow{2}{*}{ oil temperature, water } & \multirow{2}{*}{$289 \mathrm{~K}$} & $+10 \%$ & $3.9 \%$ & $-0.038 \%$ & $-0.030 \%$ & $2.6 \%$ & $-0.19 \%$ & $-0.0080 \%$ \\
\hline & & $-10 \%$ & $-27 \%$ & $0.24 \%$ & $0.34 \%$ & $-22 \%$ & $1.4 \%$ & $0.082 \%$ \\
\hline \multirow{2}{*}{ oil temperature, air } & \multirow{2}{*}{$304 \mathrm{~K}$} & $+10 \%$ & $-43 \%$ & $268 \%$ & $-68 \%$ & $-70 \%$ & $95 \%$ & $-22 \%$ \\
\hline & & $-10 \%$ & $21 \%$ & $-100 \%$ & $43 \%$ & $89 \%$ & $-98 \%$ & $25 \%$ \\
\hline \multirow{2}{*}{ oil density } & \multirow{2}{*}{$950 \mathrm{~kg} / \mathrm{m} 3$} & $+10 \%$ & $-4.4 \%$ & $-0.95 \%$ & $1.2 \%$ & $-3.3 \%$ & $-1.1 \%$ & $1.4 \%$ \\
\hline & & $-10 \%$ & $5.2 \%$ & $1.1 \%$ & $-1.4 \%$ & $3.8 \%$ & $1.3 \%$ & $-1.7 \%$ \\
\hline \multirow{2}{*}{ oil viscosity } & \multirow{2}{*}{$0.361 \mathrm{~Pa} \mathrm{~s}$} & $+10 \%$ & $0 \%$ & $-1.2 \%$ & $0.067 \%$ & $0.30 \%$ & $-0.23 \%$ & $0.0033 \%$ \\
\hline & & $-10 \%$ & $-0.17 \%$ & $1.3 \%$ & $-0.071 \%$ & $-0.34 \%$ & $0.24 \%$ & $-0.0033 \%$ \\
\hline \multirow{2}{*}{ molar volume } & \multirow{2}{*}{$0.0003 \mathrm{m3} / \mathrm{mol}$} & $+10 \%$ & $4.7 \%$ & $2.5 \%$ & $-1.3 \%$ & $3.1 \%$ & $1.5 \%$ & $-1.5 \%$ \\
\hline & & $-10 \%$ & $-4.9 \%$ & $-2.6 \%$ & $1.4 \%$ & $-3.2 \%$ & $-1.5 \%$ & $1.6 \%$ \\
\hline \multirow{2}{*}{ diffusivity, air ${ }^{\mathrm{b}}$} & \multirow{2}{*}{$6.6 \times 10^{-6} \mathrm{~m}^{2} / \mathrm{s}$} & $+10 \%$ & $-0.84 \%$ & $4.3 \%$ & $-2.0 \%$ & $-2.2 \%$ & $2.9 \%$ & $-1.8 \%$ \\
\hline & & $-10 \%$ & $0.84 \%$ & $-4.7 \%$ & $2.1 \%$ & $2.4 \%$ & $-3.2 \%$ & $1.9 \%$ \\
\hline \multirow{2}{*}{ diffusivity, water ${ }^{\mathrm{b}}$} & \multirow{2}{*}{$8.6 \times 10^{-10} \mathrm{~m}^{2} / \mathrm{s}$} & $+10 \%$ & $8.9 \%$ & $-0.08 \%$ & $-0.35 \%$ & $7.6 \%$ & $-0.38 \%$ & $-1.0 \%$ \\
\hline & & $-10 \%$ & $-9.3 \%$ & $0.07 \%$ & $0.36 \%$ & $-7.9 \%$ & $0.40 \%$ & $1.0 \%$ \\
\hline \multirow{2}{*}{ diffusivity, oil ${ }^{b, c}$} & \multirow{2}{*}{$8.0 \times 10^{-12} \mathrm{~m}^{2} / \mathrm{s}$} & $+10 \%$ & $-0.17 \%$ & $1.4 \%$ & $-0.076 \%$ & $-0.37 \%$ & $0.26 \%$ & $-0.0033 \%$ \\
\hline & & $-10 \%$ & $0 \%$ & $-1.6 \%$ & $0.088 \%$ & $0.40 \%$ & $-0.30 \%$ & $0.0040 \%$ \\
\hline \multirow{2}{*}{ Ksalt $^{b}$} & 0.15 & $+10 \%$ & $-8.4 \%$ & $0.06 \%$ & $0.33 \%$ & $-7.2 \%$ & $0.36 \%$ & $0.94 \%$ \\
\hline & 0.10 & $-10 \%$ & $9.9 \%$ & $-0.08 \%$ & $-0.39 \%$ & $8.5 \%$ & $-0.42 \%$ & $-1.1 \%$ \\
\hline aqueous solubility & $10^{-3.05} \mathrm{~mol} / \mathrm{m}^{3}$ & $+10 \%$ & $8.9 \%$ & $-0.076 \%$ & $-0.35 \%$ & $7.6 \%$ & $-0.38 \%$ & $-1.0 \%$ \\
\hline & & $-10 \%$ & $-9.3 \%$ & $0.069 \%$ & $0.36 \%$ & $-7.9 \%$ & $0.40 \%$ & $1.0 \%$ \\
\hline vapor pressureb & $10^{1.54} \mathrm{~Pa}$ & $+10 \%$ & $-0.84 \%$ & $4.3 \%$ & $-2.0 \%$ & $-2.2 \%$ & $2.9 \%$ & $-1.8 \%$ \\
\hline & & $-10 \%$ & $0.84 \%$ & $-4.7 \%$ & $2.1 \%$ & $2.4 \%$ & $-3.2 \%$ & $1.9 \%$ \\
\hline molar mass $^{b}$ & $.122 \mathrm{~kg} / \mathrm{mol}$ & $+10 \%$ & $-1.0 \%$ & $-1.7 \%$ & $0.25 \%$ & $-0.43 \%$ & $-0.43 \%$ & $0.29 \%$ \\
\hline & & $-10 \%$ & $1.2 \%$ & $2.0 \%$ & $-0.34 \%$ & $0.60 \%$ & $0.53 \%$ & $-0.40 \%$ \\
\hline
\end{tabular}


Table 5. Parameters and estimated uncertainties. Bold indicates parametrs included in the uncertainty analysis.

\begin{tabular}{|c|c|c|}
\hline Parameter & Model value ${ }^{a}$ & $\begin{array}{c}\text { Estimated parameter } \\
\text { uncertainty }\end{array}$ \\
\hline \multirow{2}{*}{ oil film thickness } & \multirow{2}{*}{$0.00085 \mathrm{~m}$} & $+50 \%^{\mathrm{b}}$ \\
\hline & & $-50 \%{ }^{b}$ \\
\hline \multirow{2}{*}{$\begin{array}{l}\text { water-side boundary } \\
\text { layer thickness }\end{array}$} & \multirow{2}{*}{$0.0002 \mathrm{~m}$} & $+50 \%$ \\
\hline & & $-50 \%$ \\
\hline \multirow{2}{*}{$\begin{array}{l}\text { air-side boundary } \\
\text { layer thickness }\end{array}$} & \multirow{2}{*}{$0.002 \mathrm{~m}$} & $+500 \%{ }^{\mathrm{c}}$ \\
\hline & & $-50 \%{ }^{c}$ \\
\hline \multirow{2}{*}{ diffusivity, air } & \multirow{2}{*}{$6.6 \times 10^{-6} \mathrm{~m}^{2} / \mathrm{s}$} & $+60 \%{ }^{\dagger}$ \\
\hline & & $-20 \%{ }^{\dagger}$ \\
\hline \multirow{2}{*}{ diffusivity, water } & \multirow{2}{*}{$8.6 \times 10^{-10} \mathrm{~m}^{2} / \mathrm{s}$} & $+60 \%{ }^{e}$ \\
\hline & & $-20 \%{ }^{e}$ \\
\hline \multirow{2}{*}{ diffusivity in oil } & \multirow{2}{*}{$8.0 \times 10^{-12} \mathrm{~m}^{2} / \mathrm{s}$} & $+25 \%^{d}$ \\
\hline & & $-25 \%^{d}$ \\
\hline \multirow{2}{*}{ oil temperature, water } & \multirow{2}{*}{282 to $298 \mathrm{~K}$ (avg $288 \mathrm{~K}$ ) } & $+5 \%$ \\
\hline & & $-5 \%$ \\
\hline \multirow{2}{*}{ oil temperature, air } & \multirow{2}{*}{279 to $345 \mathrm{~K}$ (avg $302 \mathrm{~K}$ ) } & $+10 \%^{g}$ \\
\hline & & $-5 \%^{g}$ \\
\hline \multirow{2}{*}{ oil density } & \multirow{2}{*}{$950 \mathrm{~kg} / \mathrm{m}^{3}$} & $+5 \%{ }^{\mathrm{h}}$ \\
\hline & & $-5 \%{ }^{h}$ \\
\hline \multirow{2}{*}{ oil viscosity } & \multirow{2}{*}{$0.361 \mathrm{~Pa} \cdot \mathrm{s}$} & $+10 \%{ }^{i}$ \\
\hline & & $-10 \%{ }^{i}$ \\
\hline \multirow{2}{*}{ molar mass } & \multirow{2}{*}{$.122 \mathrm{~kg} / \mathrm{mol}$} & $+50 \%{ }^{\mathrm{j}}$ \\
\hline & & $-50 \%{ }^{j}$ \\
\hline \multirow{2}{*}{ molar volume } & \multirow{2}{*}{$3.2 \times 10^{-4} \mathrm{~m}^{3} / \mathrm{mol}$} & $+50 \%{ }^{k}$ \\
\hline & & $-50 \%^{k}$ \\
\hline \multirow{2}{*}{ aqueous solubility } & \multirow{2}{*}{$10^{-3.05} \mathrm{~mol} / \mathrm{m}^{3}$} & $+100 \%$ \\
\hline & & $-50 \% '$ \\
\hline \multirow{2}{*}{ vapor pressure } & \multirow{2}{*}{$10^{1.54} \mathrm{~Pa}$} & $+100 \%$ \\
\hline & & $-50 \%$ \\
\hline \multirow{2}{*}{$\mathbf{K}_{\text {salt }}$} & \multirow{2}{*}{0.15} & $+50 \%{ }^{\mathrm{m}}$ \\
\hline & & $-50 \%^{m}$ \\
\hline
\end{tabular}

${ }^{a}$ for parameters whos value depends on compound of interest values for naphthelene are given at $\mathrm{t}=0$; $\mathrm{Di}$, oil value is given for water temperatures

${ }^{b}$ based on variability observed in measured oil thickness of field samples.

${ }^{\mathrm{c}}$ large variation comes from use of this term to compensate for processes not directly included within the model such as convective transport due to thermal heating and wind speed.

${ }^{d}$ from Davis et al., 1980

${ }^{e}$ based on difference between model estimates of naphthalene diffusivity in water and calculated values using actual molecular weights

${ }^{\dagger}$ based on difference between model estimates of naphthalene diffusivity in water and calculated values using actual molecular weights

${ }^{g}$ based on air temperatures as minimum possible rock temperatures

${ }^{\mathrm{h}}$ based on approximate range of densities for heavy fuel oils (International Organization for Standardization, 2010)

' based on definition of IFO 380

${ }^{\mathrm{j}}$ based on difference between actual molar mass of naphthalene and model predicted values (errors decrease for species with higher molar masses)

${ }^{k}$ error calculated based on propogation of error for oil density and molar masses (Vm=molar mass/density)

' from Arey et al., 2005

$\mathrm{m}$ from $\mathrm{Ni}$ et al., 2003 
Table 6. Results from ten model runs demonstrating errors on evaporation and dissolution estimates. Changes in dissolution and evaporative loss are reported as percentage changes from the base run where modeled values were used without alteration (Table 1).

Naphthalene and phenanthrene were chosen to examine differences in model behavior across a range of vapor pressures, solubilities and molar masses.

\begin{tabular}{|c|c|c|c|c|}
\hline & \multicolumn{2}{|c|}{ Naphthalene } & \multicolumn{2}{|c|}{ Phenanthrene } \\
\hline & $\begin{array}{c}\% \text { change in } \\
\text { amount dissolved }\end{array}$ & $\begin{array}{c}\% \text { change in } \\
\text { amount } \\
\text { evaporated }\end{array}$ & $\begin{array}{c}\% \text { change in } \\
\text { amount dissolved }\end{array}$ & $\begin{array}{c}\% \text { change in } \\
\text { amount } \\
\text { evaporated }\end{array}$ \\
\hline $\begin{array}{l}\text { Base model } \\
\text { predicted loss (\%) }\end{array}$ & $18 \%$ & $82 \%$ & $36 \%$ & $63 \%$ \\
\hline 1 & $77 \%$ & $-17 \%$ & $72 \%$ & $-40 \%$ \\
\hline 2 & $-18 \%$ & $4.0 \%$ & $-19 \%$ & $11 \%$ \\
\hline 3 & $-59 \%$ & $13 \%$ & $25 \%$ & $-15 \%$ \\
\hline 4 & $-20 \%$ & $4.5 \%$ & $50 \%$ & $-27 \%$ \\
\hline 5 & $-52 \%$ & $12 \%$ & $-16 \%$ & $11 \%$ \\
\hline 6 & $-72 \%$ & $16 \%$ & $-56 \%$ & $32 \%$ \\
\hline 7 & $-27 \%$ & $6.0 \%$ & $9.6 \%$ & $-5.5 \%$ \\
\hline 8 & $18 \%$ & $-4.0 \%$ & $25 \%$ & $-15 \%$ \\
\hline 9 & $-17 \%$ & $3.9 \%$ & $-0.02 \%$ & $1.8 \%$ \\
\hline 10 & $-29 \%$ & $6.4 \%$ & $56 \%$ & $-31 \%$ \\
\hline$\%$ standard error ${ }^{a}$ & $14 \%$ & $3 \%$ & $12 \%$ & $7 \%$ \\
\hline
\end{tabular}

${ }^{\mathrm{a}}$ based on standard deviation of mass losses across the ten model runs. 


\section{Supplemental Information}

for

\section{Quantifying petroleum hydrocarbon input from oil-covered rocks into San Francisco Bay following the M/V Cosco Busan oil spill: Development of a mass transfer model}

\section{Contents of Supplemental Information}

Figure S1. Map of San Francisco Bay showing sampling sites and location of temperature and insolation data collection sites. Page 155.

Figure S2. GC $\times$ GC-FID chromatogram of the $n-\mathrm{C}_{10}$ to $n-\mathrm{C}_{24}$ region showing finite boundaries for vapor pressure (vertical lines) and solubility (curved lines). Page 157.

Figure S3. Plot of water temperatures and estimated oil temperature during air exposure data. Page 159.

S1. Supplemental references. Page 160. 


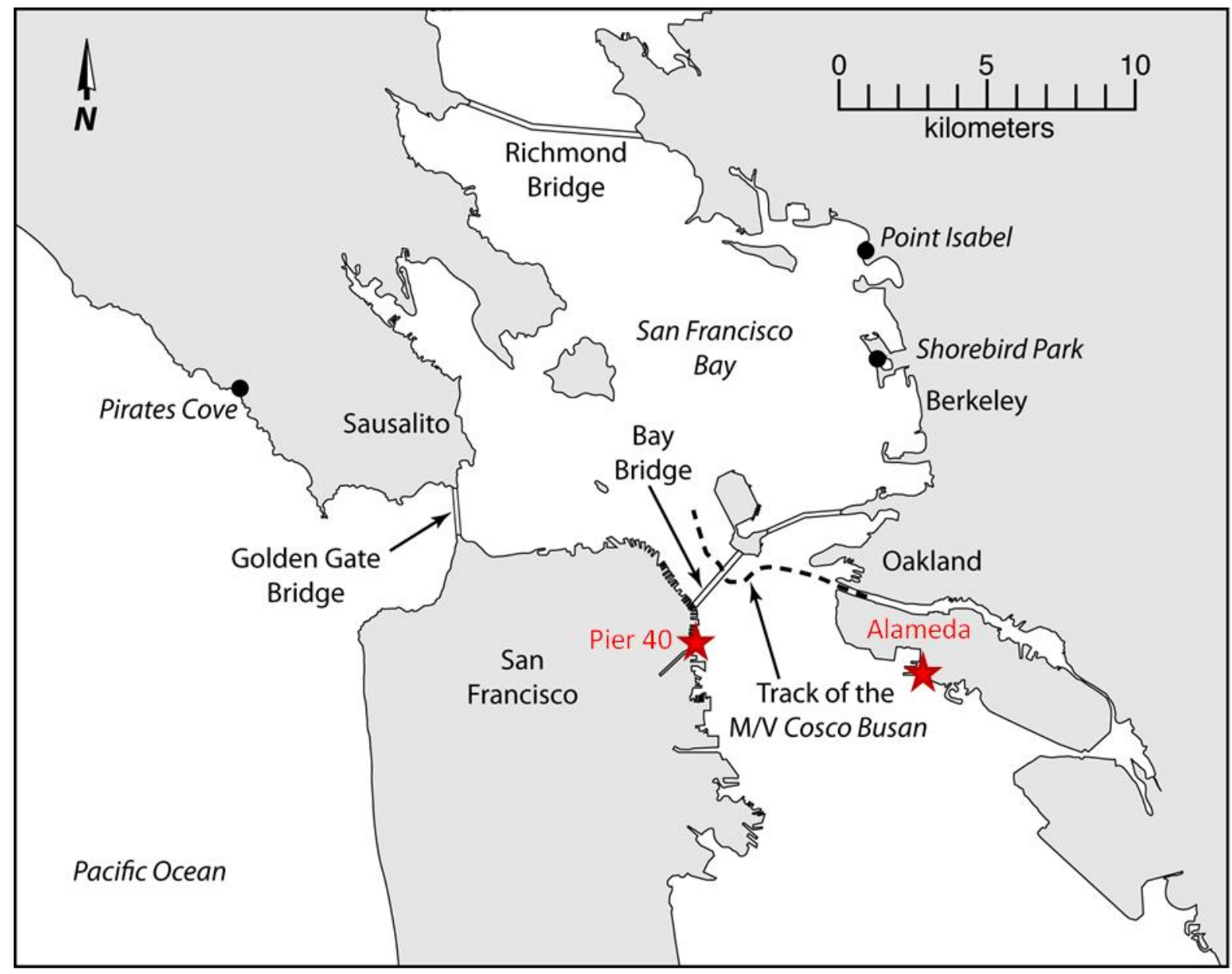

Figure S1. Map of San Francisco Bay showing track of the M/V Cosco Busan, location of sampling sites and collection sites of temperature and insolation data used in modeling. Sampling sites are indicated by black dots. Insolation data was collected from a weather station located at Pier 40 (San Francisco Public Utilities Commission, 2011). Air and water temperatures were obtained from a weather station located in Alameda (National Oceanic and Atmospheric Administration, 2011). 


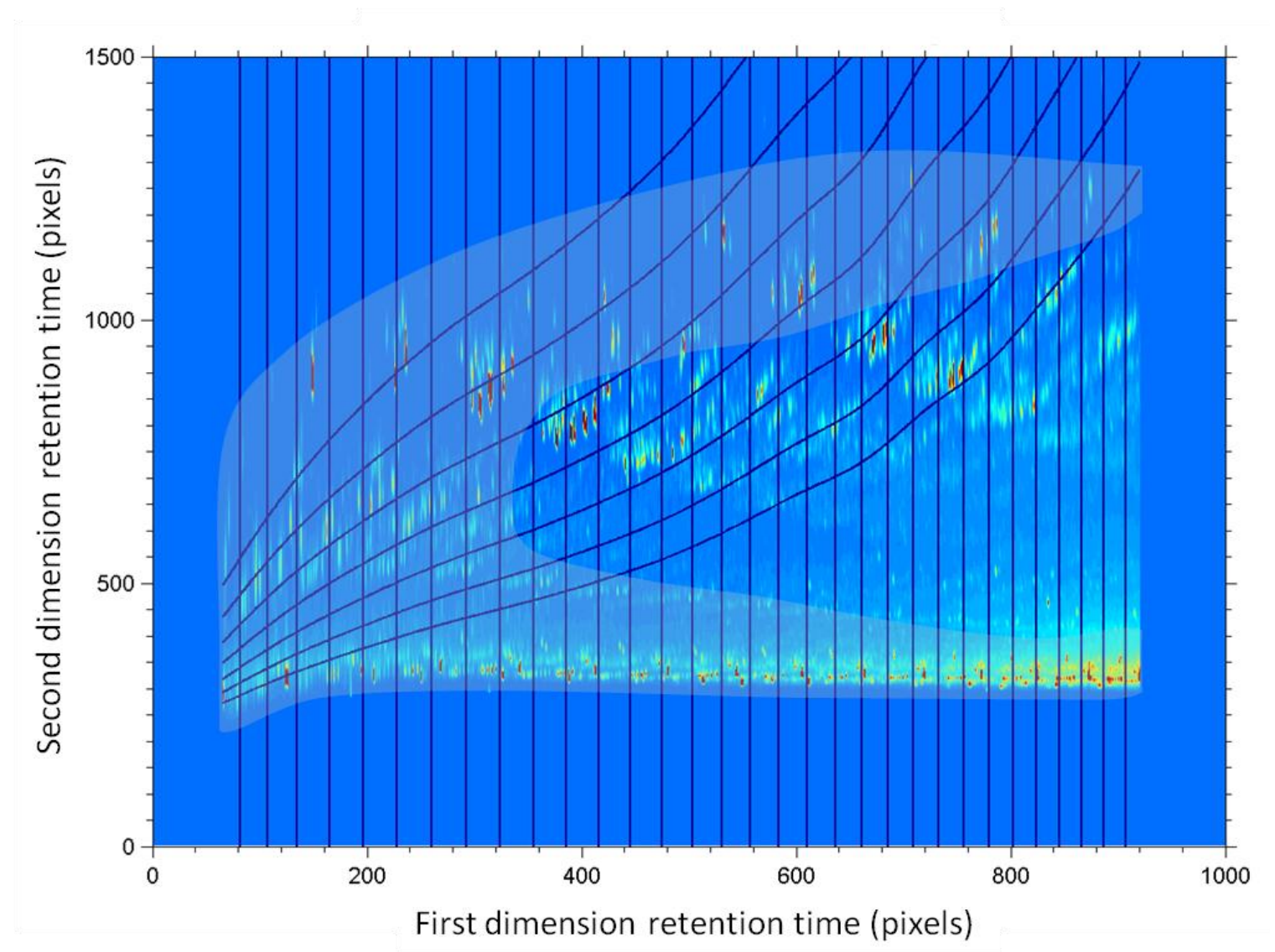

Figure S2. GC $\times$ GC-FID chromatogram of the $n-\mathrm{C}_{10}$ to $n-\mathrm{C}_{24}$ region showing finite boundaries for vapor pressure (vertical lines) and solubility (curved lines) used to create cells of mass loss tables. Grey mask indicates location of training set used for determination of linear free energy relationships (Table 1; Arey et al., 2005). Axis units are in pixels. Pixels can be converted to time using the $\mathrm{GC} \times \mathrm{GC}$ modulation time and data sampling rate. 


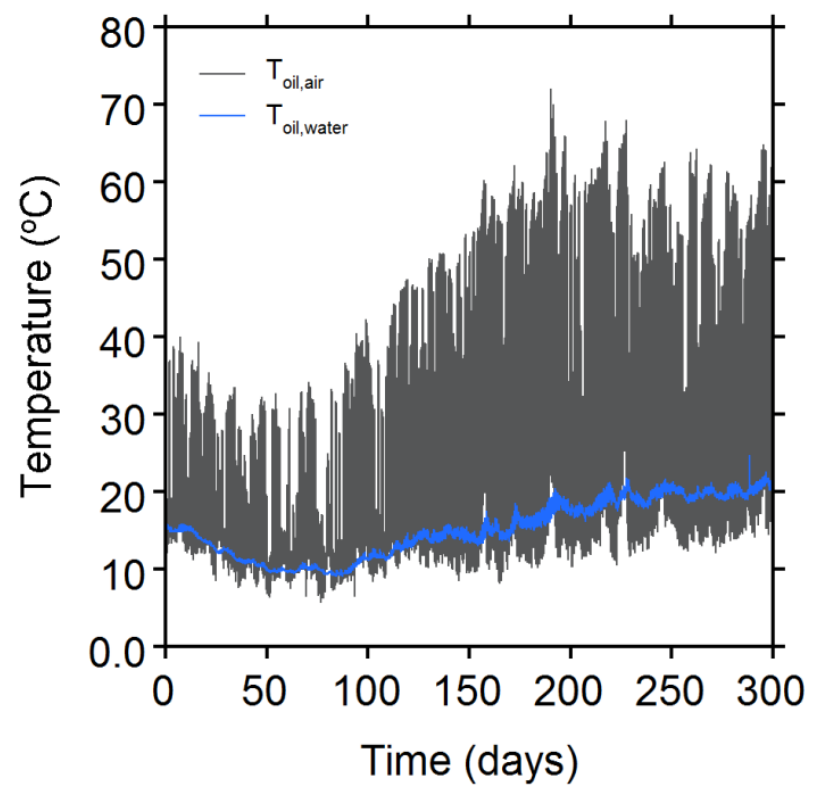

Figure S3. Plot of oil temperatures during air and water exposure. Oil temperature during water exposure $\left(\mathrm{T}_{\text {oil,water }}\right)$ was taken directly as measured water temperatures. Oil temperature during air exposure $\left(\mathrm{T}_{\text {oil,air }}\right)$ was estimated from measured air temperatures and insolation data assuming the oil to be a black body. 


\section{S1. Supplemental references}

Arey, J. S., Nelson, R. K., Xu, L. and Reddy, C. M. (2005). "Using comprehensive twodimensional gas chromatography retention indices to estimate environmental partitioning properties for a complete set of diesel fuel hydrocarbons." Analytical Chemistry 77(22): 7172-7182.

National Oceanic and Atmospheric Administration. (May 7, 2011). "Tides and Currents." National Ocean Service. Retrieved May 7, 2011, from http://tidesandcurrents.noaa.gov/geo.shtml?location=9414750.

San Francisco Public Utilities Commission (2011). Solar Radiation Data - Pier 40. 


\section{Chapter 5}

Oil Spill Weathering: Expanding the analytical window beyond gas chromatography

Karin L. Lemkau 


\section{ABSTRACT}

The study of oil spills has relied predominantly on one-dimensional, gas chromatography (GC)-based techniques. However, higher molecular weight and polar components prominent in heavy fuel oils (HFOs) are not detectable via traditional GC-based techniques without prior modification and are often overlooked after a spill. We refer to these overlooked compounds as the non-GC amenable fraction. Here we use bulk and molecular-level techniques (Fourier transform ion cyclotron resonance mass spectrometry; FT-ICR MS) to examine the compositional evolution of this fraction in a HFO from the 2007 M/V Cosco Busan spill (San Francisco Bay, CA). With time, this fraction of the oil underwent numerous compositional changes likely due to biodegradation and photodegradation. Because of the higher molecular weights and heteroatom content of the compounds examined here (compared with smaller GCamenable species), evaporation and dissolution will not have a direct effect on these compounds. With increased weathering, trends consistent with general oxidation and dealkylation of aromatic structures were observed. In addition, naphthenic acids, compounds of interest for their potential toxicity, appear recalcitrant following the spill; these compounds may be useful in fingerprinting oils. These results suggest that the nonGC amenable fraction of oil potentially contains indicators for source identification and can provide new insights into oil spill weathering. Research findings from previous analyses of the GC amenable fraction, and from the non-GC amenable oil fraction examined here, indicate that environmental weathering results in removal or alteration of larger alkylated compounds as well as loss of lower molecular weight species, with a resultant fraction of stable compounds likely to remain in the environment years after the spill. Coupling analytical methods to examine GC and non-GC amenable oil components may provide insights into the transformation and subsequent transfer of petroleum hydrocarbons between these pools, which will shed light on the fate of spilled oils.

Keywords: Oil Spill, petroleum, heavy fuel oil (HFO), weathering 


\section{INTRODUCTION}

Decades of oil spill research have relied predominantly on one-dimensional, gas chromatography (GC)-based techniques to study weathering, source identification and toxicity of oil samples. However, GC requires volatilization of the extracted samples and typical methods restrict the analytical window for characterization of petroleum hydrocarbons to compounds that volatilize below $500^{\circ} \mathrm{C}$.[1] Generally, the target compounds are $n$-alkanes, select branched and cyclic alkanes, polycyclic aromatic hydrocarbons (PAHs) and various biomarkers from the hopane and sterane series. Many compounds, even in light crude oils, are not measured during typical GC-based studies due to low abundance, poor resolution, inability to identify and/ or other factors. For example, GC analysis of the Macondo well oil from the Deepwater Horizon blowout, totaling 141 typical target analytes, could only account for $\sim 50 \%$ of the mass of the light crude.[2]

Comprehensive two-dimensional gas chromatography $(\mathrm{GC} \times \mathrm{GC})$ has allowed improved visualization and detection of 1400 GC-amenable compounds [3] that are useful for source apportionment, weathering profiles, and predicting biochemical response.[4] Yet, like one-dimensional GC, $\mathrm{GC} \times \mathrm{GC}$ is limited with regard to the analysis of compounds that have high boiling points or are thermally unstable or highly polar. Hence, these compounds present an unexplored fraction of oil that likely contains useful molecular tools for oil spill science. We define compounds that are not GC-amenable using traditional oil spill techniques, as those beyond the saturates, aromatics and several classes of heterocyclic aromatics typically examined. Here we use bulk and molecularlevel techniques to examine the compositional evolution of this fraction of a HFO from the M/V Cosco Busan spill which occurred in San Francisco Bay, CA.

Higher molecular weight (> $1000 \mathrm{Da}$ ) and polar compounds are often not detectable by traditional GC due to irreversible adhesion to GC-column stationary phases, limited mass-range of bench-top mass spectrometers, or incomplete volatilization at temperatures that preserve typical chromatographic columns $\left(<400^{\circ} \mathrm{C}\right)$. Polar species are especially problematic for GC-based techniques. These compounds have elevated boiling 
points due to uneven electron distribution within their covalent bonds.[1] Compounds containing electronegative heteroatoms such as $\mathrm{O}, \mathrm{N}$, and $\mathrm{S}$ are common in petroleum and contribute to electron imbalances and compound polarity. Consequently, many heteroatom-containing petroleum compounds are not detected with conventional oil spill characterization techniques and have received limited attention in past studies.

Polar compounds comprise less than $15 \%$ of crude oil by weight, yet are implicated in production and deposition problems at nearly every stage of crude oil production and refining.[5-7] Recalcitrance of these compounds within the refining process may be a predictor of their environmental stability.[5, 6, 8] Based on laboratory and time-series experiments using bulk measurements such as infrared spectroscopy, thin layer chromatography, gravimetric analysis and visual inspection, numerous studies have found that these compounds comprise the most recalcitrant fraction of petroleum [9-11] and can remain in the environment long after non-polar saturate and aromatic oil components have been removed or degraded.[10, 12] Detailed examination of polar petroleum compounds is generally overlooked in oil spill studies due to the difficulty associated with their characterization. However, release and chemical transformations of polar species may have implications for oil spill toxicity.[10, 13, 14] Fundamental knowledge of their environmental fate may be useful for source identification and forensics. Also, this fraction may allow detection and monitoring of oil weathering after saturate and aromatic compounds have been lost from the oil.

Heavy fuel oils (HFO) are of particular interest because they are enriched in non$\mathrm{GC}$ amenable species. On average, non-GC amenable components make up $40 \%$ of the mass of a HFO.[15] HFOs are prepared from high-boiling refinery residues combined with a lighter distillate (cutting oil) to reduce viscosity.[15, 16] HFOs are also of interest because of their extensive use to power marine vessels, creating high potential for accidental release.

While oil spill studies have relied primarily on GC and bulk analyses, scientists studying petroleum reservoirs have developed techniques to examine these typically overlooked compounds. Application of these techniques can aid in our understanding of 
oil spill weathering and forensics. Bulk measurements alone are insufficient to determine the environmental fate of non-GC amenable oil components; this requires molecular level information obtainable only by advanced analytical techniques.

Fourier transform ion cyclotron resonance mass spectrometry (FT-ICR MS) provides accurate mass measurement that is sufficient for elemental composition assignment for heavy petroleum fractions without prior separation.[17] The ultrahigh resolving power $\left(\mathrm{m} / \Delta \mathrm{m}_{50 \%}>400000\right.$, in which $\Delta \mathrm{m}_{50 \%}$ is the magnitude-mode mass spectral full peak width at half-maximum peak height) of FT-ICR MS allows baseline resolution of closely-spaced isobaric species. Sub-ppm mass accuracy (50-300 ppb rms error) enables molecular formulae assignment to the $>26,000$ species present in a heavy crude residue.[18] Although FT-ICR-MS has been used extensively to examine petroleum and petroleum products[6, 18-21], refinery deposits[5, 6, 22, 23] and changes due to various refinery operations [17, 22, 24-27], its application to environmental petroleum samples and processes has been limited.[8, 17, 28, 29]

In 2007, the carrier vessel M/V Cosco Busan released approximately 200,000 L of HFO into San Francisco Bay. Previous work on the Cosco Busan spill attributed compositional changes in the GC-amenable fraction to environmental weathering processes including evaporation/dissolution, biodegradation and photodegradation. Lemkau et al. (2010) characterized oil from three contaminated sites around San Francisco Bay by GC and reported dramatic losses of low molecular weight compounds eluting before $n-\mathrm{C}_{16}$, during the initial eleven weeks of weathering. Compound ratios indicative of evaporation/water washing, biodegradation, and photodegradation suggested that these processes were responsible for observed changes.[30] More recent work by Incardona et al., (2011) found unexpectedly high toxicity of this spill and suggested that this was the result of products formed through photochemical alteration of the non-GC amenable portion of oil.[31] The present work expands on our previous work by investigating weathering of the non-GC amenable fraction of this oil.

Here, we use traditional bulk techniques and ultrahigh resolution FT-ICR paired with negative ion atmospheric pressure photoionization (APPI; see supplemental 
information for a complete discussion on choice of ionization method) to study the nonGC amenable fraction of samples collected after the M/V Cosco Busan HFO spill. Samples for the current study were chosen based on weathering demonstrated by GC-FID analysis. The present work exploits similarities in the complex nature of dissolved organic matter and petroleum and combines data processing and reduction techniques from both the petroleum and dissolved organic matter fields to aid in data interpretation. Specific goals of this work are to: 1) characterize the parent HFO prior to environmental exposure, 2) monitor the molecular evolution of APPI-amenable compounds as a function of environmental exposure, 3 ) highlight the potential for this fraction to contain new molecular tools and 4) explore the benefits of collaborative use of GC and non-GC techniques to more fully understand oil composition and weathering.

\section{MATERIALS AND METHODS}

2.1. Sample Collection. Oil residues were scraped from a rocky shoreline along San Francisco Bay following the 2007 M/V Cosco Busan oil spill as described elsewhere.[30] The samples analyzed in the present study were collected from Shorebird Park (Berkeley, $\mathrm{CA}$; Figure S1) where significant and variable degrees of biodegradation and evaporation/water washing, and no significant photodegradation trends were observed.[30] Oil was scraped with a stainless steel spatula from coastal rocks and stored in combusted Al-foil envelopes. Samples were transported to Woods Hole, MA, frozen ($20^{\circ} \mathrm{C}$ ) and subsequently shipped to the National High Magnetic Field Laboratory in Tallahassee, FL. Six representative samples collected from 55 to 617 days post spill were analyzed in the current work. The unweathered parent HFO from Tank 4 was provided by the National Oceanic and Atmospheric Administration per chain-of-custody procedures.

\subsection{Bulk Analyses and Biomarkers}

2.2.1. Elemental Analysis. Elemental analysis was performed by Midwest Microlab, LCC (Indianapolis, IN). Oxygen content was determined via sample pyrolysis in the presence of purified carbon. To determine oxygen content, resulting $\mathrm{CO}$ gas was purified, 
oxidized to $\mathrm{CO}_{2}$, trapped and weighed. Oxygen content was measured to $+/-0.30 \%$. Analysis of carbon, hydrogen, and nitrogen content was performed using an elemental analyzer. Samples were pyrolized with ultra-pure oxygen in a closed system. Combustion products $\left(\mathrm{H}_{2} \mathrm{O}, \mathrm{CO}_{2}\right.$ and $\left.\mathrm{N}_{2}\right)$ were measured to determine elemental composition (+/$0.01 \%)$.

\subsubsection{Thin Layer Chromatography with Flame Ionization Detection (TLC-FID).}

TLC-FID was used to examine the composition of the operationally-defined saturate, aromatic, and polar fractions within the parent HFO and field samples. TLC-FID was performed on whole oil samples dissolved in dichloromethane. Stock solutions $(25 \mathrm{mg} / \mathrm{mL}$ in DCM) of the parent HFO and field samples were prepared. The parent HFO was used as a standard and run with each set of samples. Each sample was analyzed in triplicate. Samples $(0.3 \mu \mathrm{L})$ were applied to SIII chromarods (quartz rods with $0.9 \mathrm{~mm}$ silica film thickness; Shell-USA, Spotsylvania, PA). Rods were developed in $n$-hexane (31 $\mathrm{min}, \sim 10 \mathrm{~cm})$, toluene $(13 \mathrm{~min}, \sim 4 \mathrm{~cm})$ and dichloromethane/methanol $(97: 3 ; 4.5$ $\min , \sim 2 \mathrm{~cm}$ ) and analyzed on a MK-5 Iatroscan. Scan speed was set at $30 \mathrm{sec} / \mathrm{rod}$ and hydrogen and air flow rates were $160 \mathrm{~mL} / \mathrm{min}$ and $2.1 \mathrm{~L} / \mathrm{min}$ respectively.

2.2.3. High Temperature Simulated Distillation (HTSD). HTSD is a GC-based method that uses a specialized column and allows visualization of species with boiling points up to $750{ }^{\circ} \mathrm{C}$, typically not amenable to $\mathrm{GC}$ analysis.[32] This technique is not extensively used within oil spill studies and was performed to examine the boiling point range and composition of the parent HFO. Analysis was performed by Triton Analytics (Houston, TX) according to ASTM-D7169.

2.2.4. Biodegradation Indices. Biomarkers were measured by $\mathrm{GC} \times \mathrm{GC}-\mathrm{FID}$ with conditions similar to those previously described.[30] Compound class evolution was used to estimate biodegradation indices as done by Peters and Moldowen.[33, 34] Biomarker ratios were also used for source identification (Table S1). 


\subsection{FT-ICR MS Analysis}

2.3.1. Sample preparation. Stock solutions of parent HFO and field samples were prepared $(\sim 1 \mathrm{mg} / \mathrm{mL})$ in toluene. Stock solutions were further diluted 1:4 and analyzed with no additional modification. All solutions and samples were stored in amber glass vials to minimize photodegradation.

2.3.2. APPI. The APPI source and conditions have been described previously.[35] [36] Briefly, the tube lens was set at $50 \mathrm{~V}$ and the heated metal capillary kept at a current of 4.5 A to minimize fragmentation. Samples were injected $(50 \mu \mathrm{L} / \mathrm{min})$ into the heated vaporizer region $\left(300^{\circ} \mathrm{C}\right)$ of the APPI source with nitrogen as the sheath gas $(50 \mathrm{psi})$. A krypton vacuum ultraviolet gas discharge lamp (10 eV photons, $120 \mathrm{~nm}$ ) was used for photoionization. Toluene solvent acted as a dopant to increase ionization efficiency.[3538]

2.3.3. FT-ICR MS. Samples were analyzed on a custom-built 9.4 Tesla FT-ICR MS (Oxford Corp., Oxney Mead, U.K.) described in detail elsewhere.[39, 40] Ions were accumulated for 50-1000 ms and transferred to a 7-segment open cylindrical cell. Broadband frequency sweep (chirp) dipolar excitation $(700-70 \mathrm{kHz}$ at $50 \mathrm{~Hz} / \mu$ s sweep rate and $350 \mathrm{~V}_{\mathrm{p}-\mathrm{p}}$ amplitude) was followed by direct-mode image current detection to yield 8 MWord time-domain data sets. Individual time-domain transients $(80-200 ; 6.1$ sec each) for each spectrum were signal averaged, apodized with a full-Hanning (magnitude mode) or half-Hanning (absorption mode) weight function, and zero-filled once, prior to fast Fourier transformation. [41, 42] The time-signal did not dampen to zero during the acquisition period. Due to increased complexity at higher $m / z$, a broadband phase correction was applied to each mass spectrum to produce absorption-mode display with increased mass resolution.[42, 43]

2.3.4. Elemental Formula Assignment. Ion masses were calculated from ICR frequencies.[44] Experimentally measured masses were converted to the Kendrick mass 
scale and peak assignments made by Kendrick mass defect analysis[45] to identify homologous series for each heteroatom class (i.e., species with the same $\mathrm{C}_{\mathrm{c}} \mathrm{H}_{\mathrm{h}} \mathrm{N}_{\mathrm{n}} \mathrm{O}_{\mathrm{o}} \mathrm{S}_{\mathrm{s}}$ content, differing only by degree of alkylation).[46] Each FT-ICR mass spectrum was internally calibrated with respect to an abundant homologous series confirmed by isotopic fine structure based on the "walking" calibration.[23] Elemental composition for formula assignment was limited to ${ }^{12} \mathrm{C},{ }^{13} \mathrm{C},{ }^{1} \mathrm{H},{ }^{16} \mathrm{O},{ }^{14} \mathrm{~N},{ }^{32} \mathrm{~S}$ and ${ }^{34} \mathrm{~S}$. Elemental ratios were calculated as weighted averages using relative abundance data.[47] All ions were singly charged, as evident from the unit $m / z$ spacing between species differing by ${ }^{12} \mathrm{C}_{c}$ vs. ${ }^{13} \mathrm{C}_{1}{ }^{12} \mathrm{C}_{c-1}$.

2.3.5. Multivariate Statistics. Compositional differences among samples were assessed using cluster analysis as described by Kujawinski et al.[48] Relative peak heights were transformed to presence (peak height $=1$ ) or absence $($ peak height $=0)$. Presence/absence and unaltered relative abundance data were processed independently. Because many factors influence the number of peaks detected at six times the baseline rms noise (i.e. MW distribution, intensity and number of noise peaks and ions within ICR cell etc.), both data sets were normalized to the total number of $m / z$ values for each spectrum. Distances between field samples and the parent HFO were calculated with the Bray-Curtis distance measure (code written by David Jones, University of Miami, as part of the Fathom toolbox)[49] and cluster analysis was performed using Ward's linkage method.

We restricted our analysis to monoisotopic data with assigned elemental formulas (mass error $<100-300 \mathrm{ppb} ; 50-60 \%$ of total detected peaks) to mitigate the impact of ionization efficiency on detection of heavy isotopomers and electronic noise peaks. Heavy isotopes are present in petroleum samples, as dictated by stable isotope abundances in nature. These species are chemically identical to monoisotopic species and are therefore not considered in the current analysis. In addition, noise can be highly variable between samples and the number and prominence of these peaks can affect the detection of lower abundance species (such as heavy isotopomers). Here, we restrict our 
analyses to the most abundant chemical species, i.e. the monoisotopic species, and remove variability associated with ion detection and noise.

2.3.6. Indicator Species Analysis (ISA). ISA, adapted from Dufrene and Legendre [50], was used to determine indicator $m / z$ values for chosen sample groups. Indicator values (IVs), calculated as the product of relative abundance and relative frequency within a predefined group, range from 0 to 100 . High IVs indicate species present at high relative abundance and occurring in most (if not all) samples within each group. Calculated IVs were compared to Monte-Carlo simulations of randomized data to determine statistical significance.

This analysis requires a priori assignment of samples to groups. Samples were assigned to groups based on their similarity as determined by distance along the hierarchical cluster diagram. Groupings resulting in the largest number of indicator values (greatest \# of species defining the chosen groups) and the lowest average p value (highest confidence) determined the optimal group assignments.[51] For our relative abundance and presence/absence data, this resulted in three groups: Group $1=0,55,139$ and 296 days; Group $2=402$, and 511 days; and Group $3=617$ days. Indicator species for presence/absence and relative abundance data sets were determined based on these optimal group assignments. Indicator species for the chosen group assignments were then culled according to criteria described in Kujawinski et al.[48]

\section{RESULTS AND DISCUSSION}

3.1. Bulk Analyses. Elemental analysis supports an increased prominence of heteroatomcontaining species with weathering (Table 1). The nitrogen content of samples increases slightly from parent HFO values but remains relatively constant with extended environmental exposure. Sulfur content does not change markedly from parent HFO values. The largest change across the sample set is the increase in oxygen content with environmental exposure. By 617 days post spill, the oxygen content of the oil triples, consistent with environmental oxidation from biotic/abiotic (photochemical) 
processes.[10, 52, 53] Loss of non-oxygen-containing species may also contribute to the observed change in oxygen content. However, overall compound loss $(2.6 \%$, estimated in Chapter 3 ) can only account for a $<0.1 \%$ increase in oxygen content (assuming all compounds lost are non-oxygen containing species). The observed increase in oxygen content is much larger and suggests that extended environmental weathering results in a higher abundance of polar species.

The one exception to these observed trends is the 139 day sample. This sample has nearly double the oxygen content of the 617 day sample suggesting that it has undergone environmental oxidation. This unexpectedly high oxygen value is likely due to the discrete and environmental nature of our samples and may be the result of water contamination introduced during sample collection. Although water may be affecting all of our samples, the 139 day sample appears to fall outside of general oxygen trends observed, suggesting it is impacted to a larger extent than other samples.

TLC-FID analysis also supports an increased prominence of polar species with weathering. To determine the amount (weight \%) of polars within the parent HFO and field samples as a function of time, TLC-FID was used to separate and measure the relative abundance of saturates, aromatics and polars within our samples.

Saturate, aromatic, polar content (weight \%) for the parent HFO and field samples as a function of time are presented in Table 1. Overall, an increase in the amount of polar material and a decrease in saturates and aromatics was observed with time. Polar compounds are operationally defined as those not migrated on a TLC-FID rod by hexane and toluene. Polar components account for $36 \%$ the total mass of the parent HFO; however, after 296 days this fraction increases to $65 \%$ of the total mass. After 617 days, $78 \%$ of the total mass of petroleum is polar in nature.

The continuing increase in the relative abundance of polar content through 617 days suggests sample composition is changing even at this later stage of weathering. Much of this increase is likely due to the loss of lower-molecular-weight saturate and aromatic compounds; [30] however, polar compounds may be formed from LMW saturate and aromatic fractions, too. Previous work proposed conversion of aromatic compounds 
to more polar species through photo- and biodegradation.[10, 52, 54] Mechanistic studies on environmental weathering processes are beyond the scope of this work. However, trends observed within this data are consistent with this proposed conversion.

High-temperature simulated distillation of the parent HFO provides weight percent composition of oil as a function of boiling point. On a non-polar column, 15, 25 and $50 \%$ of the injected mass eluted before $n-\mathrm{C}_{18}, n-\mathrm{C}_{22}$ and $n-\mathrm{C}_{32}$ respectively (Figure 1). Only $\sim 63 \%$ of the mass was detectable using traditional GC-FID techniques, highlighting the necessity for alternative methods to examine the non-GC amenable fraction.

Samples were also categorized according to the Peters and Moldowen biodegradation scale.[34] This scale was developed for use in oil reservoirs and uses the presence/absence of common compounds to examine its overall biodegradation.

Although this is not an accurate scale for environmental weathering outside of a reservoir where processes other than biodegradation may play a role, it is a common metric that allows comparison with past studies (Table 1).[34, 55] Generally, the most weathered samples are more biodegraded, according the Peters and Moldowen biodegradation scale, and have higher oxygen content than earlier samples. The biodegradation index for the 139 day sample is consistent with expected weathering trends and suggests biodegradation is not responsible for the unexpectedly high oxygen content of this sample.

In summary, an increase in the polar fraction with time was observed. To understand the alterations taking place on a molecular level and to achieve a more complete understanding of how this fraction is affected by weathering processes, we take advantage of the ultrahigh mass resolution and accuracy of FT-ICR MS.

3.2. FT-ICR MS. FT-ICR MS is a molecular-level technique that can detect tens of thousands of compounds within a sample. Because of the immense datasets generated by this method, automated data processing and visualization techniques are critical for data interpretation. We examined samples from the M/V Cosco Busan spill, combining the 
visualization techniques and broad overview approach of the petroleum industry with multivariate statistical tools.

3.2.1 Broadband Mass Spectral Evolution with time. The broadband negative-ion APPI FT-ICR mass spectra of the parent HFO and our field samples are presented in Figure 2a. The observed bimodal distribution centered at $\mathrm{m} / \mathrm{z}, 300$ and 600 and is likely due to the blended nature of HFO with light distillates to reduce viscosity.[56] With increased environmental weathering, broadband spectra of samples show a clear shift to lower molecular weight, suggesting a qualitative change in composition over time.

Mass-scale expanded segments for both the parent HFO and samples collected 139 and 511 days post spill (representing Groups 1 and 2 used for ISA analysis) demonstrate increased relative abundance and compositional complexity in the lower $\mathrm{m} / \mathrm{z}$ region and decreasing complexity in the higher $\mathrm{m} / \mathrm{z}$ region with increased weathering (Figure $2 b-c)$. In the lower mass region, weathering results in a $100 \%$ increase in the number of detected species per Da, with an increase from 25 peaks per Da in the parent HFO to $~ 50$ peaks in the 511 day sample. At higher molecular weights, a nearly $50 \%$ decrease in peaks per Da is observed with $\sim 30$ peaks decreasing to $\sim 15$ peaks in later samples. The detection of species not native to the parent HFO, most of which contain oxygen, agrees with previous studies[28] and is supported by results from ISA and bulk analyses.

3.2.2. Multivariate Statistics. Our first approach to examine compositional changes that occur between the samples over time was statistical. Cluster analysis allows examination of the relationship between samples based on the detected peaks within each sample. We compared samples using peak-number normalized presence/absence and relative abundance data (Figure 3). In the presence/absence data transformation, all $\mathrm{m} / \mathrm{z}$ values have equal weight so that variability among samples is driven by $m / z$ diversity alone. In contrast, variability in the relative abundance data is determined by a combination of $\mathrm{m} / \mathrm{z}$ value and (relative) peak height. Cluster analysis of these data sets produces identical 
groupings, indicating that peak diversity (rather than relative abundance) is the dominant differentiator among our samples.

All cluster analyses showed a temporal separation among our samples, with a general decreasing similarity to the parent HFO with increased environmental exposure. This confirms our observation that increased weathering results in fewer shared peaks with the parent HFO (Table S2) and is consistent with prior GC-FID analyses[30] and current understanding of oil weathering.

3.2.3. Indicator Species Analysis. ISA was performed to determine which $m / z$ values drive the major groupings identified by cluster analysis. ISA of presence/absence data resulted in 3284 indicator species for Group 1 and 5 indicator species for Group 2. Indicator species for Group 1 are higher in molecular weight than Group 2 indicators. Group 1 indicator species have an average $\mathrm{m} / \mathrm{z}$ of $860 \pm 104$ (one standard deviation) while Group 2 indicator species have an average $\mathrm{m} / \mathrm{z}$ of $441 \pm 102$. Analysis of relative abundance data yielded 3707 and 142 unique indicator species for Groups 1 and 2 respectively. Similar differences in molecular weight as those observed in the presences/absences ISA, were present between the two groups. All Group 1 and Group 2 indicator species identified by ISA of the presence/absence data set were also identified as Group 1 and Group 2 indicator species using the relative abundance data set.

The indicator species in both data treatments indicate that high molecular-weight compounds in the HFO determine the differences between Groups 1 and 2. In the presence/absence ISA, the indicator species in each group are unique to that group, suggesting that compound loss from the HFO is responsible for compositional change between the two groups. In contrast, the indicator species identified using relative abundance data are present in many, if not all, samples and their distinction as indicator species is driven by their greater relative abundance in later samples; this is especially true for Group 2 indicator species, most of which are present in all of the earlier Group 1 samples (Figure 2b-c). 
These trends indicate a loss of higher carbon number species with time and an increased abundance and diversity of lower carbon number species with weathering. There is no evidence that observed losses of higher compound species are due to physical processes. The increase in lower molecular weight species could be interpreted either as the result of compound formation with weathering or increased ionization of these compounds as other species are removed.

Indicator species identified within the presence/absence data set show trends consistent with increased environmental oxidation. From Group 1 to Group 2 the percent of indicator species containing oxygen increases, as does the oxygen content and aromaticity of these oxygen-containing species (Table 2). Examining all indicator species (including those not containing oxygen) results in similar trends. This increasing oxygen content is consistent with the trends observed in bulk elemental analysis. Indicator species identified within the relative abundance data set show similar trends; oxygencontaining indicator species for Group 2 have higher oxygen content and increased aromaticity compared to oxygen-containing indicator species for Group 1 (Table 2).

These results support the increased relative abundance of oxidation products through environmental weathering. $\mathrm{H} / \mathrm{C}$ ratios suggest increased aromaticity with time, consistent with dealkylation of larger aromatic structures or formation of aromatic species with weathering. These trends underscore the need for more in-depth compositional analysis and for further investigation of oxygen-containing classes.

3.2.4. Heteroatom Class Distribution. Within the petroleum industry, heteroatom distribution is often used to examine sample compositions. Using determined molecular formulas, samples are broken down into compounds containing specific heteroatoms. For example, compounds containing one nitrogen atom are termed the $\mathrm{N}_{1}$ class, while compounds containing one nitrogen and two oxygen atoms are grouped into the $\mathrm{N}_{1} \mathrm{O}_{2}$ class.

For the parent HFO, compounds containing one nitrogen atom $\left(\mathrm{N}_{1}\right.$ class) were the most abundant, followed by the $\mathrm{O}_{1}, \mathrm{~N}_{1} \mathrm{O}_{1}$ and $\mathrm{O}_{2}$ classes (Figure 4a). Assuming similar 
ionization efficiencies of compound classes across samples (i.e., minimal matrix effects), observed changes across heteroatom classes reveal trends with increased environmental exposure. Because relative abundances are normalized within each sample but not across samples, observed trends must be interpreted with caution. Decreasing trends can easily be caused by an increase in species with higher ionization efficiencies (such as oxygencontaining compounds); however, increasing trends, especially of oxygen compounds with high ionization efficiencies, more reliably indicate real changes in a given class. Comparison of observed trends with elemental analysis can aid in confirming real trends in compositional changes.

A unique aspect of this study was that we analyzed the parent HFO in triplicate. This allowed determination of sample variability between measurements and subsequently, the identification of trends resulting in changes outside this variability. Based on the precision of triplicate analysis of the parent HFO, two statistically significant trends are apparent in the heteroatom class distribution: decreasing $\mathrm{N}_{1}$ and increasing $\mathrm{O}_{2}$ content. Weaker, statistically insignificant decreasing trends are observed within the $\mathrm{O}_{1}, \mathrm{~N}_{1} \mathrm{O}_{1}, \mathrm{HC}$, and $\mathrm{N}_{2}$ classes with time. Sulfur-containing classes $\left(\mathrm{S}_{1}, \mathrm{~S}_{1} \mathrm{O}_{1}\right.$ and $\mathrm{S}_{1} \mathrm{O}_{2}$ ) remain relatively unchanged with increased exposure. The decrease in $\mathrm{N}_{1}$ content is observed only within the last sample and is inconsistent with the elemental analysis in which a slight increase in $\mathrm{N}$ content is measured. If this decrease is the result of biodegradation, we would expect to see the $\mathrm{N}_{1}$ class double bond equivalent (DBE; defined as the number of rings plus double bonds to carbon)[57] distribution shift towards higher DBE with time and/or formation of NO intermediates. [8] No such changes are evident (Figure S3), suggesting that the observed decrease in $\mathrm{N}_{1}$ content is due to the increase in more efficiently ionized $\mathrm{O}_{2}$ species.[8, 28]

Because of their higher ionization efficiencies, oxygen-containing species are less sensitive to changes within other compound classes. $\mathrm{O}_{2}$ species increase from $\sim 5$ to $\sim 13 \%$ across our time series. Because of the observed increase in relative abundance of the $\mathrm{O}_{2}$ class and in the number of oxygen-containing species determined to be indicator species 
for later samples, we examined the oxygen-containing classes in greater detail (Figure 4b).

Weathered samples show higher relative abundance and diversity of oxygencontaining species than does the parent HFO. $\mathrm{S}_{1} \mathrm{O}_{5}, \mathrm{~N}_{1} \mathrm{O}_{5}$ and $\mathrm{O}_{5}$ species are all present in the final sample of the time series but absent in the parent HFO. This increase in multiheteroatomic classes and polarity with weathering is consistent with trends observed in previous studies examining distillate cuts from heavy crude and bitumen.[18, 19, 58] As the $\mathrm{N}_{1}$ class decreases with time, so does the $\mathrm{N}_{1} \mathrm{O}_{1}$ class; however, more oxygenated nitrogen classes increase with time. Similar increases are observed in the $\mathrm{O}_{x}$ and $\mathrm{S}_{1} \mathrm{O}_{\mathrm{x}}$ classes with time.

The loss of $\mathrm{O}_{1}$ compounds corresponds to a relative increase in the presence of $\mathrm{O}_{2}$ compounds, a trend consistent with the oxidation of alcohols to form acids.[28] If such a process is occurring, a corollary relationship between $\mathrm{O}_{1}$ and $\mathrm{O}_{2}$ heteroatom classes would be expected. Using a log-log plot, the correlation for our data is much weaker than that observed by Hughey et al. (2008) ( $\mathrm{r}^{2}$ correlation coefficient of $0.47 \mathrm{vs} 0.88$ ). This could be due to our smaller sample set, the discrete nature of our samples, or the presence of other processes affecting the $\mathrm{O}_{1}$ and $\mathrm{O}_{2}$ heteroatom class relative abundances (i.e., matrix effects between samples or photodegradation processes).

\subsubsection{Compositional Differences among Weathered Samples. To examine}

compositional differences as a function of environmental exposure, we compared experimental DBE and carbon number distributions of selected heteroatom classes for the parent HFO and the field samples. Because we can only examine the relative abundance changes within each sample, the figures illustrate compositional shifts within APPIamenable compounds but may not reflect quantitative changes within the total sample.

$\mathbf{N}_{1}$ Class. Examining the most abundant $\mathrm{N}_{1}$ class (Figure 5), the parent HFO shows a continuous distribution of compounds ranging from 19 to 84 carbons, with neutral species DBEs from 8 to 33. The compositional makeup is dominated by a well-defined 
maximum, as indicated by the red in Figure 5a, and is termed a "core" structure. This point represents the most abundant compositional makeup in the parent $\mathrm{HFO}\left(\mathrm{C}_{45}, \mathrm{DBE}\right.$ 14; Table 3). From this core structure, changes in alkylation result in the observed spread in carbon numbers (more and less alkylated), while changes in aromaticity from this central structure result in compounds spanning the observed DBE range of the sample. By 617 days, the abundance-weighted average carbon number (hereafter referred to as average carbon number) decreases from 49 to 32 , indicating the loss of $\sim 17$ carbon atoms per structure. The abundance-weighted average DBE (hereafter referred to as average DBE) also decreased with time (16 in the parent HFO to 15 in our final sample). After only 55 days, several local maxima are present, most notably at neutral species DBEs of 13 and 16.

Preservation of compounds with specific DBE and carbon number ranges (such as those observed at $\mathrm{C}_{20}$ DBE 13, $\mathrm{C}_{23}$ DBE 16 and $\mathrm{C}_{34}$ DBE 13; Table 3) through the timeseries suggests that these formulas represent more environmentally stable structures and that weathering results in removal or transformation of less environmentally-stable structures. These preserved structures are highly aromatic and approach the planar-limit line (the aromaticity ceiling for a given carbon content for which a planar structure is still possible), consistent with non-alkylated nitrogen-containing PAH structures. The observed three DBE jump between stable DBE maxima indicates that preferentially preserved DBEs are related by the addition or subtraction of a fused aromatic ring to an already aromatic system (change of three DBE). These trends are consistent with an increase in relative abundance of aromatic species and with dealkylation over time.

Hydrocarbon (HC) Class. Although HCs comprise a large fraction of all oils, they have relatively low ionization efficiencies. Thus only the most acidic $\mathrm{HC}$ species that can stabilize a negative charge or radical (such as fluorene, where removal of a proton results in formation of a stable aromatic anion) will be detected using negative ion APPI. The parent HFO HC class shows a broad compound distribution with neutral species DBEs from 9 to 32 with 23 to 88 carbon atoms (Figure 6). Two apparent maxima are observed 
at $\mathrm{C}_{26}$ and $\mathrm{C}_{36}-\mathrm{C}_{56}$, both centered at a DBE of 17 (Table 3). The maxima along the planar limit line is consistent with a high content of PAHs with little or no alkyl substitution.[59] The parent HFO PAH content is consistent with a relatively aromatic HFO, likely from the No. 2 fuel oil used to cut the M/V Cosco Busan cargo fuel.[15, 56] With increased environmental exposure, the average carbon number and DBE of compounds that are present decrease. As in the $\mathrm{N}_{1}$ class, we see the development of relative maxima at specific carbon numbers $\left(\mathrm{C}_{21}\right.$ and $\left.\mathrm{C}_{24}\right)$ and DBEs (13 and 16, respectively), which suggest the presence of environmentally stable core structures, again, related by the addition or loss of a fused aromatic ring.

$\mathbf{O}_{1}$ Class. Within the parent HFO, compounds range from 15 to 82 carbons, with neutral species DBEs between 5 and 31 (Figure 7). There is one primary maximum centered at $\mathrm{C}_{50}$ with neutral species DBE values from 5 to 23 (Table 3). As seen in other classes, with increased environmental exposure we see a concomitant decrease in average carbon number and a concentration around specific DBEs. There is also a shift in compositions towards the planar limit line. These results are consistent with increased aromaticity and decreased alkylation. The distribution observed in the parent HFO is carried forward through the samples, and there is a gradual shift in relative abundance towards the maxima along the planar limit line. By 617 days post spill, nearly all peaks within region of the second maxima have been either removed from the sample or transformed to non$\mathrm{O}_{1}$ compounds.

$\mathbf{O}_{2}$ Class. The $\mathrm{O}_{2}$ class shows the most reliable changes in relative abundance across our sample set (Figure 4). Compound distributions within the $\mathrm{O}_{2}$ class for the parent $\mathrm{HFO}$ range from 14-80 carbon atoms with neutral species DBEs from 2 to 31 (Figure 8). The parent $\mathrm{HFO}$ has relative abundance maxima at $\mathrm{C}_{24}$ (DBE of 2) and approximately $\mathrm{C}_{40}$ to $\mathrm{C}_{52}$ (DBE of 16; Table 3). With environmental exposure, the average carbon number and DBE of $\mathrm{O}_{2}$ class compounds decreases, indicating a reduced alkylation and aromaticity. The DBE max at 2 becomes more prominent with time, indicative of stable structures 
either formed or preferentially preserved within our samples. This maximum corresponds to a particular group of compounds called naphthenic acids.

Naphthenic acids are naturally-occurring alkyl-substituted saturated cyclic and non-cyclic carboxylic acids that are of interest because of their environmental recalcitrance,[8] potential toxicity[13] and role in emulsion stabilization.[60] Naphthenic acids form ionic bonds with ions in the environment to form naphthenates. The naphthenic acids within our samples are consistent with sodium naphthenates, monoprotic carboxylic acids characterized by low DBEs and ranging from 15-35 carbon atoms.[5] Typically, sodium naphthenates are defined with a DBE of 1; however, the naphthenic acid species within our samples are slightly more aromatic with a minimum DBE value of 2 .

Defining naphthenates as $\mathrm{O}_{2}$ species with low DBE values (DBE from 1-2), we can examine the changes in relative abundance of these compounds alone (as distinct from the $\mathrm{O}_{2}$ class as a whole shown in Figure 4). In the parent HFO, the naphthenates comprise $5.5 \%$ (by relative abundance) of the $\mathrm{O}_{2}$ class $(0.3 \%$ relative abundance of all detected species). This percentage increases as the sample exposure increases; at 617 days the naphthenates comprise over $40 \%$ of detected species in the $\mathrm{O}_{2}$ class $(2.8 \%$ of all species detected). While we cannot quantify the naphthenic acids in the present work, their increasing relative abundance with time is in agreement with observations of Hughey et al. (2008).[28] The nearly 10 fold increase in relative abundance of these species with environmental exposure supports their recalcitrance in natural systems.

Knowledge of these compounds may have implications for oil spill remediation $[5,6,61,62]$ and for identifying sources of severely weathered oils. [5, 28, 63] Kim et al., (2005) proposed the ratio of acyclic $(\mathrm{DBE}=1)$ to $1-3$ ring cyclic $(\mathrm{DBE}=2$ to 4$)$ naphthenic acids (A/C ratio) as a weathering indicator.[8] This ratio decreases with increasing biodegradation as the acyclic naphthenic acids are consumed more quickly than those with cyclic moieties. Weathering indicators are developed to allow standard measures of weathering across all types of spills and environmental settings. Because naphthenic acids within our oil are more aromatic $(\mathrm{DBE}=2)$ this ratio cannot be used 
here. A slight modification of this ratio for the current oil, such that we define a weathering ratio using monocyclic $(\mathrm{DBE}=2)$ over di- and tricyclic $(\mathrm{DBE}=3$ to 4$)$ or dithrough tetracyclic (DBE $=3$ to 5), reveals no apparent trend with time (Figure S3). Previous work calculated the $\mathrm{A} / \mathrm{C}$ ratio for crude oil samples, whereas the HFO studied here underwent refining which may impact compounds used in the $\mathrm{A} / \mathrm{C}$ ratio making it inaccurate for use on this spill.

\section{BRINGING TECHNOLOGIES TOGETHER: A MORE COMPLETE PICTURE}

Use of APPI FT-ICR MS alone is insufficient for developing a complete picture of the evolution of oil subsequent to a spill. Negative ion APPI selects for aromatic and polar compounds that can form radical molecular ions or anions, so compounds that cannot be photoionized (including alkanes and branched alkanes) will not be detected. In addition, lower molecular weight compounds are generally not detectable in the same analysis as the higher molecular weight compounds examined here. Thus, although this technique allows an unprecedented look into a particular fraction of an oil sample, it fails to detect many other compounds within the oil. Combining multiple ionization methods and alternative approaches (such as traditional GC techniques) provides our best option to achieve comprehensive understanding of how oil changes when it enters the environment.

Because of their high molecular weight and polarity, these compounds are not significantly affected by evaporation and dissolution; instead, biodegradation and photodegradation will likely be the dominant processes affecting the non-GC amenable oil fraction. The general decrease in carbon number observed with time is consistent with previous investigations of the impact of biodegradation on petroleum samples by FT-ICR MS.[8] Kim et al. examined biodegradation trends on a geologic timescale by looking at genetically related reservoirs with differing degrees of degradation. The present study provides evidence that similar dealkylation trends occur on a much shorter timescale in non-GC amenable species from environmentally exposed samples. Signs of biodegradation beginning approximately one month after the spill were also seen in $n$ $\mathrm{C}_{18}$ /phytane ratios obtained from GC analysis of our field samples.[30] The time series 
presented here covers a much longer time span than previously explored for this spill,[30] and weathering impacts are still observed 617 days post spill. FT-ICR MS signatures allow us to see trends consistent with biodegradation long after pristane and phytane and their associated $n$-alkanes have been removed. Such alteration of non-GC amenable compounds on this timescale indicates that this is a dynamic fraction of the oil that should be explored in greater detail in relation to long-term toxicity.

Photooxidation preferentially affects the more alkylated aromatic compounds and results in reduction of these highly alkylated aromatics.[10,52] This weathering pattern is seen in all examined compound classes. The observed increase in relative abundance of the $\mathrm{O}_{2}$ class is also consistent with carboxylic acid formation through photodegradation.[52, 64] Previous GC-based work on this spill revealed no significant photodegradation at this field site.[30] However, because of the greater absorption of environmentally relevant wavelengths of larger aromatic structures, the HMW and more aromatic fraction of the oil examined here are likely more susceptible to photodegradation than are the LMW PAHs previously examined.[65] Photodegradation is thought to have played a role in the unexpected toxicity of this spill,[31] and access to the non-GC amenable species examined here has the potential to aid in detection and identification of compounds contributing to oil spill toxicity.

Biomarker indices analyzed by $\mathrm{GC} \times \mathrm{GC}$ showed no signs of degradation even with the strong dealkylation and oxidation trends observed within the non GC-amenable fraction via FT-ICR MS. These biomarkers are a proven method of linking an oil spill source to relevant environmental impacts; this work demonstrates their relative stability compared with many GC and non-GC amenable oil components.

Coupled analysis by GC and FT-ICR MS provide evidence that a zone of stable compounds likely remain in the environment for years after a spill. Prior research using GC-based techniques has shown complete losses of LMW species through $\sim n$-C16, with decreasing losses of larger compounds.[30] However, the work here shows the opposite trend, with preferential losses of the largest and most alkylated species with time. These two different weathering trends provide evidence for a stable fraction of oil in the 
overlapping analytical windows of these technologies. In addition to providing insights into weathering as discussed here, this overlap may aid integration of these techniques and in the development of quantitative FT-ICR MS methods in the future.

\section{CONCLUSIONS}

TLC-FID analysis of field samples collected after the M/V Cosco Busan oil spill show an increasing prominence of the polar fraction with time. An increase in diversity and relative abundance of oxygen-containing compounds is observed across the sample set as well as a progressive loss of higher carbon number species as aromatic core structures are dealkylated to form condensed PAH structures. Concentration over time of compounds around specific DBE core structures could result from increased ionization efficiencies or from the formation or preferential preservation of environmentally stable structures, including environmentally recalcitrant naphthenic acids.[28] These compounds may prove useful as molecular tools for source identification and weathering and highlight the potential of this understudied oil fraction to contribute new tools for future oil spill investigations. Observed changes suggest that environmental weathering processes such as biodegradation and photodegradation affect this non-GC amenable oil fraction. Coupled with previous studies, this research suggests that environmental weathering results in removal or alteration of larger alkylated compounds as well as loss of lower molecular weight species through evaporation/dissolution, bio and photo degradation, with a resultant fraction of stable compounds likely to remain in the environment years after the spill.

\section{ACKNOWLEDGEMENTS}

I would like to thank Amy M. McKenna, David C. Podgorski, Ryan P. Rodgers, Alan G. Marshall, Elizabeth B. Kujawinski, and Christopher M. Reddy, who will be co-authors on the submitted version of this manuscript. The authors thank Krista Longnecker and Maya Bhatia for their assistance in answering questions and for creating the Matlab code used 
for the cluster and ISA analysis. We also thank Bob Nelson for help with the biomarker analyses, John P. Quinn for maintenance of the 9.4 Tesla instrument, Christopher L. Hendrickson for help in optimization of instrument parameters and Jade Velasquez for help in data visualization. This work was supported by WHOI academic program funds, the Coastal Ocean Institute and NSF grants EAR-0950670 and OCE-0960841. National High Magnetic Field Laboratory work was supported by NSF Division of Materials Research through DMR-06-54118, NSF CHE-10-49753 (RAPID) and the State of Florida.

\section{REFERENCES}

1. McNair, H.M. and Miller, J.M., Basic Gas Chromatography. 2nd ed. 2009, Hoboken, New Jersey: John Wiley \& Sons, Inc. 239.

2. Reddy, C.M., Arey, J.S., Seewald, J.S., Sylva, S.P., Lemkau, K.L., Nelson, R.K., Carmichael, C.A., McIntyre, C.P., Fenwick, J., Ventura, G.T., Van Mooy, B.A.S., and Camilli, R., Composition and fate of gas and oil released to the water column during the Deepwater Horizon oil spill. Proceedings of the National Academy of Sciences, 2011.

3. Wardlaw, G.D., Arey, J.S., Reddy, C.M., Nelson, R.K., Ventura, G.T., and Valentine, D.L., Disentangling oil weathering at a marine seep using GCxGC: broad metabolic specificity accompanies subsurface petroleum biodegradation. Environmental Science \& Technology, 2008. 42(19): p. 7166-7173.

4. Tcacuic, A.P., Nelson, R.K., Reddy, C.M., and Gschwend, P.M., Estimating phospholipid membrane-water partition coefficients using comprehensive twodimensional gas chromatography. Environmental Science \& Technology, 2012.

5. Mapolelo, M.M., Stanford, L.A., Rodgers, R.P., Yen, A.T., Debord, J.D., Asomaning, S., and Marshall, A.G., Chemical speciation of calcium and sodium naphthenate deposits by electrospray ionization FT-ICR mass spectrometry. Energy \& Fuels, 2009. 23(1): p. 349-355.

6. Mapolelo, M.M., Rodgers, R.P., Blakney, G.T., Yen, A.T., Asomaning, S., and Marshall, A.G., Characterization of naphthenic acids in crude oils and naphthenates by electraspray ionization FT-ICR mass spectrometry. International Journal of Mass Spectrometry, 2011. 300(2-3): p. 149-157. 
7. Kane, R.D. and Cayard, M.S., Understanding critical factors that influence refinery crude corrosiveness. Materials Performance, 1999. 38(7): p. 48-54.

8. Kim, S., Stanford, L.A., Rodgers, R.P., Marshall, A.G., Walters, C.C., Qian, K., Wenger, L.M., and Mankiewicz, P., Microbial alteration of the acidic and neutral polar NSO compounds revealed by Fourier transform ion cyclotron resonance mass spectrometry. Organic Geochemistry, 2005. 36(8): p. 1117-1134.

9. Boukir, A., Aries, E., Guiliano, M., Asia, L., Doumenq, P., and Mille, G., Subfractionation, characterization and photooxidation of crude oil resins. Chemosphere, 2001. 43(3): p. 279-286.

10. Maki, H., Sasaki, T., and Harayama, S., Photo-oxidation of biodegraded crude oil and toxicity of the photo-oxidized products. Chemosphere, 2001. 44(5): p. 1145-1151.

11. Saeed, T., AlBloushi, A., and AlMatrouk, K., Kuwait oil lakes: composition of the oil and effects of weathering. Arabian Journal for Science and Engineering, 1997. 22(1B): p. 51-61.

12. Wang, Z.D., Fingas, M., and Sergy, G., Study of 22-year-old Arrow oil samples using biomarker compounds by GC/MS. Environmental Science \&amp; Technology, 1994. 28(9): p. 1733-1746.

13. Clemente, J.S. and Fedorak, P.M., A review of the occurrence, analyses, toxicity, and biodegradation of naphthenic acids. Chemosphere, 2005. 60(5): p. 585-600.

14. Vrabie, C.M., Sinnige, T.L., Murk, A.J., and Jonker, M.T.O., Effect-directed assessment of the bioaccumulation potential and chemical nature of Ah receptor agonists in crude and refined oils. Environmental Science \& Technology, 2012.

15. Uhler, A.D., Stout, S.A., and Douglas, G.S., Chemical heterogeneity in modern marine residual fuel oils, in Oil Spill Environmental Forensics: Fingerprinting and Source Identification, Z. Wang and S.A. Stout, Editors. 2007, Academic Press: Boston. p. 327-348.

16. Boduszynski, M.M., Composition of heavy petroleums. 1. Molecular-weight, hydrogen deficiency, and heteroatom concentration as a function of atmospheric equivalent boiling point up to $1400{ }^{\circ} \mathrm{F}\left(760^{\circ} \mathrm{C}\right)$. Energy \& Fuels, 1987. 1(1): p. 2-11.

17. Rodgers, R., Blumer, E.N., Freitas, M.A., and Marshall, A.G., Complete compositional monitoring of the weathering of transportation fuels based on elemental compositions from Fourier transform ion cyclotron resonance mass spectrometry. Environmental Science \& Technology, 2000. 34(9): p. 1671-1678. 
18. McKenna, A.M., Blakney, G.T., Xian, F., Glaser, P.B., Rodgers, R.P., and Marshall, A.G., Heavy petroleum composition. 2. Progression of the Boduszynski model to the limit of distillation by ultrahigh-resolution FT-ICR mass spectrometry. Energy \& Fuels, 2010. 24: p. 2939-2946.

19. McKenna, A.M., Purcell, J.M., Rodgers, R.P., and Marshall, A.G., Heavy petroleum composition. 1. Exhaustive compositional analysis of Athabasca bitumen HVGO distillates by Fourier transform ion cyclotron resonance mass spectrometry: a definitive test of the Boduszynski model. Energy \& Fuels, 2010. 24: p. 2929-2938.

20. Hsu, C.S., Dechert, G.J., Robbins, W.K., and Fukuda, E.K., Naphthenic acids in crude oils characterized by mass spectrometry. Energy \& Fuels, 2000. 14(1): p. 217-223.

21. Schrader, W., Panda, S.K., Brockmann, K.J., and Benter, T., Characterization of non-polar aromatic hydrocarbons in crude oil using atmospheric pressure laser ionization and Fourier transform ion cyclotron resonance mass spectrometry (APLI FTICR MS). Analyst, 2008. 133(7): p. 867-869.

22. Klein, G.C., Kim, S., Rodgers, R.P., Marshall, A.G., and Yen, A., Mass spectral analysis of asphaltenes. II. Detailed compositional comparison of asphaltenes deposit to its crude oil counterpart for two geographically different crude oils by ESI FT-ICR MS. Energy \& Fuels, 2006. 20(5): p. 1973-1979.

23. Savory, J.J., Kaiser, N.K., McKenna, A.M., Xian, F., Blakney, G.T., Rodgers, R.P., Hendrickson, C.L., and Marshall, A.G., Parts-per-billion Fourier transform ion cyclotron resonance mass measurement accuracy with a "walking" calibration equation. Analytical Chemistry, 2011. 83(5): p. 1732-1736.

24. Rodgers, R.P., White, F.M., Hendrickson, C.L., Marshall, A.G., and Andersen, K.V., Resolution, elemental composition, and simultaneous monitoring by Fourier transform ion cyclotron resonance mass spectrometry of organosulfur species before and after diesel fuel processing. Analytical Chemistry, 1998. 70(22): p. 4743-4750.

25. Fu, J.M., Klein, G.C., Smith, D.F., Kim, S., Rodgers, R.P., Hendrickson, C.L., and Marshall, A.G., Comprehensive compositional analysis of hydrotreated and untreated nitrogen-concentrated fractions from syncrude oil by electron ionization, field desorption ionization, and electrospray ionization ultrahigh-resolution FT-ICR mass spectrometry. Energy \& Fuels, 2006. 20(3): p. 1235-1241.

26. Wu, Z.G., Rodgers, R.P., and Marshall, A.G., Comparative compositional analysis of untreated and hydrotreated oil by electrospray ionization Fourier transform ion cyclotron resonance mass spectrometry. Energy \& Fuels, 2005. 19(3): p. 1072-1077. 
27. Smith, D.F., Rodgers, R.P., Rahimi, P., Teclemariam, A., and Marshall, A.G., Effect of thermal treatment on acidic organic species from Athabasca bitumen heavy vacuum gas oil, analyzed by negative-ion electrospray Fourier transform ion cyclotron resonance (FT-ICR) mass spectrometry. Energy \& Fuels, 2009. 23(1): p. 314-319.

28. Hughey, C.A., Minardi, C.S., Galasso-Roth, S.A., Paspalof, G.B., Mapolelo, M.M., Rodgers, R.P., Marshall, A.G., and Ruderman, D.L., Naphthenic acids as indicators of crude oil biodegradation in soil, based on semi-quantitative electrospray ionization Fourier transform ion cyclotron resonance mass spectrometry. Rapid Communications in Mass Spectrometry, 2008. 22(23): p. 3968-3976.

29. Rodgers, R.P., Blumer, E.N., Freitas, M.A., and Marshall, A.G., Jet fuel chemical composition, weathering, and identification as a contaminant at a remediation site, determined by Fourier transform ion cyclotron resonance mass spectrometry. Analytical Chemistry, 1999. 71(22): p. 5171-5176.

30. Lemkau, K.L., Peacock, E.E., Nelson, R.K., Ventura, G.T., Kovecses, J.L., and Reddy, C.M., The M/V Cosco Busan spill: source identification and short-term fate. Marine Pollution Bulletin, 2010. 60(11): p. 2123-2129.

31. Incardona, J.P., Vines, C.A., Anulacion, B.F., Baldwin, D.H., Day, H.L., French, B.L., Labenia, J.S., Linbo, T.L., Myers, M.S., Olson, O.P., Sloan, C.A., Sol, S., Griffin, F.J., Menard, K., Morgan, S.G., West, J.E., Collier, T.K., Ylitalo, G.M., Cherr, G.N., and Scholz, N.L., Unexpectedly high mortality in Pacific Herring embryos exposed to the 2007 Cosco Busan oil spill in San Franciso Bay. Proceedings of the National Academy of Sciences, 2012. 109(9): p. E51-E58.

32. Villalanti, D.C., Raia, J.C., and Maynard, J.B., High-temperature simulated distillation applications in petroleum characterization, in Encyclopedia of Analytical Chemistry, R.A. Meyers, Editor. 2000, John Wiley \& Sons Ltd: Chichester. p. 67266741.

33. Ventura, G.T., Raghuraman, B., Nelson, R.K., Mullins, O.C., and Reddy, C.M., Compound class oil fingerprinting techniques using comprehensive two-dimensional gas chromatography (GC $x$ GC). Organic Geochemistry, 2010. 41(9): p. 1026-1035.

34. Peters, K.E., Walters, C.C., and Moldowan, J.M., Biodegradation parameters, in The Biomarker Guide: Biomarkers and Isotopes in Petroleum Exploration and Earth History. 2005, Cambridge University Press: New York. p. 645-708. 
35. Purcell, J.M., Hendrickson, C.L., Rodgers, R.P., and Marshall, A.G., Atmospheric pressure photoionization Fourier transform ion cyclotron resonance mass spectrometry for complex mixture analysis. Analytical Chemistry, 2006. 78(16): p. 5906-5912.

36. Purcell, J.M., Hendrickson, C.L., Rodgers, R.P., and Marshall, A.G., Atmospheric pressure photoionization proton transfer for complex organic mixtures investigated by fourier transform ion cyclotron resonance mass spectrometry. Journal of the American Society for Mass Spectrometry, 2007. 18(9): p. 1682-1689.

37. Robb, D.B. and Blades, M.W., Atmospheric pressure photoionization for ionization of both polar and nonpolar compounds in reversed-phase LC/MS. Analytical Chemistry, 2006. 78(23): p. 8162-8164.

38. Robb, D.B. and Blades, M.W., Factors affecting primary ionization in dopantassisted atmospheric pressure photoionization (DA-APPI) for LC/MS. Journal of the American Society for Mass Spectrometry, 2006. 17(2): p. 130-138.

39. Kaiser, N.K., Quinn, J.P., Blakney, G.T., Hendrickson, C.L., and Marshall, A.G., A novel 9.4 tesla FTICR mass spectrometer with improved sensitivity, mass resolution, and mass range. Journal of the American Society for Mass Spectrometry, 2011. 22(8): p. 1343-1351.

40. Kaiser, N.K., Savory, J.J., McKenna, A.M., Quinn, J.P., Hendrickson, C.L., and Marshall, A.G., Electrically compensated Fourier transform ion cyclotron resonance cell for complex mixture mass analysis. Analytical Chemistry, 2011. 83(17): p. 69076910.

41. Marshall, A.G., Hendrickson, C.L., and Jackson, G.S., Fourier transform ion cyclotron resonance mass spectrometry: a primer. Mass Spectrometry Reviews, 1998. 17(1): p. 1-35.

42. Xian, F., Hendrickson, C.L., Blakney, G.T., Beu, S.C., and Marshall, A.G., Automated broadband phase correction of Fourier transform ion cyclotron resonance mass spectra. Analytical Chemistry, 2010. 82(21): p. 8807-8812.

43. Beu, S.C., Blakney, G.T., Quinn, J.P., Hendrickson, C.L., and Marshall, A.G., Broadband phase correction of FT-ICR mass spectra via simultaneous excitation and detection. Analytical Chemistry, 2004. 76(19): p. 5756-5761.

44. Shi, S.D.H., Drader, J.J., Freitas, M.A., Hendrickson, C.L., and Marshall, A.G., Comparison and interconversion of the two most common frequency-to-mass calibration functions for Fourier transform ion cyclotron resonance mass spectrometry. International Journal of Mass Spectrometry, 2000. 195: p. 591-598. 
45. Hughey, C.A., Hendrickson, C.L., Rodgers, R.P., Marshall, A.G., and Qian, K.N., Kendrick mass defect spectrum: A compact visual analysis for ultrahigh-resolution broadband mass spectra. Analytical Chemistry, 2001. 73(19): p. 4676-4681.

46. Kendrick, E., A mass scale based on $\mathrm{CH}_{2}=14.0000$ for high resolution mass spectrometry of organic compounds. Analytical Chemistry, 1963. 35(13): p. 2146-\&.

47. Sleighter, R.L., McKee, G.A., and Hatcher, P.G., Direct Fourier transform mass spectral analysis of natural waters with low dissolved organic matter. Organic Geochemistry, 2009. 40(1): p. 119-125.

48. Kujawinski, E.B., Longnecker, K., Blough, N.V., Del Vecchio, R., Finlay, L., Kitner, J.B., and Giovannoni, S.J., Identification of possible source markers in marine dissolved organic matter using ultrahigh resolution mass spectrometry. Geochimica Et Cosmochimica Acta, 2009. 73(15): p. 4384-4399.

49. Jones, D.L. David L. Jones: Biology of larval and juvenile mangrove and reef fishes. [MatLab Toolbox] 2011 [cited 2011 September]; Available from: http://www.rsmas.miami.edu/personal/djones/matlab/matlab.html.

50. Dufrene, M. and Legendre, P., Species assemblages and indicator species: the need for a flexible asymmetrical approach. Ecological Monographs, 1997. 67(3): p. 345-366.

51. McCune, B. and Grace, J.B., Analysis of Ecological Communities. 2002, Gleneden Beach, Oregon: MjM Software Design. 300.

52. Garrett, R.M., Pickering, I.J., Haith, C.E., and Prince, R.C., Photooxidation of crude oils. Environmental Science \& Technology, 1998. 32(23): p. 3719-3723.

53. Tjessem, K. and Aaberg, A., Photochemical transformation and degradation of petroleum residues in the marine environment. Chemosphere, 1983. 12(11-1): p. 13731394.

54. Walker, J.D., Colwell, R.R., and Petrakis, L., Microbial petroleum degradation: application of computerized mass spectrometery. Canadian Journal of Microbiology, 1975. 21(11): p. 1760-1767.

55. Slater, G.F., Nelson, R.K., Kile, B.M., and Reddy, C.M., Intrinsic bacterial biodegradation of petroleum contamination demonstrated in situ using natural abundance, molecular-level ${ }^{14}$ C analysis. Organic Geochemistry, 2006. 37(9): p. 981989. 
56. Incardona, J.P., Ylitalo, G., Myers, M., Scholz, N., Collier, T., Vines, C., Griffin, F., Smith, E., and Cherr, G., The 2007 Cosco Busan oil spill: Assessing toxic injury to Pacific herring empryos and larvae in the San Francisco estuary. 2008, National Oceanic and Atmospheric Administration Fisheries Bodega Marine Laboratory. p. 107.

57. McLafferty, F.W. and Turecek, F., Interpretation of Mass Spectra. 4th ed. 1993, Mill Vallet, CA: University Science Books. 371.

58. Smith, D.F., Rahimi, P., Teclemariam, A., Rodgers, R.P., and Marshall, A.G., Characterization of Athabasca bitumen heavy vacuum gas oil distillation cuts by negative/positive electrospray ionization and automated liquid injection field desorption ionization Fourier transform ion cyclotron resonance mass spectrometry. Energy \& Fuels, 2008. 22(5): p. 3118-3125.

59. McKenna, A.M., Detailed Characterization of Heavy Crude Oils and Asphaltenes by Ultrahigh Resolution Fourier Transform Ion Cyclotron Resonance Mass Spectrometry, in Department of Chemistry and Biochemistry. 2009, The Florida State University:

Tallahassee. p. 222.

60. Gallup, D.L., Curiale, J.A., and Smith, P.C., Characterization of sodium emulsion soaps formed from production fluids of Kutei Basin, Indonesia. Energy \& Fuels, 2007. 21(3): p. 1741-1759.

61. Albaiges, J., Morales-Nin, B., and Vilas, F., The Prestige oil spill: a scientific response. Marine Pollution Bulletin, 2006. 53(5-7): p. 205-207.

62. Irvine, G.V., Mann, D.H., and Short, J.W., Multi-year persistence of oil mousse on high energy beaches distant from the Exxon Valdez spill origin. Marine Pollution Bulletin, 1999. 38(7): p. 572-584.

63. Kim, S., Rodgers, R.P., Blakney, G.T., Hendrickson, C.L., and Marshall, A.G., Automated electrospray ionization FT-ICR mass spectrometry for petroleum analysis. Journal of the American Society for Mass Spectrometry, 2009. 20(2): p. 263-268.

64. Larson, R.A., Bott, T.L., Hunt, L.L., and Rogenmuser, K., Photo-oxidation products of a fuel oil and their antimircobial activity. Environmental Science \& Technology, 1979. 13(8): p. 965-969.

65. Schwarzenbach, R.P., Gschwend, P.M., and Imboden, D.M., Environmental Organic Chemistry. 2 ed. 2003, Hoboken: Wiley-Interscience. 1328. 
Table 1. Saturate, aromatic, and polar content, elemental composition data (weight percent by mass) and biodegradation indices of the parent HFO and field samples.

\begin{tabular}{lccccccc} 
& $\begin{array}{c}\text { Parent } \\
\text { HFO }\end{array}$ & Day 55 & Day 139 & Day 296 & Day 402 & Day 511 & Day 617 \\
\hline \hline saturate* $^{*}$ aromatic* $_{\text {polars* }}^{*}$ & $19 \%$ & $18 \%$ & $19 \%$ & $17 \%$ & $17 \%$ & $16 \%$ & $15 \%$ \\
& $46 \%$ & $36 \%$ & $35 \%$ & $18 \%$ & $15 \%$ & $30 \%$ & $7 \%$ \\
carbon & $36 \%$ & $46 \%$ & $47 \%$ & $65 \%$ & $68 \%$ & $54 \%$ & $78 \%$ \\
hydrogen & & & & & & & \\
nitrogen & $85 \%$ & -- & $67 \%$ & $79 \%$ & $80 \%$ & $79 \%$ & $77 \%$ \\
sulfur & $10 \%$ & -- & $8.6 \%$ & $9.5 \%$ & $9.3 \%$ & $9.4 \%$ & $9.2 \%$ \\
oxygen & $0.53 \%$ & -- & $0.59 \%$ & $0.76 \%$ & $1.0 \%$ & $0.77 \%$ & $1.0 \%$ \\
ash & $1.8 \%$ & -- & $1.8 \%$ & $1.9 \%$ & $1.5 \%$ & $1.8 \%$ & $1.7 \%$ \\
& $1.8 \%$ & -- & $10.5 \%$ & $2.6 \%$ & $6.2 \%$ & $5.3 \%$ & $6.6 \%$ \\
H:C ratio & -- & -- & $9.4 \%$ & $6.6 \%$ & $2.3 \%$ & $3.0 \%$ & $3.9 \%$ \\
& 1.43 & -- & 1.54 & 1.43 & 1.39 & 1.42 & 1.42 \\
biodegradation index & & & & & & & \\
\hline
\end{tabular}

${ }^{*}$ Average errors based on triplicate analysis are $+/-5 \% .{ }^{* *}$ Developed by Peters et al. (2005) based on hydrocarbon biomarkers. † See text for discussion regarding this sample. 


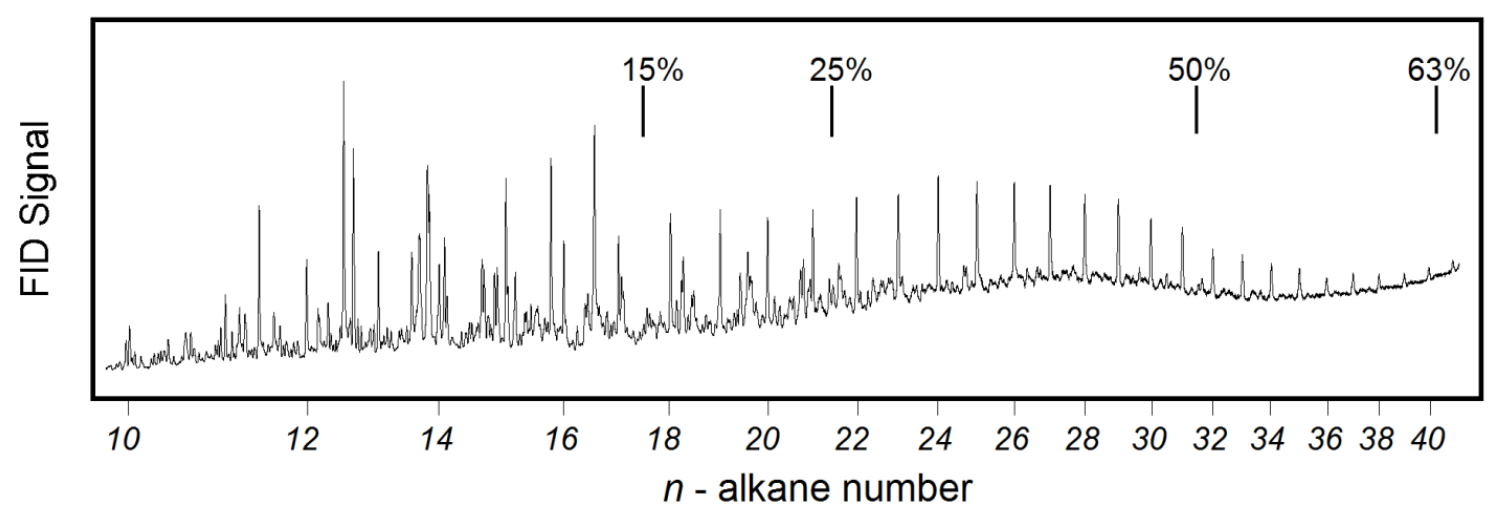

Figure 1. Traditional GC-FID chromatogram of the parent HFO. Results from high temperature simulated distillation (HTSD) are annotated and indicate 15, 25 and 50\% of the mass in the GC-amenable fraction elutes before $n-\mathrm{C}_{18}, n-\mathrm{C}_{22}$ and $n$ - $\mathrm{C}_{32}$ respectively. Only $\sim 63 \%$ of the GC-amenable mass is detectable using traditional GC-FID analysis. 


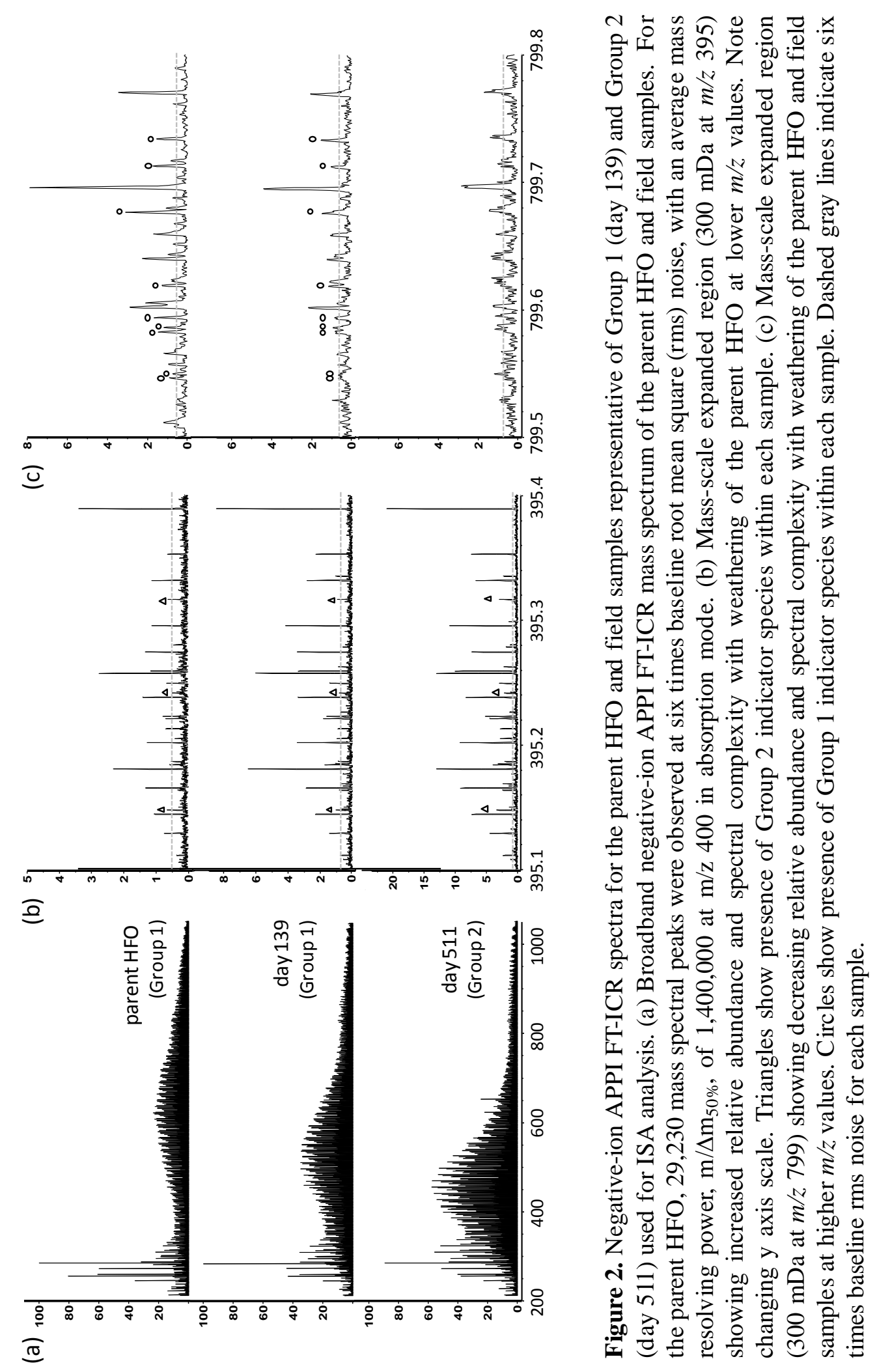




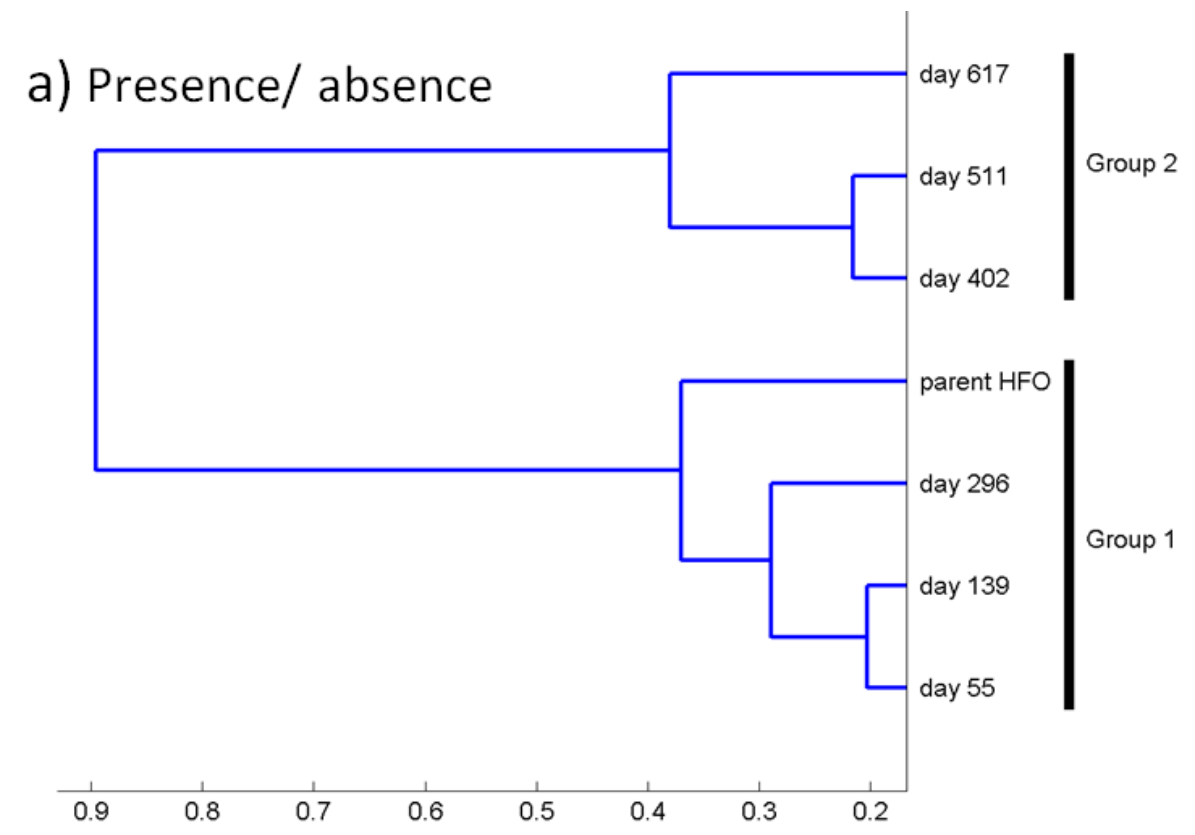

b) Relative abundance

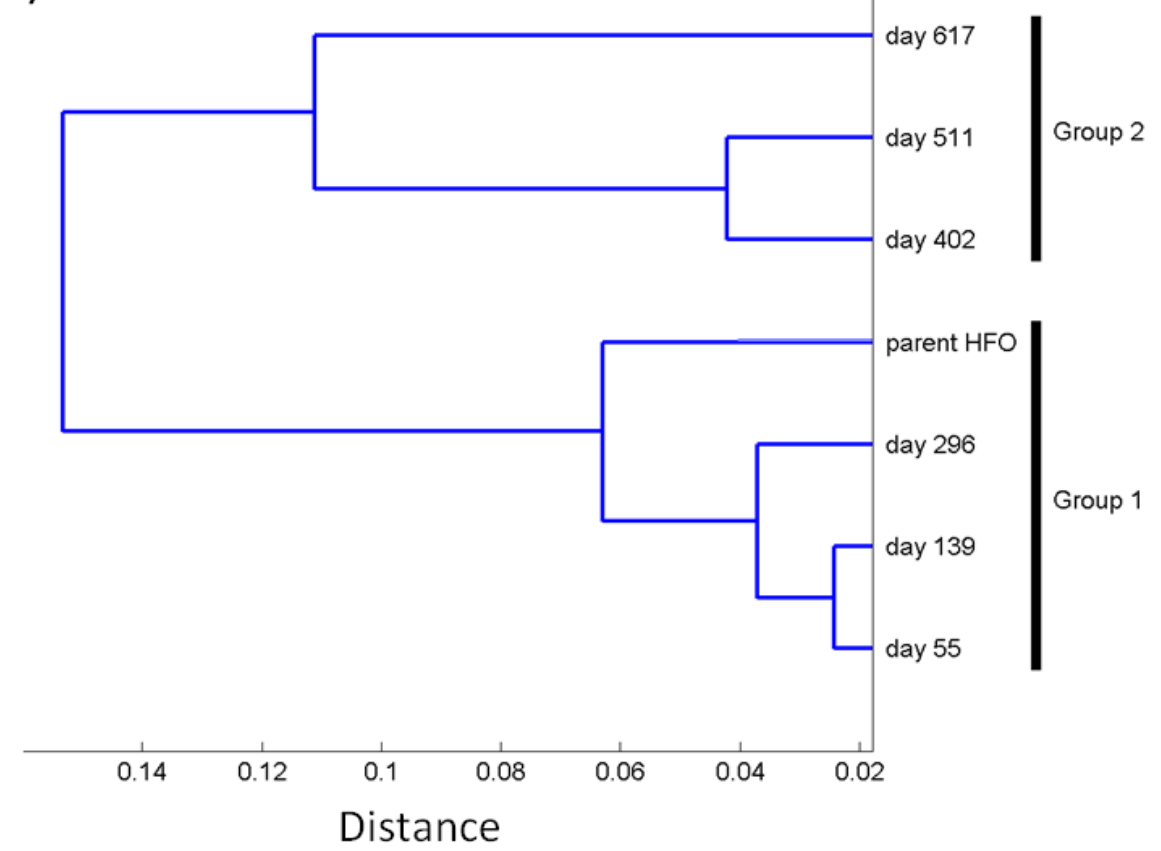

Figure 3. Linkage diagrams of the cluster analysis results for the peak \# normalized presence/absence (a) and peak \# normalized relative abundance data (b). Note the different scales for presence/absence and relative abundance data. A distance of zero indicates samples are identical with respect to peak diversity (a) or peak diversity and relative abundance (b). 
Table 2. Oxygen content and aromaticity of Group 1 (early samples) and Group 2 (later samples) indicator species (IS) for presence/absence and relative abundance data sets. Calculated values are weighted averages based on average relative abundance across group samples.

\begin{tabular}{cccccccc} 
Data set & $\begin{array}{c}\text { Group } \\
\text { number }\end{array}$ & $\begin{array}{c}\text { number } \\
\text { of IS }\end{array}$ & $\begin{array}{c}\text { O/C } \\
\text { ratio }\end{array}$ & $\begin{array}{c}\mathrm{H} / \mathrm{C} \\
\text { ratio }\end{array}$ & $\begin{array}{c}\text { IS } \\
\text { containing } \\
\text { oxygen }\end{array}$ & $\begin{array}{c}\text { O/C ratio } \\
\text { (oxygen- } \\
\text { contaning IS) }\end{array}$ & $\begin{array}{c}\mathrm{H} / \mathrm{C} \text { ratio } \\
\text { (oxygen- } \\
\text { containing IS) }\end{array}$ \\
\hline \hline \multirow{2}{*}{ PA } & Group 1 & 3284 & 0.021 & 1.43 & $72 \%$ & 0.029 & 1.44 \\
& Group 2 & 5 & 0.093 & 0.70 & $100 \%$ & 0.093 & 0.70 \\
\hline \multirow{2}{*}{ RA } & Group 1 & 3707 & 0.017 & 1.46 & $73 \%$ & 0.029 & 1.46 \\
& Group 2 & 142 & 0.032 & 1.08 & $75 \%$ & 0.042 & 1.18 \\
\hline
\end{tabular}


a)

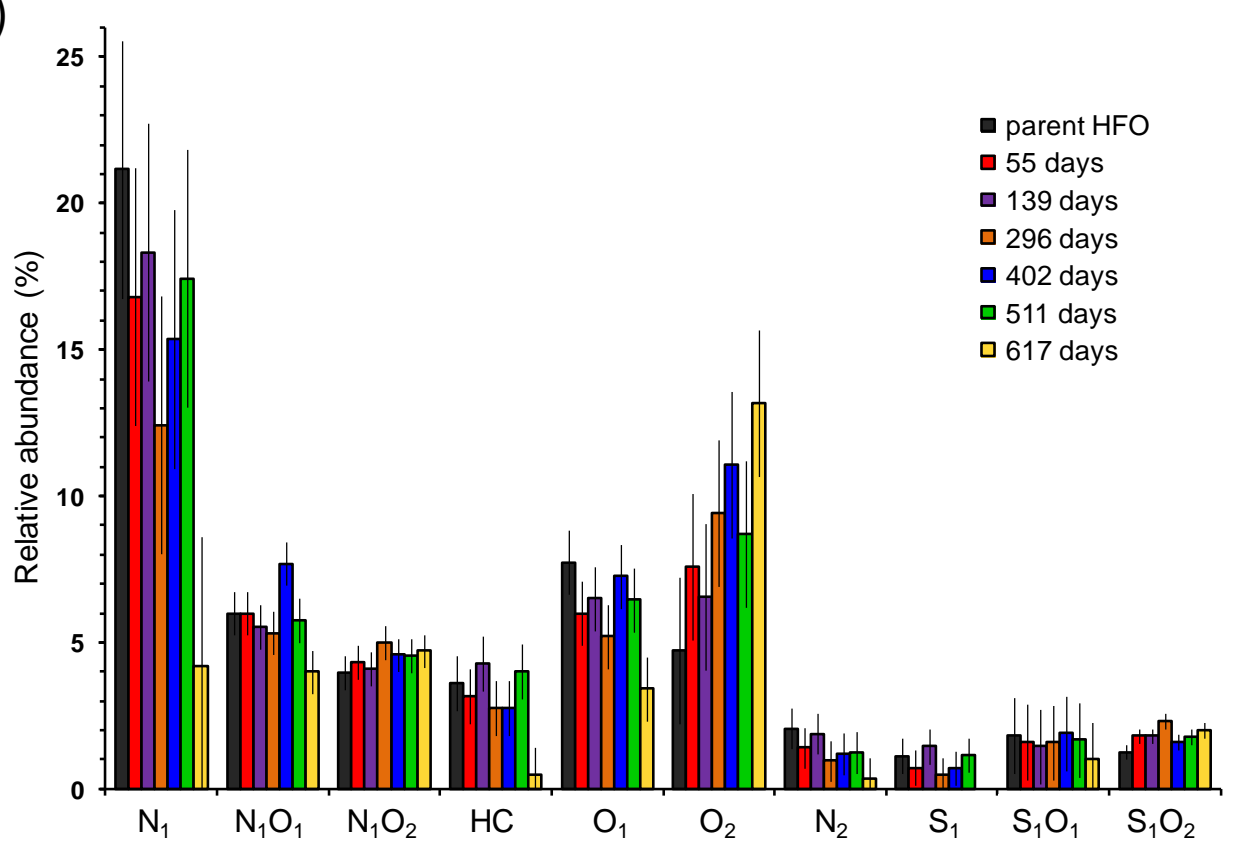

b)

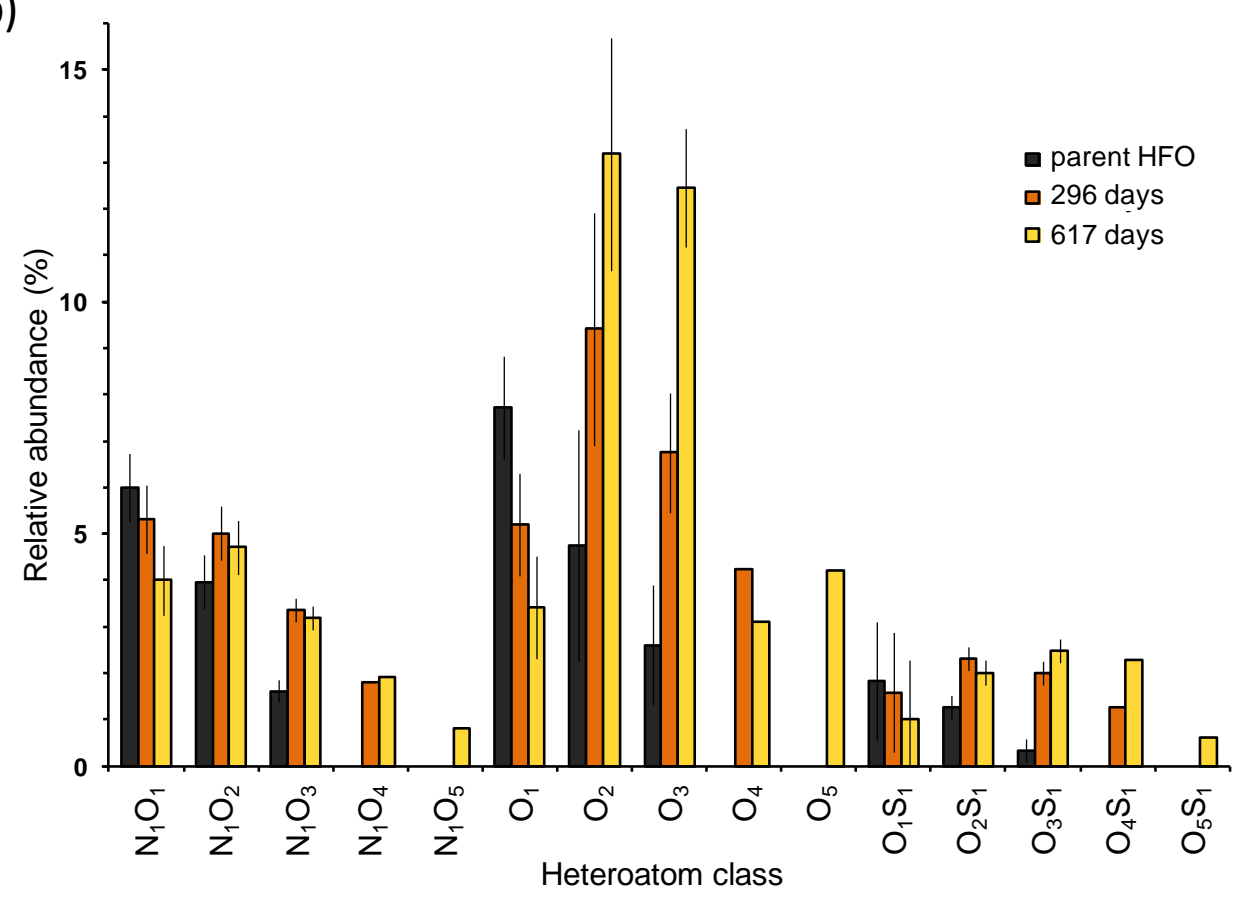

Figure 4. Heteroatom class distribution (heteroatom content) of select species for the parent HFO and field samples from negative-APPI FT-ICR MS a) select species of $>1 \%$ relative abundance and b) expanded view of oxygen-containing heteroatom classes. Error bars on class relative abundances represent instrument and ionization variability based on triplicate analysis of the parent HFO. 


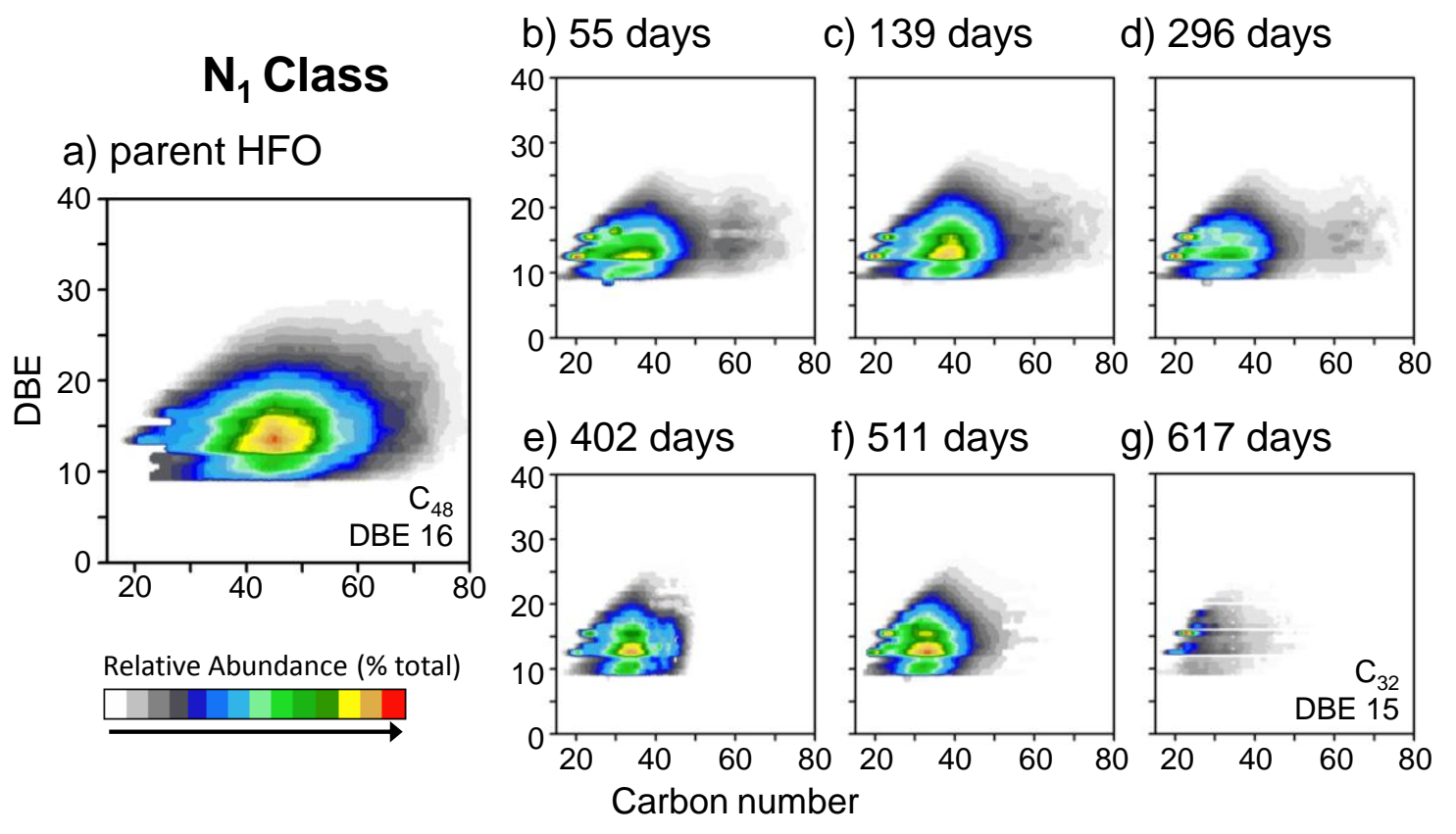

Figure 5. Isoabundance-contoured plots of double bond equivalents (DBE) versus carbon number for the $\mathrm{N}_{1}$ class of the parent HFO and field samples collected from 55 to 617 days post-spill. Each compositional image is normalized to the most abundant species within that heteroatom class for that sample. Average carbon number and DBE values for parent HFO and the 617 day sample are indicated. 
Table 3. Summary table of average carbon number (C \#), average DBE and core structures found in parent HFO and 617 day samples for each heteroatom classes.

\begin{tabular}{|c|c|c|c|c|c|c|}
\hline $\begin{array}{l}\text { Heteroatom } \\
\text { Class }\end{array}$ & $\begin{array}{c}\text { Average } \\
\text { C \# }\end{array}$ & $\begin{array}{l}\text { Parent HF } \\
\text { Average } \\
\text { DBE }\end{array}$ & $\begin{array}{c}\text { Core } \\
\text { Structures }\end{array}$ & $\begin{array}{c}\text { Average } \\
\text { C \# }\end{array}$ & $\begin{array}{l}617 \text { days } \\
\text { Average } \\
\text { DBE }\end{array}$ & $\begin{array}{c}\text { Core } \\
\text { Structures }\end{array}$ \\
\hline $\mathrm{N} 1$ & 49 & 16 & $\mathrm{C}_{45}$ DBE 14 & 32 & 15 & $\begin{array}{l}\mathrm{C}_{20} \text { DBE } 13 \\
\mathrm{C}_{23} \text { DBE } 16^{*} \\
\mathrm{C}_{34} \text { DBE } 13\end{array}$ \\
\hline $\mathrm{HC}$ & 49 & 18 & $\begin{array}{c}\mathrm{C}_{26} \text { DBE } 17 \\
\mathrm{C}_{36-56} \text { DBE } 17\end{array}$ & 29 & 16 & $\begin{array}{l}C_{21} \text { DBE } 13 \\
C_{24} \text { DBE } 16\end{array}$ \\
\hline O1 & C48 & 14 & $\mathrm{C}_{50}$ DBE 5-23 & 29 & 14 & $\begin{array}{l}C_{21} \text { DBE } 13 \\
C_{24} \text { DBE } 16\end{array}$ \\
\hline $\mathrm{O} 2$ & 46 & 14 & $\begin{array}{c}\mathrm{C}_{24} \text { DBE } 2 \\
\mathrm{C}_{40-52} \text { DBE } 16\end{array}$ & 27 & 9 & $\mathrm{C}_{24}$ DBE 2 \\
\hline
\end{tabular}

* present through 511 days post spill. Not detected in 617 day sample 


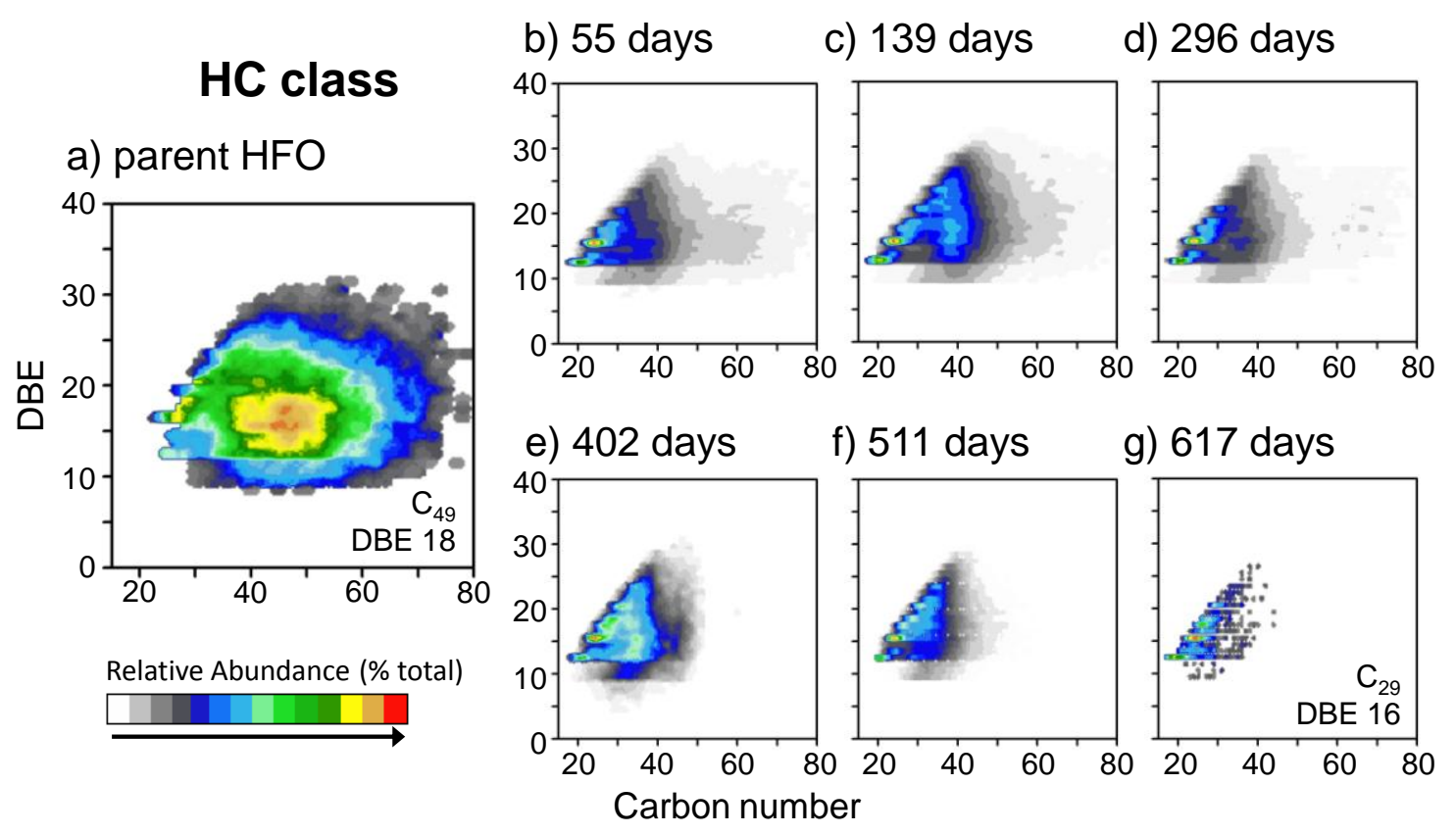

Figure 6. Isoabundance-contoured plots of DBE versus carbon number for the hydrocarbon class of the parent HFO and field samples. 


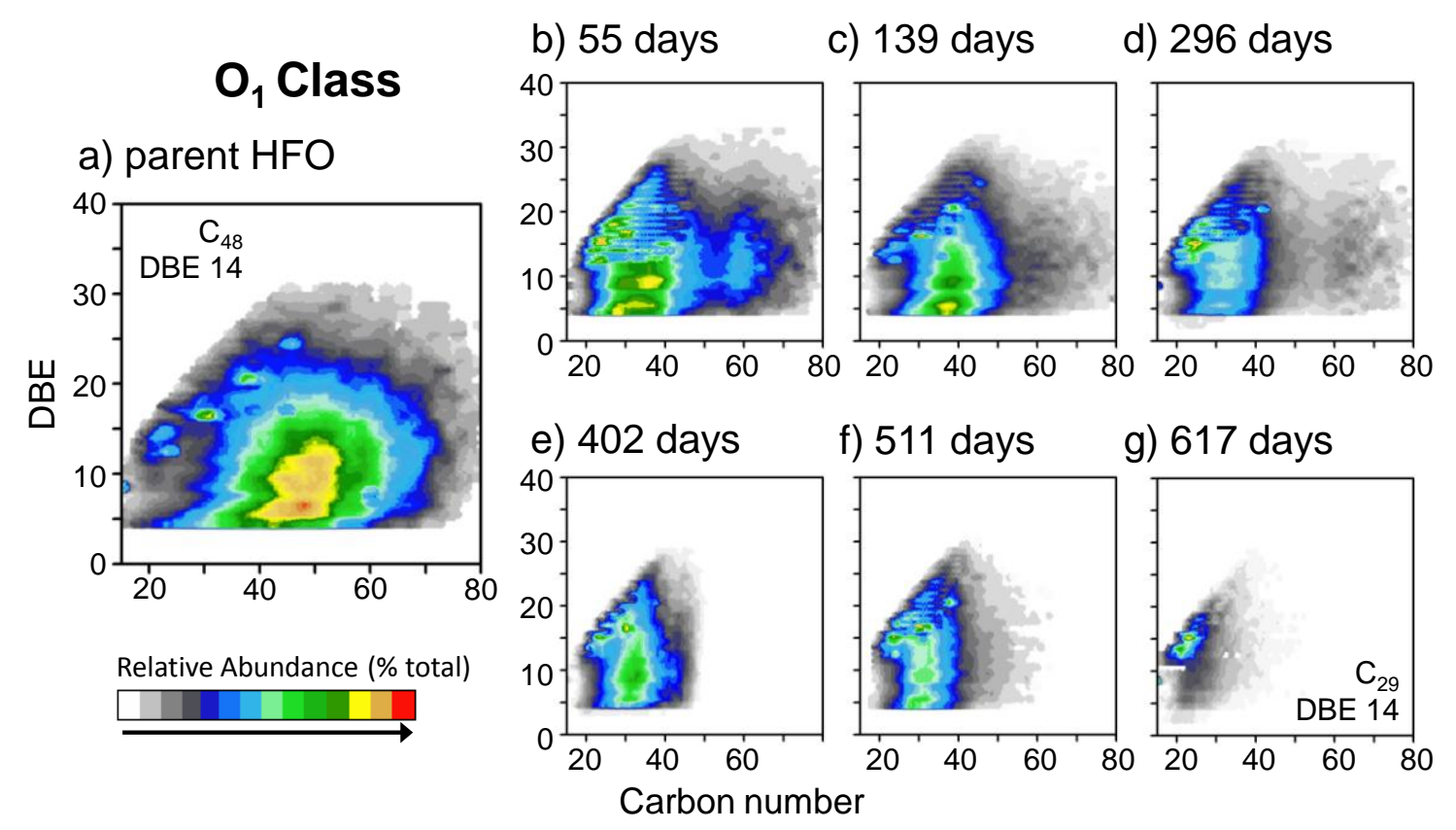

Figure 7. Isoabundance-contoured plots of DBE versus carbon number for the $\mathrm{O}_{1}$ class of the neat oil and field samples. 


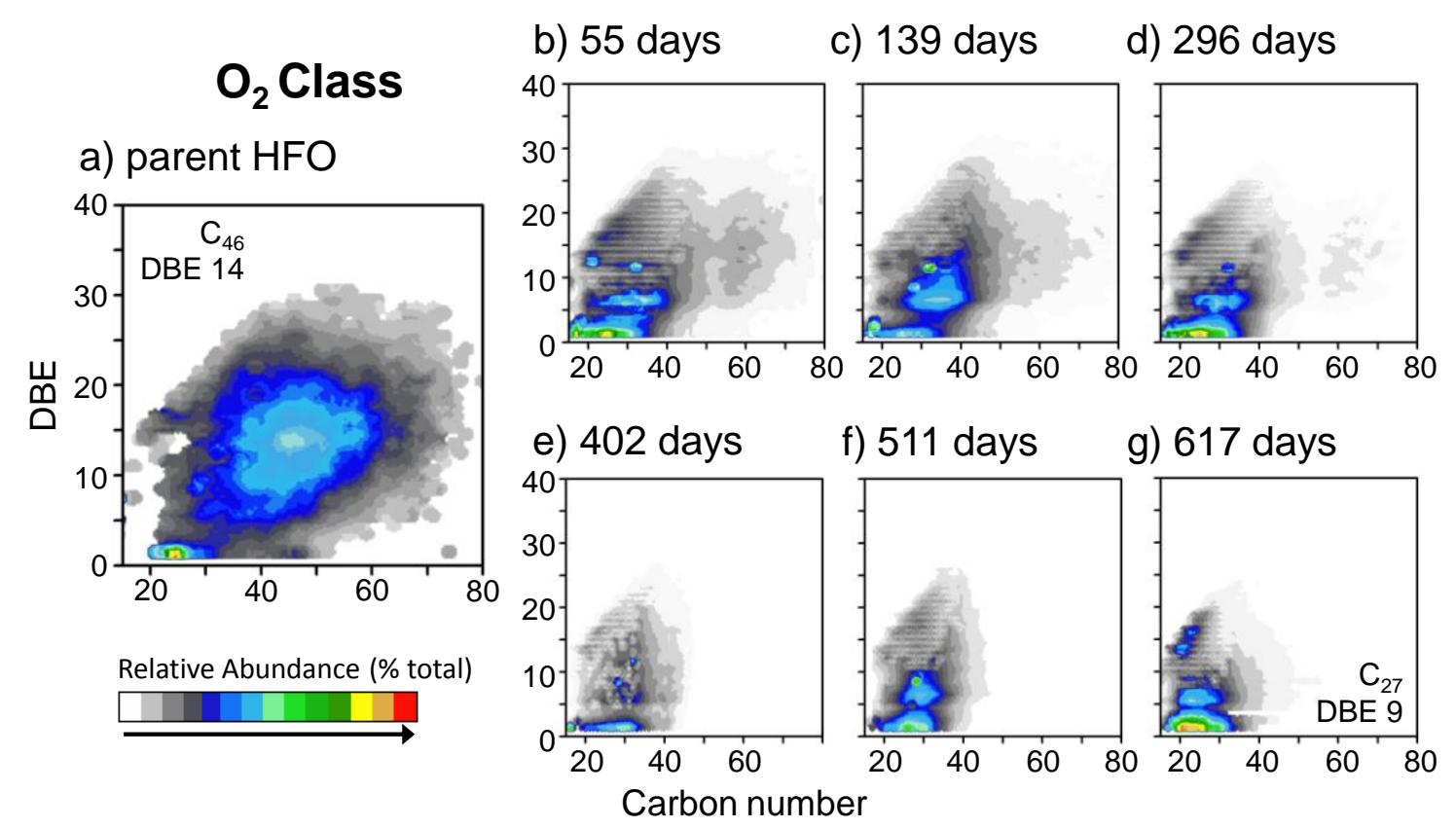

Figure 8. Isoabundance-contoured plots of DBE versus carbon number for the $\mathrm{O}_{2}$ class of the parent HFO and field samples. 


\section{Supplemental Information}

for

\section{Oil Spill Weathering: Expanding the analytical window beyond gas chromatography}

\section{Contents of Supplemental Information}

S1. Discussion on choice of ionization method. Page 208.

Figure S1. Map of San Francisco Bay and Shorebird Park field site. Page 209.

Table S1. Select biomarker ratios used to identify the source of field samples. Page 210.

Table S2. Percent of negative ion APPI peaks shared between parent HFO and field samples analyzed. Page 211.

Figure S2. N1 and NO DBE distribution for parent HFO and field samples. Page 212.

Figure S3. Modified naphthenic acid A/C ratios for parent HFO and field samples. Page 213.

S2. Supplemental references. Page 214. 


\section{S1. Discussion on choice of ionization method}

FT-ICR can be paired with various ionization methods including electrospray (ESI) and atmospheric pressure photoionization (APPI), both of which are commonly used. Although petroleum samples have been most frequently analyzed by ESI (i.e., Stanford, 2006; Hughey, 2007; Mapolelo, 2010; Hughey, 2008; Wu, 2003; Kim, 2009; Wu, 2005; Rodgers, 2001; McKenna, 2010a; McKenna, 2010b)[1-10] APPI offers several advantages over ESI for this particular study. First, negative APPI is well-suited to our interest in the water-soluble acidic compounds within our samples that are of environmental interest. Second, adduct formation with environmental salts is common when examining environmental samples such as dissolved organic matter; in ESI these adducts complicate the mass spectra whereas in APPI the thermal energy imparted during sample injection and subsequent collisional cooling allows adducts to be broken apart prior to detection in the ICR cell. Finally, APPI allows simultaneous detection of polar and non-polar species within petroleum through charge exchange reactions which do not occur in ESI.[11-14]

Unlike electrospray ionization, which forms molecular ions through protonation/deprotonation reactions,[15] APPI produces radical anions and deprotonated species in a single experiment.[12] Molecular ions detected by negative ion APPI FTICR MS of petroleum samples include carboxylic acids, five and six membered-ring (pyrrolic and pyridinic) nitrogen, aromatic sulfur (thiophenes), and polyaromatic hydrocarbons (PAHs, PASH, PANH, PAOH). Many of these substances have environmentally significant implications with regards to oil spill toxicity. 


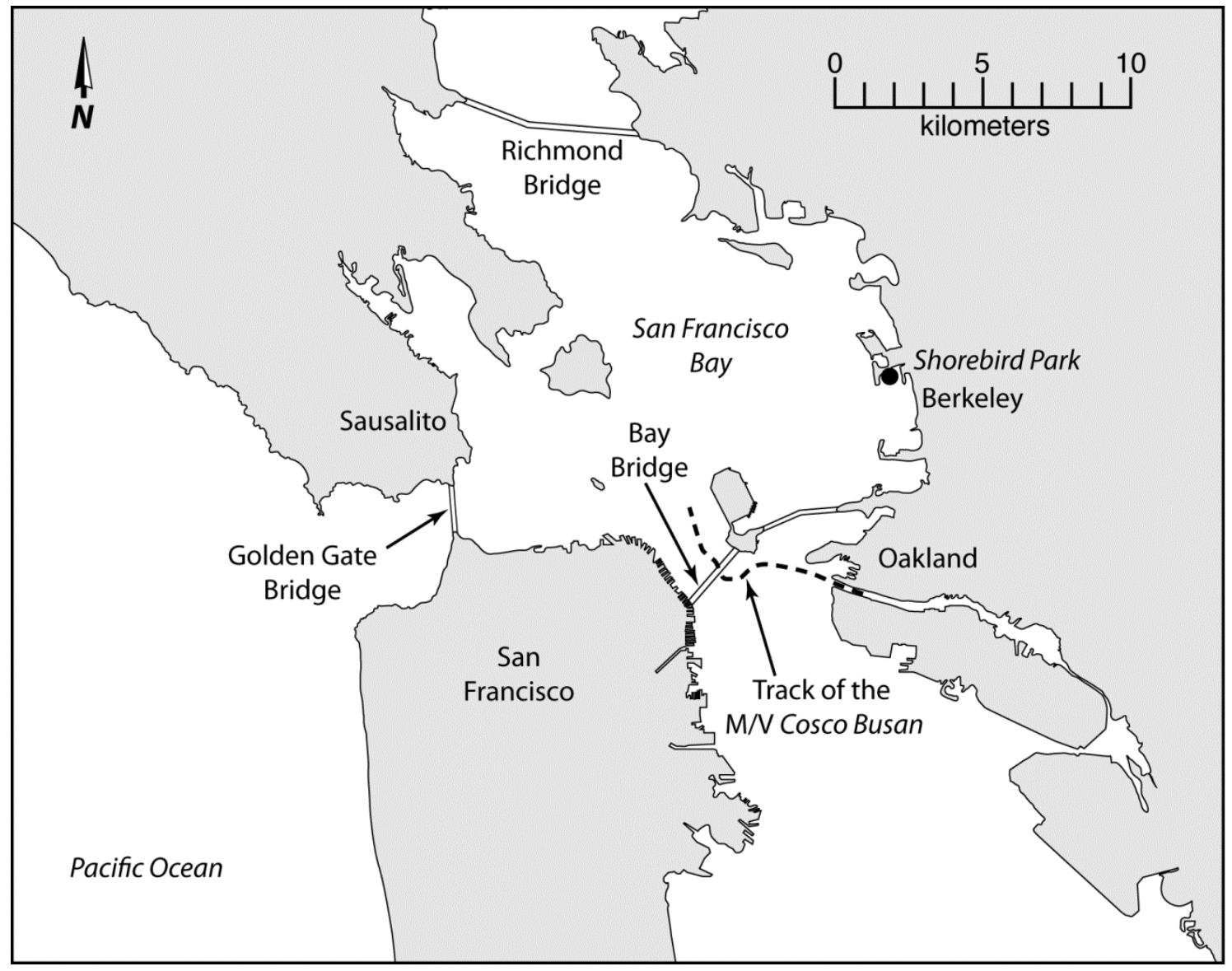

Figure S1. Map of San Francisco Bay area showing track of the M/V Cosco Busan and location of Shorebird Park sampling site. 
Table S1. Select biomarker ratios used for source identification of field samples.

\begin{tabular}{lcc} 
Biomarker ratio & parent HFO & field samples \\
\hline \hline $\mathrm{C}_{29} \alpha \beta / \mathrm{C}_{30} \alpha \beta^{a}$ & 0.808 & $0.831 \pm 0.023$ \\
$\mathrm{C}_{30} \mathrm{O} / \mathrm{C}_{30} \alpha \beta^{\mathrm{b}}$ & 0.207 & $0.228 \pm 0.014$ \\
$\mathrm{C}_{23} / \mathrm{Tm}^{\mathrm{c}}$ & 1.45 & $1.41 \pm 0.11$ \\
$\mathrm{C}_{29}(22 \mathrm{~S}+22 \mathrm{R}) / \mathrm{Tm}^{\mathrm{d}}$ & 0.876 & $0.764 \pm 0.059$ \\
$\mathrm{C}_{28} \alpha \beta / T m^{\mathrm{e}}$ & 0.472 & $0.505 \pm 0.069$ \\
$\mathrm{Ts} / \mathrm{Tm}^{\dagger}$ & 0.487 & $0.483 \pm 0.010$ \\
$\mathrm{C}_{30} \alpha \beta / \mathrm{C}_{29} \alpha \alpha \alpha \mathrm{R}^{\mathrm{g}}$ & 5.45 & $5.45 \pm 0.30$ \\
$\mathrm{C}_{28} \alpha \beta \beta S / \mathrm{C}_{29} \alpha \beta \beta \mathrm{S}^{\mathrm{h}}$ & 0.939 & $0.948 \pm 0.029$ \\
\hline
\end{tabular}

${ }^{a}$ ratio of $17 \alpha(H), 21 \beta(H)$-30-norhopane to $17 \alpha(H), 21 \beta(H)$-hopane

${ }^{b}$ ratio of $18 \alpha(\mathrm{H})$-oleanane to $17 \alpha(\mathrm{H}), 21 \beta(\mathrm{H})$-hopane

${ }^{c}$ ratio of $\mathrm{C}_{23}$ tricyclic terpanoids to $17 \alpha(\mathrm{H})-22,29,30$-trisnorhopane

${ }^{d}$ ratio of $\mathrm{C}_{29}$ tricyclic terpanoids ( $\mathrm{S}+\mathrm{R}$ epimers) to $17 \mathrm{a}(\mathrm{H})-22,29,30$-trisnorhopane

${ }^{e}$ ratio of $17 \alpha(\mathrm{H}), 21 \beta(\mathrm{H})-28,30$-bisnorhopane to $17 \alpha(\mathrm{H})-22,29,30$-trisnorhopane

${ }^{f}$ ratio of $18 \alpha(H)-22,29,30$-trisnorneohopane to $17 \alpha(H)-22,29,30$-trisnorhopane

${ }^{9}$ ratio of $17 \alpha(\mathrm{H}), 21 \beta(\mathrm{H})$-hopane to 24-ethyl-5a $(\mathrm{H}), 14 \alpha(\mathrm{H}), 17 \alpha, 20 \mathrm{R}$-cholestane

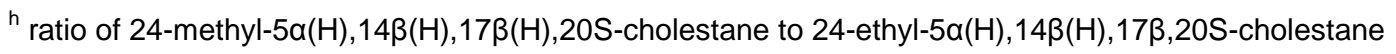


Table S2. Percent of negative ion APPI peaks shared beteen parent HFO and field samples analyzed.

\begin{tabular}{lccccccc} 
& $\begin{array}{c}\text { parent } \\
\text { HFO }\end{array}$ & day 55 & day 139 & day 296 & day 402 & day 511 & day 617 \\
\hline \hline \% parent HFO shared with & 100 & 91 & 89 & 81 & 46 & 50 & 31 \\
$\%$ day 55 shared with & 67 & 100 & 79 & 79 & 47 & 48 & 33 \\
$\%$ day 139 shared with & 74 & 89 & 100 & 81 & 49 & 53 & 34 \\
$\%$ day 296 shared with & 58 & 76 & 69 & 100 & 50 & 52 & 40 \\
$\%$ day 402 shared with & 58 & 80 & 74 & 89 & 100 & 79 & 64 \\
$\%$ day 511 shared with & 63 & 83 & 80 & 91 & 78 & 100 & 65 \\
$\%$ day 617 shared with & 41 & 61 & 55 & 77 & 69 & 70 & 100 \\
\hline
\end{tabular}



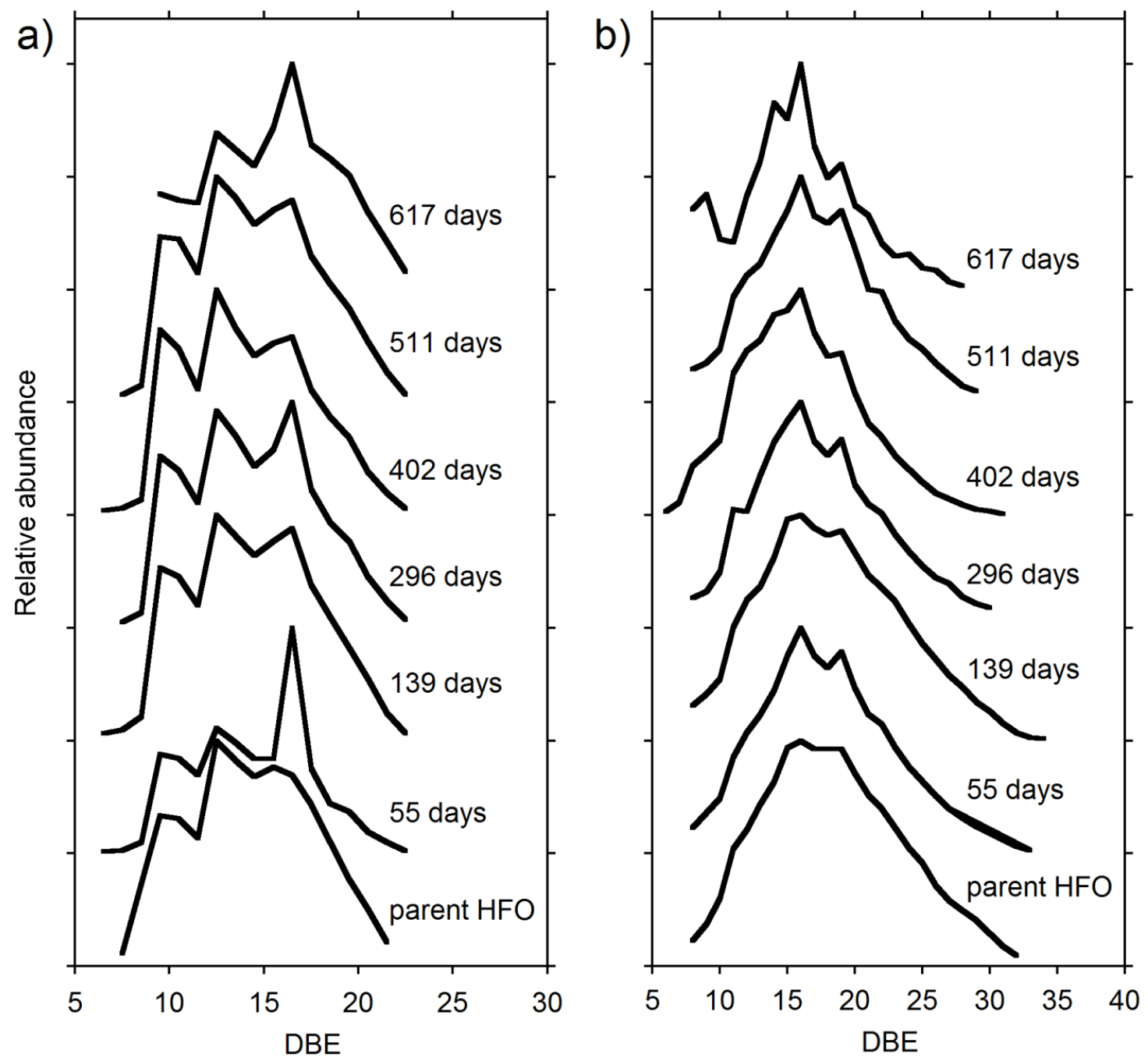

Figure S2. Relative abundance vs. DBE plots for parent $\mathrm{HFO}$ and field samples a) $\mathrm{N}_{1}$ $\mathrm{DBE}$ distribution of $\mathrm{C}_{30}$ compounds and b) NO DBE distribution with time. All samples are normalized to the DBE of maximum abundance within a given sample to highlight changes in DBE distributions with time. Profiles have been stacked to allow visual distinction between samples. No distinct shifts in N1 or NO DBE distribution with time suggests biodegradation is not responsible for the observed decrease in N1 heteroatom class abundance over time.[16] 


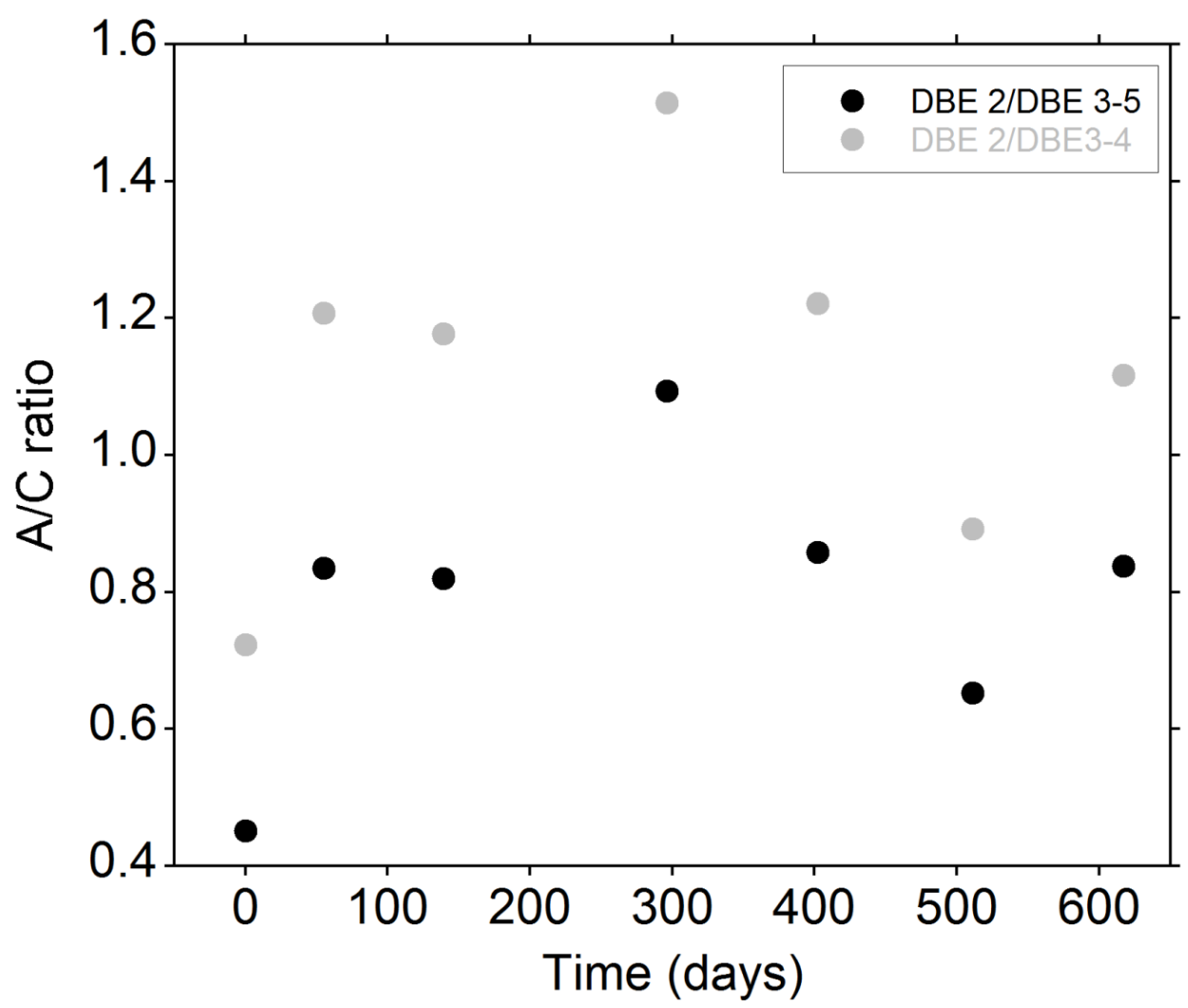

Figure S3. Weathering indicator modified from Kim et al.,[16] Because of the lack of acyclic naphthenic acids in the parent HFO, we have modified this ratio to use monocyclic (DBE of 2) to di- and tricyclic (DBE 3 to 4) or di-through tetracyclic (DBE 3 to 5) naphthenic acids. This ratio is expected to decrease with increasing biodegradation as naphthenic acids with fewer cyclic moieties are preferentially degraded. No trend is observed with increased weathering within our data set. The inability to use the $\mathrm{A} / \mathrm{C}$ ratio as defined by Kim et al. and the lack of trends with time in the modified ratios used here suggest this ratio is not a universal measure of biodegradation.

S2. Supplemental references 
1. Hughey, C.A., Galasso, S.A., and Zumberge, J.E., Detailed compositional comparison of acidic NSO compounds in biodegraded reservoir and surface crude oils by negative ion electrospray Fourier transform ion cyclotron resonance mass spectrometry. Fuel, 2007. 86(5-6): p. 758-768.

2. Hughey, C.A., Minardi, C.S., Galasso-Roth, S.A., Paspalof, G.B., Mapolelo, M.M., Rodgers, R.P., Marshall, A.G., and Ruderman, D.L., Naphthenic acids as indicators of crude oil biodegradation in soil, based on semi-quantitative electrospray ionization Fourier transform ion cyclotron resonance mass spectrometry. Rapid Communications in Mass Spectrometry, 2008. 22(23): p. 3968-3976.

3. Mapolelo, M.M., Rodgers, R.P., Blakney, G.T., Yen, A.T., Asomaning, S., and Marshall, A.G., Characterization of naphthenic acids in crude oils and naphthenates by electraspray ionization FT-ICR mass spectrometry. International Journal of Mass Spectrometry, 2011.300(2-3): p. 149-157.

4. McKenna, A.M., Blakney, G.T., Xian, F., Glaser, P.B., Rodgers, R.P., and Marshall, A.G., Heavy petroleum composition. 2. Progression of the Boduszynski model to the limit of distillation by ultrahigh-resolution FT-ICR mass spectrometry. Energy \& Fuels, 2010. 24: p. 2939-2946.

5. McKenna, A.M., Purcell, J.M., Rodgers, R.P., and Marshall, A.G., Heavy petroleum composition. 1. Exhaustive compositional analysis of Athabasca bitumen HVGO distillates by Fourier transform ion cyclotron resonance mass spectrometry: a definitive test of the Boduszynski model. Energy \& Fuels, 2010. 24: p. 2929-2938.

6. Rodgers, R.P., Hendrickson, C.L., Emmett, M.R., Marshall, A.G., Greaney, M., and Qian, K.N., Molecular characterization of petroporphyrins in crude oil by electrospray ionization Fourier transform ion cyclotron resonance mass spectrometry. Canadian Journal of Chemistry-Revue Canadienne De Chimie, 2001. 79(5-6): p. 546-551.

7. Stanford, L.A., Kim, S., Rodgers, R.P., and Marshall, A.G., Characterization of compositional changes in vacuum gas oil distillation cuts by electrospray ionization Fourier transform-ion cyclotron resonance (FT-ICR) mass spectrometry. Energy \& Fuels, 2006. 20(4): p. 1664-1673.

8. Wu, Z.G., Jernstrom, S., Hughey, C.A., Rodgers, R.P., and Marshall, A.G., Resolution of 10,000 compositionally distinct components in polar coal extracts by negative-ion electrospray ionization Fourier transform ion cyclotron resonance mass spectrometry. Energy \& Fuels, 2003. 17(4): p. 946-953. 
9. Wu, Z.G., Rodgers, R.P., and Marshall, A.G., Comparative compositional analysis of untreated and hydrotreated oil by electrospray ionization Fourier transform ion cyclotron resonance mass spectrometry. Energy \& Fuels, 2005. 19(3): p. 1072-1077.

10. Kim, S., Rodgers, R.P., Blakney, G.T., Hendrickson, C.L., and Marshall, A.G., Automated electrospray ionization FT-ICR mass spectrometry for petroleum analysis. Journal of the American Society for Mass Spectrometry, 2009. 20(2): p. 263-268.

11. Kauppila, T.J., Kotiaho, T., Kostiainen, R., and Bruins, A.P., Negative ionatmospheric pressure photoionization-mass spectrometry. Journal of the American Society for Mass Spectrometry, 2004. 15(2): p. 203-211.

12. Purcell, J.M., Hendrickson, C.L., Rodgers, R.P., and Marshall, A.G., Atmospheric pressure photoionization Fourier transform ion cyclotron resonance mass spectrometry for complex mixture analysis. Analytical Chemistry, 2006. 78(16): p. 5906-5912.

13. Robb, D.B. and Blades, M.W., Atmospheric pressure photoionization for ionization of both polar and nonpolar compounds in reversed-phase LC/MS. Analytical Chemistry, 2006. 78(23): p. 8162-8164.

14. Kauppila, T.J., Kuuranne, T., Meurer, E.C., Eberlin, M.N., Kotiaho, T., and Kostiainen, R., Atmospheric pressure photoionization mass spectrometry. Ionization mechanism and the effect of solvent on the ionization of naphthalenes. Analytical Chemistry, 2002. 74(21): p. 5470-5479.

15. Zhan, D.L. and Fenn, J.B., Electrospray mass spectrometry of fossil fuels. International Journal of Mass Spectrometry, 2000. 194(2-3): p. 197-208.

16. Kim, S., Stanford, L.A., Rodgers, R.P., Marshall, A.G., Walters, C.C., Qian, K., Wenger, L.M., and Mankiewicz, P., Microbial alteration of the acidic and neutral polar NSO compounds revealed by Fourier transform ion cyclotron resonance mass spectrometry. Organic Geochemistry, 2005. 36(8): p. 1117-1134. 


\section{Chapter 6}

\section{Conclusions and future research}

Karin L. Lemkau 


\section{Major findings}

In summary, my work has yielded insight into the weathering of a heavy fuel oil spill. This has been accomplished by combining traditional techniques with techniques newly developed by the petroleum industry that have just begun to be applied in the study of oil spills. Additionally I developed a model that provides predictive capabilities for the environmental fate of diverse oil components, accounting for important potential variation in spill conditions and environment.

Understanding the behavior of oil when spilled and the response of nature to such impacts is crucial for determining appropriate oil spill response efforts, abating damages and assisting in cleanup and restoration. This work focused on the four primary weathering mechanisms affecting oil in the environment: evaporation, dissolution, biodegradation and photodegradation.

Across my sampling sites I observed varying degrees of weathering. Analysis of a subset of samples showed evaporation was the most consistent weathering process, with all samples analyzed showing signs of evaporative loss. Dissolution also affected most of the samples. Biodegradation and photodegradation were much more variable. Samples across different sites and within individual sites showed varying impacts from these processes. Photodegradation was only detected at my least-shaded site. Biodegradation was detected to varying degrees at all sites.

Dissolution and evaporation are two of the most challenging weathering processes to disentangle after a spill. Consistent with previous studies, I observed evaporative losses to be most important in the initial days to weeks following the spill. The physiochemical model developed in Chapter 4 was able to predict these evaporative losses, and the model accounted for total oil mass loss with an error of $\sim 20 \%$. The predicted partitioning between evaporative and dissolution losses matched well with observations from field samples. Relative evaporative and dissolution losses depend on the location of a compound with the log solubility-log vapor pressure space of the mass loss tables. Model 
results differed from those obtained by Arey et al. (2007b). For naphthalene specifically, Arey et al. estimated $51 \%$ evaporative losses relative to the $82 \%$ evaporative losses predicted by my model. The variation between these two models is primarily due to different methods of estimating oil temperature and highlights the important role of oil temperature during exposure to the atmosphere.

Temperature was the primary driving factor in determining the magnitude of evaporative losses. Oil film thickness also affected evaporation though, compared to oil temperature, the model is much less sensitive to this parameter. Dissolution was also dependent on oil film thickness in addition to water-side boundary layer thickness, aqueous solubilities, diffusivities with the water and salting out effects $\left(\mathrm{K}_{\mathrm{salt}}\right)$. These results have real-world implications. In terms of mitigation of spills, we have no control over temperature or salinity of the environment. Oil spills occurring in cooler settings would be expected to have much slower evaporation. Though we cannot control environmental temperatures, through, mitigation strategies we can alter the thickness of the oil layer. This work suggests thinner oil film thicknesses would increase weathering through both evaporation and dissolution.

Similarly, models such as this could also be used to explore hypothetical spills such as arctic spills that will likely occur with increased arctic shipping over the coming decades. Because temperature plays such an important role in determining the fate of the oil with regards to evaporation and dissolution, spills at higher latitudes will likely see a greater degree of dissolution, and possible greater toxicity than those at low latitudes.

In contrast to typical ratio-based techniques, this modeling approach accounts for the hundreds of GC-amenable compounds within the $n-\mathrm{C}_{10}$ to $n-\mathrm{C}_{24}$ region. This comprehensive approach removes the need to know individual compound identity in order to predict weathering behavior, as is necessary with ratio-based techniques. With a sample of the unweathered oil it is possible to estimate the amount of any compound, whether its identity is known or not, transferred into the water column or air after a spill. 
This is accessible a priori knowledge that would enable faster, more informed and more efficient management and mitigation decisions should a spill occur. The model described here was developed for examining heavy fuel oil spills and is particularly relevant for cargo fuels used to power marine vessels and carried on board every ship.

Heavy fuel oils are distinct in composition from other crude oil products due to their high proportion of non-GC amenable components. These high molecular weight heteroatom enriched fractions (a.k.a. resins and asphaltenes) have traditionally been considered recalcitrant in the environment. As more studies on these fraction are performed we are gaining a better understanding that, like the saturates and aromatics, the resins and asphaltenes are dynamic oil components which may have long lasting environmental effects. Applying molecular-level techniques I found potentially toxic, naphthenic acid compounds to be produced or preferentially preserved in the non-GC amenable components, which may have long-term implications for the toxic effects of these residues in the environment. This thesis also demonstrated that changes occurring within this non-GC amenable fraction are similar to changes in composition observed on geologic timescales in oil reservoirs.

\section{Methodological Advances}

Traditional one-dimensional GC techniques provide information on oil spill weathering and allow examination of the saturate and aromatic fractions of oil. These techniques provide a cost effective method for gaining basic knowledge on oil weathering. Though these approaches have many shortcomings, their relative cost, availability, high throughput and ability to provide basic information on spilled oil should not be overlooked. Particularly with funding budgets being cut, more expensive and timeconsuming $\mathrm{GC} \times \mathrm{GC}$ analysis is not possible in all situations. However, we must be aware that by isolating analyses to these simpler techniques we are not analyzing the complete 
oil. Additionally, the GC-FID approaches are also unable to quantitatively distinguish the important processes of evaporation and dissolution.

Operationally, $\mathrm{GC}$ techniques are hampered by detection limits and coelution. $\mathrm{GC} \times \mathrm{GC}$ provides much lower detection limits and can dramatically reduce if not eliminate compound coelution. The result is a much more comprehensive inventory of compounds within an oil. This comprehensive inventory can aid with oil fingerprinting and source identification as well as gaining a more thorough and quantitative understanding of weathering processes of evaporation and dissolution, as demonstrated in chapter 3 . However, these techniques do not examine a significant fraction of oil. Even comprehensive examination of traditionally examined compounds can account for only $\sim 50 \%$ (by mass) of a light sweet crude oil (Reddy et al., 2011). Because heavy fuel oils are made from high-boiling refinery residues, this undetectable oil fraction will be larger for these oils.

Finally, the ultrahigh resolution technique of FT-ICR MS examines a separate fraction of oil previously not accessible. This fraction has the potential to provide insight into weathering processes experienced by samples long after the lower molecular weight, more volatile and biodegradable compounds have been removed. This could aid in longterm oil spill investigations and allow determination of important weathering processes years after the spill.

The study of environmental oil spill weathering can greatly benefit from the technologies developed within the petroleum and DOM communities. With current technology, we are nearing the point where we will have a complete inventory of compounds comprising an oil. It is to our advantage to use this knowledge to provide a better understanding of oil behavior in the environment. With more comprehensive sample analysis, every compound can be used to examine weathering trends and new analytical tools can replace traditional less informative ratio-based techniques that examine only one or two compounds. 
Here I have presented a first step towards this goal with consideration and integrated data analysis of negative ion APPI and various GC-based techniques to examine field samples from the 2007 M/V Cosco Busan oil spill. Combining data analysis approaches from different fields, this thesis showed that it is possible to obtain a detailed view into the evolution of oil after a spill.

\section{$\underline{\text { Future Research }}$}

The potential of FT-ICR MS to enhance the investigation of oil spill chemistry is clear, although as with all nascent methods there are limitations and areas for improvement. Currently FT-ICR MS is not a quantitative technique because of the highly variable ionization efficiencies between different molecules. A more complete understanding of ionization efficiencies is an essential step towards development of quantitative FT-ICR MS method. Controlled experiments focusing on specific environmental process, such as biodegradation and photodegradation, would potentially allow FT-ICR MS to aid in detection of these processes in environmental samples. Coupled with quantitative FT-ICR (when available) it may be possible to quantify the changes due to these individual processes and create models, similar to the model developed here and previously described (Arey et al., 2005; Arey et al., 2007a; Arey et al., 2007b) to examine the nonGC amenable fraction.

Further exploration of the region of overlap between GC-amenable oil components and FT-ICR MS-amenable oil components could reveal information about exchange processes between these two pools of low-molecular weight and high-molecular weight carbon. Combined with the quantitative abilities of $\mathrm{GC} \times \mathrm{GC}-\mathrm{FID}$, this overlapping region may also provide insights useful for advancing quantitative FT-ICR MS.

Another aspect of the $\mathrm{GC} \times \mathrm{GC}$ is the ability to map additional properties onto the $\mathrm{GC} \times \mathrm{GC}$ chromatogram. For example, recent work has used $\mathrm{GC} \times \mathrm{GC}$ to predict octanol-water 
partition coefficients, phospholipid partition coefficients, and toxicity (Arey et al., 2005; Tcacuic et al., 2012; Mao et al., 2009). These techniques could enable future models to provide information not only on oil partitioning between air and water, but also on the toxicity or bioaccumulation potential of these compounds.

Future oil spill studies should incorporate a multi-pronged approach using established and new techniques. We now have the instrumentation to visualize a large portion of oil components in great detail. With FT providing a picture of a different portion of the oil than GC, beyond being simply additive the use of multiple techniques in the future could potentially have multiplicative benefits. Results observed through one method could point to areas to focus on within the other data set that would not be detectible with either technique alone. GC data could also be used to gain structural information on compounds detected by FT-ICR MS, and quantitative benefits of GC $\times \mathrm{GC}$ may be useful in working toward quantitative FT-ICR MS. Combining data from these techniques with detailed predictive models can provide unprecedented understanding of the holistic behavior of oil in the environment. Exploring these new areas will undoubtedly lead to the development of new tools for environmental forensics, management and mitigation.

\section{$\underline{\text { References }}$}

Arey, J. S., Nelson, R. K., Plata, D. L. and Reddy, C. M. (2007b). "Disentangling oil weathering using GC $\times$ GC. 2. Mass transfer calculations." Environmental Science \& Technology 41(16): 5747-5755.

Arey, J. S., Nelson, R. K. and Reddy, C. M. (2007a). "Disentangling oil weathering using GC $\times$ GC. 1. Chromatogram analysis." Environmental Science \& Technology 41(16): 5738-5746.

Arey, J. S., Nelson, R. K., Xu, L. and Reddy, C. M. (2005). "Using comprehensive twodimensional gas chromatography retention indices to estimate environmental partitioning properties for a complete set of diesel fuel hydrocarbons." Analytical Chemistry 77(22): 7172-7182. 
Mao, D. B., Lookman, R., Van De Weghe, H., Weltens, R., Vanermen, G., De Brucker, N. and Diels, L. (2009). "Estimation of ecotoxicity of petroleum hydrocarbon mixtures in soil based on HPLC-GCXGC analysis." Chemosphere 77(11): 1508-1513.

Reddy, C. M., Arey, J. S., Seewald, J. S., Sylva, S. P., Lemkau, K. L., Nelson, R. K., Carmichael, C. A., McIntyre, C. P., Fenwick, J., Ventura, G. T., Van Mooy, B. A. S. and Camilli, R. (2011). "Composition and fate of gas and oil released to the water column during the Deepwater Horizon oil spill." Proceedings of the National Academy of Sciences.

Tcacuic, A. P., Nelson, R. K., Reddy, C. M. and Gschwend, P. M. (2012). "Estimating phospholipid membrane-water partition coefficients using comprehensive twodimensional gas chromatography." Environmental Science \& Technology 46(6): 34493456. 